\title{
ESTRUTURAS DE EDIFÍCIOS EM CONCRETO ARMADO SUBMETIDAS A AÇÕES DE CONSTRUÇÃO
}

José Fernão Miranda de Almeida Prado

Tese apresentada à Escola de Engenharia de São Carlos, da Universidade de São Paulo, como parte dos requisitos para a obtenção do título de Doutor em Engenharia de Estruturas.

ORIENTADOR: Prof. Dr. Márcio Roberto Silva Corrêa

São Carlos

1999 


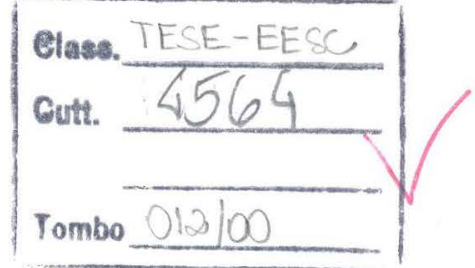

Ficha catalográfica preparada pela Seção de Tratamento da Informação do Serviço de Biblioteca - EESC/USP

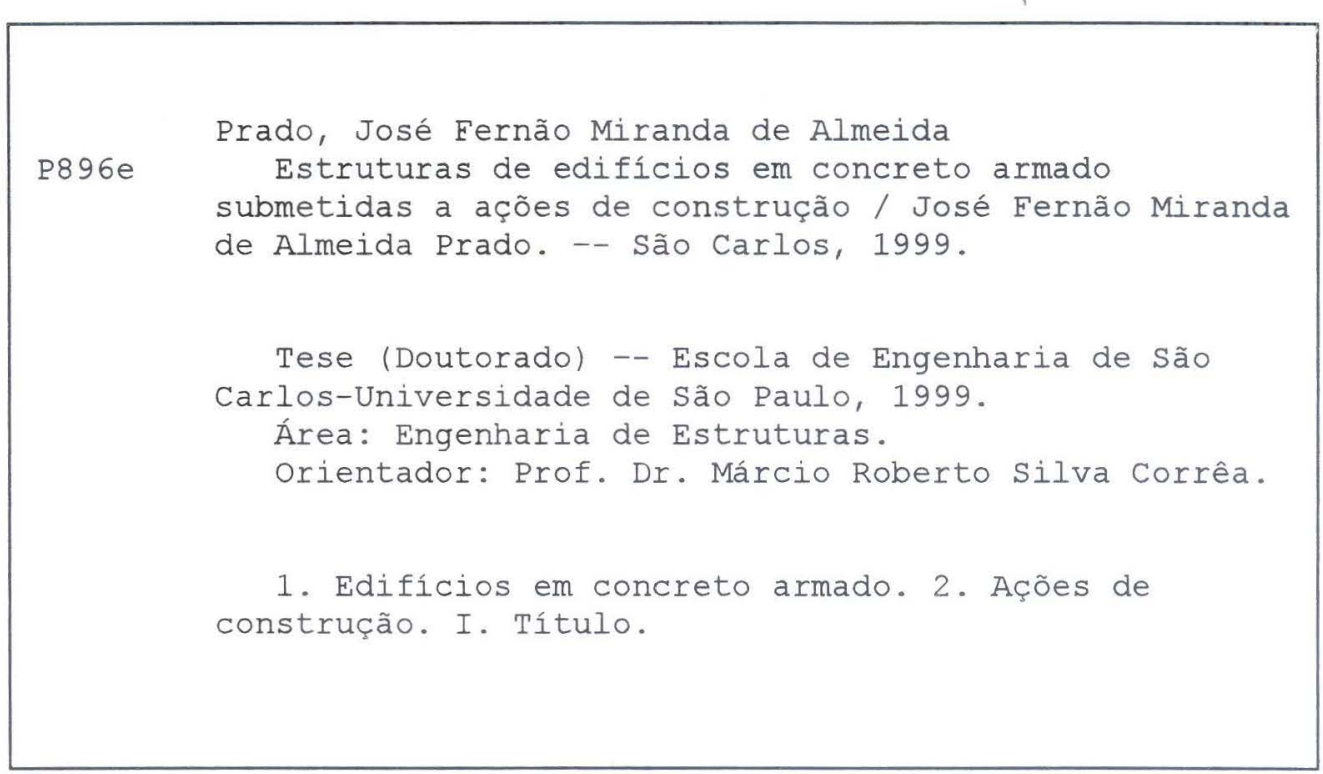


Candidato: Engenheiro JOSÉ FERNÃO MIRANDA DE ALMEIDA PRADO

Tese defendida e aprovada em 13.12 .1999

pela Comissão Julgadora:

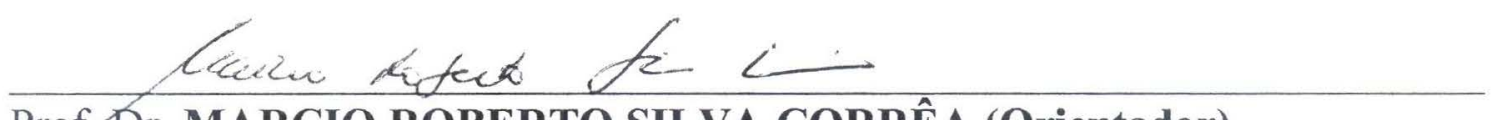

Prof. Dr. MARCIO ROBERTO SILVA CORRÊA (Orientador)

(Escola de Engenharia de São Carlos - Universidade de São Paulo)

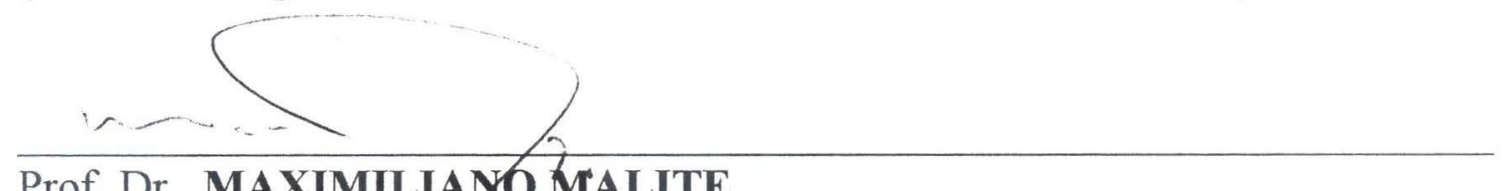

Prof. Dr. MAXIMILIANO MALITE

(Escola de Engenhariade São Carlos - Universidade de São Paulo)

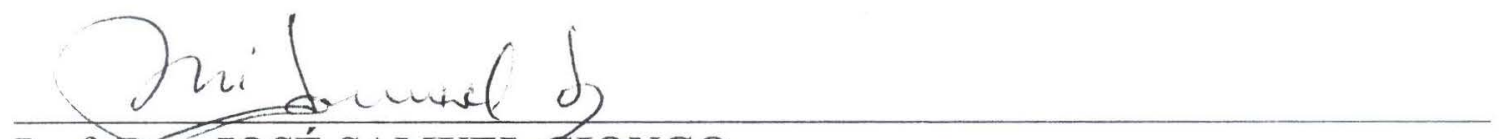

Prof.ĐT. JOSÉ SAMUEU GIONGO

(Escola de Engenharia de São Carlos - Universidade de São Paulo)

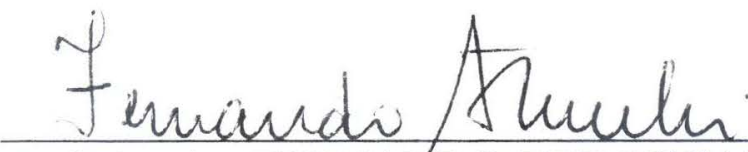

Prof. Assoc. FERNANDO REBOUCAAS STUCCHI

(Escola Politécnica - Universidade de São Paulo)

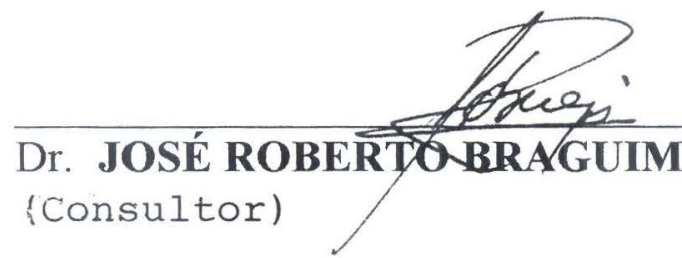

$$
\text { hr. h de Cinuir }
$$

Profa. Doutora ANA LÚCIA HOMCE DE CRESCE EL DEBS

Coordenadora da Área de Engenharia de Estruturas

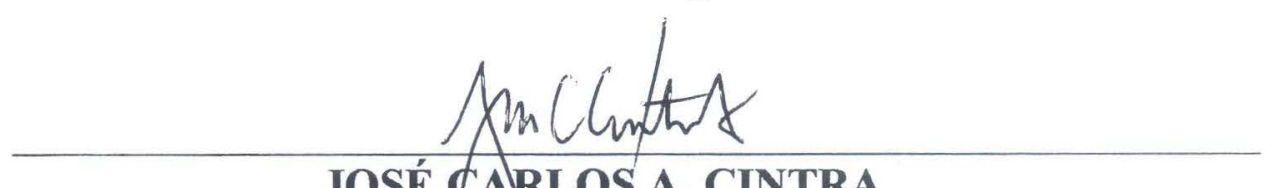

\section{JOSÉ CARLOS A. CINTRA}

Presidente da Coṇissão de Pós-Graduação da EESC 
Aos meus pais, Waldemar e Maria Helena, meus grandes mestres. À minha avó, Hermantina, sempre companheira. 


\section{AGRADECIMENTOS}

A DEUS, por tudo.

Ao professor Márcio Roberto Silva Corrêa, pela excelente orientação fornecida durante a elaboração deste trabalho.

Ao professor Marcio Antonio Ramalho, pela cooperação e sugestões oportunas.

Ao Eng. ${ }^{o}$ Marcos de Carvalho, pela amizade e pelo amplo conhecimento transmitido.

À Coordenadoria de Aperfeiçoamento de Pessoal de Nível Superior - CAPES, pela Bolsa de Estudos fornecida.

Ao professor José Samuel Giongo, pela amizade e apoio sempre presentes.

À TQS Informática Ltda, pelo uso de seus softwares mediante convênio com a EESC/USP.

Aos funcionários do Departamento de Engenharia de Estruturas da EESC/USP, pela colaboração.

Aos meus irmãos, André e Afonso, pela convivência harmoniosa.

A todos aqueles que, de alguma maneira, contribuíram para a elaboração deste trabalho.

À minha avó e aos meus pais, minha eterna gratidão. 


\section{SUMÁRIO}

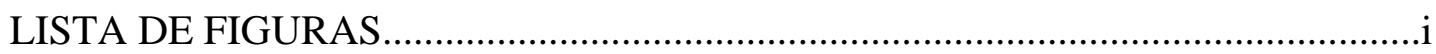

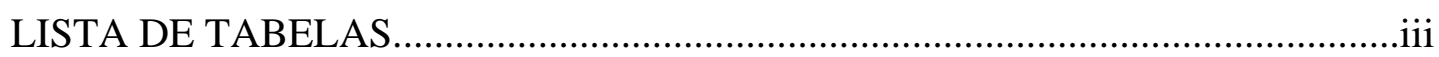

LISTA DE ABREVIATURAS E SIGLAS..............................................................

LISTA DE SÍMBOLOS.....................................................................................

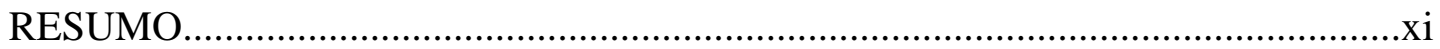

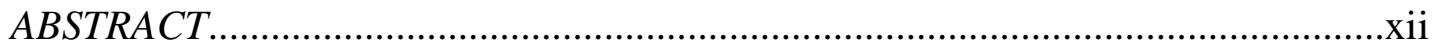

1 INTRODUÇÃO

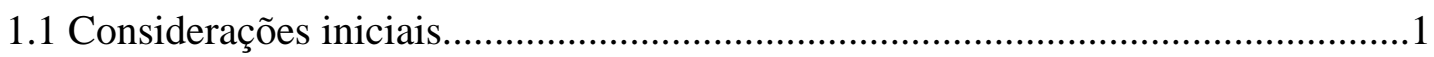

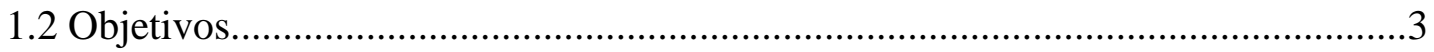

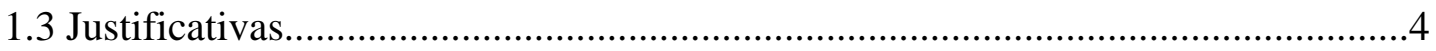

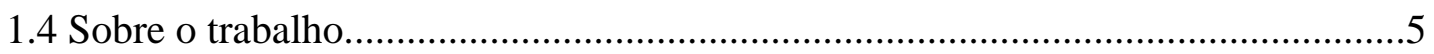

2 PROCESSO DE CONSTRUÇÃO DA ESTRUTURA..............................................

3 AÇÕES PRESENTES NAS ETAPAS DE CONSTRUÇÃO....................................12

4 PROPRIEDADES DO CONCRETO EM IDADES INICIAIS..................................14

5 SEGURANÇA DOS ELEMENTOS ESTRUTURAIS E PONTALETES..............23

6 DEFORMAÇÃO DOS ELEMENTOS ESTRUTURAIS...........................................

6.1 Verificação da deformação excessiva considerando as ações de construção.........26

6.2 Expressões para a quantificação da deformação lenta............................................35

6.3 Expressões para a quantificação da deformação por retração.................................39

7 O MÉTODO SIMPLIFICADO DE GRUNDY E KABAILA....................................4

8 ANÁLISE SEQÜENCIAL DAS ETAPAS DE CONSTRUÇÃO..............................52 


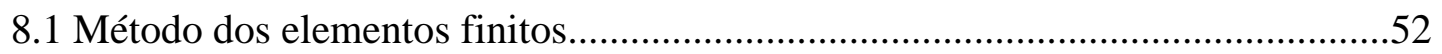

8.2 Justificativa para a consideração da análise seqüencial da estrutura....................53

8.3 Definição da análise seqüencial considerando o processo de construção..............57

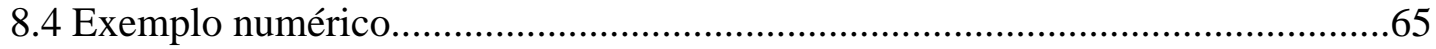

9 CARACTERÍSTICAS DO EDIFÍCIO COM ESTRUTURA USUAL.....................

UTILIZADO COMO EXEMPLO_.............................................................. 75

9.1 Considerações sobre a análise seqüencial construtiva.......................................75

9.2 Descrição da estrutura do edifício e do processo de construção............................76

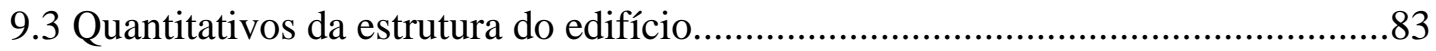

9.4 Dimensionamento da estrutura do edifício........................................................86

10 VERIFICAÇÃO DA SEGURANÇA..........................................................90

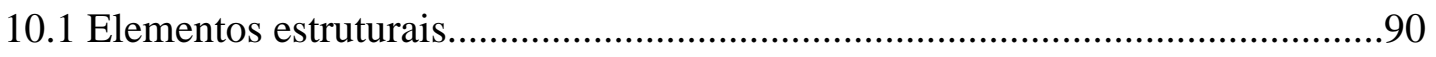

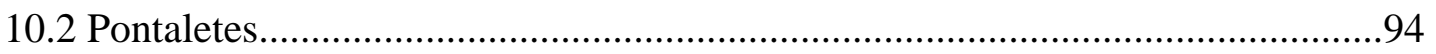

11 VERIFICAÇÃO DA DEFORMAÇÃO EXCESSIVA.......................................98

11.1 Deformação considerando as etapas de construção............................................98

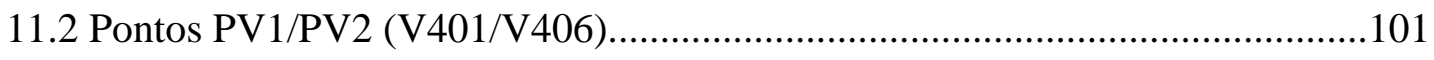

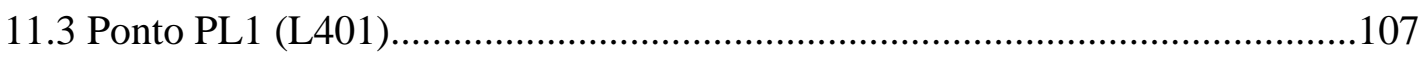

12 DEFINIÇÃO DO MÉTODO APROXIMADO..............................................114

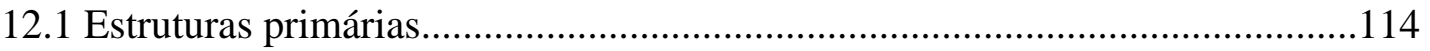

12.2 Aplicação do método aproximado à estrutura do capítulo 8............................117

12.3 Aplicação do método aproximado à estrutura do capítulo 9............................125

12.4 Análise dos resultados do método aproximado.............................................131

13 NOVA METODOLOGIA PARA VERIFICAÇÃO DOS ESTADOS.

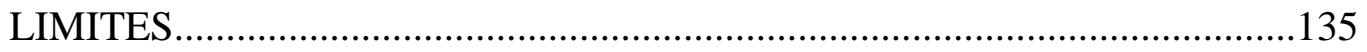

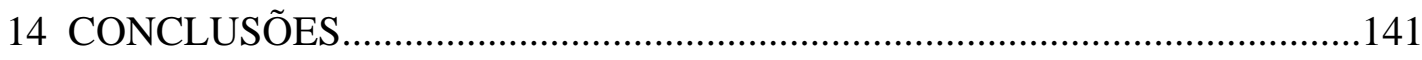

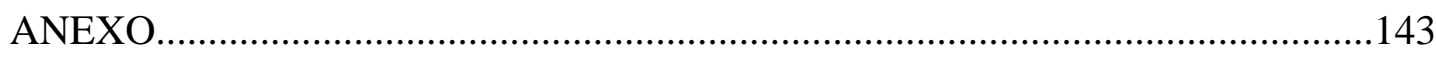

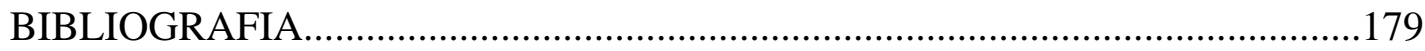




\section{LISTA DE FIGURAS}

FIGURA 2.1 - Operações básicas em processos de construção de edifícios. 10

FIGURA 4.1 - Desenvolvimento da resistência à compressão do concreto para diferentes temperaturas

FIGURA 4.2 - Desenvolvimento da resistência à compressão do concreto para diferentes tempos de cura úmida.

FIGURA 6.1 - Curva típica de deformação do concreto..........................................29

FIGURA 6.2 - Curva típica de retração do concreto.................................................30

FIGURA 7.1 - Fatores de carga (k) para pavimentos e pontaletes $(2+2) \ldots \ldots \ldots \ldots \ldots \ldots . . . .46$

FIGURA 7.2 - Fatores de carga máximos para cada pavimento...............................48

FIGURA 7.3 - Diagrama de fatores de carga para o quarto pavimento.....................49

FIGURA 7.4 - História de carregamentos construtivos para o quarto pavimento.....50

FIGURA 8.1 - Modelo representativo de fase intermediária de construção...............53

FIGURA 8.2 - Análise seqüencial da estrutura de um edifício..................................54

FIGURA 8.3 - Pórtico plano submetido à ação de peso próprio da estrutura.............55

FIGURA 8.4 - Momentos fletores nas vigas do pórtico.............................................56

FIGURA 8.5 - Modelo utilizado para a determinação da distribuição das ações no instante da concretagem

FIGURA 8.6 - Análise seqüencial para um edifício de 4 pavimentos com processo de construção com dois níveis de escoras mais um nível de reescora $(2+1)$

FIGURA 8.7 - Forma dos pavimentos e posição dos pontaletes $(\mathrm{em} \mathrm{cm})$

FIGURA 9.1 - Forma do pavimento-tipo (em $\mathrm{cm}$ ). 
FIGURA 9.2 - Posição dos pontaletes no pavimento (em cm)

FIGURA 9.3 - Pontos do pavimento para verificações da segurança e da deformação excessiva $(\mathrm{em} \mathrm{cm})$ .86

FIGURA 12.1 - Distribuição das ações quando não há pontaletes ligados à fundação rígida. 116

FIGURA 12.2 - Distribuição das ações nas etapas de descarregamento. 116

FIGURA 12.3 - Distribuição da ações de construção segundo fatores de carga $\mathrm{k}$ (x G), para a estrutura do cap.8.

FIGURA 12.4 - Distribuição da ações de construção segundo fatores de carga $\mathrm{k}(\mathrm{x} \mathrm{G})$, para a estrutura do cap.9. 126 


\section{LISTA DE TABELAS}

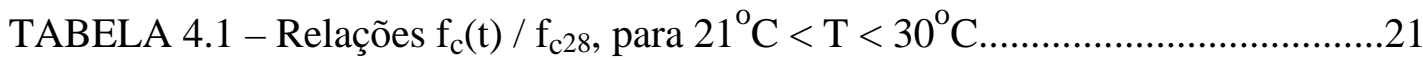

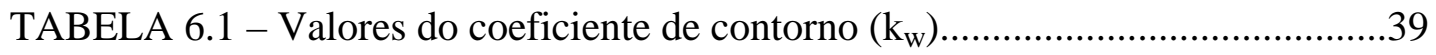

TABELA 7.1 - Valores máximo e convergente dos fatores de carga para os pavimentos

TABELA 8.1 - Desenvolvimento da resistência característica e do módulo de elasticidade secante.

TABELA 8.2 - Volume de concreto e peso próprio para um andar. .68

TABELA 8.3 - Peso próprio dos tramos de pilar. .68

TABELA 8.4 - Ações aplicadas no pavimento imediatamente inferior ao que está sendo concretado

TABELA 8.5 - Evolução dos momentos fletores em pontos do $1^{\circ}$ pavimento............70

TABELA 8.6 - Diferenças entre momentos fletores com e sem análise seqüencial..71

TABELA 8.7 - Valores de cálculo dos momentos fletores atuantes e armaduras necessárias.....

TABELA 8.8 - Valores de cálculo dos momentos fletores resistentes e armaduras utilizadas. .72

TABELA 8.9 - Valores de cálculo dos momentos fletores resistentes aos 7 dias.....73

TABELA 8.10 - Valores característicos dos momentos fletores resistentes aos 7 dias. .73

TABELA 9.1 - Desenvolvimento da resistência característica e do módulo de elasticidade.

TABELA 9.2 - Volume de concreto e peso próprio para um andar. .83

TABELA 9.3 - Peso próprio dos tramos de pilar. .84 
TABELA 9.4 - Ações aplicadas no pavimento imediatamente inferior ao que está sendo concretado .85

TABELA 9.5 - Valores característicos para momento fletor positivo em pontos de viga e armadura inferior tracionada

TABELA 9.6 - Valores característicos para momento fletor negativo em pontos de viga e armadura superior tracionada.

TABELA 9.7 - Valores característicos para momento fletor positivo no ponto PL1 e armadura inferior tracionada. .87

TABELA 9.8 - Valores característicos de momento fletor e deslocamento considerando as ações em serviço .88

TABELA 9.9 - Valores característicos de momento fletor e deslocamento considerando as ações em serviço, com $20 \%$ da sobrecarga de utilização.

TABELA 9.10 - Valores característicos de momento fletor e deslocamento considerando somente o peso próprio.

TABELA 10.1 - Momentos fletores atuantes no $2^{\circ}$ pavimento em cada etapa de construção.

TABELA 10.2 - Momentos fletores atuantes no $2^{\circ}$ pavimento, de acordo com análise global

TABELA 11.1 - Desenvolvimento da resistência característica à tração axial........101

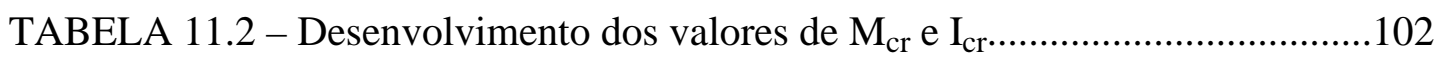

TABELA 11.3 - Valores obtidos para os pontos PV1/PV2 do $2^{\circ}$ pavimento...........103

TABELA 11.4 - Deslocamentos transversais para os pontos PV1/PV2 do $2^{\circ}$ pavimento. 104

TABELA 11.5 - Valores obtidos para os pontos PV1/PV2 (28 dias).... 105

TABELA 11.6 - Deslocamentos transversais para os pontos PV1/PV2 (28 dias)...105

TABELA 11.7 - Valores obtidos para os pontos PV1/PV2 (28-365 dias) 105

TABELA 11.8 - Deslocamentos transversais para os pontos PV1/PV2 
TABELA 11.9 - Deslocamentos transversais para os pontos PV1/PV2 do $2^{\mathrm{O}}$ pavimento com variação da data de entrada em serviço. .106

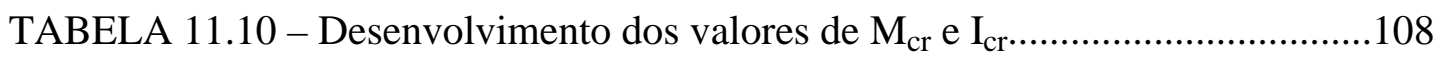

TABELA 11.11 - Valores obtidos para o ponto PL1 do $2^{\circ}$ pavimento. 108

TABELA 11.12 - Deslocamentos transversais para o ponto PL1 do $2^{\circ}$ pavimento

TABELA 11.13 - Deslocamentos transversais para o ponto PL1 do $2^{\circ}$ pavimento. 110

TABELA 11.14 - Valores obtidos para o ponto PL1 (28 dias)

TABELA 11.15 - Deslocamentos transversais para o ponto PL1 (28 dias).

TABELA 11.16 - Valores obtidos para o ponto PL1 (28-365 dias).

TABELA 11.17 - Deslocamentos transversais para o ponto PL1 (28-365 dias).....112

TABELA 11.18 - Deslocamentos transversais para o ponto PL1 do $2^{\circ}$ pavimento com variação da data de entrada em serviço.

TABELA 12.1 - Ações de construção máximas para pavimentos segundo fatores de carga $\mathrm{k}$ (x G) - etapa 9A.

TABELA 12.2 - Ações de construção máximas para pontaletes segundo fatores de carga $\mathrm{k}(\mathrm{x} \mathrm{G})$ - etapa $2 \mathrm{~A}$.

TABELA 13.1 - Dados fornecidos com o processo aproximado, para a estrutura do cap.9

TABELA 13.2 - Valores de flecha imediata + deformação lenta, para a estrutura do cap.9

TABELA 13.3 - Dados fornecidos com o processo aproximado, para a estrutura do cap. 8

TABELA 13.4 - Valores de flecha imediata + deformação lenta, para a estrutura do cap. 8 


\section{LISTA DE ABREVIATURAS E SIGLAS}

\begin{tabular}{|c|c|}
\hline ABNT & - Associação Brasileira de Normas Técnicas \\
\hline ACI & - American Concrete Institute \\
\hline ASCE & - American Society of Civil Engineers \\
\hline BS & - British Standards \\
\hline CAPES & - Coordenadoria de Aperfeiçoamento de Pessoal de Nível Superior \\
\hline CEB & - Comité Euro-International du Béton \\
\hline \multirow[t]{2}{*}{ CILAMCE } & - Iberian Latin-American Congress on Computational Methods in \\
\hline & Engineering \\
\hline COPPE & - Comissão de Pós-Graduação e Pesquisa de Engenharia \\
\hline EESC & - Escola de Engenharia de São Carlos \\
\hline FIP & - Fédération Internationale de la Précontrainte \\
\hline IACM & - International Association for Computational Mechanics \\
\hline IBRACON & - Instituto Brasileiro do Concreto \\
\hline LASER & - Linguagem para Análise de Sistemas Estruturais Reticulados \\
\hline NBR & - Norma Brasileira Registrada \\
\hline OSHA & - Occupational Safety and Health Administration \\
\hline PUC & - Pontifícia Universidade Católica \\
\hline SUPERSAP & - Super Structural Analysis Program \\
\hline UFRJ & - Universidade Federal do Rio de Janeiro \\
\hline USP & - Universidade de São Paulo \\
\hline
\end{tabular}




\section{LISTA DE SÍMBOLOS}

$\mathrm{E}_{\mathrm{C}} \quad$ - módulo de elasticidade longitudinal secante do concreto

$I_{t} \quad$ - momento de inércia à torção

$\mathrm{f}_{\mathrm{c}} \quad$ - resistência média à compressão do concreto

$\mathrm{f}_{\mathrm{c} 28}$ - resistência média à compressão do concreto aos 28 dias

$\mathrm{T} \quad$ - temperatura

$\sigma_{\mathrm{c}} \quad$ - tensão normal no concreto

$\varepsilon_{\mathrm{c}} \quad$ - deformação específica do concreto

$\varepsilon_{\mathrm{s}} \quad$ - deformação específica da armadura

t - idade do concreto

$\beta_{\mathrm{E}} \quad$ - fator para o módulo de elasticidade do concreto em função do tempo

$\beta_{\mathrm{CC}}$ - fator para a resistência à compressão do concreto em função do tempo

t' - idade fictícia do concreto

$\Delta \mathrm{t} \quad$ - número de dias em que a temperatura média diária pode ser admitida constante

$\mathrm{f}_{\mathrm{ck}} \quad$ - resistência característica do concreto

$F_{d} \quad$ - ação vertical de cálculo

$\gamma_{\mathrm{g}}$ - coeficiente de ponderação das ações características verticais permanentes

$\mathrm{F}_{\mathrm{g}} \quad$ - ação característica vertical permanente

$\gamma_{\mathrm{q}} \quad$ - coeficiente de ponderação das ações características verticais variáveis

$\mathrm{F}_{\mathrm{q}} \quad$ - ação característica vertical variável

$\mathrm{R}_{\mathrm{d}} \quad$ - capacidade resistente

$\gamma_{c} \quad$ - coeficiente de minoração da resistência do concreto

$\gamma_{\mathrm{s}}$ - coeficiente de minoração da resistência da armadura

d - altura útil da seção transversal 
b - largura da seção transversal

$\Delta \mathrm{f} \quad$ - deformação final

L - menor vão da laje

$\Delta \mathrm{i} \quad$ - deformação imediata

$\Delta \mathrm{L} \quad$ - deformação lenta

$\Delta \mathrm{r}$ - deformação por retração

$\mathrm{t}_{\mathrm{u}} \quad$ - tempo de cura úmida

$\mathrm{I}_{\mathrm{e}} \quad$ - momento de inércia efetivo

$M_{\mathrm{cr}}$ - momento de fissuração

$\mathrm{M}_{\mathrm{a}} \quad$ - momento fletor atuante

M - momento fletor

$M_{d} \quad$ - momento fletor de cálculo

$\mathrm{M}_{\mathrm{k}} \quad$ - momento fletor característico

$\mathrm{M}_{\mathrm{rd}}$ - momento fletor resistente de cálculo

$\mathrm{M}_{\mathrm{rk}}$ - momento fletor resistente característico

$I_{c} \quad$ - momento de inércia da seção não-fissurada

$\mathrm{I}_{\mathrm{cr}} \quad$ - momento de inércia da seção totalmente fissurada

h - altura da seção transversal

$\rho \quad$ - taxa de armadura tracionada

$\mathrm{I}_{\mathrm{g}} \quad$ - momento de inércia da seção bruta

$\mathrm{A}_{\mathrm{s}} \quad$ - área de aço tracionada

$\mathrm{f}_{\mathrm{ctm}}$ - resistência média do concreto à tração na flexão

$\mathrm{f}_{\mathrm{tk}} \quad$ - resistência característica do concreto à tração axial

$\mathrm{I}_{\mathrm{em}} \quad$ - momento de inércia médio

$\mathrm{t}_{\mathrm{o}} \quad$ - idade do carregamento

$\xi \quad$ - fator que leva em conta a presença da armadura na deformação lenta

$\mathrm{A}_{\mathrm{s}}^{\prime} \quad$ - área de aço comprimida

RH - umidade do ar 
$\Delta_{\mathrm{i} 28} \quad$ - deformação imediata aos 28 dias

$\mathrm{h}_{\text {fic }} \quad$ - espessura fictícia

$\mathrm{A}_{\mathrm{c}} \quad$ - área da seção transversal de concreto

u - perímetro da seção transversal de concreto exposto ao ambiente

$\mathrm{k}_{\mathrm{w}} \quad$ - coeficiente de contorno

$\phi_{\mathrm{SH}}$ - curvatura do elemento devida à retração

$\varepsilon_{\mathrm{SH}} \quad$ - deformação específica do elemento devida à retração

$\rho$ ' - taxa de armadura comprimida

k - fator de carga construtiva

$\mathrm{N} \quad$ - número de pavimentos do sistema de suporte

pp - peso próprio

$v_{\mathrm{c}} \quad$ - coeficiente de Poisson do concreto

$\mathrm{f}_{\mathrm{yk}}$ - resistência do aço ao escoamento

$\mathrm{E}_{\mathrm{s}} \quad$ - módulo de elasticidade do aço

$\sigma_{\mathrm{sd}} \quad$ - tensão na armadura para solicitação de cálculo

1/r - curvatura da seção transversal

$\alpha_{e} \quad$ - relação entre os módulos de elasticidade do aço e do concreto

x - altura da linha neutra medida a partir da borda comprimida

$\sigma_{\mathrm{s}} \quad$ - tensão na armadura tracionada

$A_{S N}$ - área de aço tracionada necessária

$\mathrm{A}_{\mathrm{SE}}$ - área de aço tracionada existente

A’ ${ }_{\mathrm{SN}}$ - área de aço comprimida necessária

A' ${ }_{S E}$ - área de aço comprimida existente

$\mathrm{N}_{\mathrm{d}} \quad$ - ação axial de cálculo nos pontaletes

$\mathrm{f}_{\mathrm{co}, \mathrm{m}}$ - resistência média da madeira à compressão paralela às fibras

$\mathrm{E}_{\mathrm{co}, \mathrm{m}}$ - módulo de elasticidade médio paralelamente às fibras da madeira

$\mathrm{k}_{\text {mod }}$ - coeficiente de modificação

$\mathrm{E}_{\mathrm{co}, \mathrm{ef}}$ - módulo de elasticidade efetivo paralelamente às fibras da madeira 
$\mathrm{f}_{\mathrm{co}, \mathrm{k}}$ - resistência característica à compressão paralela às fibras da madeira

$\mathrm{f}_{\mathrm{c}, \mathrm{d}} \quad$ - resistência de cálculo à compressão paralela às fibras da madeira

$\sigma_{\mathrm{cd}} \quad$ - tensão para solicitação de cálculo

A - área da seção transversal

$\mathrm{L}_{\mathrm{o}} \quad$ - comprimento de flambagem

i - raio de giração

$\lambda \quad$ - índice de esbeltez

I - momento de inércia

$\sigma_{\mathrm{Nd}}$ - tensão de cálculo provocada por solicitação normal

$\sigma_{\mathrm{Md}}$ - tensão de cálculo provocada por solicitação de flexão

$\mathrm{e}_{1, \mathrm{ef}} \quad$ - excentricidade efetiva de primeira ordem

$F_{E} \quad$ - carga crítica para flambagem

$\mathrm{e}_{1} \quad$ - excentricidade de primeira ordem

$e_{c} \quad$ - excentricidade suplementar de primeira ordem devida a fluência

$e_{i} \quad$ - excentricidade inicial de primeira ordem

$\mathrm{e}_{\mathrm{a}} \quad$ - excentricidade acidental mínima

$\Delta \mathrm{e} \quad$ - flecha elástica total

$\Delta \mathrm{i}^{*} \quad$ - acréscimo de flecha imediata a cada etapa construtiva

$\Delta \mathrm{i}_{28}^{*}$ - acréscimo de flecha imediata a cada etapa construtiva supondo a idade de 28 dias

CF - contra-flecha

G - ação de peso próprio do pavimento por $\mathrm{m}^{2}$

f - flecha elástica 


\section{RESUMO}

PRADO, J.F.M.A. (1999). Estruturas de edifícios em concreto armado submetidas a ações de construção. São Carlos, 1999. 184p. Tese (Doutorado) - Escola de Engenharia de São Carlos, Universidade de São Paulo.

As ações presentes durante a construção de estruturas de edifícios em concreto armado são significantemente influenciadas pelo processo construtivo e podem ultrapassar a capacidade resistente definida no projeto estrutural. Os pavimentos recém concretados são suportados por pavimentos previamente concretados, através de um sistema de fôrmas, escoras e reescoras. Se houver fissuração prematura os pavimentos terão maiores deformações ao longo do tempo. Assim sendo, o trabalho apresenta um procedimento de análise estrutural que leva em conta a seqüência natural de construção. A definição das ações nos pavimentos durante a construção estabelece a história de carregamentos dos elementos estruturais do início ao fim da obra. Os modelos tridimensionais (utilizando o método dos elementos finitos) aqui apresentados consideram que o tempo altera as propriedades de resistência e deformabilidade do concreto antes dos 28 dias. Com isso, é definido um novo método para a determinação da distribuição das ações de construção entre o sistema de escoramento e os pavimentos interligados (Método Aproximado). Além disso, propõe-se uma nova metodologia para verificação dos estados limites considerando a existência das etapas de construção.

Palavras-chave: ações de construção; análise seqüencial; edifícios em concreto armado; estados limites; retração; fluência; concreto jovem. 


\begin{abstract}
PRADO, J.F.M.A. (1999). Multistory reinforced concrete structures under construction loads. São Carlos, 1999. 184p. Tese (Doutorado) - Escola de Engenharia de São Carlos, Universidade de São Paulo.

The loads during construction of multistory reinforced concrete structures are significantly influenced by the construction schedule and can exceed the supporting structure's design capacity. The fresh floors are supported by previously cast floors, through a system of forms, shores and reshores. If cracked prematurely, the floors will have larger time-dependent deflections. Then, the text presents a procedure for structural analysis that takes into account the natural sequence of construction. Definition of the loads on floors during construction provides a view of the history of structural element loads from the beginning to the end of construction work. The tridimensional models (using the finite element method) presented herein considers that the time affects the strenght and deformability properties of concrete before 28 days. Then, a new method for determining how the construction loads are distributed among the shoring system and the interconnected floors is defined (Approximated Method). Further, a new methodology for the limit states verification taking into account the construction phases is proposed.
\end{abstract}

Keywords: construction loads; sequential analysis; reinforced concrete buildings; limit states; shrinkage; creep; early-age concrete. 


\section{INTRODUÇÃO}

\subsection{Considerações iniciais}

As estruturas de edifícios em concreto armado são normalmente construídas usando-se um sistema de suporte de pavimentos composto por fôrmas, escoras e reescoras. Através desse sistema os pavimentos recém concretados são sustentados por pavimentos inferiores já com uma certa resistência adquirida.

Além das ações de peso próprio do concreto, das fôrmas, escoras e reescoras, que podem ser estimadas com razoável precisão, atuam também durante a construção outras ações. Estas ações são de difícil determinação e compreendem: peso dos trabalhadores, equipamentos, materiais, entulhos, impacto produzido pelo lançamento do concreto, vento, etc..

As ações que atuam nos pavimentos durante a construção podem ultrapassar as ações em serviço consideradas no projeto. Além disso, as ações de construção normalmente solicitam o concreto antes que o mesmo tenha atingido as características de resistência e deformabilidade previstas, aos 28 dias.

A preocupação com esse carregamento prematuro se torna cada vez maior na medida em que, nos últimos anos, tem-se assistido a uma tendência de aceleração do processo de construção dos edifícios em concreto armado.

Desta maneira, torna-se clara a importância das relações entre as equipes de projeto e construção para garantir a segurança e as condições de utilização da estrutura. Se houver uma sobrecarga que comprometa a estrutura durante a construção, são estas equipes em conjunto que devem estudar as alternativas possíveis, onde dentre elas pode-se destacar: alterar o processo de construção, utilizar concreto com resistência mais elevada e até mesmo refazer o projeto estrutural. 
No Brasil, indicações a respeito do assunto são dadas pela NBR-6118 (1978), atualmente em processo de revisão.

Segundo esta norma, "o escoramento deverá ser projetado de modo a não sofrer, sob a ação de seu peso, do peso da estrutura e das cargas acidentais que possam atuar durante a execução da obra, deformações prejudiciais à forma da estrutura ou que possam causar esforços no concreto na fase de endurecimento".

Ainda, "deverão ser tomadas as precauções necessárias para evitar recalques prejudiciais provocados no solo ou na parte da estrutura que suporta o escoramento, pelas cargas por este transmitidas".

Quanto à retirada das fôrmas e do escoramento esta "só poderá ser feita quando o concreto se achar suficientemente endurecido para resistir às ações que sobre ele atuarem e não conduzir a deformações inaceitáveis, tendo em vista o baixo valor de $\mathrm{E}_{\mathrm{c}}$ e a maior probabilidade de grande deformação lenta quando o concreto é solicitado com pouca idade". Esta indicação está muito bem colocada. No entanto, também é dito que se não for demonstrado o atendimento das condições anteriores, a retirada do escoramento não deverá dar-se antes dos 21 dias. Esta informação significa que o escoramento pode ser automaticamente retirado após 21 dias sem qualquer verificação, o que não é coerente.

$\mathrm{Na}$ verdade o estabelecimento de qualquer prazo não deveria ser posto, já que, como será mostrado ao longo deste trabalho, isso depende de inúmeros fatores.

Percebe-se que a NBR-6118 (1978) expressa preocupação com os efeitos das ações que atuam durante a construção, embora não indique qualquer procedimento para que uma avaliação desses efeitos possa ser feita.

Quando definida a distribuição das ações de construção na estrutura, pode-se verificar a segurança comparando os valores das tensões provocadas por essas ações com os valores das resistências alcançadas no momento em que foram aplicadas.

No que se refere às condições de utilização da estrutura deve-se dar atenção especial às deformações. A NBR-6118 (1978), bem como algumas normas internacionais, especificam que os deslocamentos transversais (flechas) nos elementos estruturais de um pavimento não precisam ser verificados quando as alturas úteis de suas seções forem superiores a um determinado valor. 
Quando há a necessidade de verificar a flecha em determinado elemento, isso é feito considerando as ações em serviço e as propriedades do concreto aos 28 dias. A flecha adicional no tempo infinito pode ser obtida através de uma majoração da flecha imediata. Entretanto, as ações de construção produzem efeitos prematuros como fissuração e perda de rigidez que irão aumentar as deformações, tanto as imediatas quanto as previstas para o tempo infinito. Em outras palavras, os valores das deformações dependem da história de carregamentos da estrutura.

\subsection{Objetivos}

O presente trabalho estuda o comportamento das estruturas de edifícios em concreto armado compostas por lajes, vigas e pilares considerando as ações que atuam durante as etapas de construção.

Com esse intuito, o trabalho estabelece as ações atuantes desde o início da obra e propõe uma modelagem de introdução e retirada das mesmas, tentando um afastamento menor possível em relação ao comportamento real da estrutura. É definida, então, a análise seqüencial construtiva.

Esta análise seqüencial proposta é aplicada a uma estrutura usual com o objetivo de mostrar a possibilidade de ocorrência de esgotamento da capacidade resistente de elementos do pavimento (vigas e lajes) durante a construção. Também verifica-se a necessidade da consideração da história de carregamentos para uma determinação mais precisa das deformações do pavimento ao longo do tempo. No entanto, esta simulação seqüencial da construção demanda um exaustivo procedimento de modelagem passo a passo.

Com a finalidade de aproximar as práticas adotadas em escritórios de projeto aos estudos realizados no meio acadêmico, o trabalho define então um novo método de análise, o qual fornece a distribuição das ações entre os pavimentos durante o processo de construção previamente definido. Assim, espera-se consolidar um método simples o suficiente para permitir uma utilização prática e, ao mesmo tempo, confiável. 
Em conformidade com o novo método de análise (denominado método aproximado) o conteúdo do trabalho objetiva estabelecer um procedimento geral para a verificação do estado limite último de esgotamento da capacidade resistente e do estado limite de utilização no que se refere às deformações excessivas do pavimento, ambos abrangendo as etapas de construção.

Espera-se que os resultados deste trabalho possam dar subsídios ao processo atual de revisão da NBR-6118 (1978) para que, no mínimo, mais indicações sejam colocadas a respeito do assunto.

Por fim, deve-se dizer que não há a preocupação com o estudo dos pilares, uma vez que CORRÊA \& RAMALHO (1993) já o fizeram. Segundo os mesmos, utilizando processos de construção usuais, não há qualquer tipo de problema com a segurança dos pilares durante a execução das obras. Sendo assim, analisam-se aqui somente vigas e lajes dos pavimentos.

\subsection{Justificativas}

Basicamente, a escassez de publicações sobre as ações de construção atuantes em estruturas de concreto armado juntamente com a relevância do assunto justificam a pesquisa.

A revisão bibliográfica apontou para uma pequena quantidade de trabalhos no Brasil sobre ações de construção. Além disso, esses trabalhos não tratam o assunto com a objetividade que o mesmo requer. Não há a proposição de um método eficiente para verificação dos estados limites último e de utilização abrangendo as etapas de construção.

Já as pesquisas desenvolvidas no exterior foram elaboradas em sua grande maioria nos Estados Unidos, estando voltadas para sistemas estruturais em lajecogumelo com processos construtivos usuais neste país. Também não há novas propostas eficazes de análise das ações de construção para utilização prática. Nesse sentido muitos trabalhos internacionais ainda se utilizam de um tradicional procedimento desenvolvido na década de 60, o método simplificado de Grundy e Kabaila. 
É bom lembrar que nos últimos 25 anos ocorreram mais de 85 colapsos em estruturas durante a construção, só nos Estados Unidos. Segundo STIVAROS \& KAMINETZKY (1994), esses colapsos tiveram como causas a ruptura dos pontaletes (escoras ou reescoras) ou a ruptura do concreto, devidas à sobrecarga de construção ou à resistência insuficiente. Também foram detectadas remoções prematuras de fôrmas e pontaletes. Alguns desses colapsos originaram, inclusive, rupturas progressivas dos pavimentos (efeito dominó). É o caso dos edifícios Commonwealth Avenue, em Boston, e Willow Island, na Virgínia.

No Brasil, recentemente, dois colapsos durante a construção tiveram destaque: o do anexo do Hotel Intercontinental no Rio de Janeiro em 1993 e o de um prédio na zona norte de São Paulo em 1994. Ambos acabaram resultando na perda de vidas humanas.

Outro dado importante é o indicado por LEE et al.(1988), que após diversas pesquisas chegou à conclusão de que $70 \%$ dos colapsos envolvendo estruturas de concreto armado têm origem em problemas construtivos, principalmente remoção prematura de pontaletes.

Infelizmente problemas como estes podem até ser considerados comuns, uma vez que o processo de construção é geralmente guiado com base na experiência do mestre de obras e pela urgência de finalização da obra, sem uma análise estrutural prévia mais detalhada.

\subsection{Sobre o trabalho}

As determinações de esforços solicitantes e deslocamentos nas estruturas de edifícios analisadas neste trabalho são feitas com a utilização dos programas da biblioteca do sistema LASER, desenvolvidos por RAMALHO (1990) e CORRÊA (1991).

O sistema LASER possibilita o uso de elementos de barra e de placa discretizados através do método dos elementos finitos. Neste trabalho é sempre utilizada uma discretização bastante refinada, tomando-se como referência uma malha de $50 \mathrm{~cm}$. 
Embora o sistema LASER permita modelagens tridimensionais, ele não contém dispositivos para a geração automática de pavimentos subseqüentes. Assim sendo, para esse fim são usados os programas PUSH e SUBSTRUCT, que fazem parte da biblioteca do sistema SUPERSAP (compatível com o sistema LASER).

O sistema LASER possui uma entrada gráfica de dados do pavimento, com geometria e carregamentos, sendo posteriormente criado um arquivo de dados em padrão ASCII. Utilizando esse arquivo, onde o pavimento está definido com uma cota vertical z, o programa PUSH gera um outro arquivo idêntico porém com uma translação de cotas ao longo do eixo z. Feito isso, o programa SUBSTRUCT faz a compatibilização dos dados, juntando os dois arquivos e acertando a numeração de barras e placas bem como todos os outros parâmetros necessários. Nesse instante, tem-se um só arquivo de dados (com os dois pavimentos interligados) pronto para ser processado pelo sistema LASER. Esse procedimento é muito útil para as modelagens das etapas de construção.

Nos processamentos do sistema LASER feitos neste trabalho é considerada uma redução para o momento de inércia à torção $\left(\mathrm{I}_{\mathrm{t}}\right)$ das barras. Além disso, nos pavimentos são incorporados trechos rígidos de pilares como barras horizontais do modelo com elevada inércia à flexão.

Nas modelagens das etapas de construção os pontaletes são representados por elementos de barra articulados nas extremidades. A fundação é admitida como um suporte totalmente rígido, com os pilares engastados.

Admite-se comportamento elástico-linear para os materiais (linearidade física) e equilíbrio da estrutura na posição indeformada (linearidade geométrica). Essas duas hipóteses são fundamentais para a caracterização do relacionamento entre as ações e seus efeitos sobre a estrutura.

No que se refere à adoção da linearidade física, de acordo com OLIVEIRA (1997) para pavimentos armados com esforços solicitantes obtidos em regime elástico-linear (o que acontece neste trabalho), a diferença entre esses esforços e os obtidos com uma análise não-linear física é pequena. Isso já não acontece no caso das deformações.

Sendo assim, para os deslocamentos transversais do pavimento é utilizada a chamada expressão de Branson a fim de levar em conta, de maneira aproximada, os 
efeitos da não-linearidade física nas deformações dos elementos estruturais. As deformações ao longo do tempo são consideradas.

Aliás, no que se refere ao tempo, todas as modelagens e verificações dos estados limites último e de utilização são tratadas com esse fator. As características de resistência e deformabilidade do concreto jovem são sempre atualizadas.

O corpo do trabalho é composto pelos capítulos 2 ao 13 .

O capítulo 2 envolve a caracterização do processo construtivo das estruturas de edifícios em concreto armado, enquanto no capítulo 3 são definidas as ações atuantes durante a execução da obra.

As propriedades do concreto em idades iniciais são estudadas no capítulo 4, sendo apresentadas as indicações de várias normas a respeito do assunto.

Os capítulos 5 e 6 descrevem as verificações dos estados limites último de esgotamento da capacidade resistente e de utilização no que se refere à deformação excessiva, respectivamente. São dadas ênfases às verificações durante a construção. Especificamente no capítulo 6 também são caracterizados os fenômenos de retração e deformação lenta do concreto, além de apresentada a expressão de Branson para peças fissuradas.

No capítulo 7 é descrito o tradicional método simplificado de Grundy e Kabaila. Esse método determina a distribuição das ações de construção entre os pavimentos e, embora pouco preciso, é utilizado até hoje em grande parte das pesquisas sobre o assunto.

Tentando simular o comportamento da estrutura em construção, o capítulo 8 apresenta a análise seqüencial construtiva. Através de modelagens tridimensionais e com o auxílio do método dos elementos finitos pôde-se estudar a melhor maneira de considerar as introduções e retiradas de cargas durante a obra. É feito um exemplo numérico para uma estrutura com um pavimento simples.

Já no capítulo 9 a análise seqüencial construtiva é aplicada a uma estrutura de edifício usual com pavimento dimensionado do modo como normalmente se faz nos escritórios de projeto, ou seja, admitindo-se comportamento elástico-linear, equilíbrio na posição indeformada e desconsiderando-se a existência da fase de construção. 
Com os resultados desta análise seqüencial, nos capítulos 10 e 11 são verificadas respectivamente a segurança durante a construção e a influência dos carregamentos prematuros nos deslocamentos do pavimento ao longo do tempo, para o edifício em questão.

A observação da distribuição das ações de construção entre os pavimentos obtida através da análise anterior permite que, no capítulo 12 , seja proposto um novo método de análise. O chamado método aproximado apresenta bons resultados quando comparado com a análise seqüencial construtiva.

No capítulo 13 apresenta-se uma nova metodologia para verificação dos estados limites em estruturas de edifícios em concreto armado, considerando a fase de construção. O método aproximado viabiliza uma utilização prática desta nova metodologia nos escritórios de projeto.

No capítulo 14 constam as conclusões, enquanto o anexo apresenta diversos gráficos ilustrativos para as ações de construção, esforços solicitantes e deslocamentos. 


\section{PROCESSO DE CONSTRUÇÃO DA ESTRUTURA}

Como já dito, durante a construção dos múltiplos andares de um edifício em concreto armado, os pavimentos recém concretados são temporariamente sustentados por pavimentos inferiores através de um conjunto constituído por fôrmas, escoras e reescoras. Esse conjunto, associado aos pavimentos que servem de apoio, é denominado de sistema de suporte.

As fôrmas, normalmente em madeira, servem para moldar os elementos estruturais, conferindo ao edifício a forma especificada em projeto.

As escoras são pontaletes verticais (em madeira ou aço) que dão sustentação a um pavimento, apoiando-o no imediatamente inferior.

As reescoras são semelhantes às escoras, porém sem fôrma associada. Elas permitem a remoção das fôrmas de níveis inferiores para reutilização na concretagem de níveis superiores.

As ações são introduzidas nos pavimentos durante o período de construção através de uma sequiência repetida de operações. Normalmente há cinco operações básicas, num processo que pode ter um número variado de níveis escorados e reescorados. Essas operações constituem-se em:

1. Remoção do nível mais baixo de reescoras;

2. Remoção do nível mais baixo de escoras e fôrmas;

3. Instalação das reescoras no nível onde as escoras e fôrmas foram removidas;

4. Instalação das escoras e fôrmas para concretagem do próximo pavimento;

5. Concretagem.

Se o processo de construção não utilizar reescoras as operações 1 e 3 são eliminadas. 
A figura 2.1 ilustra as operações básicas citadas, para dois processos de construção diferentes. O primeiro processo apresenta três níveis de escoras $(3+0)$, enquanto o segundo mostra dois níveis de escoras mais um nível de reescora $(2+1)$.

$山$ ESCLRA / FURMA
$\square$ REESCRRA

a) 3 NIVEIS DE ESCLRAS $(3+0)$

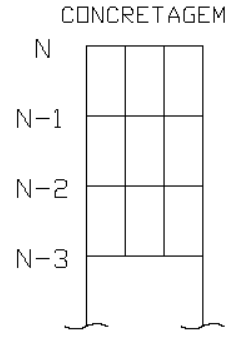

ETAPA E

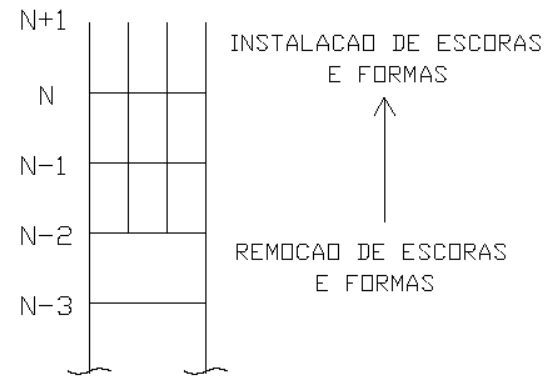

ETAPA E+1

b) 2 NIVEIS DE ESCGRAS MAIS 1 NIVEL DE REESCGRA $(2+1)$

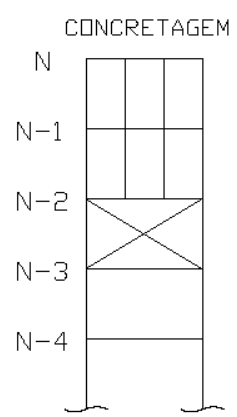

ETAPA E

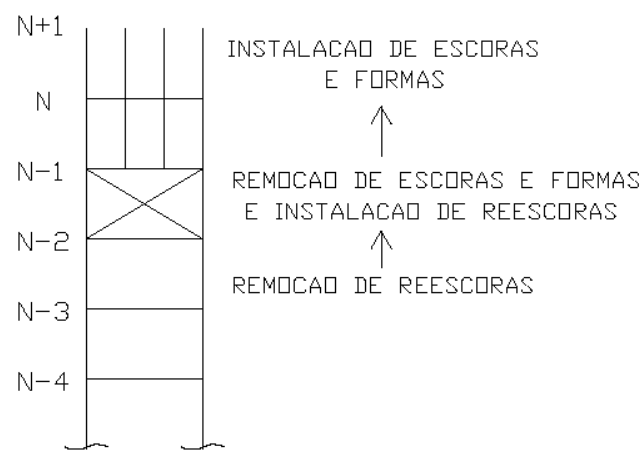

ETAPA E+1

FIGURA 2.1 - Operações básicas em processos de construção de edifícios

Deve-se lembrar que existem variações dentro das operações básicas apresentadas. Por exemplo, a operação de instalação das reescoras pode se dar de modo total ou parcial, ou seja, nem todos os pontos que estavam escorados são necessariamente reescorados. 
Outra variação se refere à retirada dos pontaletes feita somente para vigas, numa primeira etapa. Posteriormente repete-se a operação para as lajes.

$\mathrm{Na}$ verdade, no âmbito da construção civil nacional, encontram-se grandes variações no que diz respeito à quantidade e posicionamento dos pontaletes, esquema de construção, tempo de desforma, etc.. Este fato foi constatado "in loco" através de visitas feitas a algumas obras de construtoras do estado de São Paulo.

No Brasil, na maioria das obras ainda é utilizada a madeira como material para os pontaletes, embora cresça a cada dia o uso destes elementos em aço.

A madeira normalmente utilizada para a confecção dos pontaletes é o Pinus Elliottii, uma espécie conífera. Entretanto, como um ótimo substituto para o Pinus Elliottii tem-se destacado o Eucalipto Citriodora. O eucalipto é uma espécie dicotiledônea e apresenta suas fibras torcidas. Desta maneira, se utilizado serrado ou esquadrejado, como normalmente é feito com o pinus, não há condições de avaliar sua resistência mecânica. Por essa razão é aconselhável utilizá-lo sem interromper a disposição natural de suas fibras, ou seja, como peça roliça.

Já a madeira para confecção de fôrmas deve se destacar pelas seguintes qualidades:

- ter elevado módulo de elasticidade e razoável resistência;

- exibir bom desempenho quanto à trabalhabilidade, tendo-se em vista a serragem, penetração e extração dos pregos;

- apresentar baixo custo, já que a quantidade de madeira utilizada na construção de edifícios é muito grande;

- permitir vários reaproveitamentos.

Nos dias atuais, as chapas de madeira compensada já tomaram conta da grande maioria das obras civis substituindo as tradicionais tábuas de madeira serrada, na utilização como fôrmas. Os compensados são constituídos por uma associação de lâminas coladas com adesivos, geralmente obtidas do Pinus Elliottii, totalizando normalmente uma espessura de $12 \mathrm{~mm}$ quando utilizados em estruturas de edifícios. 


\section{AÇÕES PRESENTES NAS ETAPAS DE CONSTRUÇÃO}

Durante a construção de um edifício com múltiplos pavimentos estão presentes ações verticais e horizontais.

Dentre as ações horizontais destacam-se as provenientes do vento, do movimento produzido pelo lançamento do concreto e do funcionamento dos equipamentos. Algumas normas, dentre elas o ACI-347 (1988), especificam que o sistema fôrma/pontalete deve ser projetado para suportar uma ação horizontal (aplicada nas bordas do pavimento a ser concretado) de $1,5 \mathrm{kN} / \mathrm{m}$ ou $2 \%$ do total da ação vertical de peso próprio do pavimento (a que for maior). O tratamento das ações horizontais não faz parte desse trabalho.

As ações verticais referentes ao peso próprio dos materiais são de fácil estimativa. Os materiais, além do concreto armado, são a madeira (normalmente Eucalipto Citriodora ou Pinus Elliottii) e eventualmente o aço, utilizados em fôrmas e pontaletes. Os pesos específicos destes materiais são, aproximadamente:

Concreto Armado - $25 \mathrm{kN} / \mathrm{m}^{3}$

Eucalipto Citriodora - $10 \mathrm{kN} / \mathrm{m}^{3}$

Pinus Elliottii - $5,2 \mathrm{kN} / \mathrm{m}^{3}$

Aço $-78 \mathrm{kN} / \mathrm{m}^{3}$

Se as fôrmas utilizadas forem de madeira, por simplificação, pode-se considerar que o peso do seu conjunto seja igual a aproximadamente 5\% do peso próprio do pavimento.

Quanto às demais ações verticais (peso dos trabalhadores, equipamentos, materiais, entulhos, impacto produzido pelo lançamento do concreto, etc.) a bibliografia sugere tratamentos diferenciados. 
As normas que se referem ao assunto apenas indicam um determinado valor para essas ações variáveis, não especificando se elas atuariam em todos os pavimentos, só nos que pertencem ao sistema de suporte ou, ainda, apenas no que está sendo preparado para a concretagem. O ACI-347 (1988) indica um valor igual a $2,4 \mathrm{kN} / \mathrm{m}^{2}$, enquanto o OSHA (1972) recomenda $1,0 \mathrm{kN} / \mathrm{m}^{2}$.

Já alguns autores sugerem etapas nas quais tais ações atuariam.

Os estudos feitos por FATTAL (1983) mostram que quando o concreto é lançado por meio de baldes, provoca uma ação no pavimento da ordem de $2,0 \mathrm{kN} / \mathrm{m}^{2}$ a $2,5 \mathrm{kN} / \mathrm{m}^{2}$. LASISI \& NG (1979) consideram uma ação de $2,4 \mathrm{kN} / \mathrm{m}^{2}$, removida após a concretagem do pavimento.

MOSSALAM \& CHEN (1992) entendem que essas ações atuam onde houver pontaletes e devem ser consideradas com o valor de $50 \%$ do peso próprio do pavimento.

SBAROUNIS (1984) também possui estudos sobre o assunto. Analisando a distribuição de uma ação igual a $2,4 \mathrm{kN} / \mathrm{m}^{2}$, aplicada no pavimento que está sendo concretado, ele chegou à conclusão que, desprezando-se a fissuração, pode-se considerar uma ação de $(2,64 / \mathrm{N}) \mathrm{kN} / \mathrm{m}^{2}$ no pavimento de apoio do nível mais baixo de escoras. $\mathrm{O}$ valor de $\mathrm{N}$ representa o número de pavimentos pertencentes ao sistema de suporte. Segundo este autor, de maneira aproximada, essa ação pode ser simplesmente somada à máxima ação de construção do pavimento. Se for considerada a fissuração, SBAROUNIS (1984) indica uma ação de $(1,68 / \mathrm{N}) \mathrm{kN} / \mathrm{m}^{2}$. GARDNER (1985) sugere sempre o valor de $(1 / \mathrm{N})$ do peso próprio do pavimento.

Diante das controvérsias sobre esse carregamento variável, nas simulações das etapas de construção feitas adiante será considerada unicamente uma ação vertical que corresponde a $85 \%$ do peso próprio do pavimento, atuante só no momento da concretagem. A adoção desse valor para as ações variáveis é coerente, pois reflete uma média dos valores indicados pela bibliografia. 


\section{PROPRIEDADES DO CONCRETO EM IDADES INICIAIS}

Para que se possam formular modelos representativos de cada etapa de construção, devem-se estabelecer valores confiáveis para a resistência e deformabilidade do concreto em idades iniciais.

A pega e o endurecimento do concreto são muito influenciados pelo tipo de cimento, temperatura ambiente e condições de cura. $\mathrm{O}$ aumento da resistência e do módulo de elasticidade não está limitado ao período de 28 dias, sendo o ganho subsequente denominado de endurecimento posterior.

Admitindo-se condições de cura úmida e utilizando cimento portland comum, para o tempo infinito há um ganho de resistência à compressão de aproximadamente $35 \%$ em relação à resistência atingida aos 28 dias. Aos 180 dias esse ganho posterior já atinge aproximadamente $30 \%$. Deve-se destacar que a temperatura durante o período de endurecimento tem pouca influência na resistência final no tempo infinito.

Entretanto, esse ganho de resistência seria anulado por efeitos dos carregamentos de longa duração. Na verdade, a perda de resistência sob carga mantida no tempo infinito (Efeito Rüsch) pode acabar até superando o ganho por endurecimento posterior.

No presente trabalho interessam somente as propriedades do concreto jovem, ou seja, em idades inferiores aos 28 dias.

A influência do tipo de cimento no desenvolvimento da resistência do concreto não será abordada, admitindo-se o uso do cimento portland comum. Outro fator que também não será tratado, por sua pequena influência na maioria dos casos, é a dimensão do elemento concretado.

Quanto às temperaturas, estas são favoráveis ao desenvolvimento normal da resistência quando estão entre $20^{\circ} \mathrm{C}$ e $25^{\circ} \mathrm{C}$. As temperaturas mais elevadas aceleram 
o endurecimento. A umidade com calor é favorável até $90^{\circ} \mathrm{C}$, temperatura que acaba ocorrendo somente com cura a vapor.

Para temperaturas abaixo de $5^{\mathrm{O}} \mathrm{C}$ o endurecimento é perigosamente retardado, sendo necessário adotar medidas de aquecimento devido à hipótese de congelamento. Para temperaturas abaixo de $-10^{\circ} \mathrm{C}$ o processo químico da pega fica totalmente paralisado.

Apenas a título ilustrativo, o gráfico da figura 4.1 mostra o desenvolvimento da resistência à compressão do concreto para diferentes temperaturas, admitindo-se condições normais de cura úmida por 7 dias. Os dados do gráfico foram obtidos através de ensaios realizados por PRICE (1951). As condições normais de cura úmida são definidas mais adiante.

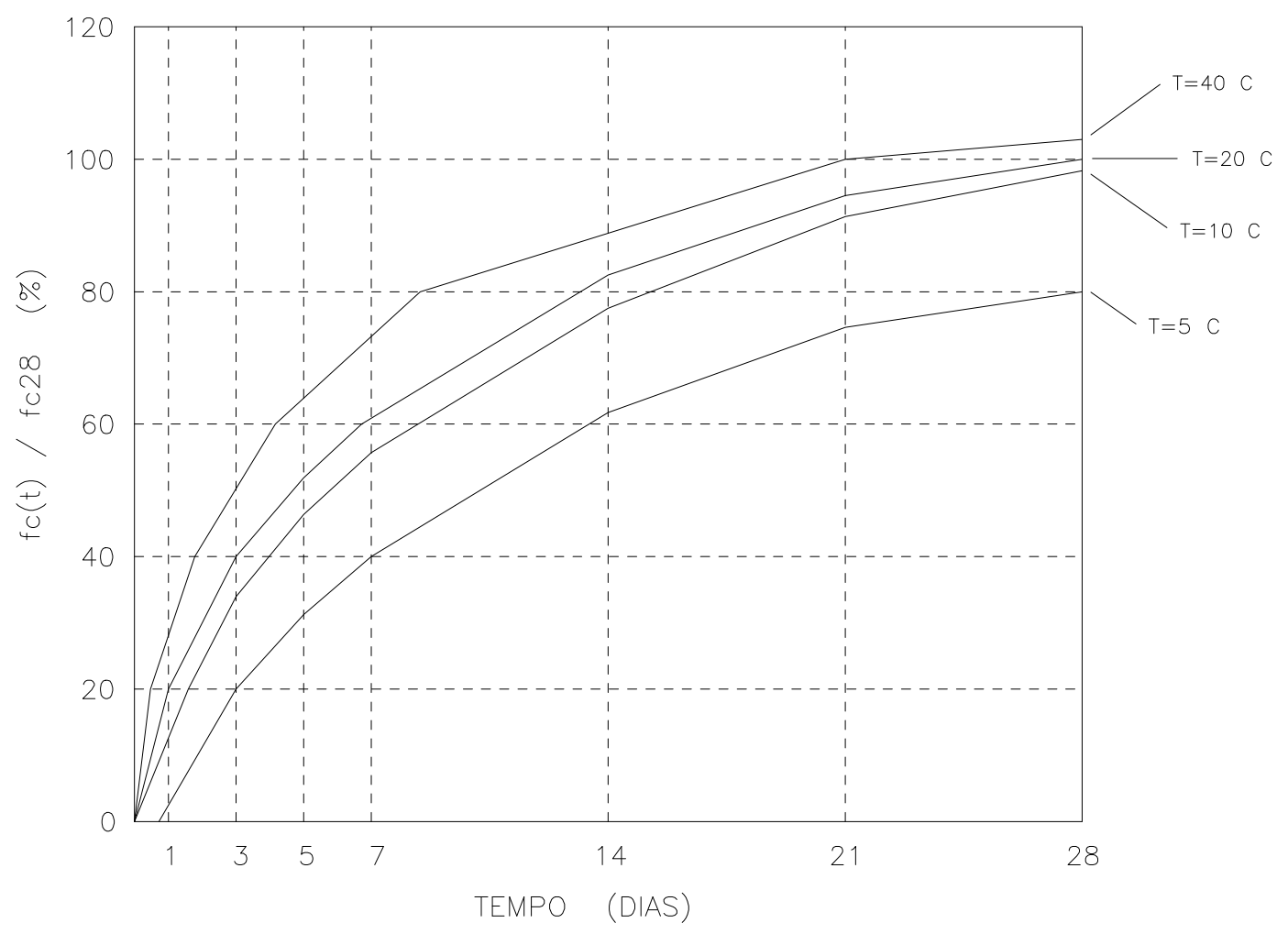

FIGURA 4.1 - Desenvolvimento da resistência à compressão do concreto para diferentes temperaturas [PRICE (1951)]

As condições de cura também influenciam a evolução do endurecimento do concreto em idades iniciais. 
Pode-se designar por cura o conjunto de operações ou procedimentos adotados para evitar que a água de hidratação do cimento evapore das regiões superficiais do elemento concretado. A hidratação é uma reação química do cimento com a água, gerando produtos que possuem características fundamentais à pega e ao endurecimento.

A água consumida internamente nesta reação química também pode ser associada a uma água perdida, por isso é preciso viabilizar a entrada externa desse elemento. As secagens prematuras das regiões superficiais resultam em camadas porosas de concreto, com baixa durabilidade. Para elementos com pequena espessura (lajes, por exemplo) esse problema se torna mais grave.

Existem vários procedimentos a adotar para garantir uma cura adequada: represamento ou imersão, irrigação, cobertura com panos ou areia molhada e o uso de membranas ou películas de revestimento que impedem a perda de umidade.

Neste trabalho, são consideradas as chamadas condições normais de cura úmida, as quais envolvem:

a) proteção contra o vento ou chuva forte;

b) irrigação com água à temperatura normal $\left(\sim 25^{\circ} \mathrm{C}\right)$;

c) umidade relativa do ar superior a $40 \%$.

Deve-se destacar que a irrigação com água muito fria pode provocar grandes diferenças de temperatura entre o interior (calor de hidratação) e o exterior do concreto e, consequentemente, causar fissuras na superfície.

Quando há a necessidade de acelerar o endurecimento deve-se usar cura a vapor. Tal procedimento consiste em aquecer as fôrmas com a utilização de vapor d'água a temperaturas em torno de $90^{\circ} \mathrm{C}$. Posteriormente é essencial um resfriamento prolongado, caso contrário surgirão fissuras. A resistência final do concreto curado a vapor é, no entanto, cerca de $10 \%$ inferior à do concreto curado normalmente.

Quanto ao tempo de cura necessário há controvérsias na literatura, sendo que a NBR-6118 (1978) especifica um período mínimo de 7 dias.

Para mostrar a influência do tempo de cura no desenvolvimento da resistência à compressão, o gráfico da figura 4.2 indica curas de 3, 7 e 14 dias consecutivos. Os 
dados foram obtidos em ensaios e adaptados de LEVY \& HELENE (1996). Foram consideradas condições normais de cura úmida e temperatura de $20^{\circ} \mathrm{C}$.

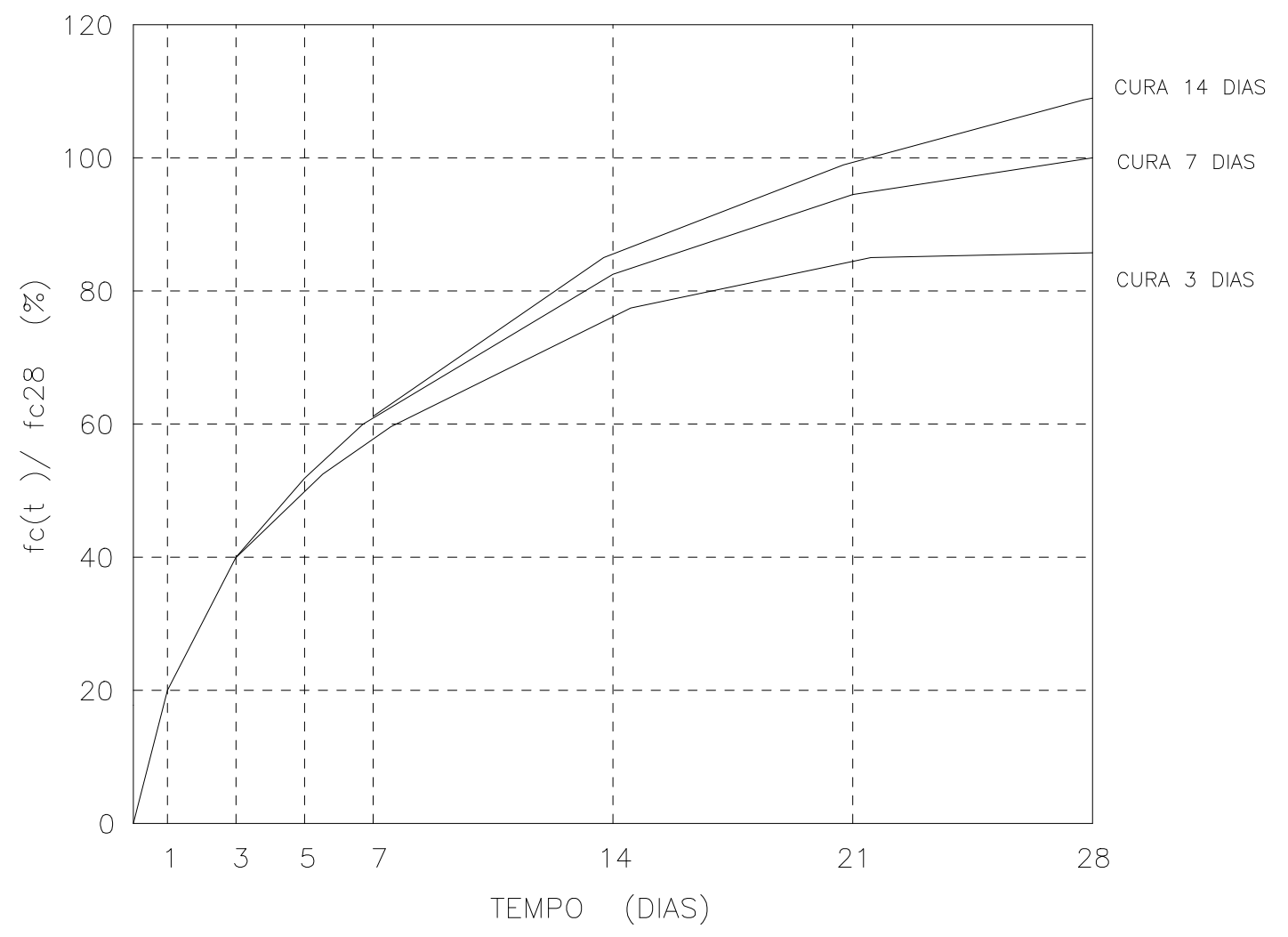

FIGURA 4.2 - Desenvolvimento da resistência à compressão do concreto para diferentes tempos de cura úmida [LEVY \& HELENE (1996)]

Segundo o gráfico anterior pode-se notar um decréscimo de aproximadamente $15 \%$ na resistência à compressão aos 28 dias quando, ao invés de 7 dias, procede-se à cura durante somente 3 dias. Já quando a cura é feita por 14 dias consecutivos há um acréscimo de cerca de $10 \%$.

De acordo com LEVY \& HELENE (1996) a partir de 14 dias não há mais nenhum ganho substancial de resistência aos 28 dias, por mais tempo que o concreto permaneça em condições normais de cura úmida.

Para determinar de maneira segura as características do concreto em idades iniciais deve-se proceder a ensaios constantes do material utilizado. No entanto, como é difícil pensar em ensaios que a cada instante reproduzam o que ocorre na obra, pesquisadores e normas ligadas ao assunto têm procurado estabelecer fórmulas 
que traduzam antecipadamente, e de maneira confiável, o desenvolvimento das características de resistência e deformabilidade do concreto com o tempo.

Via de regra, as características do concreto aos 28 dias são consideradas como funções apenas da sua resistência média à compressão $\mathrm{f}_{\mathrm{c}}$ nesta idade.

Não obstante, teorias de materiais compostos mostram que o valor do módulo de elasticidade $\mathrm{E}_{\mathrm{c}}$, por exemplo, depende diretamente dos módulos de elasticidade e das proporções relativas dos materiais que compõem o concreto, ou seja, os agregados (basalto, quartzo, gnaisse, granito, diabásio, calcário, arenito, etc.).

Assim, além de estabelecer valores confiáveis para as características do concreto em função da resistência média à compressão aos 28 dias, resta ainda saber se as relações se mantém para o concreto jovem.

A seguir são apresentadas as indicações de algumas normas e pesquisadores a respeito do assunto.

Deve-se esclarecer que o módulo de elasticidade $\mathrm{E}_{\mathrm{c}}$ a ser aqui indicado referese ao valor secante, utilizado em análises elástico-lineares, ou seja, admitindo uma relação linear entre tensões $\sigma_{\mathrm{c}}$ e deformações $\varepsilon_{\mathrm{c}}$. Esse valor é definido como sendo igual a $\sigma_{\mathrm{c}} / \varepsilon_{\mathrm{c}}$ quando $\sigma_{\mathrm{c}}=0,4 \mathrm{f}_{\mathrm{c}}$.

Todas as expressões mostradas a seguir, relativas ao amadurecimento do concreto com o tempo, consideram o uso do cimento portland comum e condições normais de cura úmida durante 7 dias consecutivos.

A unidade para a resistência média à compressão $\mathrm{f}_{\mathrm{c}} \mathrm{e}$ para o módulo de elasticidade secante $\mathrm{E}_{\mathrm{c}}$ é o MPa. $\mathrm{O}$ tempo $\mathrm{t}$ deve ser introduzido nas expressões em dias.

a) GARDNER \& ZHAO (1993)

$$
\mathrm{f}_{\mathrm{C}}(\mathrm{t})=\left(\frac{\mathrm{t}^{0,75}}{2,8+0,77 \mathrm{t}^{0,75}}\right) \mathrm{f}_{\mathrm{C}_{28}}
$$




$$
E_{C}(t)=3500+4300 \sqrt{f_{C}(t)}
$$

para $\mathrm{T}=20^{\circ} \mathrm{C}$

b) BS-8110 (1985)

$$
\begin{aligned}
& \mathrm{f}_{\mathrm{C}}(\mathrm{t}) \rightarrow \text { ensaiar corpo de prova na obra aos } \mathrm{t} \text { dias. } \\
& \mathrm{E}_{\mathrm{C}}(\mathrm{t})=\left(0,4+0,6 \frac{\mathrm{f}_{\mathrm{C}}(\mathrm{t})}{\mathrm{f}_{\mathrm{C}_{28}}}\right) \mathrm{E}_{\mathrm{C}}
\end{aligned}
$$

c) ACI-318 (1989)

$$
\begin{aligned}
& \mathrm{f}_{\mathrm{C}}(\mathrm{t})=\left(\frac{\mathrm{t}}{4+0,85 \mathrm{t}}\right) \mathrm{f}_{\mathrm{C}_{28}} \\
& \mathrm{E}_{\mathrm{C}}(\mathrm{t})=4730 \sqrt{\mathrm{f}_{\mathrm{C}}(\mathrm{t})}
\end{aligned}
$$

para $20^{\circ} \mathrm{C}<\mathrm{T}<25^{\circ} \mathrm{C}$.

d) CEB-90 (1990)

$$
\begin{aligned}
& \mathrm{f}_{\mathrm{C}}(\mathrm{t})=\beta_{\mathrm{CC}}(\mathrm{t}) \cdot \mathrm{f}_{\mathrm{C}_{28}} \text {, onde } \beta_{\mathrm{CC}}(\mathrm{t})=\mathrm{e}^{0,25\left[1-\left(\frac{28}{\mathrm{t}}\right)^{1 / 2}\right]} \\
& \mathrm{E}_{\mathrm{C}}(\mathrm{t})=\beta_{\mathrm{E}}(\mathrm{t}) \cdot \mathrm{E}_{\mathrm{C}} \text {, onde } \beta_{\mathrm{E}}(\mathrm{t})=\sqrt{\beta_{\mathrm{CC}}(\mathrm{t})} \\
& \operatorname{para} \mathrm{T}=20^{\circ} \mathrm{C} \text {. }
\end{aligned}
$$

NOTA: Para temperaturas diferentes de $20^{\circ} \mathrm{C}$, o CEB-90 (1990) indica a utilização de uma idade fictícia $t^{\prime}$ : 


$$
\mathrm{t}^{\prime}=\sum_{\mathrm{i}=1}^{\mathrm{n}} \Delta \mathrm{t}_{\mathrm{i}} \cdot \mathrm{e}^{\left[-\left(\frac{4000}{273+\mathrm{T}_{\mathrm{i}}}-13,65\right)\right]}
$$

onde $\Delta \mathrm{t}_{\mathrm{i}}=$ número de dias em que a temperatura média diária do ambiente $\left(\mathrm{T}_{\mathrm{i}}\right)$ pode ser admitida constante.

e) NBR-7197 (1989)

$$
f_{C}(t)=\left[\frac{13,26 t(t+42)}{(9 t+40)(t+61)}\right] f_{C_{28}}
$$

para $\mathrm{T}=20^{\circ} \mathrm{C}$.

NOTA: Para temperaturas diferentes de $20^{\circ} \mathrm{C}$, a NBR-7197 (1989) também indica a utilização de uma idade fictícia t'.

$$
t^{\prime}=2 \cdot \sum_{i=1}^{n} \Delta t_{i} \cdot\left(\frac{T_{i}+10}{30}\right)
$$

onde $\Delta \mathrm{t}_{\mathrm{i}}=$ número de dias em que a temperatura média diária do ambiente $\left(\mathrm{T}_{\mathrm{i}}\right)$ pode ser admitida constante.

f) Revisão da NBR-6118 (1978)

Segundo SHEHATA et al. (1993) o novo texto desta norma deve indicar o uso da tabela 4.1 para a resistência média à compressão, na ausência de dados mais precisos. 
TABELA 4.1 - Relações $\mathrm{f}_{\mathrm{c}}(\mathrm{t}) / \mathrm{f}_{\mathrm{C} 28}$, para $21^{\circ} \mathrm{C}<\mathrm{T}<30^{\circ} \mathrm{C}$

\begin{tabular}{|c|c|c|c|}
\hline $\mathrm{f}_{\mathrm{C} 28}(\mathrm{MPa})$ & 3 dias & 7 dias & 91 dias \\
\hline 18 & 0,34 & 0,50 & 1,26 \\
\hline 23 & 0,36 & 0,61 & 1,25 \\
\hline 28 & 0,42 & 0,66 & 1,20 \\
\hline 35 & 0,49 & 0,71 & 1,16 \\
\hline 43 & 0,54 & 0,74 & 1,14 \\
\hline
\end{tabular}

Em relação ao módulo de elasticidade esse novo texto deve estabelecer, ainda segundo SHEHATA et al. (1993):

$$
E_{C}(t)=\sqrt{\frac{f_{C}(t)}{f_{C_{28}}}} E_{C}
$$

para $21^{\circ} \mathrm{C}<\mathrm{T}<30^{\circ} \mathrm{C}$.

No presente trabalho, o valor da resistência característica do concreto $\mathrm{f}_{\text {ck }}$ será considerado como sendo o indicado pela expressão 4.12 a seguir, de acordo com o prescrito pela NBR-6118 (1978).

$$
\mathrm{f}_{\mathrm{ck}}(\mathrm{t})=\mathrm{f}_{\mathrm{c}}(\mathrm{t})-3,5
$$

onde:

$\mathrm{f}_{\mathrm{c}}(\mathrm{t})=$ resistência média do concreto à compressão na idade de $\mathrm{t}$ dias.

Apresentadas as expressões que quantificam o amadurecimento do concreto com o tempo, surge a necessidade de se eleger quais delas utilizar neste trabalho. Não é objetivo fazer comparações entre as mesmas. 
A princípio, a consideração da idade fictícia t' fornece mais precisão aos resultados. Somente o CEB-90 (1990) e a NBR-7197 (1989) incluem esse fator em suas formulações.

Talvez, então, seja mais coerente adotar a norma brasileira NBR-7197 (1989). Entretanto, segundo SHEHATA et al. (1993) o novo texto da NBR-6118 (1978) deve trazer valores diferentes, dados pela tabela 4.1. Esses valores, talvez mais apropriados para os concretos feitos em nosso país, são indicados para uma faixa de temperatura e somente para algumas idades.

Desta maneira, serão utilizadas as expressões indicadas pelo CEB-90 (1990), que consideram a idade fictícia t' e possuem uma eficácia amplamente comprovada pelo meio técnico. 


\section{SEGURANÇA DOS ELEMENTOS ESTRUTURAIS E PONTALETES}

Para verificar a segurança de uma estrutura pronta, em relação ao estado limite último de esgotamento da capacidade resistente de seus elementos estruturais, deve ser considerada a combinação última normal de ações. Segundo a NBR-8681 (1984), a ação vertical de cálculo $\mathrm{F}_{\mathrm{d}}$ resultante desta combinação é dada por:

$$
F_{d}=\gamma_{g} \cdot F_{g}+\gamma_{q} \cdot F_{q}
$$

onde:

$\gamma_{\mathrm{g}}, \gamma_{\mathrm{q}}$ : coeficientes de ponderação das ações características verticais permanentes e variáveis, respectivamente;

$\mathrm{F}_{\mathrm{g}}, \mathrm{F}_{\mathrm{q}}$ : ações características verticais permanentes e variáveis, respectivamente.

Ainda, de acordo com a NBR-8681 (1984), para esta combinação o coeficiente de ponderação $\gamma_{\mathrm{q}}$ das ações variáveis deve ser igual a 1,4. Para as ações permanentes, se consideradas de grande variabilidade (ou seja, o peso próprio da estrutura não supera $75 \%$ da totalidade das ações permanentes), o coeficiente de ponderação $\gamma_{\mathrm{g}}$ também deve valer 1,4 .

Obtida a ação solicitante $\mathrm{F}_{\mathrm{d}}$, há a necessidade de compará-la com a capacidade resistente $R_{d}$, também afetada por coeficientes que, neste caso, minoram as resistências dos materiais. Segundo a NBR-6118 (1978) esses coeficientes valem $\gamma_{C}$ $=1,4$ e $\gamma_{\mathrm{S}}=1,15$, respectivamente para o concreto e para $\mathrm{o}$ aço. 
Assim, para garantir a segurança de maneira econômica deve-se ter $F_{d}=R_{d}$, condição utilizada para dimensionamento da estrutura.

No entanto, é necessário garantir a segurança não só quando a estrutura estiver pronta mas também em todas as suas etapas de construção, como já comentado neste trabalho. Nestas etapas as ações são outras, e as resistências não são as de projeto, consideradas aos 28 dias.

Para a verificação da segurança em etapas de construção deve-se utilizar a combinação última de construção, definida na NBR-8681 (1984) também pela expressão 5.1. Entretanto, para esta combinação o coeficiente $\gamma_{\mathrm{q}}$ que pondera as ações verticais variáveis deve valer 1,2. Admitindo-se que as ações verticais permanentes durante a construção sejam de pequena variabilidade (ou seja, o peso próprio da estrutura supera $75 \%$ da totalidade das ações permanentes) a NBR-8681 (1984) estabelece que o coeficiente de ponderação $\gamma_{\mathrm{g}}$ também seja igual a 1,2.

Segundo a bibliografia sobre o assunto existe uma grande dificuldade em se estabelecer quais seriam os valores adequados para os coeficientes de ponderação das ações durante a construção.

Alguns autores, tais como STIVAROS \& KAMINETZKY (1994) preferem utilizar valores mais conservadores. Assim, os coeficientes seriam iguais a 1,4 e 1,7, respectivamente para as ações permanentes e para as ações variáveis.

Os autores que defendem valores mais conservadores para os coeficientes $\gamma_{\mathrm{g}} \mathrm{e}$ $\gamma_{\mathrm{q}}$ chamam a atenção para dois pontos importantes. Primeiramente, a grande maioria dos colapsos registrados pela literatura ocorreram em estruturas ainda em construção. Além disso, os trabalhadores da construção passam praticamente toda a vida nas obras, correndo riscos maiores que os ocupantes das estruturas prontas.

GARDNER (1985) sugere outros valores, com $\gamma_{\mathrm{g}}=1,4$ e $\gamma_{\mathrm{q}}=1,0$. Adotar $\gamma_{\mathrm{q}}=$ 1,0 talvez não seja adequado, considerando-se as grandes incertezas existentes na determinação das ações variáveis durante a construção.

Para a determinação da capacidade resistente em idades iniciais são considerados válidos os mesmos coeficientes de minoração das resistências do 
concreto $\left(\gamma_{C}=1,4\right)$ e do aço $\left(\gamma_{S}=1,15\right)$ adotados para o concreto com a idade de 28 dias.

No que se refere à verificação da segurança dos pontaletes (ruptura e estabilidade) recentemente entrou em vigor a NBR-7190 (1997) que regulamenta o assunto. Basicamente, de uma norma determinista de tensões admissíveis passou-se a uma norma probabilista de estados limites.

Como os pontaletes são solicitados durante as etapas de construção deve-se utilizar a combinação última de construção definida pela expressão 5.1 para a determinação da ação vertical de cálculo $\mathrm{F}_{\mathrm{d}}$.

Foram citados vários coeficientes de ponderação $(\gamma)$ das ações durante a construção para exemplificar a diversidade de valores indicados pela bibliografia. Entretanto, deve-se deixar claro que neste trabalho serão utilizados os valores prescritos pela NBR-8681 (1984), por ser a norma que regulamenta as ações e a segurança em nossas estruturas. Assim, considera-se $\gamma_{\mathrm{g}}=\gamma_{\mathrm{q}}=1,2$ nas combinações últimas de construção.

Esses coeficientes, com valores mais baixos do que aqueles utilizados nas combinações últimas normais, se justificam devido ao menor tempo de atuação das ações de construção em relação às ações em serviço. 


\section{DEFORMAÇÃO DOS ELEMENTOS ESTRUTURAIS}

\subsection{Verificação da deformação excessiva considerando as ações de construção}

Segundo a NBR-8681 (1984) os estados limites de utilização são "estados que por sua ocorrência, repetição ou duração causam efeitos estruturais que não respeitam as condições especificadas para o uso normal da construção, ou que são indícios de comprometimento da durabilidade da estrutura".

O estado limite de utilização no que se refere à deformação excessiva deve ser verificado de modo a garantir, em geral:

- a aparência da estrutura;

- o conforto sensorial;

- a integridade e o funcionamento dos elementos não-estruturais;

- a utilização adequada da própria estrutura e de possíveis equipamentos existentes.

Usualmente, a avaliação do estado limite de deformação excessiva nos pavimentos de concreto é feita, segundo as normas que tratam do assunto, por dois caminhos. O primeiro deles se aplica exigindo-se simplesmente que o elemento possua uma altura útil (d) superior a um valor mínimo determinado em função da sua geometria e da tensão na armadura. Para os elementos que não atendam à condição acima, a avaliação das deformações imediata e ao longo do tempo é feita considerando as características do concreto aos 28 dias e as ações em serviço.

Antes de estar submetido às ações em serviço o pavimento passa por etapas de construção nas quais é solicitado por outras ações estando o concreto ainda jovem. A consideração destas ações irá compor a história de carregamentos do pavimento, incrementando sem dúvida as deformações ao longo do tempo, devido à maior 
fissuração e conseqüente perda de rigidez quando o concreto é solicitado com pouca idade.

Segundo SBAROUNIS (1984), as ações de construção podem causar um acréscimo de $20 \%$ a $25 \%$ nas deformações do pavimento no tempo infinito.

Como será visto mais adiante, a história de carregamentos de um pavimento durante a construção do edifício é composta por uma seqüência de introduções e retiradas de ações definidas em etapas independentes entre si.

Ao fim das concretagens, a estrutura está submetida exclusivamente à ação permanente de peso próprio do concreto armado, ou seja, todas as ações variáveis de construção introduzidas são retiradas. Falta, então, somente uma única etapa para que se complete a história de carregamentos. Essa etapa é definida no trabalho como a entrada em serviço, compreendendo as ações permanentes de alvenaria e revestimento, bem como as ações variáveis referentes à sobrecarga de utilização.

Definida toda a história de carregamentos, adota-se uma metodologia de superposição das curvas de deformação (imediata e lenta) de cada etapa para que se possa chegar às deformações ao longo do tempo.

Desta maneira, segundo a NBR-8681 (1984), na combinação de utilização para verificação das deformações do pavimento a ação permanente de peso próprio do concreto armado deve entrar com seu valor característico, sem ponderação. Para as ações variáveis de construção é coerente adotar também simplesmente os valores característicos, uma vez que essas são introduzidas e logo retiradas com a mesma intensidade. Ainda de acordo com a NBR-8681 (1984), as ações permanentes referentes à entrada em serviço (alvenaria e revestimento) devem ser consideradas com os valores característicos, enquanto as ações variáveis de sobrecarga de utilização entram na combinação com a parcela quase-permanente.

Nesse caso, a parcela quase-permanente se forma com a aplicação do fator de utilização $\psi_{2}=0,2$, uma vez que trata-se de local sem elevada concentração de pessoas.

Finalmente, para a obtenção dos deslocamentos finais $(\Delta \mathrm{f})$ deve-se acrescentar as deformações devidas ao fenômeno da retração (ação permanente indireta), sem qualquer ponderação. 
Obtidos os valores das flechas finais dos elementos estruturais supondo atuantes as ações ora definidas, estas devem se situar abaixo de determinados limites especificados normalmente em função do tipo de estrutura. Em geral, segundo as normas que tratam do assunto, estes limites se situam entre L/300 e L/250. Para o caso das lajes deve-se considerar o valor de L como sendo o menor vão. No caso de elemento em balanço o valor de L deve ser tomado como o dobro do comprimento do próprio balanço.

Os valores limites de deslocamento transversal supõem elementos de vão $\mathrm{L}$ e são indicados em relação ao plano que contém os apoios. Segundo a NBR-6118 (1978), o valor limite para flechas é de L/300. O texto de revisão desta norma, em elaboração, deve fixar o valor de L/250 para os casos gerais.

Não se deve esquecer que deslocamentos transversais excessivos podem ser parcialmente compensados por contra-flechas.

Como já dito, as deformações finais $(\Delta \mathrm{f})$ são avaliadas somando-se as deformações imediatas e as obtidas ao longo do tempo. As deformações imediatas ( $\Delta \mathrm{i})$ são as deformações instantâneas obtidas mediante determinado carregamento. Já as deformações ao longo do tempo dizem respeito à deformação lenta $(\Delta \mathrm{L})$ e à deformação por retração $(\Delta r)$.

Deve-se ressaltar que tanto o fenômeno de deformação lenta quanto o de retração são altamente complexos e suas previsões dependem da confiabilidade dos modelos matemáticos utilizados para representá-los.

Tanto o ACI-209R (1992) quanto o CEB-90 (1990) e a NBR-7197 (1989) utilizam equações que possuem uma correlação razoável com resultados experimentais.

A deformação lenta caracteriza-se por um acréscimo de deformação ao longo do tempo quando o concreto é submetido a uma determinada tensão. $\mathrm{O}$ valor desse acréscimo no tempo infinito pode, em alguns casos, ser bem superior à deformação imediata. A magnitude da deformação lenta depende basicamente da composição do concreto, das condições do ambiente e da história de tensões do elemento. Quando as tensões são aplicadas estando o concreto ainda jovem, há um considerável acréscimo na deformação ao longo do tempo. 
O gráfico da figura 6.1 ilustra uma curva típica de deformação do concreto submetido de início a uma carga de compressão com valor constante, sendo posteriormente descarregado. Pode-se notar que o crescimento da deformação é mais acelerado no início. Quando a carga é retirada, de imediato a deformação é parcialmente recuperada. A recuperação é parcial porque o valor do módulo de elasticidade do concreto aumenta com o tempo. Após essa recuperação imediata, há uma recuperação lenta da deformação, permanecendo entretanto uma deformação permanente.

$\mathrm{Na}$ verdade, o descarregamento pode ser considerado como um "carregamento negativo". No entanto, neste "carregamento negativo" a recuperação lenta ocorreria em uma proporção menor do que se fosse imaginada uma deformação lenta sob carregamento. Há, na literatura sobre o assunto, controvérsias a respeito do valor dessa recuperação lenta.

Neste trabalho, o descarregamento será considerado como um "carregamento negativo", sem qualquer redução para a recuperação lenta.

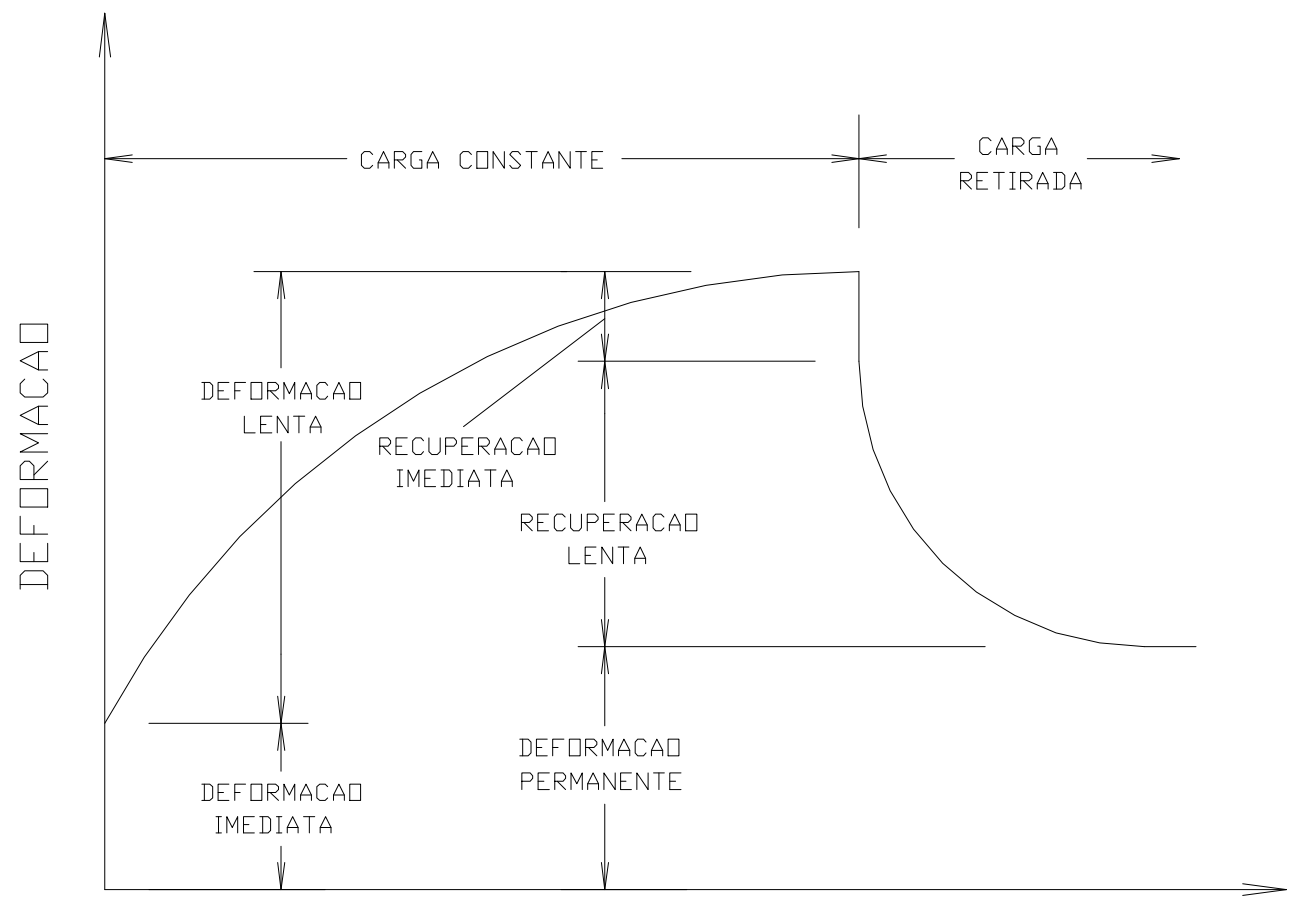

FIGURA 6.1 - Curva típica de deformação do concreto 
Já o fenômeno de retração ocorre quando existe perda de umidade por evaporação. Dessa maneira, há uma diminuição do volume do concreto com o tempo, independente da tensão a que está submetido.

Do mesmo modo que no caso da deformação lenta, o valor da retração depende da composição do concreto e das condições do ambiente. Além disso, também é fortemente influenciado pela forma do elemento, representada normalmente pela sua espessura fictícia, definida mais adiante.

A figura 6.2 mostra uma curva representando a diminuição de volume de um elemento de concreto. Pode-se notar que a diminuição de volume é desacelerada com o passar do tempo, convergindo para um valor constante. Por definição, o início da retração ocorre quando termina a cura úmida do elemento. Deve-se destacar que o fenômeno de retração é quase totalmente reversível, bastando para isso saturar o concreto com água.

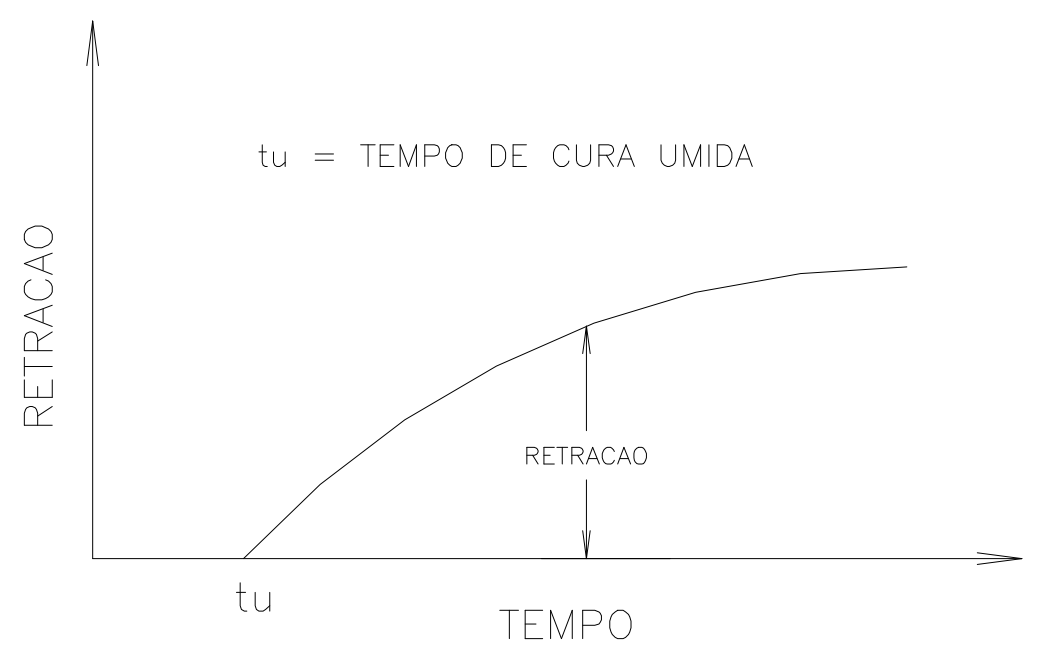

FIGURA 6.2 - Curva típica de retração do concreto

Em elementos de concreto o encurtamento devido à retração é resistido pela presença da armadura, conduzindo a tensões de compressão na própria armadura e principalmente a tensões de tração no concreto. As seções simétricas, com as armaduras inferior e superior também simétricas, apresentam uma deformação de encurtamento por retração uniforme, não ocorrendo curvatura no elemento. 
Entretanto, quando há quantidades diferentes de armadura junto às faces superior e inferior ocorre um impedimento à retração desigual entre estas faces, e conseqüentemente, uma distribuição de tensões não-uniforme na seção transversal. Há, a partir daí, o aparecimento de uma curvatura no elemento, o que conduz a um deslocamento transversal usualmente denominado flecha. Este deslocamento transversal ocorre no mesmo sentido do deslocamento devido ao peso próprio, caso a área de armadura inferior seja mais elevada que a área de armadura superior, e portanto resista mais ao encurtamento.

No caso das lajes, por serem elementos bidimensionais, a retração ocorre em todas as direções do plano. Há duas alternativas, neste caso. Pode-se fazer o cálculo independente em cada uma das direções perpendiculares adotando-se a média dos resultados obtidos. Opcionalmente, pode-se também fazer o cálculo somente para a direção do menor vão, por apresentar os maiores esforços solicitantes. Neste trabalho é adotada a segunda alternativa.

As normas que tratam do assunto permitem que sejam utilizados multiplicadores a serem aplicados nas deformações imediatas para a obtenção das deformações ao longo do tempo, fazendo uma aproximação pouco precisa da deformação lenta e da retração. É o caso do ACI-318 (1989) que indica um fator multiplicativo normalmente adotado igual a 2. Neste trabalho, as parcelas de cada fenômeno são calculadas separadamente, somando-se à deformação imediata.

No que se refere à perda de rigidez por fissuração na flexão pode-se utilizar a expressão empírica desenvolvida por BRANSON (1963) que fornece um valor efetivo para o momento de inércia $\left(\mathrm{I}_{\mathrm{e}}\right)$ em seções submetidas a momentos fletores com valor superior ao momento de fissuração:

$$
I_{e}=\left(\frac{M_{c r}}{M_{a}}\right)^{3} \cdot I_{c}+\left[1-\left(\frac{M_{c r}}{M_{a}}\right)^{3}\right] \cdot I_{c r}
$$

onde:

$I_{c}=$ momento de inércia da seção não-fissurada;

$\mathrm{I}_{\mathrm{cr}}=$ momento de inércia da seção totalmente fissurada; 
$\mathrm{M}_{\mathrm{cr}}=$ momento de fissuração;

$\mathrm{M}_{\mathrm{a}}=$ momento fletor atuante.

O valor do momento de inércia da seção totalmente fissurada $\left(\mathrm{I}_{\mathrm{cr}}\right)$ pode ser estimado igual a:

$$
I_{c r}=\left(\frac{d}{h}\right)^{3} \cdot\left[4 k^{3}+12 n \rho \cdot(1-k)^{2}\right] \cdot I_{g}
$$

onde:

$$
\begin{aligned}
& \mathrm{k}=\left[(\mathrm{n} \rho)^{2}+2 \mathrm{n} \rho\right]^{0,5}-\mathrm{n} \rho ; \\
& \mathrm{n}=\frac{\mathrm{E}_{\mathrm{S}}}{\mathrm{E}_{\mathrm{c}}} ; \\
& \rho=\frac{\mathrm{A}_{\mathrm{s}}}{\mathrm{b} \cdot \mathrm{d}}
\end{aligned}
$$

$\mathrm{I}_{\mathrm{g}}=$ momento de inércia da seção bruta de concreto.

$\mathrm{O}$ momento de inércia da seção não-fissurada $\left(\mathrm{I}_{\mathrm{c}}\right)$ pode levar em conta a presença da armadura tracionada $\mathrm{A}_{\mathrm{S}}$, sendo dado por:

$$
I_{c}=\left[1+12 \eta^{2}+12 n \rho \frac{d}{h} \cdot\left(\frac{d}{h}-\frac{1}{2}-\eta\right)^{2}\right] . I_{g}
$$

onde:

$$
\eta=\frac{n \rho \frac{d}{h} \cdot\left(\frac{2 d}{h}-1\right)}{2 \cdot\left(1+n \rho \frac{d}{h}\right)} ;
$$

n , $\rho$ e $I_{g}$ têm os mesmos significados da expressão 6.2. 
Já o momento de fissuração $\left(\mathrm{M}_{\mathrm{cr}}\right)$ depende diretamente da resistência do concreto à tração. Segundo a NBR-6118 (1978) tem-se:

$$
\mathrm{M}_{\mathrm{cr}}=\mathrm{f}_{\mathrm{ctm}} \cdot \frac{\mathrm{bh}^{2}}{6}
$$

onde:

$\mathrm{f}_{\mathrm{ctm}}=$ resistência média do concreto à tração na flexão;

$$
\begin{aligned}
& \mathrm{f}_{\mathrm{ctm}}=1,2 \cdot \mathrm{f}_{\mathrm{tk}}, \text { para vigas } \\
& \mathrm{f}_{\mathrm{ctm}}=1,5 \cdot \mathrm{f}_{\mathrm{tk}}, \text { para lajes }
\end{aligned}
$$

$\mathrm{f}_{\mathrm{tk}}=$ resistência característica do concreto à tração axial.

Como se pode notar pela expressão 6.4 o valor assumido para a resistência do concreto à tração é fundamental para a quantificação da perda de rigidez por fissuração.

Segundo o ACI-209R (1992), a expressão 6.1 que define o valor do momento de inércia efetivo $\left(\mathrm{I}_{\mathrm{e}}\right)$ para seções fissuradas pode ser utilizada como estimativa para o momento de inércia médio $\left(\mathrm{I}_{\mathrm{em}}\right)$ ao longo do vão de uma viga ou laje armada em uma direção, caso estas apresentem condições de momento fletor nulo nas extremidades. Neste caso, a fissuração deve ser calculada para a seção de máximo momento fletor.

Se a viga ou laje armada em uma direção possuir continuidade nas extremidades deve-se obter uma média simples entre os valores de $\mathrm{I}_{\mathrm{e}}$ nessas extremidades, e então novamente uma média simples entre o valor obtido e o valor de $\mathrm{I}_{\mathrm{e}}$ para a seção de máximo momento fletor positivo. Ocorrendo continuidade somente em um dos extremos, o valor para o momento de inércia médio $\left(\mathrm{I}_{\mathrm{em}}\right)$ ao longo do vão resulta de uma média simples entre o valor de $\mathrm{I}_{\mathrm{e}}$ obtido para a 
extremidade contínua e o valor de $\mathrm{I}_{\mathrm{e}}$ obtido para a seção de máximo momento fletor positivo.

Ainda, para as lajes armadas em duas direções o ACI-209R (1992) permite que o valor do momento de inércia médio $\left(\mathrm{I}_{\mathrm{em}}\right)$ seja estimado considerando apenas a direção do menor vão.

Obtido o valor do momento de inércia médio $\left(\mathrm{I}_{\mathrm{em}}\right)$, a perda de rigidez do elemento por fissuração está estimada. Assim, pode-se determinar de modo aproximado qual será a deformação imediata do elemento, considerando o referido fenômeno que dá origem a uma não-linearidade física. Para isso, deve-se simplesmente multiplicar o valor da deformação obtida considerando o momento de inércia da seção não-fissurada $\left(\mathrm{I}_{\mathrm{c}}\right)$ pela relação $\mathrm{I}_{\mathrm{C}} / \mathrm{I}_{\mathrm{em}}$. É bom lembrar que, na prática, o valor do momento de inércia da seção não-fissurada $\left(\mathrm{I}_{\mathrm{C}}\right)$ está bem próximo do valor do momento de inércia da seção bruta de concreto $\left(\mathrm{I}_{\mathrm{g}}\right)$.

A seguir são apresentadas expressões que definem o desenvolvimento da deformação lenta na flexão e da deformação por retração, válidas se atendidas as chamadas condições-padrão, aqui definidas como:

- cura úmida normal por 7 dias;

- uso do cimento portland comum;

- temperatura de $20^{\circ} \mathrm{C}$.

Para temperaturas diferentes de $20^{\circ} \mathrm{C}$ as normas geralmente definem uma idade fictícia, a ser utilizada nas expressões seguintes, no lugar da idade real do concreto. Isso serve para levar em conta o amadurecimento mais rápido do concreto para temperaturas mais elevadas, bem como o amadurecimento mais lento em presença de temperaturas mais baixas.

O ACI-209R (1992) nada indica a respeito de idades fictícias.

Já o CEB-90 (1990) indica a expressão 4.8, para ser utilizada exclusivamente na idade do carregamento $\left(\mathrm{t}_{\mathrm{o}}\right)$. 
Quanto à NBR-7197 (1989) deve ser usada a expressão 4.10 para a idade do concreto $(\mathrm{t})$ e para a idade do carregamento $\left(\mathrm{t}_{\mathrm{o}}\right)$, quando se desejar quantificar a deformação lenta. No caso da retração deve-se utilizar também a expressão 4.10, agora sem o fator multiplicativo 2, para a idade do concreto (t) e para o tempo de cura úmida $\left(\mathrm{t}_{\mathrm{u}}\right)$.

\subsection{Expressões para a quantificação da deformação lenta}

As expressões que quantificam o deslocamento transversal devido à deformação lenta $(\Delta \mathrm{L})$ em elementos fletidos, segundo algumas normas, são:

a) ACI-209R (1992)

$$
\Delta \mathrm{L}(\mathrm{t})=\xi \cdot v(\mathrm{t}) \cdot \Delta_{\mathrm{i}}
$$

onde:

$$
\begin{aligned}
\xi=0,85-0,45 & \cdot\left(\frac{\mathrm{A}_{\mathrm{s}}}{\mathrm{A}_{\mathrm{s}}}\right) \geq 0,40 ; \\
\mathrm{A}_{\mathrm{S}} & =\text { área da seção transversal da armadura tracionada } \\
\mathrm{A}{ }^{\prime} \text { s } & =\text { área da seção transversal da armadura comprimida }
\end{aligned}
$$

$$
\begin{gathered}
v(\mathrm{t})=1,25 \cdot\left(\mathrm{t}_{0}\right)^{-0,118} \cdot \gamma_{\mathrm{RH}} \cdot \gamma_{\mathrm{VS}} \cdot\left[\frac{\left(\mathrm{t}-\mathrm{t}_{0}\right)^{0,6}}{10+\left(\mathrm{t}-\mathrm{t}_{0}\right)^{0,6}}\right] \cdot v_{\mathrm{u}} ; \\
\gamma_{\mathrm{RH}}=1,27-0,0067 \cdot \mathrm{RH} \\
\mathrm{RH}=\text { umidade do ar, em } \%(\mathrm{RH}>40) \\
\gamma_{\mathrm{VS}}=\frac{2}{3} \cdot\left[1+1,13 \cdot \exp \left(-0,0213 \cdot \frac{\mathrm{V}}{\mathrm{S}}\right)\right] \\
\frac{\mathrm{V}}{\mathrm{S}}=\text { relação (volume / superfície) do elemento, em mm } \\
v_{\mathrm{u}}=2,35
\end{gathered}
$$


$\Delta_{\mathrm{i}}=$ flecha imediata, $\operatorname{com~} \mathrm{E}_{\mathrm{c}}\left(\mathrm{t}_{0}\right) ;$

$\mathrm{t}=$ idade do concreto em dias;

$\mathrm{t}_{0}=$ idade do carregamento em dias.

b) CEB-90 (1990)

$$
\Delta \mathrm{L}(\mathrm{t})=0,8 \cdot \phi(\mathrm{t}) \cdot \Delta_{\mathrm{i} 28}
$$

onde:

0,8 = fator que leva em conta a presença das armaduras;

$$
\begin{aligned}
& \phi(\mathrm{t})=\phi_{0} \cdot \beta_{\mathrm{c}}(\mathrm{t}) ; \\
& \phi_{0}=\phi_{\mathrm{RH}} \cdot \beta\left(\mathrm{f}_{\mathrm{cm}}\right) \cdot \beta\left(\mathrm{t}_{0}\right) \\
& \phi_{\mathrm{RH}}=1+\frac{1-\left(\frac{\mathrm{RH}}{100}\right)}{0,46 \cdot\left(\frac{\mathrm{h}_{\mathrm{fic}}}{100}\right)^{\frac{1}{3}}} \\
& \mathrm{RH}=\text { umidade do ar, em \% } \\
& \mathrm{h}_{\text {fic }}=\left(2 \mathrm{~A}_{\mathrm{c}}\right) / \mathrm{u}, \mathrm{em} \mathrm{mm} \\
& \mathrm{A}_{\mathrm{C}}=\text { área da seção transversal } \\
& \mathrm{u}=\text { perímetro exposto ao ambiente } \\
& \beta\left(\mathrm{f}_{\mathrm{cm}}\right)=\frac{5,3}{\left(\mathrm{f}_{\mathrm{c} 28} / \mathrm{f}_{\mathrm{cmo}}\right)^{0,5}} \\
& \mathrm{f}_{\mathrm{c} 28}=\text { resistência média à compressão aos } 28 \text { dias, em MPa } \\
& \mathrm{f}_{\mathrm{cmo}}=10 \mathrm{MPa} \\
& \beta\left(\mathrm{t}_{0}\right)=\frac{1}{0,1+\mathrm{t}_{0}{ }^{0,2}}
\end{aligned}
$$




$$
\begin{aligned}
\beta_{\mathrm{c}}(\mathrm{t})=\left[\frac{\left(\mathrm{t}-\mathrm{t}_{0}\right)}{\beta_{\mathrm{H}}+\left(\mathrm{t}-\mathrm{t}_{0}\right)}\right]^{0,3} \\
\beta_{\mathrm{H}}=150 \cdot\left[1+\left(1,2 \cdot \frac{\mathrm{RH}}{100}\right)^{18}\right] \cdot \frac{\mathrm{h}_{\mathrm{fic}}}{100}+250 \leq 1500 \\
\mathrm{RH}=\text { umidade do ar, em \% } \\
\mathrm{h}_{\mathrm{fic}}=\left(2 \mathrm{~A}_{\mathrm{c}}\right) / \mathrm{u}, \text { em mm } \\
\mathrm{A}_{\mathrm{C}}=\text { área da seção transversal } \\
\mathrm{u}=\text { perímetro exposto ao ambiente }
\end{aligned}
$$

$\Delta_{\mathrm{i} 28}=$ flecha imediata, com $\mathrm{E}_{\mathrm{c}}(28) ;$

$\mathrm{t}=$ idade do concreto em dias;

$\mathrm{t}_{0}=$ idade do carregamento em dias.

c) NBR-7197 (1989)

$$
\Delta \mathrm{L}(\mathrm{t})=\phi(\mathrm{t}) . \Delta_{\mathrm{i} 28}
$$

onde:

$$
\begin{aligned}
\phi(\mathrm{t})=\phi_{\mathrm{a}}+\phi_{\mathrm{f} \infty} \cdot\left[\beta_{\mathrm{f}}(\mathrm{t})-\beta_{\mathrm{f}}\left(\mathrm{t}_{0}\right)\right]+\phi_{\mathrm{d} \infty} \cdot \beta_{\mathrm{d}}(\mathrm{t}) ; \\
\phi_{\mathrm{a}}=0,8 \cdot\left\{1-\left[\frac{\mathrm{f}_{\mathrm{c}}\left(\mathrm{t}_{0}\right)}{\mathrm{f}_{\mathrm{c}}\left(\mathrm{t}_{\infty}\right)}\right]\right\} \\
\frac{\mathrm{f}_{\mathrm{c}}\left(\mathrm{t}_{0}\right)}{\mathrm{f}_{\mathrm{c}}\left(\mathrm{t}_{\infty}\right)}=\frac{9 \mathrm{t}_{0} \cdot\left(\mathrm{t}_{0}+42\right)}{\left(9 \mathrm{t}_{0}+40\right) \cdot\left(\mathrm{t}_{0}+61\right)} \\
\phi_{\mathrm{f} \infty}=\phi_{1 \mathrm{C}} \cdot \phi_{2 \mathrm{C}} \\
\phi_{1 \mathrm{C}}=4,45-0,035 \cdot \mathrm{RH}
\end{aligned}
$$$$
\mathrm{RH}=\text { umidade do ar, em \% }(\mathrm{RH} \leq 90)
$$ 


$$
\begin{aligned}
& \phi_{2 \mathrm{C}}=\frac{0,42+\mathrm{h}_{\mathrm{fic}}}{0,20+\mathrm{h}_{\mathrm{fic}}} \\
& \mathrm{h}_{\text {fic }}=[1+\exp (-7,8+0,1 \cdot \mathrm{RH})] \cdot \frac{2 \mathrm{~A}_{\mathrm{c}}}{\mathrm{u}}, \mathrm{em} \mathrm{m} \\
& \mathrm{RH}=\text { umidade do ar, em \% }(\mathrm{RH} \leq 90) \\
& \mathrm{A}_{\mathrm{C}}=\text { área da seção transversal } \\
& \mathrm{u}=\text { perímetro exposto ao ambiente } \\
& \beta_{f}(t)=\frac{t^{2}+A \cdot t+B}{t^{2}+C \cdot t+D} \\
& \beta_{\mathrm{f}}\left(\mathrm{t}_{0}\right)=\frac{\mathrm{t}_{0}{ }^{2}+\mathrm{A} \cdot \mathrm{t}_{0}+\mathrm{B}}{\mathrm{t}_{0}{ }^{2}+\mathrm{C} \cdot \mathrm{t}_{0}+\mathrm{D}} \\
& \mathrm{A}=42 \cdot \mathrm{h}_{\mathrm{fic}}{ }^{3}-350 \cdot \mathrm{h}_{\mathrm{fic}}{ }^{2}+588 \cdot \mathrm{h}_{\mathrm{fic}}+113 \\
& \mathrm{~B}=768 \cdot \mathrm{h}_{\mathrm{fic}}{ }^{3}-3060 \cdot \mathrm{h}_{\mathrm{fic}}{ }^{2}+3234 . \mathrm{h}_{\mathrm{fic}}-23 \\
& \mathrm{C}=-200 \cdot \mathrm{h}_{\mathrm{fic}}{ }^{3}+13 \cdot \mathrm{h}_{\mathrm{fic}}{ }^{2}+1090 \cdot \mathrm{h}_{\mathrm{fic}}+183 \\
& \mathrm{D}=7579 . \mathrm{h}_{\mathrm{fic}}{ }^{3}-31916 \cdot \mathrm{h}_{\mathrm{fic}}{ }^{2}+35343 \cdot \mathrm{h}_{\mathrm{fic}}+1931 \\
& 0,05 \leq \mathrm{h}_{\text {fic }}=[1+\exp (-7,8+0,1 \cdot \mathrm{RH})] \cdot \frac{2 \mathrm{~A}_{\mathrm{c}}}{\mathrm{u}} \geq 1,6, \mathrm{em} \mathrm{m} \\
& \mathrm{RH}=\text { umidade do ar, em } \%(\mathrm{RH} \leq 90) \\
& \mathrm{A}_{\mathrm{C}}=\text { área da seção transversal } \\
& \mathrm{u}=\text { perímetro exposto ao ambiente } \\
& \phi_{\mathrm{d} \infty}=0,4 \\
& \beta_{d}(t)=\frac{t-t_{0}+20}{t-t_{0}+70}
\end{aligned}
$$

$\Delta_{\mathrm{i} 28}=$ flecha imediata, com $\mathrm{E}_{\mathrm{c}}(28) ;$

$\mathrm{t}=$ idade do concreto em dias;

$\mathrm{t}_{0}=$ idade do carregamento em dias. 
Neste trabalho são aplicadas as expressões das três normas. No capítulo 11, bem como nos gráficos mostrados no anexo, são comparados os resultados gerados pelas mesmas.

\subsection{Expressões para a quantificação da deformação por retração}

De acordo com LEONHARDT (1978) o deslocamento transversal devido à retração do concreto $(\Delta \mathrm{r})$ em um elemento de vão L pode ser estimado através da seguinte expressão:

$$
\Delta \mathrm{r}(\mathrm{t})=\mathrm{k}_{\mathrm{w}} \cdot \phi_{\mathrm{SH}}(\mathrm{t}) \cdot \mathrm{L}^{2}
$$

onde:

$\mathrm{t}=$ idade do concreto em dias;

$\mathrm{k}_{\mathrm{W}}=$ coeficiente de contorno;

$\phi_{\mathrm{SH}}(\mathrm{t})=$ curvatura do elemento devida à retração, aos $\mathrm{t}$ dias;

$\mathrm{L}=$ comprimento do vão.

A tabela 6.1 mostra os valores a serem assumidos para o coeficiente de contorno $\left(\mathrm{k}_{\mathrm{W}}\right)$.

TABELA 6.1 - Valores do coeficiente de contorno $\left(\mathrm{k}_{\mathrm{w}}\right)$

\begin{tabular}{|c|c|}
\hline $\mathrm{k}_{\mathrm{W}}$ & CONDIÇÃO DE CONTORNO \\
\hline $1 / 2$ & Elemento em balanço \\
\hline $1 / 8$ & Ambos os apoios simples \\
\hline $11 / 128$ & 1 apoio simples / 1 apoio contínuo \\
\hline $1 / 16$ & Ambos os apoios contínuos \\
\hline
\end{tabular}


Quanto à curvatura do elemento devida à retração $\left(\phi_{\mathrm{SH}}\right)$, são mostrados a seguir os valores indicados por algumas normas.

a) ACI-209R (1992)

$$
\begin{aligned}
& \phi_{S H}(t)=\left[\frac{0,7 \cdot \varepsilon_{S H}(t)}{h}\right] \cdot\left(\rho-\rho^{\prime}\right) \frac{1}{3} \cdot\left(\frac{\rho-\rho^{\prime}}{\rho}\right)^{\frac{1}{2}}, \text { para }\left(\rho-\rho^{\prime}\right) \leq 3 \% \\
& \phi_{S H}(t)=\frac{\varepsilon_{S H}(t)}{h}, \operatorname{para}\left(\rho-\rho^{\prime}\right)>3 \%
\end{aligned}
$$

onde:

$\rho=$ taxa de armadura tracionada;

$\rho^{\prime}=$ taxa de armadura comprimida;

$\mathrm{h}=$ altura da seção transversal do elemento;

$$
\begin{aligned}
& \varepsilon_{\mathrm{SH}}(\mathrm{t})=\gamma_{\mathrm{RH}} \cdot \gamma_{\mathrm{VS}} \cdot \frac{(\mathrm{t}-7)}{35+(\mathrm{t}-7)} \cdot\left(\varepsilon_{\mathrm{SH}}\right)_{\mathrm{u}} ; \\
& \gamma_{\mathrm{RH}}=1,40-0,010 \cdot \mathrm{RH} \\
& \quad \mathrm{RH}=\text { umidade do ar, em } \%(40 \leq \mathrm{RH} \leq 80) \\
& \gamma_{\mathrm{RH}}=3,00-0,030 . \mathrm{RH} \\
& \mathrm{RH}=\text { umidade do ar, em } \%(\mathrm{RH}>80) \\
& \gamma_{\mathrm{VS}}=1,2 . \exp \left(-0,00472 \cdot \frac{\mathrm{V}}{\mathrm{S}}\right) \\
& \left.\frac{\mathrm{V}}{\mathrm{S}}=\operatorname{relação~(volume~} / \text { superfície }\right) \text { do elemento, em mm } \\
& \left(\varepsilon_{\mathrm{SH}}\right)_{\mathrm{u}}=780.10^{-6}
\end{aligned}
$$

$\mathrm{t}=$ idade do concreto em dias. 
b) CEB-90 (1990)

$$
\phi_{S H}(t)=\frac{0,75 \cdot \varepsilon_{S H}(t)}{d}
$$

onde:

$0,75=$ fator que leva em conta a presença das armaduras;

d = altura útil da seção transversal do elemento;

$$
\begin{aligned}
& \varepsilon_{S H}(t)=\varepsilon_{S H o} \cdot \beta_{S}(t) ; \\
& \varepsilon_{\mathrm{SHo}}=\varepsilon_{\mathrm{S}}\left(\mathrm{f}_{\mathrm{cm}}\right) \cdot \beta_{\mathrm{RH}} \\
& \varepsilon_{\mathrm{S}}\left(\mathrm{f}_{\mathrm{cm}}\right)=\left\{160+50 \cdot\left[9-\left(\frac{\mathrm{f}_{\mathrm{c} 28}}{\mathrm{f}_{\mathrm{cmo}}}\right)\right]\right\} \cdot 10^{-6} \\
& \mathrm{f}_{\mathrm{c} 28}=\text { resistência média à compressão aos } 28 \text { dias, em MPa } \\
& \mathrm{f}_{\mathrm{cmo}}=10 \mathrm{MPa} \\
& \beta_{\mathrm{RH}}=-1,55 \cdot\left[1-\left(\frac{\mathrm{RH}}{100}\right)^{3}\right] \\
& \mathrm{RH}=\text { umidade do ar, em } \%(40 \leq \mathrm{RH} \leq 99) \\
& \beta_{S}(t)=\left[\frac{(t-7)}{350 \cdot\left(\frac{h_{\text {fic }}}{100}\right)^{2}+(t-7)}\right]^{0,5} \\
& \mathrm{~h}_{\text {fic }}=\left(2 \mathrm{~A}_{\mathrm{c}}\right) / \mathrm{u}, \mathrm{em} \mathrm{mm} \\
& \mathrm{A}_{\mathrm{C}}=\text { área da seção transversal } \\
& \mathrm{u}=\text { perímetro exposto ao ambiente }
\end{aligned}
$$

$\mathrm{t}=$ idade do concreto em dias. 
c) NBR-7197 (1989)

$$
\phi_{S H}(t)=\frac{\varepsilon_{S H}(t)}{d}
$$

onde:

d = altura útil da seção transversal do elemento;

$$
\begin{aligned}
& \varepsilon_{S H}(t)=\varepsilon_{S H \infty} \cdot\left[\beta_{S}(t)-\beta_{S}\left(t_{u}\right)\right] \\
& \varepsilon_{\mathrm{SH} \infty}=\varepsilon_{1 \mathrm{~S}} \cdot \varepsilon_{2 \mathrm{~S}} \\
& \varepsilon_{1 \mathrm{~S}}=\left(-6,16-\frac{\mathrm{RH}}{484}+\frac{\mathrm{RH}^{2}}{1590}\right) \cdot 10^{-4} \\
& \mathrm{RH}=\text { umidade do ar, em \% } \\
& \varepsilon_{2 S}=\frac{0,33+2 \cdot h_{\mathrm{fic}}}{0,21+3 \cdot h_{\mathrm{fic}}} \\
& 0,05 \leq \mathrm{h}_{\text {fic }}=[1+\exp (-7,8+0,1 \cdot \mathrm{RH})] \cdot \frac{2 \mathrm{~A}_{\mathrm{c}}}{\mathrm{u}} \geq 1,6, \mathrm{em} \mathrm{m} \\
& \mathrm{RH}=\text { umidade do ar, em \% }(\mathrm{RH} \leq 90) \\
& \mathrm{A}_{\mathrm{C}}=\text { área da seção transversal } \\
& \mathrm{u}=\text { perímetro exposto ao ambiente } \\
& \beta_{S}(t)=\frac{\left(\frac{t}{100}\right)^{3}+a \cdot\left(\frac{t}{100}\right)^{2}+b \cdot\left(\frac{t}{100}\right)}{\left(\frac{t}{100}\right)^{3}+c \cdot\left(\frac{t}{100}\right)^{2}+d \cdot\left(\frac{t}{100}\right)+e} \\
& \beta_{S}\left(t_{u}\right)=\frac{\left(\frac{t_{u}}{100}\right)^{3}+a \cdot\left(\frac{t_{u}}{100}\right)^{2}+b \cdot\left(\frac{t_{u}}{100}\right)}{\left(\frac{t_{u}}{100}\right)^{3}+c \cdot\left(\frac{t_{u}}{100}\right)^{2}+d \cdot\left(\frac{t_{u}}{100}\right)+e} \\
& \mathrm{a}=40 \\
& \mathrm{~b}=116 \cdot \mathrm{h}_{\mathrm{fic}}{ }^{3}-282 \cdot \mathrm{h}_{\mathrm{fic}}{ }^{2}+220 \cdot \mathrm{h}_{\mathrm{fic}}-4,8 \\
& \mathrm{c}=2,5 \cdot \mathrm{h}_{\mathrm{fic}}{ }^{3}-8,8 \cdot \mathrm{h}_{\mathrm{fic}}+40,7
\end{aligned}
$$




$$
\begin{gathered}
\mathrm{d}=-75 \cdot \mathrm{h}_{\mathrm{fic}}{ }^{3}+585 \cdot \mathrm{h}_{\mathrm{fic}}{ }^{2}+496 \cdot \mathrm{h}_{\mathrm{fic}}-6,8 \\
\mathrm{e}=-169 \cdot \mathrm{h}_{\mathrm{fic}}{ }^{4}+88 \cdot \mathrm{h}_{\mathrm{fic}}{ }^{3}+584 \cdot \mathrm{h}_{\mathrm{fic}}{ }^{2}-39 \cdot \mathrm{h}_{\mathrm{fic}}+0,8 \\
0,05 \leq \mathrm{h}_{\mathrm{fic}}=[1+\exp (-7,8+0,1 \cdot \mathrm{RH})] \cdot \frac{2 \mathrm{~A}_{\mathrm{c}}}{\mathrm{u}} \geq 1,6, \mathrm{em} \mathrm{m} \\
\mathrm{RH}=\text { umidade do ar, em } \%(\mathrm{RH} \leq 90) \\
\mathrm{A}_{\mathrm{C}}=\text { área da seção transversal } \\
\mathrm{u}=\text { perímetro exposto ao ambiente }
\end{gathered}
$$

$\mathrm{t}=$ idade do concreto em dias;

$\mathrm{t}_{\mathrm{u}}=$ tempo de cura úmida (7 dias).

Do mesmo modo que para as expressões que quantificam a deformação lenta, são utilizadas mais adiante as indicações das três normas. Novamente, a comparação entre elas se dá no capítulo 11 e nos gráficos do anexo. 


\section{O MÉTODO SIMPLIFICADO DE GRUNDY E KABAILA}

Um edifício em construção compõe um sistema estrutural que muda com o tempo. Além disso, como já comentado, o tempo altera as características de resistência e deformabilidade do concreto, mais acentuadamente nas idades iniciais.

Tanto a NBR-6118 (1978) quanto as normas internacionais não definem qualquer procedimento para determinação da distribuição das ações de construção nas estruturas de edifícios em concreto armado com múltiplos pavimentos.

Sendo assim nota-se que estudos a respeito do assunto, como aqui estão sendo feitos, são extremamente oportunos.

O ACI - Formwork for concrete (1989) apenas recomenda o método descrito por GRUNDY \& KABAILA (1963) para avaliar a distribuição das ações de construção. Esse método praticamente pioneiro, denominado neste trabalho de método simplificado, tem servido até hoje como base para a maioria das pesquisas na área.

Para utilizar o método simplificado há a necessidade de se definir o conceito de fatores de carga.

Os fatores de carga (k) expressam as ações de construção no pavimento ou nos pontaletes, sendo definidos como:

$$
\mathrm{k}=\frac{\text { ação atuante no pavimento(ou pontaletes })}{\text { peso próprio do pavimento }}
$$

O método simplificado admite as seguintes hipóteses: 
a) os pontaletes são considerados infinitamente rígidos em comparação com os pavimentos, no que se refere aos deslocamentos verticais;

b) os pontaletes estão posicionados suficientemente próximos entre si, de maneira que suas ações nos pavimentos podem ser consideradas como uniformemente distribuídas;

c) os valores das ações não dependem da velocidade de construção, uma vez que não são consideradas as diferentes idades do concreto;

d) a fundação é considerada como um suporte totalmente rígido;

e) após a remoção das escoras, as fôrmas são retiradas permitindo-se a deformação do pavimento antes que qualquer reescora seja instalada;

f) os fatores de carga obtidos devem ser majorados ( 10\%) para levar em conta o peso próprio das fôrmas e pontaletes;

g) deve-se somar à máxima ação de construção obtida para pavimentos (ou pontaletes) um valor correspondente às seguintes ações variáveis: peso dos trabalhadores, equipamentos, materiais, entulhos e impacto produzido pelo lançamento do concreto.

A figura 7.1 mostra os fatores de carga obtidos no caso de um processo de construção com dois níveis de escora mais dois níveis de reescora (2+2). 

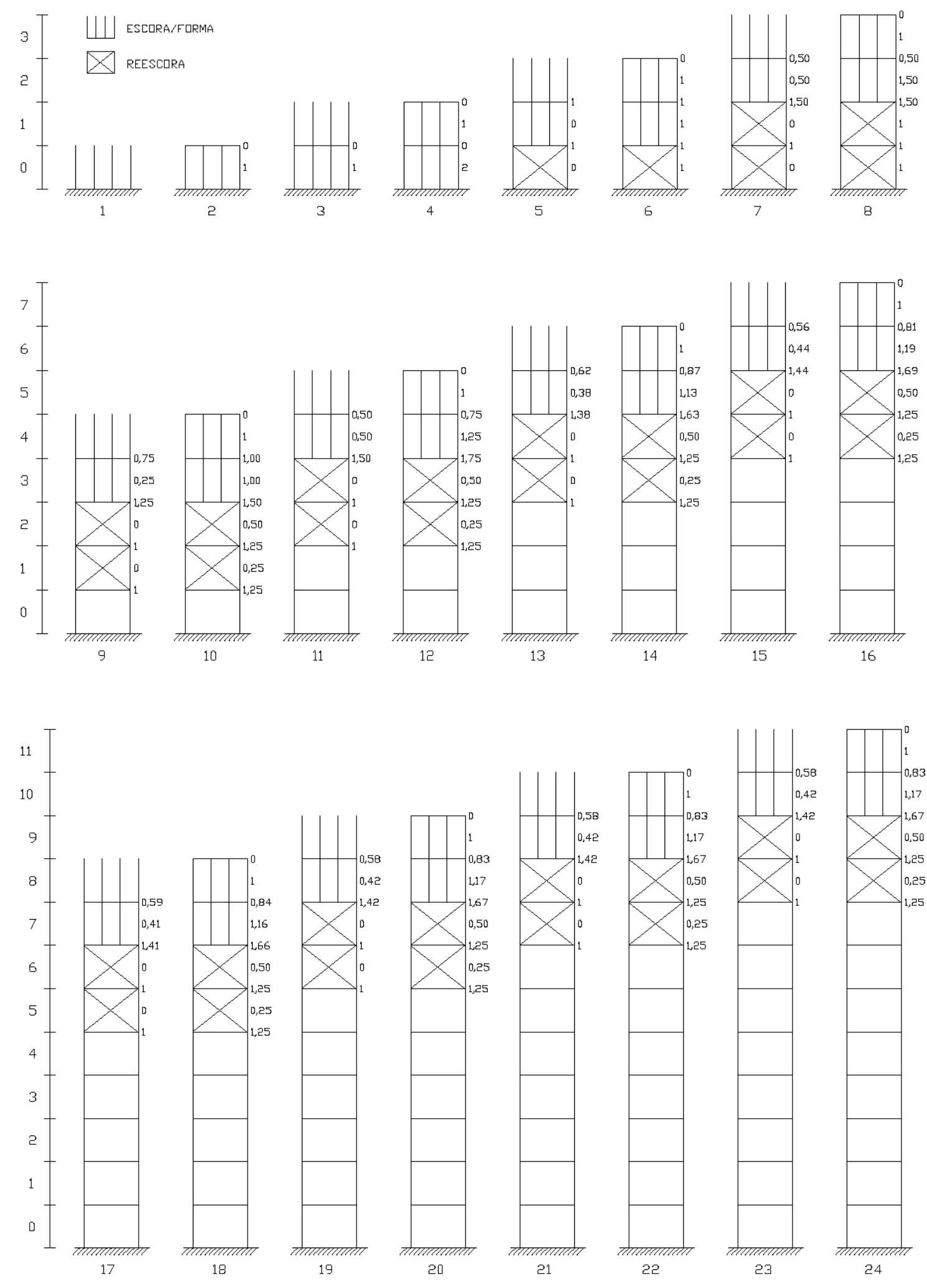

FIGURA 7.1 - Fatores de carga (k) para pavimentos e pontaletes $(2+2)$ 
$\mathrm{Na}$ operação (1) as escoras são instaladas, apoiando-se numa fundação rígida. $\mathrm{Na}$ operação (2) o primeiro pavimento é concretado, moldando-se nas fôrmas. O peso do concreto fresco é transmitido diretamente à fundação.

Na operação (3) o segundo nível de escoras é instalado sobre o primeiro pavimento e então o segundo pavimento é concretado na etapa (4). Como as escoras do primeiro nível estão apoiadas sobre fundação rígida, o peso do segundo pavimento também é transmitido totalmente à base. Por hipótese o primeiro pavimento não se deforma, não recebendo portanto qualquer carga.

A operação (5) consiste na remoção das fôrmas e escoras do primeiro pavimento, que se deforma juntamente com o segundo pavimento. Satisfazendo o equilíbrio, o fator de carga (de valor 2) presente nas escoras removidas é distribuído igualmente entre os dois pavimentos do sistema de suporte. Ainda nesta operação, escoras são instaladas no terceiro nível e reescoras são instaladas no primeiro nível, sem qualquer carga.

A operação (6) envolve a concretagem do terceiro pavimento, sendo a carga transmitida diretamente à fundação, já que os pavimentos não se deformam. $\mathrm{Na}$ operação (7) remove-se o nível mais baixo de fôrmas e escoras, com o fator de carga (de valor 1) sendo distribuído igualmente entre os dois pavimentos superiores. As ações nas escoras e reescoras são obtidas por equilíbrio. Ainda nesta operação, escoras são instaladas no quarto nível e reescoras são instaladas no segundo nível, sem qualquer carga.

$\mathrm{Na}$ operação (8) é feita a concretagem do quarto pavimento, sendo a carga transmitida diretamente à fundação, através dos pontaletes rígidos. A operação (9) envolve a remoção do nível mais baixo de fôrmas e escoras, com o fator de carga (de valor 1,50) sendo distribuído igualmente entre os dois pavimentos superiores. Ainda nesta operação, as reescoras são retiradas do nível mais baixo e instaladas no terceiro nível (sem qualquer carga), enquanto simultaneamente escoras são instaladas no quinto nível. Os pavimentos abaixo do nível de fôrmas retirado suportam apenas o próprio peso. Por equilíbrio obtém-se as ações nas escoras e reescoras.

Na operação (10) é concretado o quinto pavimento, sendo a carga distribuída igualmente entre os pavimentos que formam o sistema de suporte. Novamente, as ações nas escoras e reescoras são obtidas por equilíbrio. 
A operação (11) repete a seqüência da operação (9), e assim por diante até ocorrer a convergência dos valores dos fatores de carga para pavimentos e pontaletes.

A figura 7.2 mostra os fatores de carga máximos para cada pavimento, indicando uma convergência de valores relativamente rápida.

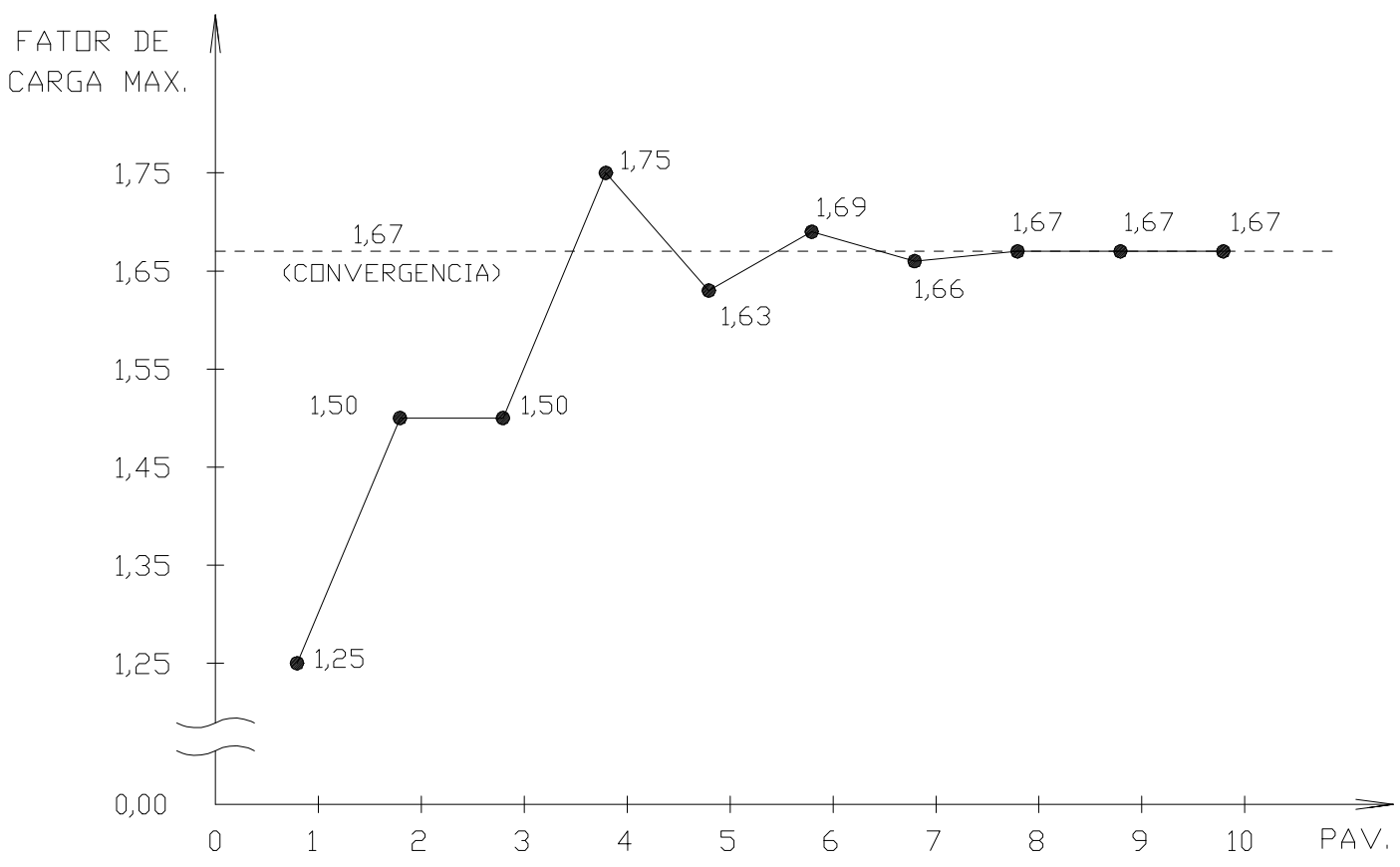

FIGURA 7.2 - Fatores de carga máximos para cada pavimento

Pode-se notar que a ação de construção mais elevada ocorre no quarto pavimento $(\mathrm{k}=1,75)$, durante a operação (12).

Já em relação aos pontaletes, o nível mais solicitado é o apoiado diretamente na fundação rígida $(\mathrm{k}=2)$, durante a operação (4).

Através do método simplificado pode-se estabelecer para cada pavimento um diagrama de fatores de carga. A figura 7.3 ilustra o diagrama obtido para o quarto pavimento. 


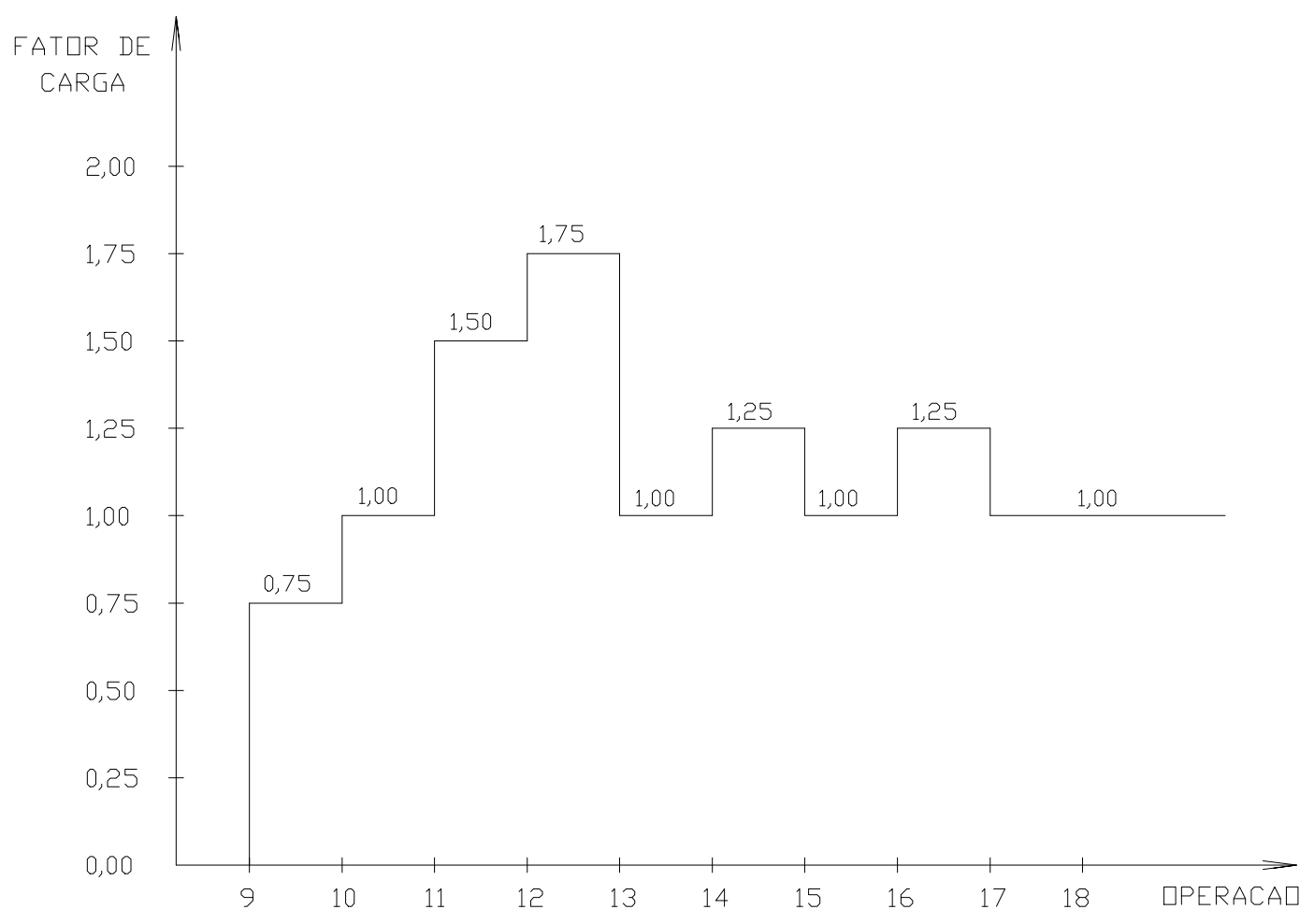

FIGURA 7.3 - Diagrama de fatores de carga para o quarto pavimento

Este diagrama define a história de carregamentos construtivos do quarto pavimento. Deve-se lembrar, ainda, de duas indicações do método simplificado. A primeira delas se refere à majoração dos fatores de carga, a fim de levar em conta o peso próprio das fôrmas e pontaletes. A segunda se refere à adição à máxima ação de construção de um valor referente às ações variáveis já citadas. Por exemplo, será feita uma majoração de $10 \%$ nos fatores de carga e, para considerar as referidas ações variáveis, somado o valor de $(2,64 / \mathrm{N}) \mathrm{kN} / \mathrm{m}^{2}$ ao patamar da máxima ação de construção, nesse caso. O número de pavimentos do sistema de suporte $(\mathrm{N})$ é igual a quatro, e o valor adicionado será de $0,66 \mathrm{kN} / \mathrm{m}^{2}$.

A figura 7.4 mostra a história de carregamentos construtivos do quarto pavimento assim obtida, supondo que este tenha um peso próprio de $3,5 \mathrm{kN} / \mathrm{m}^{2}$. 


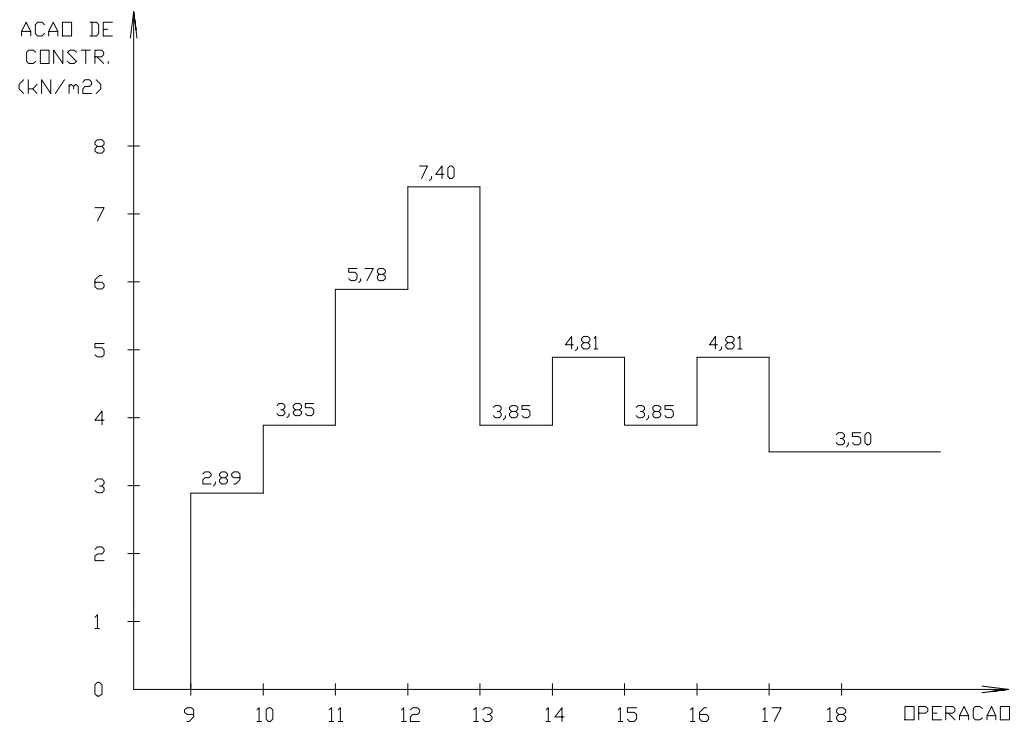

FIGURA 7.4 - História de carregamentos construtivos para o quarto pavimento

A tabela 7.1 mostra os valores máximo e convergente para os fatores de carga nos pavimentos, admitindo processos de construção combinados de até três níveis de escoras com até cinco níveis de reescoras.

Os resultados desta tabela mostram que, considerando as hipóteses do método simplificado, é preferível utilizar somente um nível de escoras e quantos níveis de reescoras forem possíveis para minimizar as ações de construção nos pavimentos.

TABELA 7.1 - Valores máx. e convergente dos fatores de carga para os pavimentos

\begin{tabular}{|c|c|c|c|c|c|c|c|}
\hline \multirow{3}{*}{$\begin{array}{c}\text { N. }{ }^{0} \text { DE NÍVEIS } \\
\text { DE ESCORAS }\end{array}$} & \multicolumn{7}{|c|}{ FATORES DE CARGA MÁXIMO E CONVERGENTE } \\
\cline { 2 - 8 } & & 0 & 1 & 2 & 3 & 4 & 5 \\
\hline \multirow{2}{*}{1} & MÁXIMO ${ }^{0}$ DE NÍVEIS DE REESCORAS \\
\cline { 2 - 8 } & CONVERGENTE & 2,00 & 1,50 & 1,33 & 1,25 & 1,20 & 1,17 \\
\hline \multirow{2}{*}{2} & MÁXIMO & 2,25 & 1,83 & 1,75 & 1,67 & 1,59 & 1,54 \\
\cline { 2 - 8 } & CONVERGENTE & 2,00 & 1,77 & 1,67 & 1,60 & 1,55 & 1,52 \\
\hline 3 & MÁXIMO & 2,38 & 2,21 & 1,98 & 1,84 & 1,78 & 1,78 \\
\cline { 2 - 8 } & CONVERGENTE & 2,00 & 1,87 & 1,83 & 1,77 & 1,72 & 1,72 \\
\hline
\end{tabular}


Embora os resultados apresentados neste capítulo devam ser respeitados, há a necessidade de se melhor estudar o assunto, por exemplo no que se refere a duas hipóteses adotadas: os pontaletes seriam infinitamente rígidos e todos os pavimentos do sistema de suporte teriam as mesmas características de resistência e deformabilidade.

Quanto à primeira hipótese, deve-se dizer que sua adoção prejudica os resultados. Enquanto o primeiro nível de pontaletes (apoiado em fundação rígida) não é retirado, todas as ações de lajes concretadas caminham diretamente para a fundação através dos mesmos. Absolutamente isso não condiz com a realidade. Está claro que, como os pontaletes são axialmente deformáveis, parte das ações de um pavimento recém concretado é absorvida pelos pavimentos inferiores do sistema de suporte.

Já a segunda hipótese significa não considerar a idade do concreto na determinação da distribuição das ações de construção. Ao tomar todos os pavimentos do sistema de suporte com a mesma rigidez (independentemente da idade de cada um), necessariamente a distribuição das ações não vai depender da velocidade de construção, mas somente do número de níveis de escoras e reescoras.

Outro ponto a discutir seria a consideração das ações nos pavimentos como distribuídas, uma vez que os pontaletes do sistema de suporte podem aparecer em pequeno número e muito espaçados entre si.

Além disso, o método simplificado ainda despreza a absorção de carga por parte dos pilares, na concretagem de um pavimento.

No que se refere à fissuração que ocorre durante a construção, esta altera a distribuição das ações entre os pavimentos. SBAROUNIS (1984) relata que a incorporação desse efeito deve reduzir os valores das máximas ações de construção. Se assim for, os valores das máximas ações de construção obtidos sem a consideração da fissuração representam um limite superior para os resultados.

No capítulo seguinte define-se um modelo de análise das etapas de construção que se aproxima mais do comportamento real da estrutura, permitindo até ser avaliada a confiabilidade do método simplificado. 


\section{ANÁLISE SEQÜENCIAL DAS ETAPAS DE CONSTRUÇÃO}

\subsection{Modelagens considerando o método dos elementos finitos}

Autores como Péricles C. Stivaros, Noel J. Gardner, John A. Sbarounis e WaiFah Chen têm pequisas voltadas para a modelagem via método dos elementos finitos considerando as ações de construção em pavimentos formados por lajes-cogumelo.

WAI-FAH CHEN et al.(1985) desenvolveu um modelo computacional em três dimensões para a análise das ações de construção, aperfeiçoando os estudos de GRUNDY \& KABAILA (1963), aparentemente os primeiros desenvolvidos sobre o assunto.

Mais tarde, o mesmo WAI-FAH CHEN et al.(1991) melhorou seu modelo considerando mais parâmetros e procedimentos construtivos, além de ações móveis variáveis.

Posteriormente, WAI-FAH CHEN et al.(1992) desenvolveu novo modelo computacional em três dimensões no intuito de simular sistemas de pontaletes com contraventamento, levando em conta ações horizontais devidas ao vento.

Vale a pena destacar que alguns autores citados consideram, em seus trabalhos, a distribuição das ações de construção de uma maneira não muito rigorosa. Assim, para analisar as etapas intermediárias de construção são adotados vários modelos representativos. Entretanto, para cada um desses modelos não é considerada uma análise seqüencial.

Como indica o modelo da figura 8.1 há a suposição de que as ações de construção atuam sobre estruturas intermediárias já prontas. 


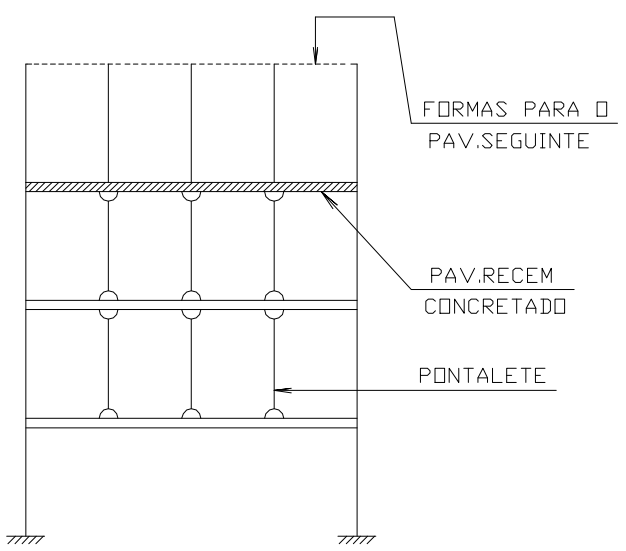

FIGURA 8.1 - Modelo representativo de fase intermediária de construção

Note-se que neste modelo as ações de peso próprio de pavimentos inferiores afetam pavimentos superiores, o que não é rigorosamente correto. A justificativa para essa afirmação é apresentada no item a seguir.

\subsection{Justificativa para a consideração da análise seqüencial da estrutura}

As análises de estruturas de edifícios em concreto armado às vezes são feitas considerando-se que toda a estrutura já existe quando as ações são impostas. Assim, obtidos os esforços solicitantes através de determinada análise, o dimensionamento das seções é feito no estado limite último, impondo-se que este seja alcançado ao majorarem-se as ações e minorarem-se as resistências dos materiais envolvidos.

A princípio, esta hipótese é válida para as ações horizontais devidas ao vento e para as ações verticais aplicadas à estrutura quando totalmente concluída. Mas para ações, como o peso próprio, que são impostas gradualmente em vários estágios de construção, estas análises globais não são muito precisas. Nesse caso, é mais conveniente que se considere a seqüência de construção do edifício.

Para as ações devidas às alvenarias, é necessário conhecer o cronograma da obra para saber em que etapas estas serão construídas. O mesmo ocorre para as ações devidas a pisos e revestimentos.

Nos projetos de edifícios, normalmente, as tensões nos pilares devidas às ações verticais apresentam valores bem distintos, o que conduz a deformações axiais 
diferenciadas nesses elementos em cada pavimento. Considerando este fato, um procedimento global de análise da estrutura acumula nos andares superiores deslocamentos verticais inexistentes. Isto faz com que os deslocamentos diferenciais entre os pontos de pilar nos pavimentos cresçam ao longo da altura da edificação, atingindo valores máximos no seu topo. Esse efeito certamente leva a valores incorretos de momentos fletores em vigas e lajes ligadas aos pilares.

Para entender bem o problema deve-se sempre ter em mente que, seja qual for o modelo utilizado para analisar a estrutura de um edifício de andares múltiplos, não é coerente admitir esforços em um elemento que ainda não exista. Por exemplo, como é possível a ação de peso próprio do $10^{\mathrm{O}}$ pavimento afetar os esforços solicitantes na estrutura do $11^{\mathrm{O}}$ pavimento, ainda não construído? Isso só é aceitável para os esforços provocados pela parcela de deformação lenta dessa ação. Fica claro que qualquer elemento só pode ser solicitado por carregamentos impostos à estrutura após a construção dele próprio.

Alguns autores têm estudado os efeitos das deformações axiais diferenciadas entre pilares através de análises seqüenciais das estruturas. Podem-se citar os trabalhos de SELVARAJ \& SHARMA (1974), CHOI \& KIM (1985) e KRIPKA \& SORIANO (1992).

Uma análise seqüencial de uma estrutura com 3 pavimentos, submetida apenas ao peso próprio, pode ser feita de acordo com os esquemas mostrados na figura 8.2, considerando válida a hipótese da superposição de esforços.

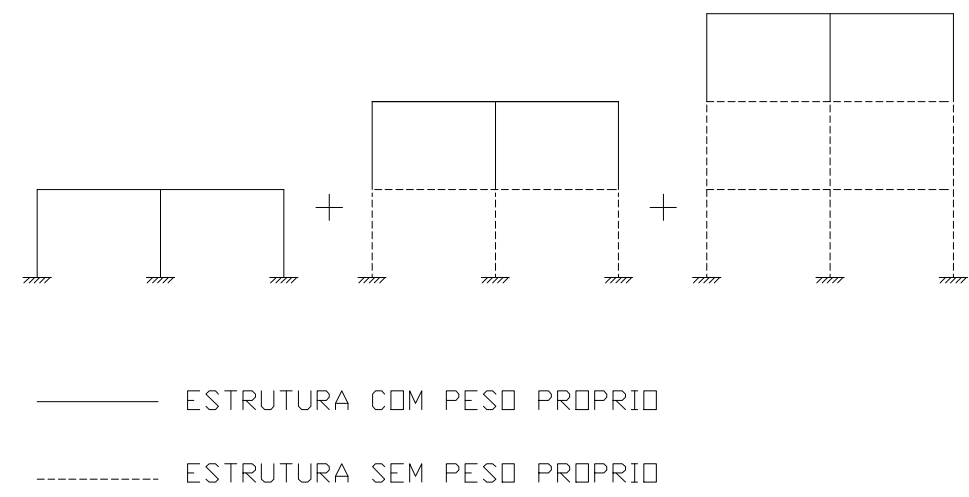

FIGURA 8.2 - Análise seqüencial da estrutura de um edifício 
Neste tipo de análise os esforços finais para dimensionamento de qualquer elemento estrutural são obtidos por simples soma dos oriundos de cada um dos 3 esquemas. Note-se que ações de peso próprio de pavimentos inferiores não afetam pavimentos superiores.

Para mostrar a importância da consideração da seqüência de construção na análise das ações verticais de peso próprio, apresenta-se um exemplo numérico, adaptado de SELVARAJ \& SHARMA (1974), para um pórtico plano com 14 pavimentos. Foi utilizada a análise seqüencial descrita.

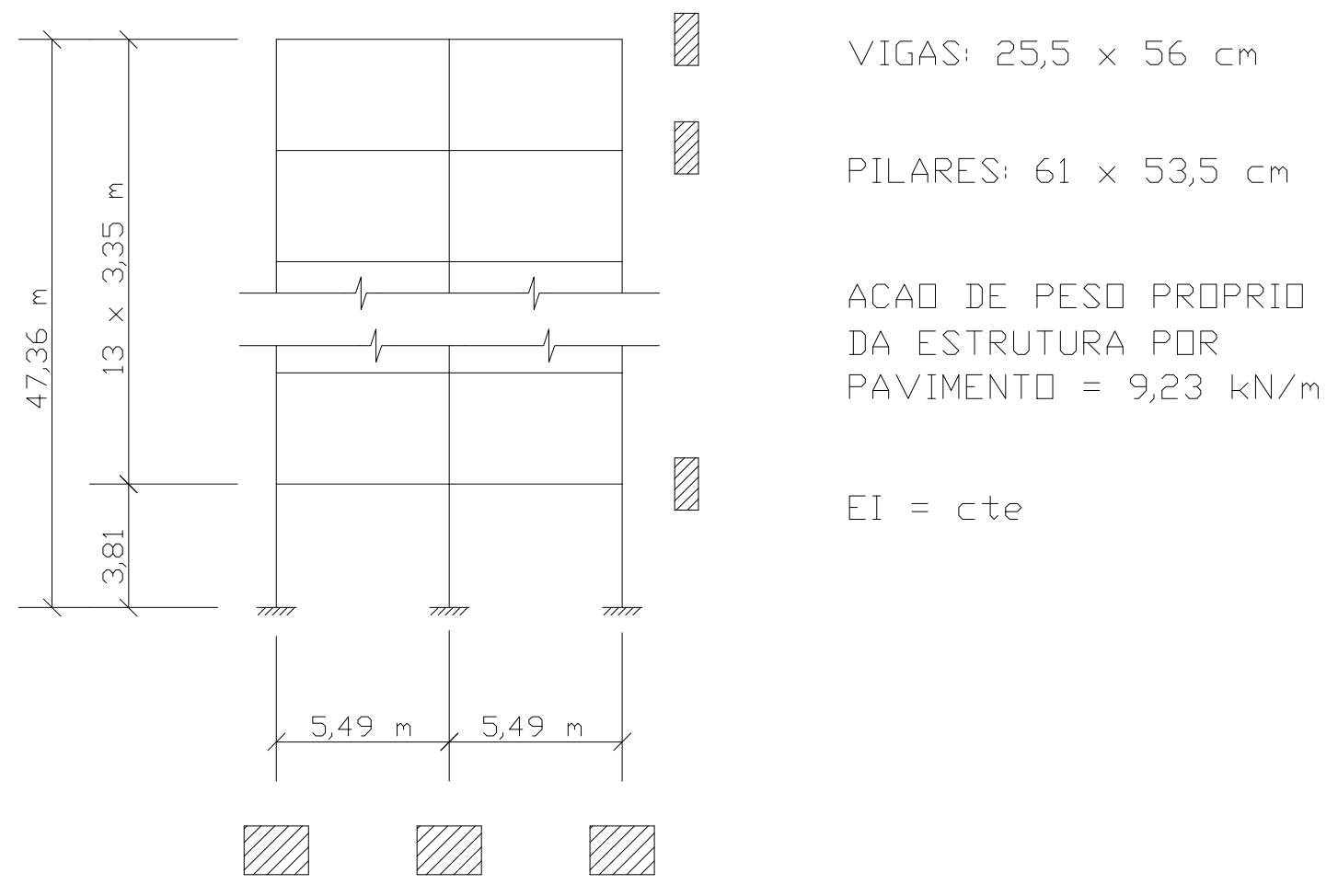

FIGURA 8.3 - Pórtico plano submetido à ação de peso próprio da estrutura

Os resultados de momentos fletores nas vigas do pórtico, considerando ou não a sequiência de construção, são mostrados na figura 8.4. 

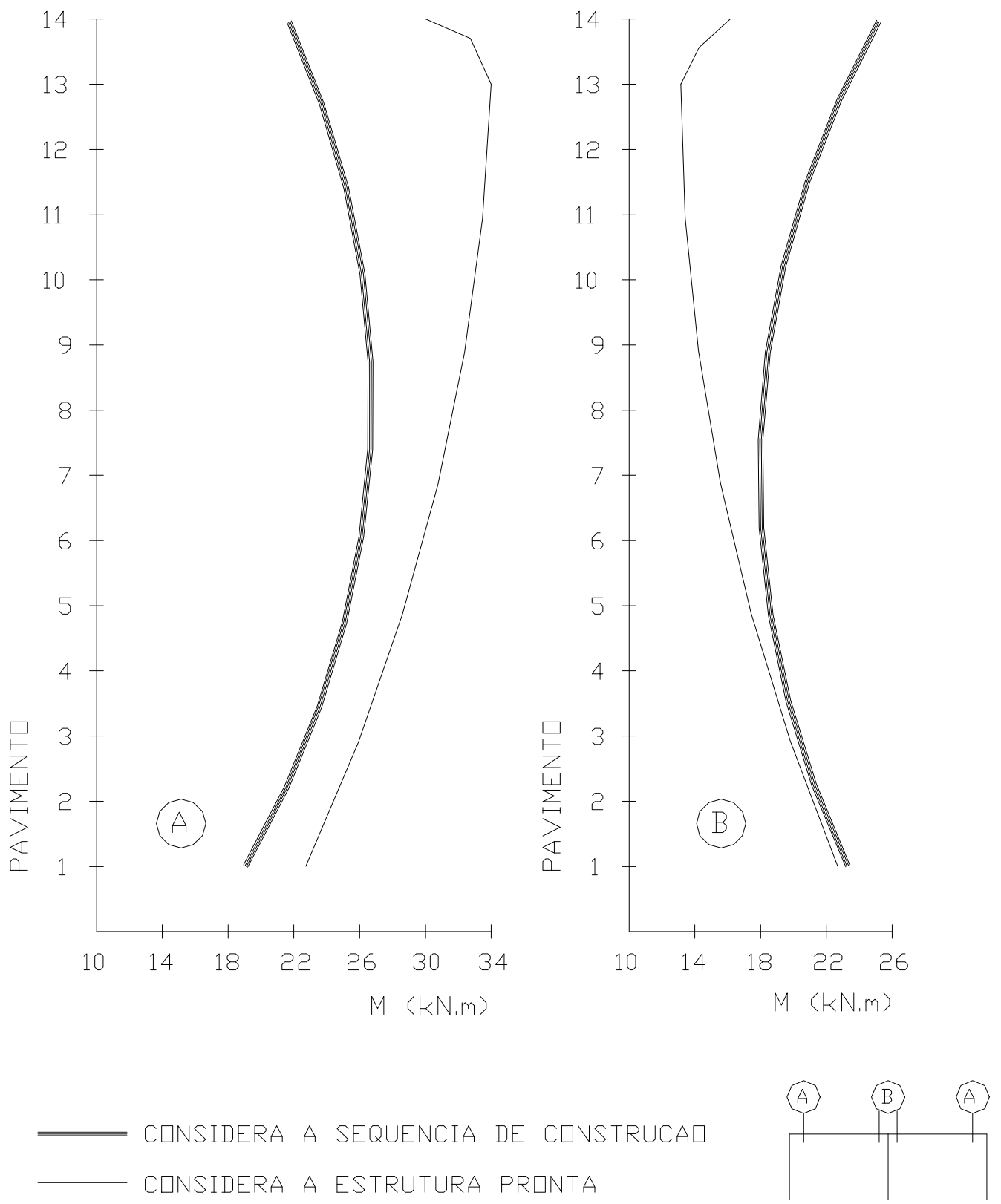

FIGURA 8.4 - Momentos fletores nas vigas do pórtico

Podem-se notar diferenças consideráveis nos valores de momento fletor obtidos. Neste caso, essas diferenças surgem porque o pilar central do pórtico está submetido a tensões mais elevadas do que os pilares de extremidade, apresentando maiores deformações axiais. 


\subsection{Definição da análise seqüencial considerando o processo de construção}

A análise estrutural proposta leva em conta a seqüência natural de construção, conduzindo a resultados de esforços solicitantes e deformações mais precisos, como mostrado no item anterior.

O procedimento leva em conta todo o cronograma construtivo com sobreposição gradual de pavimentos e modelagem do sistema de escoramento com valores representativos de rigidez e posição dos pontaletes, considerados rotulados nas ligações com as lajes e vigas. Desta maneira, são consideradas as diversas etapas de construção, todas com características de resistência e deformabilidade de lajes, vigas e pilares obtidas em função do tempo de amadurecimento do concreto.

Além dos resultados finais de esforços solicitantes e deformações, este tipo de análise possibilita a obtenção da história de carregamentos dos elementos estruturais, do início ao término da obra.

Cada etapa de construção é tratada com um modelo em três dimensões e o método dos elementos finitos é aplicado para resolver as estruturas parciais, considerando-se linearidade física e geométrica. Os programas da biblioteca do sistema LASER, desenvolvidos por RAMALHO (1990) e CORREAA (1991), foram escolhidos para executar a análise estrutural de cada etapa de construção. A fundação é admitida como um suporte totalmente rígido.

A filosofia do modelo seqüencial proposto consiste em separar as etapas de construção e analisá-las isoladamente. Cada novo evento define uma nova etapa de construção. Constituem-se em eventos: instalação de escoras e fôrmas com concretagem, retirada de escoras e fôrmas, instalação de reescoras e retirada de reescoras.

A avaliação da evolução dos esforços e deformações nos elementos estruturais e nos pontaletes é incremental, pois a estrutura é carregada à medida em que é construída. Assim, somam-se aos esforços (ou deformações) iniciais, causados por carregamentos já existentes no sistema temporário de apoio, os esforços (ou deformações) adicionais, provocados por qualquer dos eventos já mencionados. Essa sequiência evolutiva deve prosseguir até a remoção dos pontaletes de sustentação do último pavimento. 
Note-se que está sendo considerado o princípio de superposição de esforços (ou deformações), válido ao se admitir linearidade física e geométrica.

Quando um pavimento está sendo concretado não apresenta resistência alguma e, portanto, não possui capacidade de absorver qualquer parcela de carregamento. Toda a ação de peso próprio do concreto e fôrmas, bem como as ações variáveis, são transferidas diretamente para o pavimento inferior através das escoras e dos pilares já concretados anteriormente.

Entretanto, a distribuição dessa ação muda conforme o pavimento concretado amadurece. Pouco tempo após o lançamento, o concreto já é capaz de absorver alguma parcela de seu peso próprio. Considerando a confecção de um pavimento por semana, interessa de fato a nova distribuição de ações 7 dias após a concretagem. Assim, é necessário analisar novamente a estrutura parcial após esse intervalo, agora sem a presença das ações variáveis.

As modelagens das etapas onde o pavimento não possui capacidade de absorver carga (concretagem) são necessárias apenas para avaliar a segurança de construção momentânea e para estabelecer toda a história de carregamentos dos elementos estruturais. Para a obtenção dos esforços e deformações finais na estrutura pronta, essas etapas não devem ser consideradas.

De qualquer modo, para determinar a transferência de ações do pavimento recém concretado (peso próprio e ações variáveis) para as escoras e os pilares que o sustentam optou-se por um procedimento aproximado. Deve-se simplesmente processar a estrutura mostrada na figura 8.5 e verificar a distribuição das ações. As características de resistência e deformabilidade do concreto são consideradas aos 28 dias.

Seria complicado tentar obter a distribuição real com o concreto fresco sobre as fôrmas de madeira, uma vez que uma formulação teórica com interação entre os dois materiais envolvidos é complexa. Além disso, tal nível de realismo não se justifica nesse caso.

A fundação é novamente admitida como um suporte totalmente rígido, sendo os pilares engastados na base. 


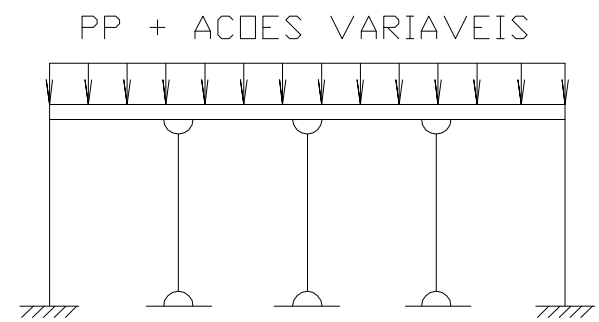

FIGURA 8.5 - Modelo utilizado para a determinação da distribuição das ações no instante da concretagem

Todo o procedimento descrito pode ser melhor entendido observando-se a figura 8.6, onde é mostrada a análise seqüencial completa de um edifício com 4 pavimentos, construído através de um processo de construção com dois níveis de escoras mais um nível de reescora $(2+1)$. Considera-se a concretagem de um pavimento por semana.

Nesta figura, nota-se que a alteração na distribuição das ações da estrutura devido à retirada de pontaletes é determinada através da aplicação de cargas concentradas de igual valor e em sentido contrário às aplicadas pelas escoras ou reescoras no momento da remoção. Também pode-se observar que a retirada das fôrmas é levada em conta através da aplicação em sentido anti-gravitacional da ação distribuída referente ao seu peso próprio.

Com relação à figura 8.6, deve-se ainda esclarecer a simbologia utilizada.

Pi: carga concentrada transmitida pelo pilar i ao pavimento imediatamente inferior aquele que está sendo concretado;

Fi: carga concentrada transmitida pela escora i ao pavimento imediatamente inferior aquele que está sendo concretado;

ei: carga absorvida pelo pontalete i exclusivamente devido a um evento de construção;

xi: carga atuante no pontalete i no momento imediatamente anterior à sua retirada; 
p: peso próprio de pontalete;

pp: peso próprio do pavimento;

formas: peso próprio estimado do conjunto das fôrmas do pavimento;

const: ações variáveis atuantes no pavimento que está sendo concretado, referentes a: peso dos trabalhadores, equipamentos, materiais, entulhos e impacto produzido pelo lançamento do concreto.

As etapas A representam os instantes de concretagem. 


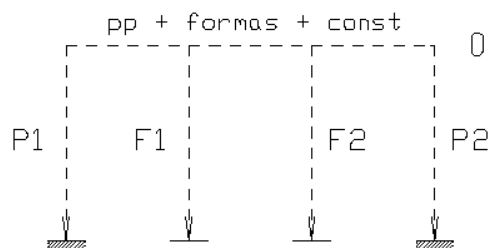

ETAPA $1 A$

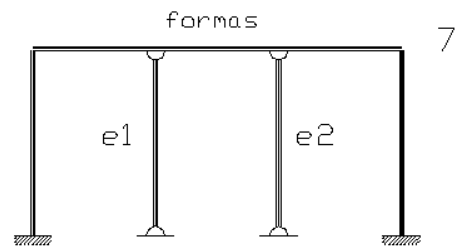

ETAPA 1

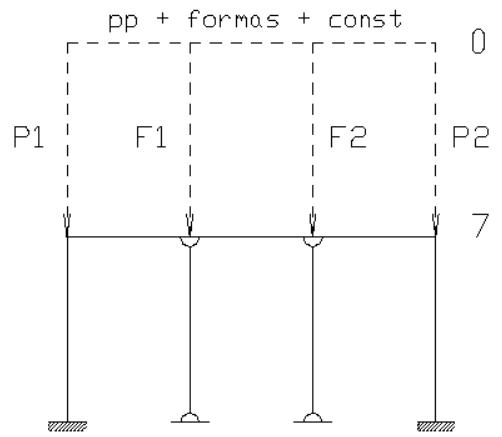

ETAPA 2A

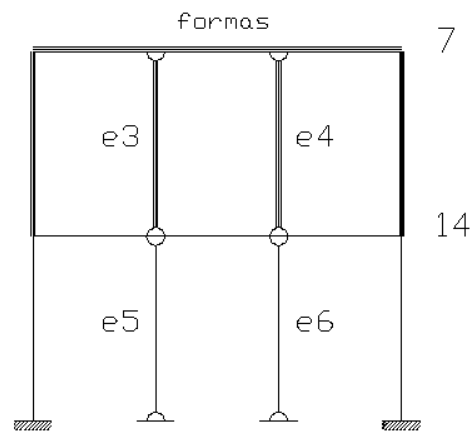

ETAPA 2

FIGURA 8.6a - Análise seqüencial para um edifício de 4 pavimentos com processo de construção com dois níveis de escoras mais um nível de reescora $(2+1)$ 


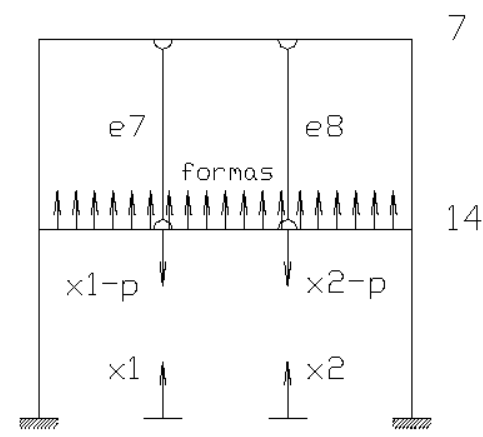

ETAPA 3

$\times 1=e 1+e 5$

$x 2=e 2+e 6$

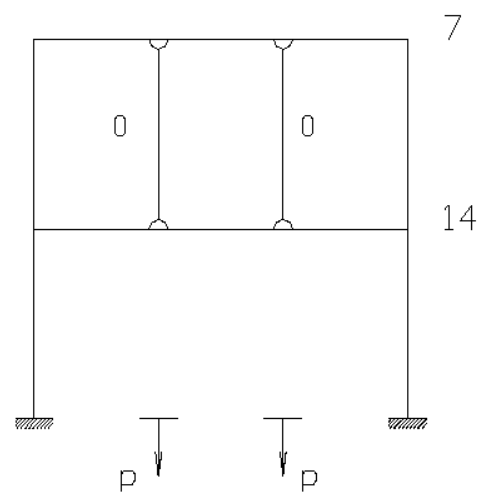

ETAPA 4

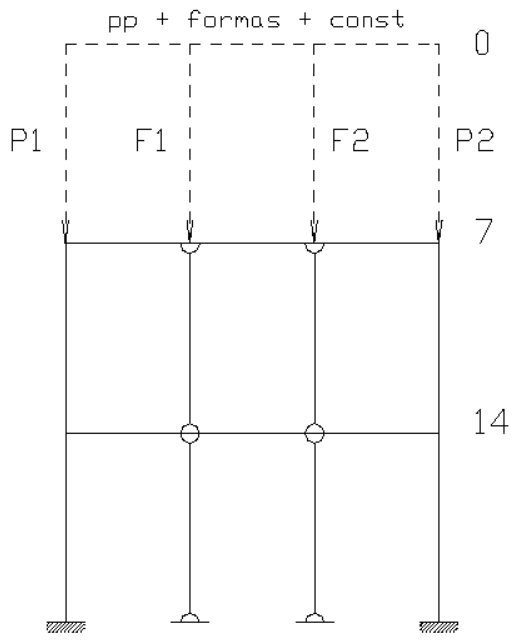

ETAPA 5A

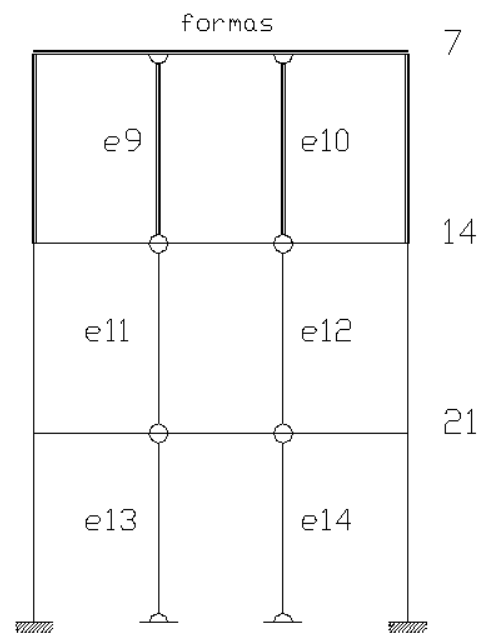

ETAPA 5

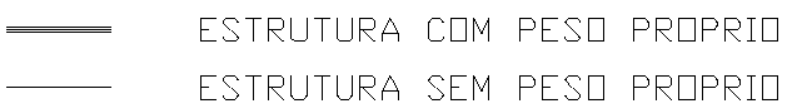

FIGURA 8.6b - Análise seqüencial para um edifício de 4 pavimentos com processo de construção com dois níveis de escoras mais um nível de reescora $(2+1)$ 


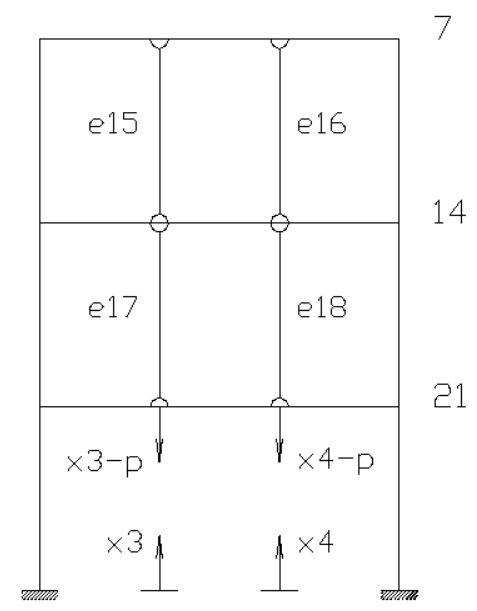

ETAPA 6

$\times 3=e 13+p$

$\times 4=e 14+p$

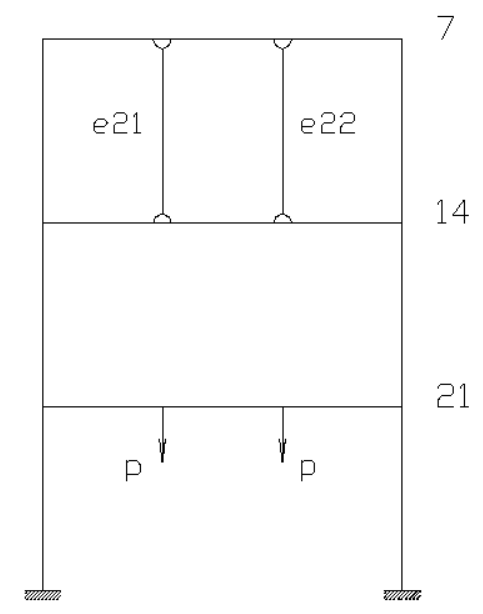

ETAPA 8

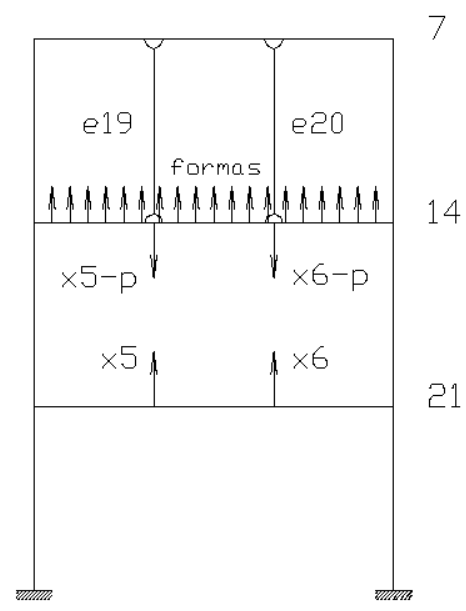

ETAPA 7

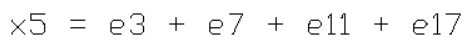

$\times 6=e^{4}+e^{8}+e^{12}+e^{18}$

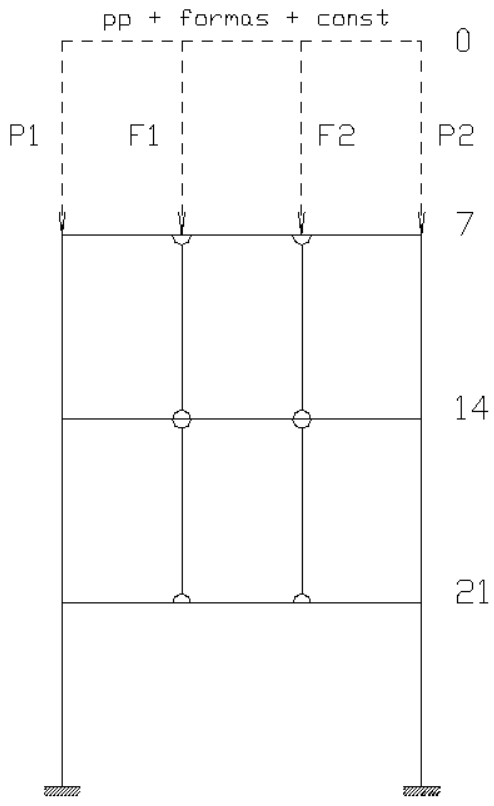

ETAPA 9A

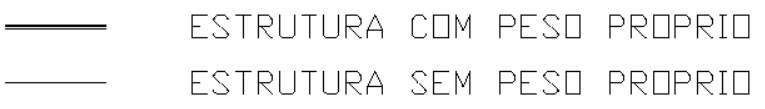

FIGURA 8.6c - Análise seqüencial para um edifício de 4 pavimentos com processo de construção com dois níveis de escoras mais um nível de reescora $(2+1)$ 

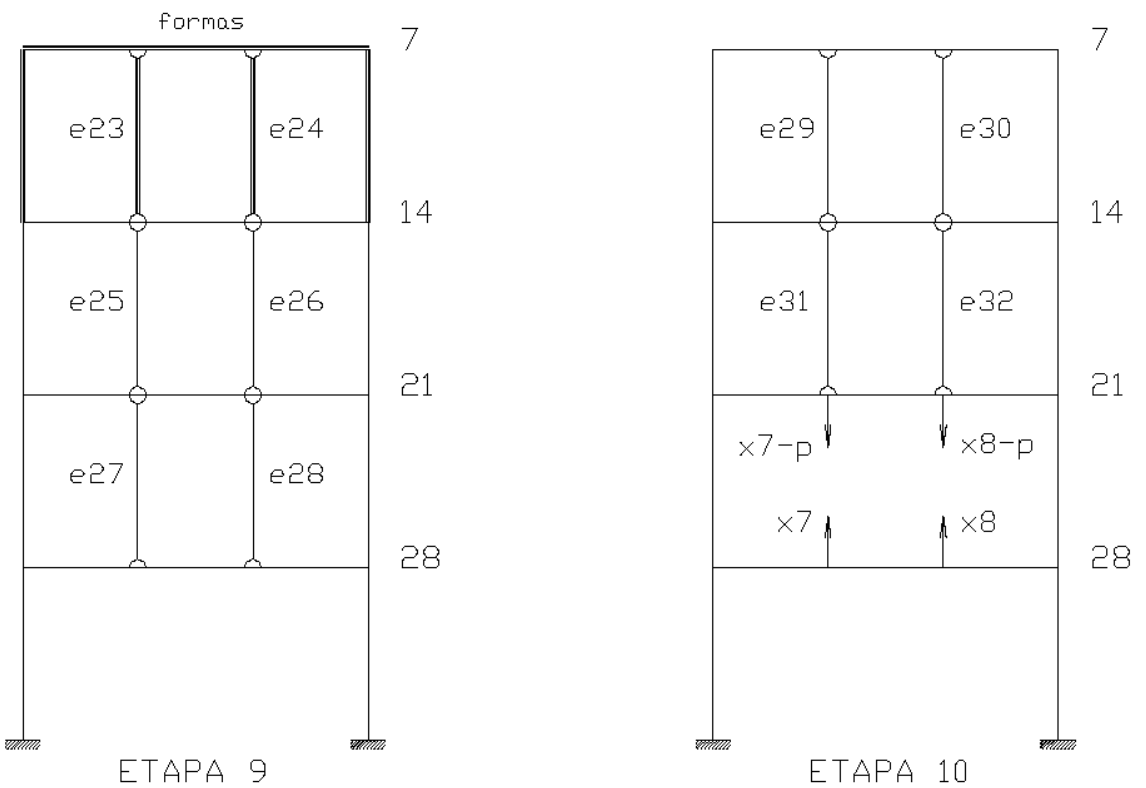

$$
\begin{gathered}
\text { ETAPA } 10 \\
\times 7=e 27+p \\
\times 8=e 28+p
\end{gathered}
$$

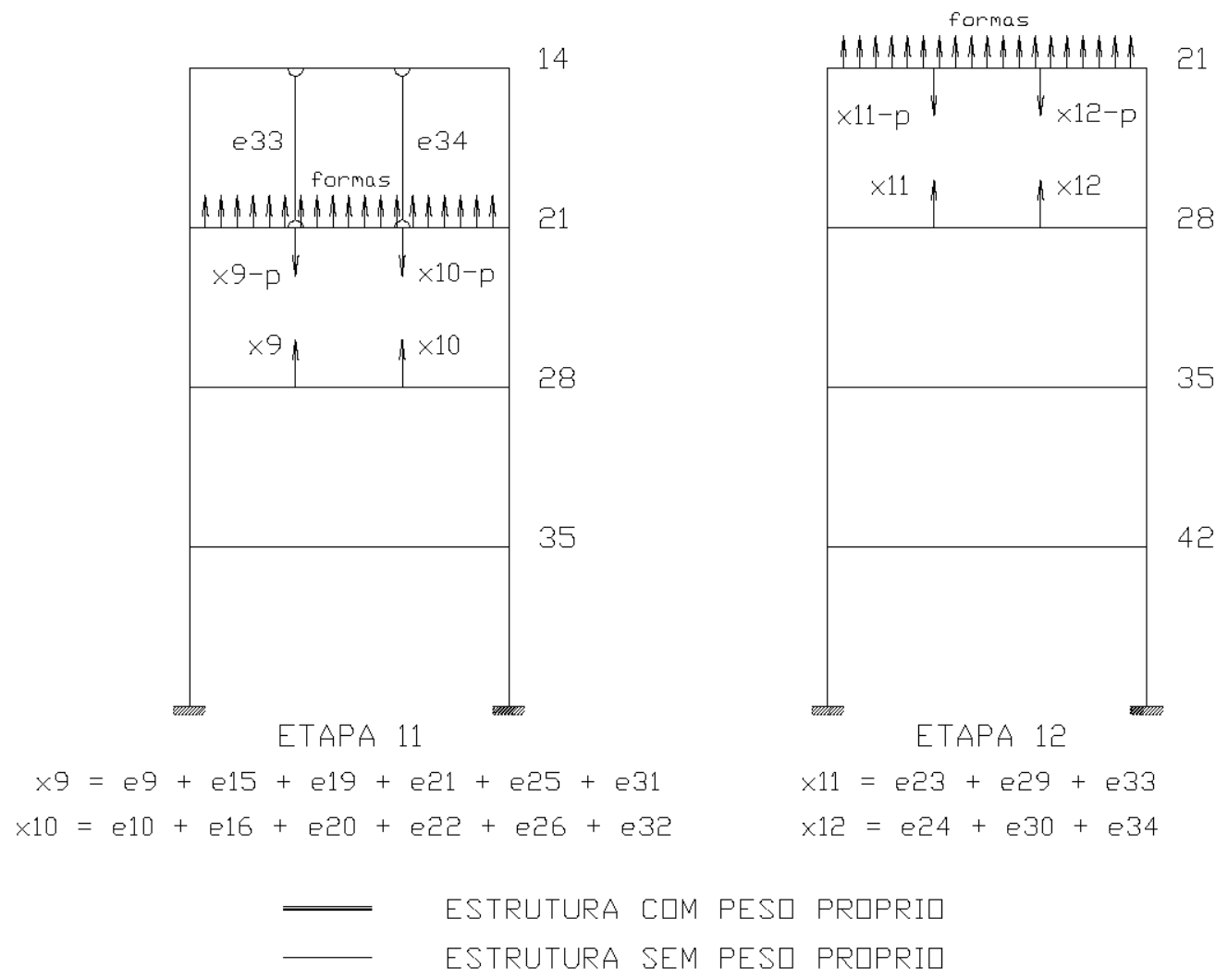

FIGURA 8.6d - Análise sequiencial para um edifício de 4 pavimentos com processo de construção com dois níveis de escoras mais um nível de reescora $(2+1)$ 
Cada etapa de construção da análise seqüencial proposta é tratada sem levar em conta um estado de tensão (ou de deformação) inicial gerado pelas etapas anteriores. Essa simplificação adotada é coerente com a adoção das hipóteses de linearidade física e geométrica.

Por fim deve-se deixar bem claro que, embora a análise seqüencial construtiva tenha sido mostrada na figura 8.6 para um processo de construção particular com dois níveis de escoras mais um nível de reescora, todas as definições estabelecidas são válidas para qualquer outro processo com um número variado de níveis escorados e reescorados. Também são válidas se houver etapas com retirada parcial de pontaletes e/ou retirada total de pontaletes com reescoramento parcial.

\subsection{Exemplo numérico}

A seguir, a análise seqüencial proposta é aplicada no processamento de uma estrutura simples, em concreto armado, com 4 pavimentos. A forma dos pavimentos e a posição dos pontaletes estão mostradas na figura 8.7, onde nota-se a existência de uma laje quadrada apoiada em vigas nos quatro lados. Em cada canto há um pilar, com distância de piso a piso igual a $3 \mathrm{~m}$.

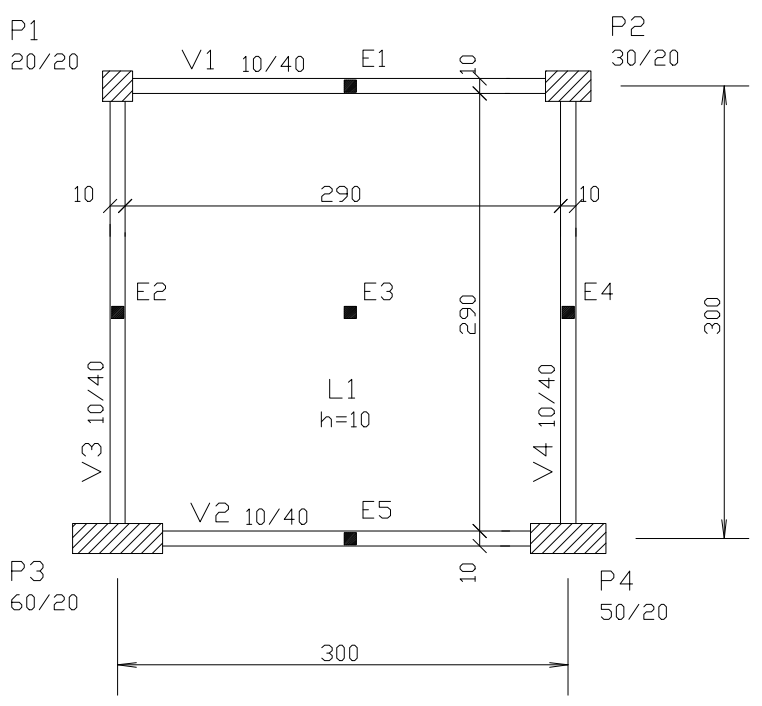

FIGURA 8.7 - Forma dos pavimentos e posição dos pontaletes $(\mathrm{em} \mathrm{cm})$ 
A escolha desta estrutura foi feita visando rapidez e facilidade de processamento, ideais para um exemplo inicial. Cabe somente uma observação a respeito das dimensões das seções transversais dos pilares: foram adotadas seções com áreas bastante distintas para que, no processamento da estrutura global totalmente concluída, os pilares apresentem deformações diferenciais significativas num mesmo pavimento, ressaltando a necessidade de utilização da análise seqüencial.

O processo de construção prevê o uso de dois níveis de escoras mais um nível de reescora, com a concretagem de um pavimento a cada 7 dias. Há cinco pontaletes para a sustentação do pavimento, cujas posições estão mostradas na figura 8.7.

Os pontaletes utilizados são de madeira (Pinus Elliottii) com seção retangular de $8 \mathrm{~cm} \times 8 \mathrm{~cm}$, totalizando um peso próprio de $0,1 \mathrm{kN}$ por peça. $\mathrm{O}$ módulo de elasticidade desse tipo de madeira é de aproximadamente $6,85.10^{6} \mathrm{kN} / \mathrm{m}^{2}$ e o coeficiente de Poisson é igual a 0,30.

O peso próprio do conjunto de fôrmas é considerado como uma ação uniformemente distribuída no pavimento igual a $0,20 \mathrm{kN} / \mathrm{m}^{2}$, enquanto as ações variáveis estão presentes somente durante a concretagem (etapas A) com valor de $3,20 \mathrm{kN} / \mathrm{m}^{2}$, aproximadamente $85 \%$ do peso próprio do pavimento.

$\mathrm{O}$ concreto utilizado tem resistência característica $\mathrm{f}_{\mathrm{ck}}=2,50.10^{4} \mathrm{kN} / \mathrm{m}^{2}$, o peso próprio é igual a $25 \mathrm{kN} / \mathrm{m}^{3}$ e o coeficiente de Poisson adotado é igual a 0,16.

Quanto ao valor secante do módulo de elasticidade $\mathrm{E}_{\mathrm{c}}$ há uma controvérsia muito grande entre as normas. Neste caso, optou-se por utilizar $\mathrm{E}_{\mathrm{c}}=2,48.10^{7} \mathrm{kN} / \mathrm{m}^{2}$. A NBR-6118 (1978) indica o uso da seguinte expressão:

$$
\mathrm{E}_{\mathrm{c}}=0,9 \cdot 6600 \cdot \sqrt{\mathrm{f}_{\mathrm{ck}}+3,5}, \mathrm{em} \mathrm{MPa}
$$

onde: 
$\mathrm{f}_{\text {ck }}=$ resistência característica do concreto à compressão.

Utilizando essa expressão, obtém-se para uma resistência característica $\mathrm{f}_{\mathrm{ck}}=$ $2,50.10^{4} \mathrm{kN} / \mathrm{m}^{2}$ um valor de $\mathrm{E}_{\mathrm{c}}=3,17 \cdot 10^{7} \mathrm{kN} / \mathrm{m}^{2}$. Pelas pesquisas atuais, há uma unanimidade em afirmar que esse é um valor muito elevado. Assim, o valor secante do módulo de elasticidade aqui adotado é o da expressão 8.1 reduzido em torno de $20 \%$, concordando com uma média dos valores atualmente indicados pelas normas.

O desenvolvimento das características de resistência e deformabilidade do concreto com a idade é estimado com base nas expressões do CEB-90 (1990), resultando nos valores da tabela 8.1. São admitidos o uso do cimento portland comum, as condições normais de cura úmida durante 7 dias consecutivos e temperatura $\mathrm{T}=25^{\mathrm{O}} \mathrm{C}$.

TABELA 8.1 - Desenvolvimento da resistência característica e do módulo de elasticidade secante

\begin{tabular}{|c|c|c|}
\hline $\begin{array}{c}\text { IDADE } \\
(\text { EM DIAS })\end{array}$ & $\begin{array}{c}\mathrm{f}_{\mathrm{ck}} \\
\left(\mathrm{kN} / \mathrm{m}^{2}\right)\end{array}$ & $\begin{array}{c}\mathrm{E}_{\mathrm{C}} \\
\left(\mathrm{kN} / \mathrm{m}^{2}\right)\end{array}$ \\
\hline 7 & $1,99.10^{4}$ & $2,24.10^{7}$ \\
\hline 14 & $2,32.10^{4}$ & $2,39.10^{7}$ \\
\hline 21 & $2,47.10^{4}$ & $2,46.10^{7}$ \\
\hline 28 & $2,50.10^{4}$ & $2,48.10^{7}$ \\
\hline
\end{tabular}

A tabela 8.2 mostra o volume de concreto e o peso próprio de lajes, vigas e pilares para um andar. 
TABELA 8.2 - Volume de concreto e peso próprio para um andar

\begin{tabular}{|c|c|c|c|}
\hline & LAJES & VIGAS & PILARES \\
\hline VOLUME $\left(\mathrm{m}^{3}\right)$ & 0,900 & 0,455 & 0,960 \\
\hline PESO PRÓPRIO $(\mathrm{kN})$ & 22,5 & 11,4 & 24,0 \\
\hline
\end{tabular}

Somando valores da tabela 8.2 conclui-se que o peso próprio de um pavimento (lajes e vigas) é igual a $33,9 \mathrm{kN}\left(3,76 \mathrm{kN} / \mathrm{m}^{2}\right)$.

Na tabela 8.3 consta o peso próprio de cada tramo de pilar, com distância de piso a piso igual a $3 \mathrm{~m}$.

TABELA 8.3 - Peso próprio dos tramos de pilar

\begin{tabular}{|c|c|}
\hline PILAR & PESO PRÓPRIO $(\mathrm{kN})$ \\
\hline P1 & 3,0 \\
\hline P2 & 4,5 \\
\hline P3 & 9,0 \\
\hline P4 & 7,5 \\
\hline
\end{tabular}

Para as modelagens das etapas de concretagem (etapas A) é necessário avaliar as ações transmitidas aos pilares e pontaletes pelo concreto fresco, do modo descrito no item anterior (figura 8.5).

Assim, somando as ações recebidas por pilares e pontaletes ao peso próprio de cada um desses elementos obtém-se as ações verticais a serem aplicadas no pavimento imediatamente inferior ao que está sendo concretado. A tabela 8.4 indica essas ações. 
TABELA 8.4 - Ações aplicadas no pavimento imediatamente inferior ao que está sendo concretado

\begin{tabular}{|c|c|}
\hline ELEMENTO & $\begin{array}{c}\text { AÇÃO VERTICAL } \\
\text { CONCENTRADA }(\mathrm{kN})\end{array}$ \\
\hline P1 & 12,66 \\
\hline P2 & 15,45 \\
\hline P3 & 21,07 \\
\hline P4 & 18,98 \\
\hline E1 & 3,34 \\
\hline E2 & 3,38 \\
\hline E3 & 8,86 \\
\hline E4 & 3,33 \\
\hline E5 & 1,87 \\
\hline
\end{tabular}

Observando a figura 8.6 nota-se que há a necessidade de processar 12 estruturas parciais (etapas 1 a 12), para que se possa chegar aos esforços solicitantes na estrutura final submetida ao peso próprio. Isso é válido também para os deslocamentos.

Para analisar alguns resultados do exemplo, definem-se pontos do $1^{\mathrm{O}}$ pavimento para os quais são apresentados os momentos fletores obtidos. Deseja-se mostrar que as diferenças entre esses valores obtidos com a análise seqüencial e com a estrutura global já existem neste pavimento inferior. Como mostrado na figura 8.4, essas diferenças tendem a aumentar nos pavimentos superiores.

Os pontos 1 e 3 referem-se às seções das extremidades da viga V1, respectivamente junto aos pilares $\mathrm{P} 1$ e P2. O ponto 2 define a seção localizada no meio do vão desta viga, enquanto o ponto 4 localiza-se exatamente no ponto central da laje. A tabela 8.5 resume a evolução dos momentos fletores para estes pontos, do início ao término da construção. 
TABELA 8.5 - Evolução dos momentos fletores em pontos do $1^{\mathrm{O}}$ pavimento

\begin{tabular}{|c|c|c|c|c|c|c|}
\hline ETAPA & $\begin{array}{c}\text { IDADE } \\
(\text { DIAS })\end{array}$ & $\begin{array}{c}\mathrm{M}_{1} \\
(\mathrm{kN} \cdot \mathrm{m})\end{array}$ & $\begin{array}{c}\mathrm{M}_{2} \\
(\mathrm{kN} \cdot \mathrm{m})\end{array}$ & $\begin{array}{c}\mathrm{M}_{3} \\
(\mathrm{kN} \cdot \mathrm{m})\end{array}$ & $\begin{array}{c}\mathrm{M}_{4 \mathrm{x}} \\
(\mathrm{kN} . \mathrm{m} / \mathrm{m})\end{array}$ & $\begin{array}{c}\mathrm{M}_{4 \mathrm{y}} \\
(\mathrm{kN} . \mathrm{m} / \mathrm{m})\end{array}$ \\
\hline $1 \mathrm{~A}$ & 0 & 0,00 & 0,00 & 0,00 & 0,00 & 0,00 \\
\hline 1 & 7 & $-0,24$ & 1,39 & $-0,96$ & 0,32 & 0,37 \\
\hline $2 \mathrm{~A}$ & 7 & $-0,62$ & 2,76 & $-1,86$ & 0,90 & 1,00 \\
\hline 2 & 14 & $-0,53$ & 1,95 & $-1,62$ & 0,57 & 0,63 \\
\hline 3 & 14 & $-0,88$ & 3,22 & $-2,49$ & 1,10 & 1,19 \\
\hline 4 & 14 & $-0,88$ & 3,22 & $-2,49$ & 1,10 & 1,19 \\
\hline $5 \mathrm{~A}$ & 14 & $-1,06$ & 3,66 & $-3,00$ & 1,34 & 1,44 \\
\hline 5 & 21 & $-0,99$ & 3,61 & $-2,79$ & 1,26 & 1,36 \\
\hline 6 & 21 & $-0,99$ & 3,61 & $-2,79$ & 1,26 & 1,36 \\
\hline 7 & 21 & $-0,70$ & 2,41 & $-2,04$ & 0,83 & 0,90 \\
\hline 8 & 21 & $-0,72$ & 2,46 & $-2,08$ & 0,84 & 0,92 \\
\hline $9 \mathrm{~A}$ & 21 & $-0,82$ & 2,84 & $-2,40$ & 1,00 & 1,08 \\
\hline 9 & 28 & $-0,78$ & 2,69 & $-2,27$ & 0,91 & 0,99 \\
\hline 10 & 28 & $-0,70$ & 2,39 & $-2,09$ & 0,82 & 0,90 \\
\hline 11 & 35 & $-0,64$ & 2,45 & $-2,01$ & 0,83 & 0,91 \\
\hline 12 (FINAL) & 42 & $-0,65$ & 2,44 & $-2,02$ & 0,83 & 0,91 \\
\hline
\end{tabular}

Para os pontos definidos no $1^{\mathrm{O}}$ pavimento são mostradas na tabela 8.6 as diferenças entre os resultados obtidos para a estrutura final submetida ao peso próprio, considerando-se ou não a análise seqüencial. Os resultados obtidos sem análise seqüencial consideram a estrutura global totalmente concluída. 
TABELA 8.6 - Diferenças entre momentos fletores com e sem análise seqüencial

\begin{tabular}{|c|c|c|c|c|c|}
\hline $\begin{array}{c}\text { ANÁLISE } \\
\text { SEQÜENCIAL }\end{array}$ & $\begin{array}{c}\mathrm{M}_{1} \\
(\mathrm{kN} . \mathrm{m})\end{array}$ & $\begin{array}{c}\mathrm{M}_{2} \\
(\mathrm{kN} . \mathrm{m})\end{array}$ & $\begin{array}{c}\mathrm{M}_{3} \\
(\mathrm{kN} . \mathrm{m})\end{array}$ & $\begin{array}{c}\mathrm{M}_{4 \mathrm{x}} \\
(\mathrm{kN} . \mathrm{m} / \mathrm{m})\end{array}$ & $\begin{array}{c}\mathrm{M}_{4 \mathrm{y}} \\
(\mathrm{kN} . \mathrm{m} / \mathrm{m})\end{array}$ \\
\hline COM & $-0,65$ & 2,44 & $-2,02$ & 0,83 & 0,91 \\
\hline SEM & $-0,83$ & 2,22 & $-2,23$ & 0,82 & 0,87 \\
\hline
\end{tabular}

Pode-se notar que as maiores diferenças estão nos pontos localizados na viga. No ponto central da laje os momentos fletores são praticamente os mesmos. Isso já era esperado, uma vez que as deformações diferenciais em pilares afetam em maior grau os esforços em vigas.

Aproveitando os resultados da tabela 8.5 pode-se verificar a segurança durante a construção nos pontos definidos do referido pavimento, em relação ao momento fletor.

Admita-se que, para efeito de dimensionamento do pavimento em questão, sejam consideradas ações uniformemente distribuídas de $1,5 \mathrm{kN} / \mathrm{m}^{2}$ referente à sobrecarga de utilização e $1,0 \mathrm{kN} / \mathrm{m}^{2}$ referente ao peso próprio do revestimento. Além disso, suponha-se a existência de uma alvenaria de vedação sobre as vigas, aplicando-lhes uma ação linearmente distribuída de 3,0 kN/m.

Os programas da biblioteca do sistema LASER foram utilizados para o processamento do pavimento isolado, considerando-se as ações citadas. Obtidos os momentos fletores em cada ponto, aplica-se a combinação última normal de ações definida na NBR-8681 (1984) para dimensionamento no estado limite último $\left(\gamma_{\mathrm{g}}=\gamma_{\mathrm{q}}\right.$ $=1,4)$.

Assim sendo, os valores de cálculo dos momentos fletores $\left(\mathrm{M}_{\mathrm{d}}\right)$ e as respectivas quantidades necessárias de armadura $\left(\mathrm{A}_{\mathrm{S}}\right)$, considerando-se as características do concreto aos 28 dias, são dadas pela tabela 8.7. Nesta tabela, bem como nas tabelas 8.8 a 8.10 , os valores de momento fletor para o centro da laje (ponto 4) estão indicados para uma faixa de $1 \mathrm{~m}$, o mesmo ocorrendo para as quantidades de armadura. Para o cálculo da quantidade de armadura do ponto 2 
poderia ter sido levada em conta a chamada mesa de compressão da seção $\mathrm{T}$, o que não foi feito.

TABELA 8.7 - Valores de cálculo dos momentos fletores atuantes e armaduras necessárias

\begin{tabular}{|c|c|c|c|c|c|}
\hline & Ponto 1 & Ponto 2 & Ponto 3 & Ponto 4 & Ponto 4 \\
\hline $\mathrm{M}_{\mathrm{d}}(\mathrm{kN} . \mathrm{m})$ & $-1,81$ & 9,48 & $-5,74$ & 2,52 & 2,80 \\
\hline $\mathrm{A}_{\mathrm{S}}\left(\mathrm{cm}^{2}\right)$ & 0,11 & 0,60 & 0,37 & 0,64 & 0,72 \\
\hline
\end{tabular}

Atendendo às recomendações da NBR-6118 (1978), há a necessidade de se utilizar uma armadura mínima nos elementos estruturais. A quantidade indicada por esta norma é de $0,15 \%$ do produto da altura útil pela largura da seção transversal do elemento. Assim, para os pontos 1, 2 e 3 (viga de $10 \mathrm{~cm}$ x $40 \mathrm{~cm}$ ) deve-se utilizar no mínimo $0,56 \mathrm{~cm}^{2}$ de aço, enquanto para o ponto 4 (laje de $10 \mathrm{~cm}$ ) no mínimo 1,35 $\mathrm{cm}^{2} / \mathrm{m}$.

A tabela 8.8 mostra os valores de cálculo dos momentos fletores resistentes e as quantidades de armadura que seriam efetivamente utilizadas, nesse caso.

TABELA 8.8 - Valores de cálculo dos momentos fletores resistentes e armaduras utilizadas

\begin{tabular}{|c|c|c|c|c|c|}
\hline & Ponto 1 & Ponto 2 & Ponto 3 & Ponto 4 & Ponto 4y \\
\hline $\mathrm{M}_{\mathrm{rd}}(\mathrm{kN} . \mathrm{m})$ & $-8,99$ & 9,48 & $-8,99$ & 5,21 & 5,21 \\
\hline $\mathrm{A}_{\mathrm{S}}\left(\mathrm{cm}^{2}\right)$ & 0,56 & 0,60 & 0,56 & 1,35 & 1,35 \\
\hline
\end{tabular}

Considerando que aos 7 dias o concreto já tenha atingido uma resistência característica à compressão $\mathrm{f}_{\mathrm{ck}}=1,99.10^{4} \mathrm{kN} / \mathrm{m}^{2}$, os valores de cálculo dos momentos fletores resistentes para essa idade são dados pela tabela 8.9. 
TABELA 8.9 - Valores de cálculo dos momentos fletores resistentes aos 7 dias

\begin{tabular}{|c|c|c|c|c|c|}
\hline & Ponto 1 & Ponto 2 & Ponto 3 & Ponto 4 & Ponto 4y \\
\hline $\mathrm{M}_{\mathrm{rd}}$ (kN.m) & $-8,89$ & 9,38 & $-8,89$ & 5,15 & 5,15 \\
\hline
\end{tabular}

Entretanto, segundo a NBR-8681 (1984) durante as etapas de construção a segurança deve ser avaliada através da combinação última de construção. Considerando para esta combinação $\gamma_{\mathrm{g}}=\gamma_{\mathrm{q}}=1,2$ podem-se obter os esforços característicos resistentes aos 7 dias, a partir dos esforços de cálculo dados pela tabela 8.9. Assim, os valores característicos dos momentos fletores resistentes $\left(\mathrm{M}_{\mathrm{k}}\right)$ aos 7 dias mostrados na tabela 8.10 são determinados dividindo-se os valores da tabela 8.9 pelo fator 1,2 .

TABELA 8.10 - Valores característicos dos momentos fletores resistentes aos 7 dias

\begin{tabular}{|c|c|c|c|c|c|}
\hline & Ponto 1 & Ponto 2 & Ponto 3 & Ponto 4 & Ponto 4y \\
\hline $\mathrm{M}_{\mathrm{rk}}$ (kN.m) & $-7,41$ & 7,82 & $-7,41$ & 4,29 & 4,29 \\
\hline
\end{tabular}

Comparando os resultados da tabela 8.10 com os da tabela 8.5 pode-se perceber que já aos 7 dias os momentos fletores resistentes atingem valores superiores aos momentos fletores atuantes em quaisquer das etapas de construção. Portanto, a segurança estaria garantida nestes pontos do $1^{\mathrm{O}}$ pavimento.

É bom ressaltar que, embora tenham-se aqui aproveitado os resultados nos pontos do $1^{\mathrm{O}}$ pavimento para exemplificar uma verificação da segurança, será visto nos capítulos seguintes que, para o processo de construção utilizado (dois níveis de escoras mais um nível de reescora), os maiores esforços solicitantes ocorrem no $2^{\mathrm{O}}$ 
pavimento. Assim, para a garantia efetiva de segurança da construção deveriam-se verificar os pontos do $2^{\mathrm{O}}$ pavimento.

No capítulo seguinte são apresentadas as características de outro edifício, desta vez com uma estrutura usual. Um pouco mais adiante, a análise seqüencial construtiva é aplicada a esta estrutura, novamente a título de exemplo. 


\section{CARACTERÍSTICAS DO EDIFÍCIO COM ESTRUTURA USUAL UTILIZADO COMO EXEMPLO}

\subsection{Considerações sobre a análise seqüencial construtiva}

No capítulo anterior foi exemplificada a análise seqüencial das etapas de construção, utilizando-se para isso uma estrutura em concreto armado com 4 pavimentos. Na verdade, o exemplo feito para esta estrutura (figura 8.6) até a etapa 11 é o mesmo para um número maior de pavimentos, obviamente se utilizado o processo de construção particularmente especificado (dois níveis de escoras mais um nível de reescora).

Além disso, ao imaginar a etapa 11 semelhante à etapa 7 (diferenciando-se somente pela defasagem de um pavimento) e lembrando que o processo de construção se repete, pode-se naturalmente supor que a etapa 12 seja semelhante à etapa 8 (diferenciando-se também pela defasagem de um pavimento). Para uma estrutura com um número maior de pavimentos define-se a etapa 13A do mesmo modo que a etapa 9A, e assim por diante.

Nos capítulos seguintes, a análise seqüencial construtiva é aplicada a uma estrutura usual de edifício em concreto armado, em fase de ante-projeto. O objetivo, nesse caso, é verificar a segurança durante as etapas de construção e a deformação excessiva considerando a história de carregamentos desde a concretagem até o estado em serviço que se mantém ao longo do tempo. As características desta estrutura necessárias à aplicação da análise seqüencial são mostradas neste capítulo.

Para esse caso, a modelagem seguirá até a etapa 14, fase em que as reescoras entre o $2 .^{\circ}$ e o $3 .^{\circ}$ pavimento são retiradas. Isso se justifica porque a partir desta etapa os resultados já apresentam convergência, lembrando que o processo de construção é repetitivo. $\mathrm{Na}$ verdade, ocorre uma perturbação nos resultados dos primeiros pavimentos devido à presença da fundação, considerada como um apoio rígido. 
A análise seqüencial construtiva do edifício em questão objetiva também uma melhor avaliação do tradicional método simplificado, para que o mesmo, ou um novo método prático, possa ser utilizado com boa confiabilidade.

Deve-se lembrar que esta simulação refinada da construção através da análise seqüencial construtiva demanda um trabalho exaustivo.

\subsection{Descrição da estrutura do edifício e do processo de construção}

O ante-projeto da estrutura deste edifício, elaborado pelo próprio autor, apresenta pavimentos compostos por vigas e lajes maciças.

Para maior facilidade, e por não comprometer os objetivos aqui propostos, considera-se que todos os pavimentos possuem a forma do pavimento-tipo.

A forma do pavimento-tipo é mostrada na figura 9.1, lembrando que a distância de piso a piso é igual a $3 \mathrm{~m}$. Por apresentar simetria em uma das direções, todas as referências feitas ao edifício consideram apenas a metade apresentada na figura 9.1. Por exemplo ao citar que a área do pavimento é de $87,5 \mathrm{~m}^{2}$, deve-se ter em mente que na realidade esta é a área da metade do pavimento.

Neste ante-projeto, o concreto especificado tem resistência característica $\mathrm{f}_{\mathrm{ck}}=$ $2,50.10^{4} \mathrm{kN} / \mathrm{m}^{2}$ e o módulo de elasticidade $\mathrm{E}_{\mathrm{c}}=2,48 \cdot 10^{7} \mathrm{kN} / \mathrm{m}^{2}$. O peso próprio do concreto armado é admitido igual a $25 \mathrm{kN} / \mathrm{m}^{3}$ e o valor $v_{\mathrm{c}}=0,16$ é considerado representativo para o coeficiente de Poisson deste material. O aço CA-50 a ser utilizado possui resistência ao escoamento $\mathrm{f}_{\mathrm{yk}}=5,0.10^{5} \mathrm{kN} / \mathrm{m}^{2}$ e módulo de elasticidade $\mathrm{E}_{\mathrm{S}}=2,1 \cdot 10^{8} \mathrm{kN} / \mathrm{m}^{2}$. 


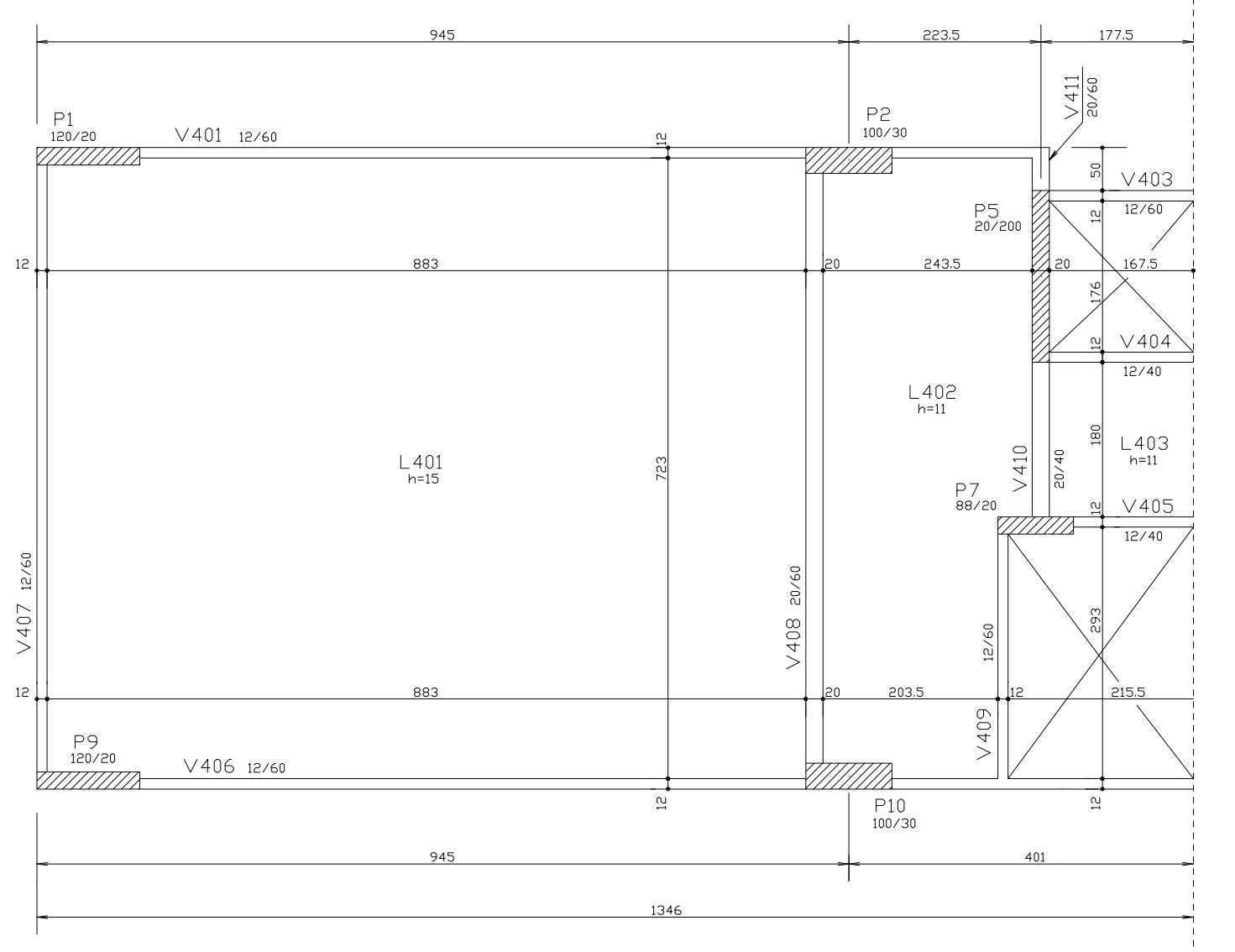

FIGURA 9.1 - Forma do pavimento-tipo (em cm)

Observando a forma do pavimento-tipo mostrada na figura 9.1 nota-se que a laje L401 apresenta grandes dimensões em planta. A sua espessura $\mathrm{h}=15 \mathrm{~cm}$ atende às prescrições da NBR-6118 (1978).

Segundo esta norma, para lajes maciças retangulares, dispensar-se-á o cálculo das flechas quando a altura útil d não for inferior ao valor $\mathrm{L} / \psi_{2} \cdot \psi_{3}$, onde $\mathrm{L}$ é o menor vão $(\mathrm{L}=7,35 \mathrm{~m})$. O coeficiente $\psi_{2}$ é função da geometria e das condições de engastamento, e para esta laje tem-se $\psi_{2}=1,57$. Já o coeficiente $\psi_{3}$ depende da tensão na armadura para solicitação de cálculo $\left(\sigma_{\mathrm{sd}}\right)$. Nos casos usuais de dimensionamento adota-se $\sigma_{\mathrm{sd}}=\mathrm{f}_{\mathrm{yd}}=4,35 \cdot 10^{5} \mathrm{kN} / \mathrm{m}^{2}$. De acordo com a NBR6118 (1978) para este nível de tensão na armadura tem-se $\psi_{3}=25$. Assim: 
Portanto, adotada esta espessura, há a necessidade de verificar a flecha final no tempo infinito, limitando-a em $\mathrm{L} / 300=2,45 \mathrm{~cm}$.

A NBR-6118 (1978) permite avaliar a flecha no tempo infinito (imediata + deformação lenta) como o produto do valor da flecha imediata pela relação das curvaturas final e inicial na seção de maior momento fletor em valor absoluto. As curvaturas são dadas por:

$$
\begin{aligned}
& \frac{1}{\mathrm{r}}=\frac{\left|\varepsilon_{\mathrm{c}}\right|+\varepsilon_{\mathrm{s}}}{\mathrm{d}} \text {, fazendo-se } \varepsilon_{\mathrm{c}} \text { final igual a três vezes o valor de } \varepsilon_{\mathrm{c}} \text { inicial, e } \\
& \varepsilon_{\mathrm{S}} \text { constante e igual ao seu valor inicial. }
\end{aligned}
$$

Há a necessidade de se determinar então os valores de deformação específica do concreto comprimido $\left(\varepsilon_{\mathrm{c}}\right)$ e da armadura tracionada $\left(\varepsilon_{\mathrm{S}}\right)$ para a seção de maior momento fletor em valor absoluto, ou seja, para o centro da laje na direção do menor vão.

Tanto esse momento fletor $(\mathrm{M})$ quanto a flecha imediata $\left(\Delta_{\mathrm{i}}\right)$ são os resultantes quando atuam os valores característicos das ações de peso próprio, alvenaria e revestimento somados ao valor quase-permanente da ação da sobrecarga de utilização. De acordo com a NBR-8681 (1984) esse valor quase-permanente deve ser obtido com o fator de utilização $\psi_{2}=0,2$ (como mostrado no capítulo 6).

No que se refere à flecha imediata, a NBR-6118 (1978) permite que, para lajes, a mesma seja determinada considerando comportamento no Estádio I, ou seja, sem os efeitos da fissuração.

Deste modo, para a seção transversal em questão tem-se:

$$
\begin{array}{ll}
\mathrm{M}=16,60 \mathrm{kN} \cdot \mathrm{m} / \mathrm{m} & \mathrm{h}=15 \mathrm{~cm} \\
\Delta_{\mathrm{i}}=1,53 \mathrm{~cm} & \mathrm{~d}=14 \mathrm{~cm} \\
\mathrm{~A}_{\mathrm{S}}=5,33 \mathrm{~cm}^{2} / \mathrm{m} & \mathrm{b}=100 \mathrm{~cm} \text { (largura da seção) } \\
\mathrm{A}_{\mathrm{S}}=0 & \alpha_{\mathrm{e}}=\mathrm{E}_{\mathrm{S}} / \mathrm{E}_{\mathrm{c}}=210000 / 24800=8,46 \\
\mathrm{c}=1,0 \mathrm{~cm} \text { (cobrimento) } & \mathrm{L}=735 \mathrm{~cm} \text { (menor vão) }
\end{array}
$$


Com esses dados, determina-se a altura da linha neutra $(\mathrm{x})$ medida a partir da borda comprimida da seção transversal.

$$
\begin{gathered}
\frac{b \cdot x^{2}}{2}+\alpha_{e} \cdot A_{s}^{\prime} \cdot(x-c)-\frac{b \cdot(h-x)^{2}}{2}-\alpha_{e} \cdot A_{s} \cdot(d-x)=0 \\
\frac{100 \cdot x^{2}}{2}+8,46 \cdot 0 \cdot(x-1,0)-\frac{100 \cdot(15-x)^{2}}{2}-8,46 \cdot 5,33 \cdot(14-x)=0 \\
50 \cdot x^{2}-50 \cdot\left(15^{2}-2 \cdot 15 \cdot x+x^{2}\right)-45,09 \cdot(14-x)=0 \\
50 \cdot x^{2}-11250+1500 \cdot x-50 \cdot x^{2}-631,26+45,09 \cdot x=0 \\
1545,09 \cdot x-11881,26=0 \\
x=7,69 \mathrm{~cm}
\end{gathered}
$$

Pode-se, com a definição da linha neutra, achar o valor do momento de inércia (I) da seção com largura unitária (1 m).

$$
\begin{gathered}
I=\frac{b \cdot x^{3}}{3}+\alpha_{e} \cdot A_{s}^{\prime} \cdot(x-c)^{2}+\alpha_{e} \cdot A_{s} \cdot(d-x)^{2}+b \cdot \frac{(h-x)^{3}}{3} \\
I=\frac{100 \cdot 7,69^{3}}{3}+8,46 \cdot 5,33 \cdot(14-7,69)^{2}+100 \cdot \frac{(15-7,69)^{3}}{3} \\
I=29974,53 \mathrm{~cm}^{4}
\end{gathered}
$$

As tensões no concreto comprimido $\left(\sigma_{\mathrm{c}}\right)$ e na armadura $\left(\sigma_{\mathrm{S}}\right)$ resultam:

$$
\begin{gathered}
\left|\sigma_{\mathrm{c}}\right|=\frac{\mathrm{M}}{\mathrm{I}} \cdot \mathrm{x}=\frac{1660}{29974,53} \cdot 7,69=0,426 \mathrm{kN} / \mathrm{cm}^{2} \\
\sigma_{\mathrm{s}}=\alpha_{\mathrm{e}} \cdot \frac{\mathrm{M}}{\mathrm{I}} \cdot(\mathrm{x}-\mathrm{c})=8,46 \cdot \frac{1660}{29974,53} \cdot(7,69-1,0)=3,13 \mathrm{kN} / \mathrm{cm}^{2}
\end{gathered}
$$


Finalmente, determinam-se as deformações específicas iniciais no concreto $\left(\varepsilon_{\mathrm{c}}\right)$ e na armadura $\left(\varepsilon_{\mathrm{s}}\right)$.

$$
\begin{aligned}
& \left|\varepsilon_{\mathrm{c}}\right|=\frac{\left|\sigma_{\mathrm{c}}\right|}{\mathrm{E}_{\mathrm{c}}}=\frac{4,26}{24800}=0,172 \% \mathrm{o} \\
& \varepsilon_{\mathrm{s}}=\frac{\sigma_{\mathrm{s}}}{\mathrm{E}_{\mathrm{s}}}=\frac{31,3}{210000}=0,149 \% \mathrm{o}
\end{aligned}
$$

Fazendo-se $\varepsilon_{\mathrm{c}}$ final igual a três vezes o valor de $\varepsilon_{\mathrm{c}}$ inicial, e $\varepsilon_{\mathrm{S}}$ constante e igual ao seu valor inicial, obtém-se os valores das curvaturas inicial e final.

$$
\begin{gathered}
\left(\frac{1}{\mathrm{r}}\right)_{\mathrm{i}}=\frac{\left|\varepsilon_{\mathrm{c}}\right|+\varepsilon_{\mathrm{s}}}{\mathrm{d}}=\frac{0,000172+0,000149}{14}=2,29 \cdot 10^{-5} / \mathrm{cm} \\
\left(\frac{1}{\mathrm{r}}\right)_{\mathrm{f}}=\frac{3 \cdot\left|\varepsilon_{\mathrm{c}}\right|+\varepsilon_{\mathrm{s}}}{\mathrm{d}}=\frac{3 \cdot 0,000172+0,000149}{14}=4,75 \cdot 10^{-5} / \mathrm{cm}
\end{gathered}
$$

Utilizando a relação entre essas curvaturas como fator majorador para a flecha imediata, tem-se a flecha total $\mathrm{a}_{\mathrm{L}}$ (imediata + deformação lenta):

$\mathrm{a}_{\mathrm{L}}=\frac{4,75}{2,29} \cdot 1,53=2,07 \cdot 1,53=3,16 \mathrm{~cm}$

Só falta, agora, acrescentar a parcela de deslocamento transversal devida à retração. Segundo a NBR-6118 (1978) a deformação específica de retração do concreto $\left(\varepsilon_{\mathrm{SH}}\right)$ pode ser considerada, nos casos correntes, igual a $15.10^{-5}$. Então, temse condições de avaliar a flecha total $\mathrm{a}_{\mathrm{r}}$ devida à retração.

$$
\begin{gathered}
\phi_{\mathrm{SH}}=\frac{\varepsilon_{\mathrm{SH}}}{\mathrm{d}}=\frac{15 \cdot 10^{-5}}{14}=1,07 \cdot 10^{-5} \\
\mathrm{a}_{\mathrm{r}}=\mathrm{k}_{\mathrm{W}} \cdot \phi_{\mathrm{SH}} \cdot \mathrm{L}^{2}=\frac{1}{8} \cdot 1,07 \cdot 10^{-5} \cdot 735^{2}=0,72 \mathrm{~cm}
\end{gathered}
$$


A flecha final no tempo infinito $\left(a_{L}+a_{r}\right)$ é igual a:

$$
\mathrm{a}_{\mathrm{L}}+\mathrm{a}_{\mathrm{r}}=3,16+0,72=3,88 \mathrm{~cm}
$$

Especificando uma contra-flecha de $1,5 \mathrm{~cm}$ para o centro da laje, tem-se:

$$
\text { Flecha Final }=3,88-1,5=2,38 \mathrm{~cm}<2,45 \mathrm{~cm}
$$

Assim sendo, mediante essa verificação, justifica-se a adoção da espessura $h=$ $15 \mathrm{~cm}$ para a laje L401. Poderia-se, ainda, subtrair da flecha final o valor do deslocamento transversal dos apoios (V401/V406).

Para uma estimativa mais rigorosa das flechas no tempo infinito, considerando a deformação lenta e a deformação por retração, são adotadas as seguintes condições:

- cura úmida normal por 7 dias;

- uso do cimento portland comum;

- temperatura média de $25{ }^{\circ} \mathrm{C}$;

- umidade relativa de $70 \%$.

O desenvolvimento das características de resistência e deformabilidade do concreto com a idade é estimado com base nas expressões do CEB-90 (1990), resultando nos valores da tabela 9.1 .

TABELA 9.1 - Desenvolvimento da resistência característica e do módulo de elasticidade

\begin{tabular}{|c|c|c|}
\hline $\begin{array}{c}\text { IDADE } \\
(\text { DIAS })\end{array}$ & $\begin{array}{c}\mathrm{f}_{\mathrm{ck}} \\
\left(\mathrm{kN} / \mathrm{m}^{2}\right)\end{array}$ & $\begin{array}{c}\mathrm{E}_{\mathrm{c}} \\
\left(\mathrm{kN} / \mathrm{m}^{2}\right)\end{array}$ \\
\hline 7 & $1,99.10^{4}$ & $2,24.10^{7}$ \\
\hline 14 & $2,32.10^{4}$ & $2,39.10^{7}$ \\
\hline 21 & $2,47.10^{4}$ & $2,46.10^{7}$ \\
\hline 28 & $2,50.10^{4}$ & $2,48.10^{7}$ \\
\hline
\end{tabular}


Admite-se que o processo de construção deste edifício utiliza dois níveis de escoras mais um nível de reescora, com a concretagem de um pavimento a cada 7 dias. Há cinquenta pontaletes para a sustentação do pavimento, cujas posições estão mostradas na figura 9.2.

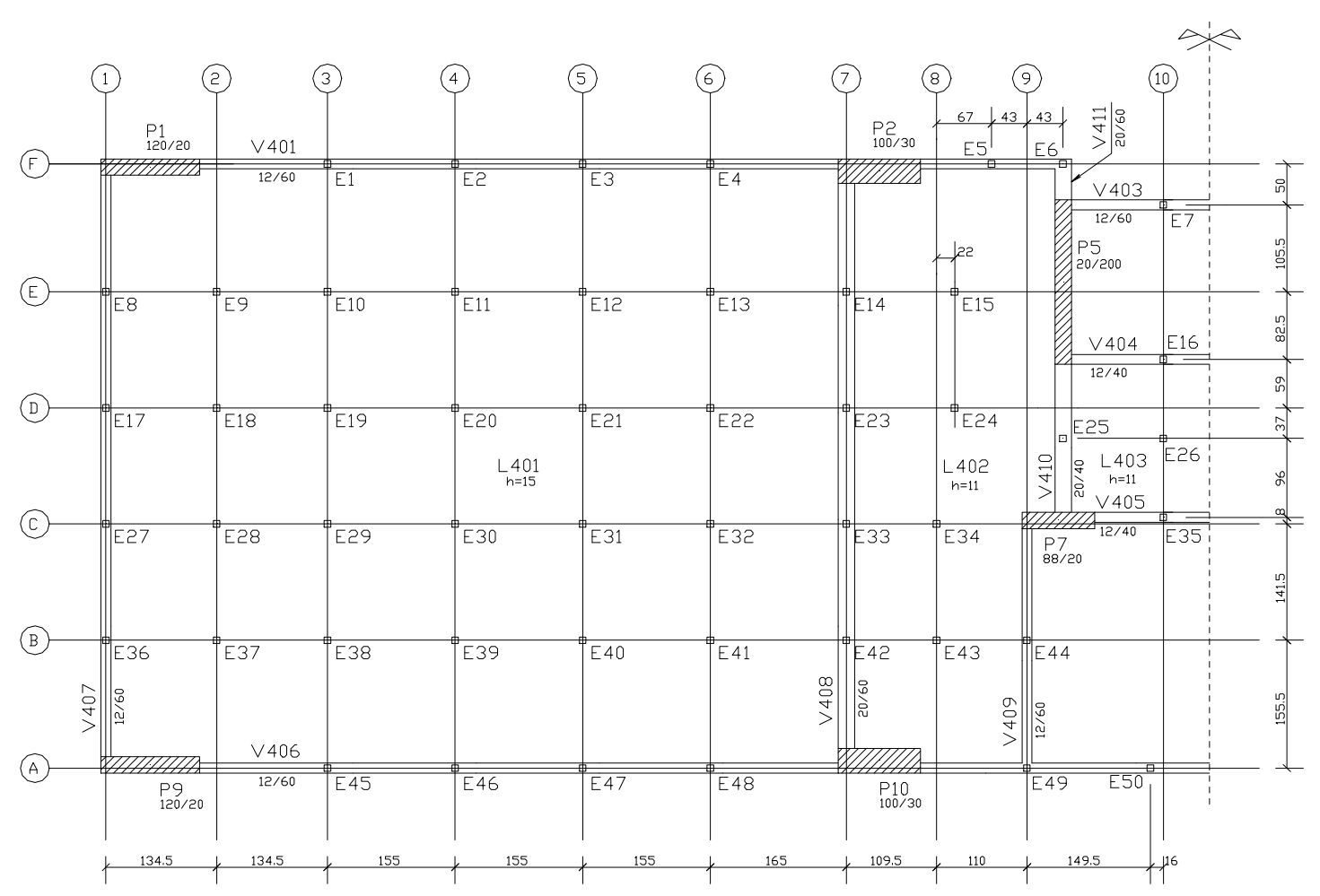

FIGURA 9.2 - Posição dos pontaletes no pavimento $(\mathrm{em} \mathrm{cm})$

Os pontaletes utilizados são de madeira (Pinus Elliottii) com seção retangular de $8 \mathrm{~cm} \times 8 \mathrm{~cm}$, totalizando um peso próprio aproximado de $0,1 \mathrm{kN}$ por peça. $\mathrm{O}$ módulo de elasticidade desse tipo de madeira pode ser considerado igual a $6,85.10^{6}$ $\mathrm{kN} / \mathrm{m}^{2}$ e o coeficiente de Poisson igual a 0,30 . 
O peso próprio do conjunto de fôrmas é considerado como uma ação uniformemente distribuída no pavimento igual a $0,15 \mathrm{kN} / \mathrm{m}^{2}$, enquanto as ações variáveis estão presentes somente durante a concretagem (etapas A) com valor de $3,81 \mathrm{kN} / \mathrm{m}^{2}$, aproximadamente $85 \%$ do peso próprio do pavimento.

\subsection{Quantitativos da estrutura do edifício}

Alguns quantitativos da estrutura são importantes para as modelagens das etapas de construção, do modo como foi definida a análise seqüencial. A tabela 9.2 mostra o volume de concreto e peso próprio de lajes, vigas e pilares para um andar.

TABELA 9.2 - Volume de concreto e peso próprio para um andar

\begin{tabular}{|c|c|c|c|}
\hline & LAJES & VIGAS & PILARES \\
\hline VOLUME $\left(\mathrm{m}^{3}\right)$ & 12,221 & 3,460 & 4,968 \\
\hline PESO PRÓPRIO $(\mathrm{kN})$ & 305,54 & 86,50 & 124,20 \\
\hline
\end{tabular}

Observando a tabela 9.2 conclui-se que o peso próprio de um pavimento (lajes e vigas) é igual a $392,04 \mathrm{kN}\left(4,48 \mathrm{kN} / \mathrm{m}^{2}\right)$. Na tabela 9.3 consta o peso próprio de cada tramo de pilar, com distância de piso a piso igual a $3 \mathrm{~m}$. 
TABELA 9.3 - Peso próprio dos tramos de pilar

\begin{tabular}{|c|c|}
\hline PILAR & PESO PRÓPRIO $(\mathrm{kN})$ \\
\hline P1 & 18,0 \\
\hline P2 & 22,5 \\
\hline P5 & 30,0 \\
\hline P7 & 13,2 \\
\hline P9 & 18,0 \\
\hline P10 & 22,5 \\
\hline
\end{tabular}

Durante a análise seqüencial, para as modelagens das etapas de concretagem (etapas A) há a necessidade de se avaliar as ações transmitidas aos pilares e aos pontaletes pelo concreto fresco. Nestas etapas atuam, além do peso próprio do concreto lançado, o peso próprio das fôrmas e ações variáveis.

A avaliação feita aqui dessa transmissão de ações considera o pavimento da figura 9.1, com os pontaletes posicionados como mostrado na figura 9.2, submetido a uma ação uniformemente distribuída de $3,96 \mathrm{kN} / \mathrm{m}^{2}(0,15+3,81)$ mais o seu peso próprio. As características do concreto são consideradas no estado endurecido aos 28 dias e a fundação é suposta um apoio rígido, exatamente como mostrado na figura 8.5 .

Somando as ações recebidas por pilares e pontaletes, obtidas desta avaliação, ao peso próprio de cada um desses elementos obtém-se as ações verticais concentradas a serem aplicadas no pavimento imediatamente inferior ao que está sendo concretado, para as modelagens das etapas A. A tabela 9.4 indica essas ações. 
TABELA 9.4 - Ações aplicadas no pavimento imediatamente inferior ao que está sendo concretado

\begin{tabular}{|c|c|}
\hline ELEMENTO & $\begin{array}{c}\text { AÇÃO VERTICAL } \\
\text { CONCENTRADA }(\mathrm{kN})\end{array}$ \\
\hline P1 & 42,0 \\
\hline P2 & 59,3 \\
\hline P5 & 67,7 \\
\hline P7 & 42,8 \\
\hline P9 & 44,7 \\
\hline P10 & 61,9 \\
\hline E9 A E13 & 16,7 \\
\hline E18 A E22 & 16,7 \\
\hline E28 A E32 & 16,7 \\
\hline E37 A E41 & 16,7 \\
\hline E1 A E4 & 8,6 \\
\hline E8,E17,E27,E36 & 8,6 \\
\hline E45 A E48 & 8,6 \\
\hline E14,E23,E33,E42 & 15,1 \\
\hline E5,E6 & 0,2 \\
\hline E7,E16,E35 & 1,6 \\
\hline E15,E24 & 10,1 \\
\hline E25 & 1,6 \\
\hline E26 & 5,1 \\
\hline E34,E43 & 7,1 \\
\hline E44 & 2,1 \\
\hline E49 & 0,6 \\
\hline E50 & 2,8 \\
\hline & \\
\hline & \\
\hline
\end{tabular}




\subsection{Dimensionamento da estrutura do edifício}

Os pontos do pavimento mostrados na figura 9.3 são importantes para verificações da segurança em relação ao momento fletor e da deformação excessiva feitas nos capítulos seguintes.

No que se refere à força cortante foi feita uma verificação preliminar a qual indicou que a capacidade resistente está muito longe do esgotamento durante as etapas de construção. Por isso não serão mostrados os resultados referentes a esse esforço.

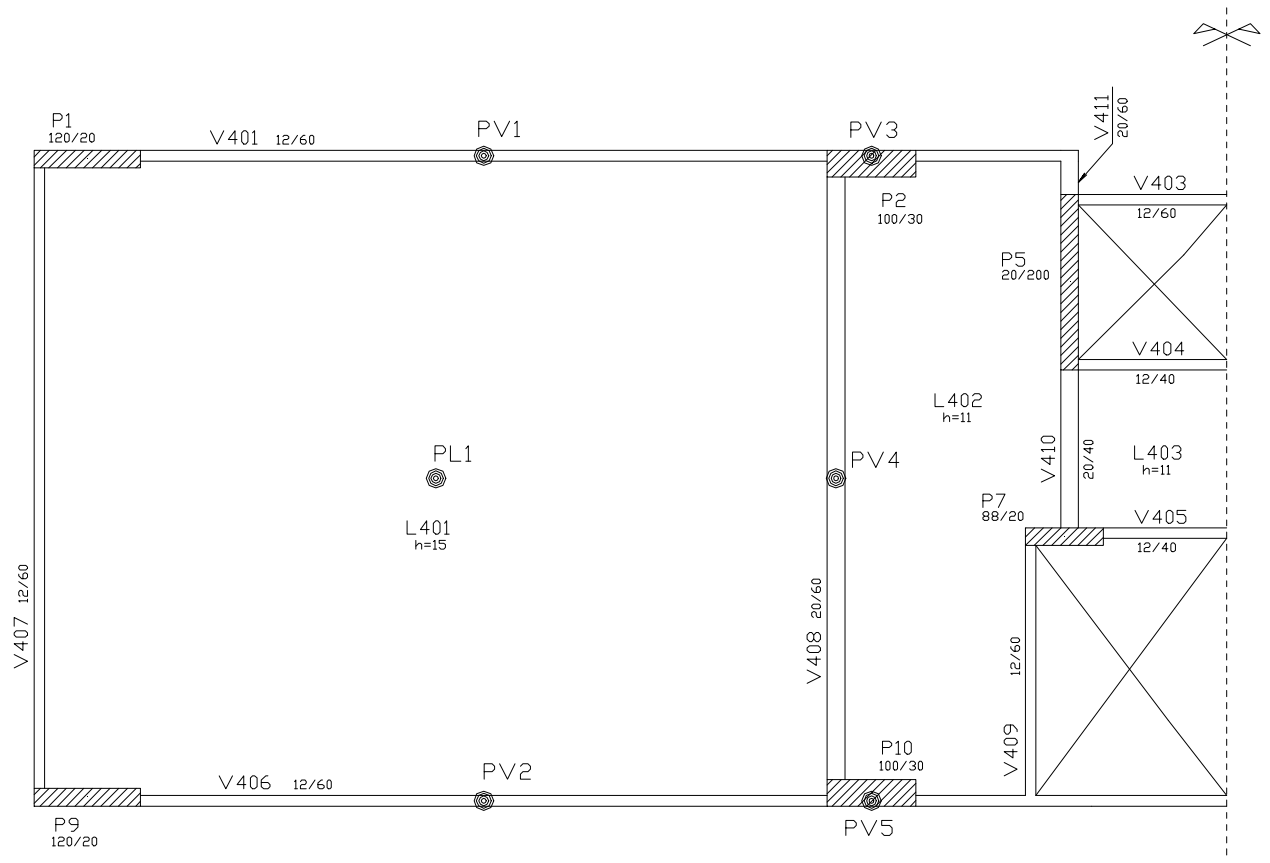

FIGURA 9.3 - Pontos do pavimento para verificações da segurança e da deformação excessiva $(\mathrm{em} \mathrm{cm})$

As tabelas 9.5 a 9.7 apresentam os valores característicos dos esforços solicitantes e a armadura dimensionada para todos os pontos, considerando o pavimento isolado submetido às ações em serviço e as características de resistência e deformabilidade do concreto aos 28 dias. As ações em serviço compreendem, além do peso próprio, ações uniformemente distribuídas relativas à sobrecarga de utilização $\left(1,5 \mathrm{kN} / \mathrm{m}^{2}\right)$ e ao revestimento $\left(1,0 \mathrm{kN} / \mathrm{m}^{2}\right)$ e as ações das alvenarias.

Está sendo considerado que as alvenarias estão presentes com a finalidade de fechamento da estrutura, gerando uma ação linearmente distribuída igual a 4,0 kN/m. Portanto, internamente não existem alvenarias. 
Novamente os programas da biblioteca do sistema LASER, desenvolvidos por RAMALHO (1990) e CORRÊA (1991), são utilizados na obtenção dos esforços solicitantes e deslocamentos, considerando linearidade física e geométrica.

TABELA 9.5 - Valores característicos para momento fletor positivo em pontos de viga e armadura inferior tracionada

\begin{tabular}{|c|c|c|c|}
\hline $\begin{array}{c}\text { PONTO } \\
\text { DE VIGA }\end{array}$ & $\begin{array}{c}\text { MOMENTO } \\
\text { FLETOR + (kN.m) }\end{array}$ & $\begin{array}{c}\mathrm{A}_{\mathrm{s}} \\
\left(\mathrm{cm}^{2}\right)\end{array}$ & $\begin{array}{c}\text { BARRAS } \\
\text { DE AÇO }\end{array}$ \\
\hline PV1 & 73,4 & 5,0 & $4 \phi 12,5$ \\
\hline PV2 & 73,4 & 5,0 & $4 \phi 12,5$ \\
\hline PV4 & 86,0 & 5,0 & $4 \phi 12,5$ \\
\hline
\end{tabular}

TABELA 9.6 - Valores característicos para momento fletor negativo em pontos de viga e armadura superior tracionada

\begin{tabular}{|c|c|c|c|}
\hline $\begin{array}{c}\text { PONTO } \\
\text { DE VIGA }\end{array}$ & $\begin{array}{c}\text { MOMENTO } \\
\text { FLETOR - (kN.m) }\end{array}$ & $\begin{array}{c}\mathrm{A}_{\mathrm{s}} \\
\left(\mathrm{cm}^{2}\right)\end{array}$ & $\begin{array}{c}\text { BARRAS } \\
\text { DE AÇO }\end{array}$ \\
\hline PV3 & $-161,1$ & 12,0 & $6 \phi 16$ \\
\hline PV5 & $-161,1$ & 12,0 & $6 \phi 16$ \\
\hline
\end{tabular}

TABELA 9.7 - Valores característicos para momento fletor positivo no ponto PL1 e armadura inferior tracionada

\begin{tabular}{|c|c|c|c|}
\hline $\begin{array}{c}\text { PONTO } \\
\text { DE LAJE }\end{array}$ & $\begin{array}{c}\text { MOMENTO } \\
\text { FLETOR }+(\mathrm{kN} . \mathrm{m} / \mathrm{m})\end{array}$ & $\begin{array}{c}\mathrm{A}_{\mathrm{s}} \\
\left(\mathrm{cm}^{2} / \mathrm{m}\right)\end{array}$ & $\begin{array}{c}\text { BARRAS } \\
\text { DE AÇO }\end{array}$ \\
\hline $\mathrm{PL}_{\mathrm{x}}$ & 15,8 & 3,85 & $\phi 8 \mathrm{c} / 13$ \\
\hline $\mathrm{PL} 1_{\mathrm{y}}$ & 22,0 & 5,33 & $\phi 10 \mathrm{c} / 15$ \\
\hline
\end{tabular}


A verificação da deformação excessiva se concentrará sobre os pontos críticos PL1, PV1 e PV2. Destaca-se que a situação do ponto PV2 é praticamente idêntica à do ponto PV1, não sendo feita aqui qualquer diferença entre eles.

Assim, as tabelas 9.8 a 9.10 mostram valores característicos de momento fletor e deslocamentos nas vigas V401/V406 e laje L401 para algumas situações de carregamento, sempre considerando o pavimento isolado. Essas tabelas serão úteis durante a análise da deformação excessiva considerando a história de carregamentos de construção.

Destaca-se que os momentos fletores positivos (+) referem-se à seção do meio do vão, enquanto os momentos fletores (-) ocorrem sobre os apoios. Nesse caso, os valores à esquerda e à direita do vão são os mesmos. Nas vigas isso ocorre devido à grande extensão de apoio conferida pelos pilares, o que acaba gerando praticamente um engastamento perfeito. Já a laje pode ser considerada simplesmente apoiada nas vigas, na direção em questão (direção y).

TABELA 9.8 - Valores característicos de momento fletor e deslocamento considerando as ações em serviço

\begin{tabular}{|c|c|c|c|}
\hline & $\begin{array}{c}\text { MOMENTO } \\
\text { FLETOR }+\end{array}$ & $\begin{array}{c}\text { MOMENTO } \\
\text { FLETOR }-\end{array}$ & FLECHA \\
\hline V401/V406 & $73,4 \mathrm{kN} . \mathrm{m}$ & $-161,1 \mathrm{kN} . \mathrm{m}$ & $0,40 \mathrm{~cm}$ \\
\hline L401 & $22,0 \mathrm{kN} . \mathrm{m} / \mathrm{m}$ & 0 & $1,86 \mathrm{~cm}$ \\
\hline
\end{tabular}

TABELA 9.9 - Valores característicos de momento fletor e deslocamento considerando as ações em serviço, com $20 \%$ da sobrecarga de utilização

\begin{tabular}{|c|c|c|c|}
\hline & $\begin{array}{c}\text { MOMENTO } \\
\text { FLETOR }+\end{array}$ & $\begin{array}{c}\text { MOMENTO } \\
\text { FLETOR }-\end{array}$ & FLECHA \\
\hline V401/V406 & $47,2 \mathrm{kN} . \mathrm{m}$ & $-153,0 \mathrm{kN} . \mathrm{m}$ & $0,34 \mathrm{~cm}$ \\
\hline L401 & $16,6 \mathrm{kN} . \mathrm{m} / \mathrm{m}$ & 0 & $1,53 \mathrm{~cm}$ \\
\hline
\end{tabular}


TABELA 9.10 - Valores característicos de momento fletor e deslocamento considerando somente o peso próprio

\begin{tabular}{|c|c|c|c|}
\hline & $\begin{array}{c}\text { MOMENTO } \\
\text { FLETOR }+\end{array}$ & $\begin{array}{c}\text { MOMENTO } \\
\text { FLETOR }-\end{array}$ & FLECHA \\
\hline V401/V406 & $29,7 \mathrm{kN} . \mathrm{m}$ & $-98,0 \mathrm{kN} . \mathrm{m}$ & $0,21 \mathrm{~cm}$ \\
\hline L401 & $12,3 \mathrm{kN} . \mathrm{m} / \mathrm{m}$ & 0 & $1,09 \mathrm{~cm}$ \\
\hline
\end{tabular}

Apresentadas as características da estrutura do edifício, bem como o seu processo de construção, cria-se condições para a aplicação da análise seqüencial construtiva. Os resultados são mostrados nos dois capítulos seguintes, que se referem às verificações da segurança e da deformação excessiva. 


\section{VERIFICAÇÃO DA SEGURANÇA}

\subsection{Elementos estruturais}

Será verificado o estado limite último de esgotamento da capacidade resistente em relação ao momento fletor durante a construção para os pontos do pavimento mostrados na figura 9.3. As situações dos pontos PV1 e PV2, bem como dos pontos PV3 e PV5, são consideradas as mesmas uma vez que seus esforços solicitantes são muito próximos em todas as etapas do processo.

De acordo com OLIVEIRA (1997) para um pavimento armado com esforços solicitantes obtidos em regime elástico, a diferença entre esses esforços e os obtidos com uma análise não-linear é pequena.

Como já ressaltado, a análise seqüencial construtiva segue até a etapa 14, a partir da qual os resultados de esforços solicitantes nos diversos pavimentos passam a convergir. Constata-se que os esforços com valores mais elevados ocorrem no $2 .^{\circ}$ pavimento, na etapa 9A. Até certo ponto isso pode parecer surpreendente, pois observando a estrutura nesta etapa poderia-se imaginar que o $1 .^{\circ}$ pavimento estivesse mais solicitado. Não obstante, é bom lembrar que o método simplificado para distribuição das ações de construção aponta exatamente para esta situação como sendo a mais crítica. Mais adiante, será feita uma comparação detalhada entre esses resultados.

A tabela 10.1 indica os valores característicos de momento fletor (M) atuante para cada ponto do $2{ }^{\circ}$ pavimento, desde a etapa 2 até a etapa $9 \mathrm{~A}$.

Somente para efeito de comparação, a tabela 10.2 apresenta os valores obtidos para estes pontos considerando-se uma análise global (não-seqüencial) da etapa 9A, como a bibliografia sobre o assunto normalmente indica. Ou seja, imagina-se que esta etapa passa a existir de uma só vez, sem uma construção feita gradativamente. 
Nota-se que os momentos fletores apresentam valores menores que os indicados através da análise seqüencial construtiva.

TABELA 10.1 - Momentos fletores atuantes no 2. ${ }^{\circ}$ pavimento em cada etapa de construção

\begin{tabular}{|c|c|c|c|c|c|}
\hline ETAPA & $\begin{array}{c}\text { PONTO } \\
\text { PV1/PV2 } \\
\text { M (kN.m) }\end{array}$ & $\begin{array}{c}\text { PONTO } \\
\text { PV4 } \\
\text { M (kN.m) }\end{array}$ & $\begin{array}{c}\text { PONTO } \\
\text { PV3/PV5 } \\
\text { M (kN.m) }\end{array}$ & $\begin{array}{c}\text { PONTO } \\
\text { PL1 } \\
\text { M (kN.m/m) }\end{array}$ & $\begin{array}{c}\text { IDADE } \\
\text { (DIAS) }\end{array}$ \\
\hline $2 \mathrm{~A}$ & 0 & 0 & 0 & 0 & 0 \\
\hline 2 & 6,32 & 10,68 & $-30,00$ & 0,70 & 7 \\
\hline 3 & 25,80 & 44,48 & $-93,94$ & 10,90 & 7 \\
\hline 4 & 25,80 & 44,48 & $-93,94$ & 10,90 & 7 \\
\hline $5 \mathrm{~A}$ & 33,77 & 62,96 & $-105,74$ & 12,80 & 7 \\
\hline 5 & 30,00 & 52,03 & $-110,29$ & 11,90 & 14 \\
\hline 6 & 35,26 & 60,96 & $-128,42$ & 14,80 & 14 \\
\hline 7 & 41,61 & 72,30 & $-151,42$ & 17,00 & 14 \\
\hline 8 & 41,61 & 72,30 & $-151,42$ & 17,00 & 14 \\
\hline $9 \mathrm{~A}$ & 57,45 & 102,10 & $-209,64$ & 24,70 & 14 \\
\hline
\end{tabular}

TABELA 10.2 - Momentos fletores atuantes no 2. ${ }^{\circ}$ pavimento, de acordo com análise global

\begin{tabular}{|c|c|c|c|c|c|}
\hline ETAPA & PONTO & PONTO & PONTO & PONTO & IDADE \\
& PV1/PV2 & PV4 & PV3/PV5 & PL1 & (DIAS) \\
& M (kN.m) & M (kN.m) & M (kN.m) & M (kN.m/m) & \\
\hline 9A & 45,00 & 80,00 & $-171,00$ & 19,00 & 14 \\
\hline
\end{tabular}


Com os resultados da tabela 10.1 pode-se verificar a segurança em cada ponto.

A obtenção dos valores de cálculo dos momentos fletores atuantes é feita multiplicando os valores característicos da tabela 10.1 pelo fator 1,2. Isso se deve ao fato de que está sendo utilizada a combinação última de construção, descrita no capítulo 5.

A seguir são feitas as verificações da segurança comparando-se a armadura necessária $\left(\mathrm{A}_{\mathrm{SN}}\right)$ para absorver os momentos fletores no 2. ${ }^{\circ}$ pavimento na etapa 9A com a armadura existente $\left(\mathrm{A}_{\mathrm{SE}}\right)$. Na etapa 9A esse pavimento tem a idade de 14 dias e portanto, segundo a tabela 9.1, apresenta uma resistência característica $\mathrm{f}_{\mathrm{ck}}=$ $2,32 \cdot 10^{4} \mathrm{kN} / \mathrm{m}^{2}$.

Durante a etapa $5 \mathrm{~A}$, crítica para a idade de 7 dias com $\mathrm{f}_{\mathrm{ck}}=1,99 \cdot 10^{4} \mathrm{kN} / \mathrm{m}^{2}$, as armaduras existentes são plenamente suficientes para absorver os esforços solicitantes.

a) Pontos PV1/PV2

Seção transversal de viga com $12 \mathrm{~cm}$ x $60 \mathrm{~cm}$

Armadura inferior de flexão tracionada $\left(\mathrm{A}_{\mathrm{SE}}\right) \quad 4 \phi 12,5 \mathrm{~mm}\left(5,0 \mathrm{~cm}^{2}\right)$

$$
\begin{aligned}
& \mathrm{M}_{\mathrm{k}}=57,45 \mathrm{kN} \cdot \mathrm{m} \quad \mathrm{M}_{\mathrm{d}}=68,94 \mathrm{kN} \cdot \mathrm{m} \\
& \mathrm{A}_{\mathrm{SN}}=2,94 \mathrm{~cm}^{2}<\mathrm{A}_{\mathrm{SE}}
\end{aligned}
$$

b) Ponto PV4

Seção transversal de viga com $20 \mathrm{~cm}$ x $60 \mathrm{~cm}$

Armadura inferior de flexão tracionada $\left(\mathrm{A}_{\mathrm{SE}}\right) \quad 4 \phi 12,5 \mathrm{~mm}\left(5,0 \mathrm{~cm}^{2}\right)$

$\mathrm{M}_{\mathrm{k}}=102,10 \mathrm{kN} \cdot \mathrm{m} \quad \mathrm{M}_{\mathrm{d}}=122,52 \mathrm{kN} \cdot \mathrm{m}$

$\mathrm{A}_{\mathrm{SN}}=5,25 \mathrm{~cm}^{2}>\mathrm{A}_{\mathrm{SE}}$ 
c) Pontos PV3/PV5

Seção transversal de viga com $12 \mathrm{~cm}$ x $60 \mathrm{~cm}$

Armadura superior de flexão tracionada $\left(\mathrm{A}_{\mathrm{SE}}\right) \quad 6 \phi 16 \mathrm{~mm}\left(12,0 \mathrm{~cm}^{2}\right)$

$\mathrm{M}_{\mathrm{k}}=209,64 \mathrm{kN} \cdot \mathrm{m} \quad \mathrm{M}_{\mathrm{d}}=251,57 \mathrm{kN} \cdot \mathrm{m}$

Nesse caso, precisa-se adicionalmente de uma armadura inferior de compressão $\left(\mathrm{A}^{\prime}{ }_{\mathrm{SN}}\right)$ :

$\mathrm{A}_{\mathrm{SN}}=12,67 \mathrm{~cm}^{2}>\mathrm{A}_{\mathrm{SE}}$

$\mathrm{A}^{\prime}{ }_{\mathrm{SN}}=2,08 \mathrm{~cm}^{2}>\mathrm{A}^{\prime}{ }_{\mathrm{SE}}=1,50 \mathrm{~cm}^{2}$ (porta-estribo com $3 \phi 8 \mathrm{~mm}$ )

d) Ponto PL1

Seção transversal de laje com $15 \mathrm{~cm}$

Armadura inferior de flexão tracionada $\left(\mathrm{A}_{\mathrm{SE}}\right) \quad \phi 10 \mathrm{c} / 15\left(5,33 \mathrm{~cm}^{2} / \mathrm{m}\right)$

$\mathrm{M}_{\mathrm{k}}=24,70 \mathrm{kN} \cdot \mathrm{m} / \mathrm{m} \quad \mathrm{M}_{\mathrm{d}}=29,64 \mathrm{kN} \cdot \mathrm{m} / \mathrm{m}$

$\mathrm{A}_{\mathrm{SN}}=5,19 \mathrm{~cm}^{2} / \mathrm{m}<\mathrm{A}_{\mathrm{SE}}$

Nos pontos PV3/PV5, durante a etapa de construção 9A, é necessária uma quantidade de armadura maior do que a existente. Isso não implica na ocorrência de um colapso nos respectivos elementos, muito menos na estrutura como um todo. Em elementos hiperestáticos a capacidade resistente não se esgota se o limite de escoamento do aço ou a deformação limite do concreto forem atingidos em uma única seção transversal. A deformação plástica em tais pontos conduz a uma maior solicitação das zonas adjacentes, ou seja, a uma redistribuição de esforços.

Já no caso do ponto PV4 a situação é um pouco diferente. Também é necessária uma quantidade de armadura maior do que a existente. Entretanto, nesse 
caso, a seção transversal está situada no meio do vão de uma viga (V408). Essa viga pode ser considerada praticamente bi-apoiada, ou seja, ela não apresenta uma continuidade após os apoios. Além disso, seus dois apoios possuem pequena extensão, não garantindo engastamento. Com uma pequena competência para redistribuição de esforços, uma falta de capacidade resistente da seção transversal do meio do vão pode causar problemas a essa viga, e consequentemente ao pavimento como um todo. Não obstante, nesse caso específico, a armadura necessária é muito pouco superior à existente $(5 \%)$. Se for considerada a contribuição da mesa de compressão provavelmente não haverá problemas.

Para os demais pontos analisados a segurança está garantida.

No final do trabalho, em anexo, constam alguns gráficos que ilustram a verificação da segurança.

\subsection{Pontaletes}

Como mostrado no capítulo 5, para a verificação da segurança dos pontaletes (ruptura e estabilidade) deve ser utilizada a combinação última de construção definida na NBR-8681 (1984), com $\gamma_{\mathrm{g}}=\gamma_{\mathrm{q}}=1,2$.

Portanto, aplica-se essa combinação às diversas etapas de construção, obtendose as solicitações axiais de cálculo $\left(\mathrm{N}_{\mathrm{d}}\right)$ nos pontaletes.

O pontalete mais solicitado foi o E20, junto com o E30 que ocupa praticamente uma posição simétrica na forma da estrutura. Ambos apresentaram uma solicitação axial de cálculo $\left(\mathrm{N}_{\mathrm{d}}\right)$ igual a $27,85 \mathrm{kN}$ durante a etapa 2A (no nível situado entre a fundação e o $1 .^{\circ}$ pavimento).

A verificação da segurança dos pontaletes é feita com base nas indicações da NBR-7190 (1997). Segundo esta norma, a madeira Pinus Elliottii possui as seguintes características (valores médios usuais):

$$
\begin{aligned}
& \mathrm{f}_{\mathrm{co}, \mathrm{m}}=4,04 \cdot 10^{4} \mathrm{kN} / \mathrm{m}^{2} \\
& \mathrm{E}_{\mathrm{co}, \mathrm{m}}=1,19 \cdot 10^{7} \mathrm{kN} / \mathrm{m}^{2}
\end{aligned}
$$


$\mathrm{k}_{\bmod , 1}=0,9$ (carregamento de curta duração)

$\mathrm{k}_{\bmod , 2}=0,8$ (classe de umidade 3$)$

$\mathrm{k}_{\bmod , 3}=0,8$ (madeira de segunda categoria)

$\mathrm{k}_{\bmod }=\mathrm{k}_{\bmod , 1} \cdot \mathrm{k}_{\bmod , 2} \cdot \mathrm{k}_{\bmod , 3}=0,9 \cdot 0,8 \cdot 0,8=0,576$

Ainda de acordo com a referida norma devem ser utilizados os seguintes parâmetros para a verificação da segurança:

$$
\begin{aligned}
& \mathrm{E}_{\mathrm{co}, \mathrm{ef}}=\mathrm{k}_{\mathrm{mod}} \cdot \mathrm{E}_{\mathrm{co}, \mathrm{m}}=0,576 \cdot 1,19 \cdot 10^{7}=6,85 \cdot 10^{6} \mathrm{kN} / \mathrm{m}^{2} \\
& \mathrm{f}_{\mathrm{co}, \mathrm{k}}=0,7 \cdot \mathrm{f}_{\mathrm{co}, \mathrm{m}}=0,7 \cdot 4,04 \cdot 10^{4}=2,83 \cdot 10^{4} \mathrm{kN} / \mathrm{m}^{2} \\
& \mathrm{f}_{\mathrm{c}, \mathrm{d}}=\mathrm{k}_{\mathrm{mod}} \cdot\left(\mathrm{f}_{\mathrm{co}, \mathrm{k}} / 1,4\right)=0,576 \cdot\left(2,83 \cdot 10^{4} / 1,4\right)=1,16 \cdot 10^{4} \mathrm{kN} / \mathrm{m}^{2}
\end{aligned}
$$

a) Verificação da resistência à compressão

Para a verificação da resistência à compressão deve-se utilizar a seguinte expressão:

$$
\begin{aligned}
& \sigma_{\mathrm{cd}} \leq \mathrm{f}_{\mathrm{c}, \mathrm{d}}=1,16 \cdot 10^{4} \mathrm{kN} / \mathrm{m}^{2} \\
& \sigma_{\mathrm{cd}}=\frac{\mathrm{N}_{\mathrm{d}}}{\mathrm{A}}=\frac{27,85}{6,4 \cdot 10^{-3}}=0,435 \cdot 10^{4} \mathrm{kN} / \mathrm{m}^{2}<1,16 \cdot 10^{4} \mathrm{kN} / \mathrm{m}^{2} \quad(\mathrm{ok} !)
\end{aligned}
$$

b) Verificação da estabilidade

$$
\begin{aligned}
& \mathrm{A}=6,4 \cdot 10^{-3} \mathrm{~m}^{2} \\
& \mathrm{I}=3,0 \cdot 10^{-6} \mathrm{~m}^{4} \\
& \mathrm{~L}_{\mathrm{O}}=2,85 \mathrm{~m} \\
& \mathrm{i}=\sqrt{\frac{\mathrm{I}}{\mathrm{A}}}=\sqrt{\frac{3,0 \cdot 10^{-6}}{6,4 \cdot 10^{-3}}}=0,0216 \mathrm{~m}
\end{aligned}
$$


$\lambda=\frac{\mathrm{L}_{\mathrm{o}}}{\mathrm{i}}=\frac{2,85}{0,0216}=131,9>80 \quad$ (peça esbelta)

A estabilidade do pontalete comprimido está garantida se atendida a condição:

$$
\begin{aligned}
& \frac{\sigma_{\mathrm{Nd}}}{\mathrm{f}_{\mathrm{c}, \mathrm{d}}}+\frac{\sigma_{\mathrm{Md}}}{\mathrm{f}_{\mathrm{c}, \mathrm{d}}} \leq 1,0 \\
& \sigma_{\mathrm{Nd}}=\sigma_{\mathrm{cd}}=0,435 \cdot 10^{4} \mathrm{kN} / \mathrm{m}^{2} \\
& \sigma_{\mathrm{Md}}=\frac{\mathrm{M}_{\mathrm{d}}}{\mathrm{I}} \cdot \mathrm{y}=\frac{\mathrm{M}_{\mathrm{d}}}{\mathrm{I}} \cdot \frac{\mathrm{h}}{2} \\
& \mathrm{M}_{\mathrm{d}}=\mathrm{N}_{\mathrm{d}} \cdot \mathrm{e}_{1, \mathrm{ef}} \cdot\left(\frac{\mathrm{F}_{\mathrm{E}}}{\mathrm{F}_{\mathrm{E}}-\mathrm{N}_{\mathrm{d}}}\right) \\
& \mathrm{F}_{\mathrm{E}}=\frac{\pi^{2} \cdot \mathrm{E}_{\mathrm{co}, \text { ef }} \cdot \mathrm{I}}{2}(\mathrm{carga} \text { crítica }) \\
& \mathrm{F}_{\mathrm{O}}{ }^{2}=\frac{\pi^{2} \cdot 6,85 \cdot 10^{6} \cdot 3,0 \cdot 10^{-6}}{2,85^{2}}=25,0 \mathrm{kN}<\mathrm{N}_{\mathrm{d}}=27,85 \mathrm{kN}
\end{aligned}
$$

Como a solicitação axial de cálculo $\left(\mathrm{N}_{\mathrm{d}}\right)$ é superior à carga crítica $\left(\mathrm{F}_{\mathrm{E}}\right)$ pode ser feito um contraventamento para diminuir o comprimento de flambagem $\left(\mathrm{L}_{\mathrm{o}}\right)$. Adotando um contraventamento à meia altura tem-se $\mathrm{L}_{\mathrm{O}}=1,425 \mathrm{~m}$, e consequentemente a carga crítica passa a valer $F_{E}=100,0 \mathrm{kN}$. Além disso, a peça deixa de ser considerada esbelta, agora $\operatorname{com} \lambda=66<80$.

Prosseguindo com a verificação da estabilidade, tem-se:

$$
\begin{aligned}
& \mathrm{e}_{1, \text { ef }}=\mathrm{e}_{1}+\mathrm{e}_{\mathrm{c}} \\
& \mathrm{e}_{1}=\mathrm{e}_{\mathrm{i}}+\mathrm{e}_{\mathrm{a}} \\
& \mathrm{e}_{\mathrm{i}}=0 \text { (compressão centrada) } \\
& \mathrm{e}_{\mathrm{c}}=0 \text { (não há fluência, pois } \lambda<80 \text { ) }
\end{aligned}
$$


$\mathrm{e}_{\mathrm{a}}=\frac{\mathrm{L}_{\mathrm{o}}}{300}=\frac{1,425}{300}=0,0048 \mathrm{~m}>\frac{\mathrm{h}}{30}=\frac{0,08}{30}=0,0027 \mathrm{~m}$

$\mathrm{e}_{1, \mathrm{ef}}=\mathrm{e}_{\mathrm{a}}=0,0048 \mathrm{~m}$

Assim:

$M_{d}=27,85 \cdot 0,0048 \cdot\left(\frac{100}{100-27,85}\right)=0,185 \mathrm{kN} \cdot \mathrm{m}$

$\sigma_{\mathrm{Md}}=\frac{\mathrm{M}_{\mathrm{d}}}{\mathrm{I}} \cdot \frac{\mathrm{h}}{2}=\frac{0,185}{3,0 \cdot 10^{-6}} \cdot \frac{0,08}{2}=2,47 \cdot 10^{3} \mathrm{kN} / \mathrm{m}^{2}$

Portanto:

$\frac{\sigma_{\mathrm{Nd}}}{\mathrm{f}_{\mathrm{c}, \mathrm{d}}}+\frac{\sigma_{\mathrm{Md}}}{\mathrm{f}_{\mathrm{c}, \mathrm{d}}}=\frac{0,435 \cdot 10^{4}}{1,16 \cdot 10^{4}}+\frac{2,47 \cdot 10^{3}}{1,16 \cdot 10^{4}}=0,588<1,0 \quad(\mathrm{ok} !)$

Ao constatar a falta de estabilidade de pontaletes há algumas outras alternativas além do contraventamento. Uma delas seria a tentativa de utilização de elementos de aço. Poderia-se pensar ainda no aumento do número de pontaletes, permanecendo a madeira como material. Outra alternativa constitui-se em adotar pontaletes com maior área da seção transversal, aumentando o valor do momento de inércia (I). 


\section{VERIFICAÇÃO DA DEFORMAÇÃO EXCESSIVA}

\subsection{Deformação considerando as etapas de construção}

Como já mencionado, a verificação do estado limite de utilização no que se refere à deformação excessiva será feita para os pontos PV1/PV2 (considerados na mesma situação) e para o ponto PL1, mostrados na figura 9.3.

A metodologia aqui utilizada permite que, levando em conta os carregamentos de construção, seja determinada para qualquer elemento estrutural do pavimento uma curva de deslocamento transversal (flecha) em função do tempo, desde a sua concretagem até o tempo infinito.

As considerações feitas no capítulo 6 são aplicadas agora, lembrando que a flecha final é dada por $\Delta \mathrm{f}(\mathrm{t})=\Delta \mathrm{i}+\Delta \mathrm{L}(\mathrm{t})+\Delta \mathrm{r}(\mathrm{t})$, parcelas que correspondem à deformação imediata, à deformação lenta e à deformação por retração, respectivamente.

Basicamente, o processo utilizado adota uma superposição dos efeitos da deformação lenta, para acréscimos de carga aplicados em instantes distintos. A NBR7197 (1989) permite que isso seja feito. Posteriormente são somados os efeitos da retração ao longo do tempo, que não dependem do carregamento atuante.

Em cada etapa de carregamento, o ponto de determinado pavimento escolhido para a verificação apresenta uma certa flecha elástica total estando submetido a um esforço de momento fletor. Tanto o deslocamento quanto o esforço solicitante são determinados através de uma simples soma dos obtidos na etapa em questão com os obtidos nos processamentos elástico-lineares das etapas cronologicamente anteriores. Aliás, essa é a filosofia da análise seqüencial construtiva aqui definida, sempre lembrando que as momentâneas etapas A (concretagem) não entram neste somatório.

Determinado elasticamente o estado em que esse ponto do elemento estrutural se encontra aplica-se a expressão desenvolvida por BRANSON (1963) que fornece 
um valor efetivo para o momento de inércia em seções fissuradas. Obviamente que isso deve ser feito caso o momento fletor atuante seja superior ao momento de fissuração definido em 6.4.

A expressão de Branson, definida em 6.1, foi obtida empiricamente e apresenta bons resultados. Uma viga bi-apoiada foi submetida a um carregamento progressivo de modo que a seção transversal do meio do vão apresentasse valores crescentes de momento fletor. Para cada incremento de carga tinha-se então o momento fletor definido e o deslocamento transversal da viga medido no meio do vão.

Com esses dados Branson encontrou uma expressão que fornece para cada nível de solicitação um valor para o momento de inércia efetivo da seção fissurada, de maneira que se a viga tivesse um comportamento elástico-linear (sem fissuração), com esse momento de inércia, apresentaria o deslocamento transversal obtido no ensaio para o referido nível de solicitação.

Desta maneira, para cada etapa de construção pós-fissuração aplica-se a expressão de Branson, majorando-se a flecha elástica total pela relação entre o momento de inércia da seção bruta de concreto e o momento de inércia efetivo $\left(\mathrm{I}_{\mathrm{g}} / \mathrm{I}_{\mathrm{e}}\right)$. Caso o elemento possua continuidade nas extremidades, ao invés de se utilizar o momento de inércia efetivo usa-se o momento de inércia médio definido no capítulo 6.

Assim procedendo, obtém-se um valor aproximado para a flecha imediata em cada etapa considerando a perda de rigidez por fissuração. Então, o acréscimo de flecha imediata a cada etapa é determinado subtraindo-se do valor da flecha imediata atual o valor da flecha imediata da etapa anterior. É a esse acréscimo de deslocamento transversal que deve ser aplicada a curva de fluência. Essa utilização da expressão de Branson num processo de carregamento em etapas também é adotada por GRAHAM (1984).

Deve-se lembrar que após o início da primeira fissura o valor do momento de fissuração a ser utilizado nas etapas seguintes para avaliação do momento de inércia efetivo, independentemente da idade do concreto, deve ser o presente nesse instante inicial. Já para o momento de inércia da seção totalmente fissurada é coerente que se use o valor sempre de acordo com a idade do concreto. Como última observação sobre os valores a serem utilizados na expressão de Branson, o momento de inércia 
da seção bruta de concreto é aqui utilizado no lugar do momento de inércia da seção não-fissurada, por seus valores serem muito próximos.

É bom lembrar que o procedimento ora descrito para os acréscimos de flecha imediata vale igualmente para os decréscimos de flecha imediata, presentes nas etapas de descarregamento do pavimento. Um acréscimo negativo de flecha, ou decréscimo, surge de um carregamento negativo, ou descarregamento (sem qualquer redução devido à inversão do sentido das ações).

Por fim, destaca-se que somando os acréscimos (ou decréscimos) de flecha imediata com as curvas de fluência por eles provocadas, sem esquecer do efeito da deformação por retração, obtém-se a curva de deslocamento transversal final em função do tempo, para qualquer ponto do pavimento.

Uma característica do concreto ainda não mencionada é necessária à avaliação da deformação em elementos estruturais do pavimento. Trata-se da resistência característica do concreto à tração axial $\left(\mathrm{f}_{\text {tk }}\right)$.

Existe uma grande divergência entre as normas a respeito do valor mais representativo a utilizar para esse parâmetro, que influencia diretamente no momento de fissuração de acordo com a expressão 6.4. Optou-se neste trabalho pela prescrição da NBR-6118 (1978).

Segundo esta norma, na falta de determinação experimental, poderão ser adotadas as seguintes relações:

$$
\begin{aligned}
& \mathrm{f}_{\mathrm{tk}}=\frac{\mathrm{f}_{\mathrm{ck}}}{10}, \operatorname{para} \mathrm{f}_{\mathrm{ck}} \leq 18 \mathrm{MPa} \\
& \mathrm{f}_{\mathrm{tk}}=0,06 . \mathrm{f}_{\mathrm{ck}}+0,7 \mathrm{MPa}, \operatorname{para} \mathrm{f}_{\mathrm{ck}}>18 \mathrm{MPa}
\end{aligned}
$$

onde:

$\mathrm{f}_{\mathrm{ck}}=$ resistência característica do concreto à compressão, em MPa.

Embora a NBR-6118 (1978) não indique nada a respeito, essas relações serão admitidas como válidas também para as idades iniciais do concreto. 
A tabela 11.1 mostra os valores de resistência característica do concreto à tração axial $\left(f_{\text {tk }}\right)$ em função da idade, com base nos valores de resistência característica à compressão $\left(\mathrm{f}_{\mathrm{ck}}\right)$ dados pela tabela 9.1 .

TABELA 11.1 - Desenvolvimento da resistência característica à tração axial

\begin{tabular}{|c|c|}
\hline $\begin{array}{c}\text { IDADE } \\
(\mathrm{DIAS})\end{array}$ & $\mathrm{f}_{\mathrm{tk}}\left(\mathrm{kN} / \mathrm{m}^{2}\right)$ \\
\hline 7 & $1,89 \cdot 10^{3}$ \\
\hline 14 & $2,09 \cdot 10^{3}$ \\
\hline 21 & $2,18 \cdot 10^{3}$ \\
\hline 28 & $2,20 \cdot 10^{3}$ \\
\hline
\end{tabular}

Serão verificados os deslocamentos transversais dos pontos PV1/PV2 e PL1 do 2. ${ }^{\circ}$ pavimento, uma vez que neste atuam os maiores carregamentos durante a construção, segundo a análise seqüencial.

O 2. ${ }^{\circ}$ pavimento é concretado na etapa $2 \mathrm{~A}$, sendo que na etapa 14 ele é definitivamente liberado das ações de construção ficando submetido unicamente ao seu peso próprio. Admite-se que 1 ano (365 dias) após a concretagem os pavimentos entrem em serviço com a colocação das alvenarias e as ações referentes à sobrecarga de utilização e revestimento, definidas no capítulo 9.

As expressões que quantificam os fenômenos de deformação lenta e retração definidas no capítulo 6 para o ACI-209R (1992), o CEB-90 (1990) e a NBR-7197 (1989) são utilizadas nesse instante. São obtidos, então, resultados de deslocamento transversal segundo as indicações das três normas, com o auxílio de planilhas do software EXCEL. O anexo apresenta gráficos ilustrativos sobre as flechas.

\subsection{Pontos PV1/PV2 (V401/V406)}

Alguns dados a respeito das vigas V401/V406 são necessários à verificação da deformação: 
Seção transversal com $12 \mathrm{~cm}$ x $60 \mathrm{~cm}$

$\mathrm{I}_{\mathrm{g}}=216,0 \cdot 10^{5} \mathrm{~m}^{4}$

Seção do meio do vão (+)

$$
\begin{array}{ll}
\mathrm{A}_{\mathrm{S}}(+)=5 \mathrm{~cm}^{2} & \mathrm{~A}_{\mathrm{S}}^{\prime}=1 \mathrm{~cm}^{2} \\
\rho(+)=0,0071 & \rho^{\prime}=0,0014
\end{array}
$$

Seções das extremidades (-)

$$
\begin{array}{ll}
A_{S}(-)=12 \mathrm{~cm}^{2} & A^{\prime}{ }_{S}=1,5 \mathrm{~cm}^{2} \\
\rho(-)=0,017 & \rho^{\prime}=0,0021
\end{array}
$$

A tabela 11.2 indica os valores do momento de fissuração $\left(M_{c r}\right)$ e do momento de inércia da seção totalmente fissurada, para o meio do vão $I_{c r}(+)$ e para as extremidades $\mathrm{I}_{\mathrm{cr}}(-)$.

TABELA 11.2 - Desenvolvimento dos valores de $\mathrm{M}_{\mathrm{cr}}$ e $\mathrm{I}_{\mathrm{cr}}$

\begin{tabular}{|c|c|c|c|}
\hline $\begin{array}{c}\text { IDADE } \\
(\text { DIAS })\end{array}$ & $\begin{array}{c}\mathrm{M}_{\mathrm{cr}} \\
(\mathrm{kN} \cdot \mathrm{m})\end{array}$ & $\begin{array}{c}\mathrm{I}_{\mathrm{cr}}(+) \\
\left(\mathrm{m}^{4}\right)\end{array}$ & $\begin{array}{c}\mathrm{I}_{\mathrm{cr}}(-) \\
\left(\mathrm{m}^{4}\right)\end{array}$ \\
\hline 7 & 16,34 & $99,96 \cdot 10^{-5}$ & $188,06 \cdot 10^{-5}$ \\
\hline 14 & 18,06 & $95,05 \cdot 10^{-5}$ & $180,04 \cdot 10^{-5}$ \\
\hline 21 & 18,83 & $92,92 \cdot 10^{-5}$ & $176,54 \cdot 10^{-5}$ \\
\hline 28 & 19,00 & $92,33 \cdot 10^{-5}$ & $175,56 \cdot 10^{-5}$ \\
\hline
\end{tabular}

De acordo com a análise seqüencial os valores obtidos para os pontos PV1/PV2 do $2{ }^{\circ}$ pavimento, em cada etapa de construção, são mostrados na tabela 11.3. 
TABELA 11.3 - Valores obtidos para os pontos PV1/PV2 do 2. ${ }^{\circ}$ pavimento

\begin{tabular}{|c|c|c|c|c|c|c|c|c|}
\hline ETAPA & $\begin{array}{c}\text { IDADE } \\
(\text { DIAS })\end{array}$ & $\begin{array}{c}\mathrm{M}_{\mathrm{a}}(+) \\
(\mathrm{kN} . \mathrm{m})\end{array}$ & $\begin{array}{c}\mathrm{M}_{\mathrm{a}}(-) \\
(\mathrm{kN} . \mathrm{m})\end{array}$ & $\begin{array}{c}\Delta \mathrm{e} \\
(\mathrm{cm})\end{array}$ & $\left(\mathrm{I}_{\mathrm{g}} / \mathrm{I}_{\mathrm{em}}\right)$ & $\begin{array}{c}\Delta \mathrm{i} \\
(\mathrm{cm})\end{array}$ & $\begin{array}{c}\Delta \mathrm{i}^{*} \\
(\mathrm{~cm})\end{array}$ & $\begin{array}{c}\Delta \mathrm{i}^{*} \\
(\mathrm{~cm})\end{array}$ \\
\hline 2 & 7 & 6,32 & $-30,00$ & 0,058 & 1,06 & 0,061 & 0,061 & 0,055 \\
\hline 3 & 7 & 25,80 & $-93,94$ & 0,220 & 1,36 & 0,300 & 0,240 & 0,220 \\
\hline 4 & 7 & 25,80 & $-93,94$ & 0,220 & 1,36 & 0,300 & 0 & 0 \\
\hline 5 & 14 & 30,00 & $-110,29$ & 0,250 & 1,47 & 0,370 & 0,070 & 0,067 \\
\hline 6 & 14 & 35,26 & $-128,42$ & 0,290 & 1,50 & 0,440 & 0,070 & 0,067 \\
\hline 7 & 14 & 41,61 & $-151,42$ & 0,340 & 1,53 & 0,520 & 0,080 & 0,077 \\
\hline 8 & 14 & 41,61 & $-151,42$ & 0,340 & 1,53 & 0,520 & 0 & 0 \\
\hline 9 & 21 & 47,64 & $-172,14$ & 0,380 & 1,57 & 0,590 & 0,070 & 0,069 \\
\hline 10 & 21 & 49,98 & $-180,07$ & 0,400 & 1,58 & 0,630 & 0,040 & 0,039 \\
\hline 11 & 21 & 27,80 & $-104,77$ & 0,250 & 1,47 & 0,360 & $-0,270$ & $-0,260$ \\
\hline 12 & 21 & 28,24 & $-106,01$ & 0,250 & 1,48 & 0,370 & 0,011 & 0,010 \\
\hline 13 & 28 & 34,03 & $-125,78$ & 0,290 & 1,53 & 0,440 & 0,070 & 0,070 \\
\hline 14 & 28 & 28,24 & $-106,01$ & 0,250 & 1,48 & 0,370 & $-0,070$ & $-0,070$ \\
\hline serviço & 365 & 45,83 & $-160,51$ & 0,380 & 1,58 & 0,600 & 0,230 & 0,230 \\
\hline
\end{tabular}

onde:

$\mathrm{M}_{\mathrm{a}}(+)=$ momento fletor total na seção do meio do vão;

$\mathrm{M}_{\mathrm{a}}(-)=$ momento fletor total nas seções das extremidades do vão;

$\Delta \mathrm{e}=$ flecha elástica total;

$I_{g}=$ momento de inércia da seção bruta de concreto;

$\mathrm{I}_{\mathrm{em}}=$ momento de inércia médio ao longo do vão;

$\Delta \mathrm{i}=$ flecha imediata total considerando a perda de rigidez por fissuração;

$\Delta \mathrm{i}^{*}=$ acréscimo de flecha imediata a cada etapa;

$\Delta \mathrm{i}^{*}{ }_{28}=$ acréscimo de flecha imediata a cada etapa supondo a idade de 28 dias. 
Na tabela 11.3 os momentos fletores e deslocamentos da etapa em serviço são obtidos considerando o acréscimo da parcela quase-permanente (20\%) da sobrecarga de utilização, além das parcelas integrais das ações de revestimento e alvenarias.

Um fato que chama a atenção ao observar os dados da tabela 11.3 refere-se aos valores elevados de momento fletor nas extremidades do vão das vigas V401/V406. Os apoios têm grande extensão, o que acaba provocando praticamente um engastamento perfeito. Poderia imaginar-se, já durante a determinação das armaduras das vigas, uma redistribuição de esforços diminuindo-se os momentos fletores sobre os apoios e aumentando-os proporcionalmente no meio do vão, obviamente dentro de certos limites. Entretanto essa prática não foi adotada neste trabalho, da mesma maneira que o arredondamento do diagrama de momentos fletores sobre os apoios.

Ainda analisando a tabela 11.3 nota-se que já na etapa 2, aos 7 dias, o momento de fissuração $\mathrm{M}_{\mathrm{cr}}=16,34 \mathrm{kN}$.m é ultrapassado nas extremidades das vigas. Na etapa 3, o mesmo é ultrapassado na seção transversal do meio do vão, também na idade de 7 dias.

Na tabela 11.4 constam os resultados de flecha elástica e flecha imediata, bem como dos deslocamentos transversais para o tempo infinito devidos à fluência e retração.

TABELA 11.4 - Deslocamentos transversais para os pontos PV1/PV2 do $2 .^{\circ}$ pavimento

\begin{tabular}{|c|c|c|c|c|c|}
\hline & $\Delta \mathrm{e}(\mathrm{cm})$ & $\Delta \mathrm{i}(\mathrm{cm})$ & $\Delta \mathrm{L}(\mathrm{cm})$ & $\Delta \mathrm{r}(\mathrm{cm})$ & $\Delta \mathrm{f}(\mathrm{cm})$ \\
\hline ACI-209 & 0,38 & 0,60 & 0,66 & 0,22 & 1,48 \\
\hline CEB-90 & 0,38 & 0,60 & 1,14 & 0,30 & 2,04 \\
\hline NBR-7197 & 0,38 & 0,60 & 1,22 & 0,22 & 2,04 \\
\hline
\end{tabular}

Lembrando que os vãos dos tramos que contém os pontos PV1/PV2 possuem $\mathrm{L}=8,85 \mathrm{~m}$ (distância entre os centros dos apoios considerados indeslocáveis) conclui-se que, pela NBR-6118 (1978), a flecha admissível é de $\mathrm{L} / 300=2,95 \mathrm{~cm}$.

Para comparação, a tabela 11.5 mostra os valores obtidos para os pontos PV1/PV2 considerando que tanto as ações de peso próprio quanto as referentes à 
entrada em serviço são aplicadas aos 28 dias, de uma só vez sobre o pavimento isolado (o que normalmente é feito nos projetos).

TABELA 11.5 - Valores obtidos para os pontos PV1/PV2 (28 dias)

\begin{tabular}{|c|c|c|c|c|c|c|c|c|}
\hline ETAPA & $\begin{array}{l}\text { IDADE } \\
\text { (DIAS) }\end{array}$ & $\begin{array}{l}\mathrm{M}_{\mathrm{a}}(+) \\
(\mathrm{kN} \cdot \mathrm{m})\end{array}$ & $\begin{array}{l}\mathrm{M}_{\mathrm{a}}(-) \\
(\mathrm{kN} . \mathrm{m})\end{array}$ & $\begin{array}{c}\Delta \mathrm{e} \\
(\mathrm{cm})\end{array}$ & $\left(\mathrm{I}_{\mathrm{g}} / \mathrm{I}_{\mathrm{em}}\right)$ & $\begin{array}{c}\Delta \mathrm{i} \\
(\mathrm{cm})\end{array}$ & $\begin{array}{c}\Delta \mathrm{i}^{*} \\
(\mathrm{~cm})\end{array}$ & $\begin{array}{l}\Delta \mathrm{i}^{*}{ }_{28} \\
(\mathrm{~cm})\end{array}$ \\
\hline $\mathrm{pp} /$ serviço & 28 & 47,20 & $-153,00$ & 0,34 & 1,57 & 0,53 & 0,53 & 0,53 \\
\hline
\end{tabular}

O momento de fissuração aos 28 dias é $\mathrm{M}_{\mathrm{cr}}=19,0 \mathrm{kN} \cdot \mathrm{m}$, ultrapassado em larga escala. A tabela 11.6 contém os resultados de deslocamento para esse caso.

TABELA 11.6 - Deslocamentos transversais para os pontos PV1/PV2 (28 dias)

\begin{tabular}{|c|c|c|c|c|c|}
\hline & $\Delta \mathrm{e}(\mathrm{cm})$ & $\Delta \mathrm{i}(\mathrm{cm})$ & $\Delta \mathrm{L}(\mathrm{cm})$ & $\Delta \mathrm{r}(\mathrm{cm})$ & $\Delta \mathrm{f}(\mathrm{cm})$ \\
\hline ACI-209 & 0,34 & 0,53 & 0,58 & 0,22 & 1,33 \\
\hline CEB-90 & 0,34 & 0,53 & 1,02 & 0,30 & 1,85 \\
\hline NBR-7197 & 0,34 & 0,53 & 1,13 & 0,22 & 1,88 \\
\hline
\end{tabular}

Nota-se uma diminuição em torno de $10 \%$ nos valores das flechas no tempo infinito.

Ainda com o intuito de comparação, a tabela 11.7 mostra os valores obtidos para os pontos PV1/PV2 considerando que as ações de peso próprio são aplicadas aos 28 dias e as ações referentes à entrada em serviço aos 365 dias (1 ano).

TABELA 11.7 - Valores obtidos para os pontos PV1/PV2 (28-365 dias)

\begin{tabular}{|c|c|c|c|c|c|c|c|c|}
\hline ETAPA & $\begin{array}{c}\text { IDADE } \\
(\mathrm{DIAS})\end{array}$ & $\begin{array}{c}\mathrm{M}_{\mathrm{a}}(+) \\
(\mathrm{kN} . \mathrm{m})\end{array}$ & $\begin{array}{c}\mathrm{M}_{\mathrm{a}}(-) \\
(\mathrm{kN} . \mathrm{m})\end{array}$ & $\begin{array}{c}\Delta \mathrm{e} \\
(\mathrm{cm})\end{array}$ & $\begin{array}{c}\left(\mathrm{I}_{\mathrm{g}} / \mathrm{I}_{\mathrm{em}}\right) \\
\mathrm{p}\end{array}$ & $\begin{array}{c}\Delta \mathrm{i} \\
(\mathrm{cm})\end{array}$ & $\begin{array}{c}\Delta \mathrm{i}^{*} \\
(\mathrm{~cm})\end{array}$ & $\begin{array}{c}\Delta \mathrm{i}^{*} 28 \\
(\mathrm{~cm})\end{array}$ \\
\hline serviço & 365 & 47,20 & $-153,00$ & 0,34 & 1,57 & 0,53 & 0,23 & 0,23 \\
\hline
\end{tabular}


O momento de fissuração $\mathrm{M}_{\mathrm{cr}}=19,0 \mathrm{kN}$.m é superado já na etapa de aplicação do peso próprio, aos 28 dias.

A tabela 11.8 contém os resultados de deslocamento para esse caso.

TABELA 11.8 - Deslocamentos transversais para os pontos PV1/PV2 (28-365 dias)

\begin{tabular}{|c|c|c|c|c|c|}
\hline & $\Delta \mathrm{e}(\mathrm{cm})$ & $\Delta \mathrm{i}(\mathrm{cm})$ & $\Delta \mathrm{L}(\mathrm{cm})$ & $\Delta \mathrm{r}(\mathrm{cm})$ & $\Delta \mathrm{f}(\mathrm{cm})$ \\
\hline ACI-209 & 0,34 & 0,53 & 0,51 & 0,22 & 1,26 \\
\hline CEB-90 & 0,34 & 0,53 & 0,85 & 0,30 & 1,68 \\
\hline NBR-7197 & 0,34 & 0,53 & 0,83 & 0,22 & 1,58 \\
\hline
\end{tabular}

Agora, a diminuição em relação aos valores da tabela 11.4 é de aproximadamente $20 \%$ para as flechas no tempo infinito.

Fica então comprovada a necessidade da consideração das solicitações prematuras devidas à construção, ou seja da história de carregamentos da estrutura, para que se possa melhor determinar as deformações do pavimento.

Para finalizar, a tabela 11.9 mostra os deslocamentos transversais no tempo infinito para os pontos PV1/PV2 do $2^{\circ}$ pavimento supondo que as ações da estrutura em serviço sejam aplicadas 5 anos após a concretagem do pavimento. Isso é relativamente comum em muitas obras do nosso país. É considerada a história de carregamentos construtivos.

TABELA 11.9 - Deslocamentos transversais para os pontos PV1/PV2 do $2^{\circ}$ pavimento com variação da data de entrada em serviço

\begin{tabular}{|c|c|c|}
\hline & $\begin{array}{c}\Delta \mathrm{f}(\infty)_{1} \text { ANO } \\
(\mathrm{cm})\end{array}$ & $\begin{array}{c}\Delta \mathrm{f}(\infty)_{5} \text { ANOS } \\
(\mathrm{cm})\end{array}$ \\
\hline ACI-209 & 1,48 & 1,45 \\
\hline CEB-90 & 2,04 & 1,96 \\
\hline NBR-7197 & 2,04 & 1,97 \\
\hline
\end{tabular}


Nesse caso, a diminuição dos valores das flechas no tempo infinito foi de aproximadamente 3\%. A parcela de ações aplicadas na entrada em serviço corresponde aqui a um valor em torno de $25 \%$ do total de ações do pavimento

Freqüentemente essa parcela de ações (revestimento, sobrecarga de utilização e alvenaria) chega a atingir $50 \%$ do total da solicitação do pavimento. Nesse caso, um retardamento da data da entrada em serviço traria uma diminuição um pouco mais significativa para a flecha no tempo infinito.

\subsection{Ponto PL1 (L401)}

De acordo com a figura 9.3 o ponto PL1 está situado no centro da laje L401, que apresenta as características listadas a seguir. A análise da deformação para esse ponto é feita considerando a direção do menor vão, ou seja, a direção y ( $\mathrm{L}=7,35 \mathrm{~m})$. Nessa direção a laje possui uma condição de apoio simples sobre vigas, nas duas extremidades.

Seção transversal com $15 \mathrm{~cm}$ de espessura $\mathrm{I}_{\mathrm{g}}=281,0 \cdot 10^{-6} \mathrm{~m}^{4}$ (para uma faixa com $1 \mathrm{~m}$ de largura)

Seção do meio do vão (+)

$$
\begin{array}{ll}
A_{S}(+)=5,33 \mathrm{~cm}^{2} / \mathrm{m} & \mathrm{A}_{\mathrm{S}}^{\prime}=0 \\
\rho(+)=0,0038 & \rho^{\prime}=0
\end{array}
$$

A tabela 11.10 indica os valores de momento de fissuração $\left(\mathrm{M}_{\mathrm{cr}}\right)$ e do momento de inércia da seção totalmente fissurada $\left(\mathrm{I}_{\mathrm{cr}}\right)$ para a laje. 
TABELA 11.10 - Desenvolvimento dos valores de $\mathrm{M}_{\mathrm{cr}}$ e $\mathrm{I}_{\mathrm{cr}}$

\begin{tabular}{|c|c|c|}
\hline $\begin{array}{c}\text { IDADE } \\
(\text { DIAS })\end{array}$ & $\begin{array}{c}\mathrm{M}_{\mathrm{cr}} \\
(\mathrm{kN} \cdot \mathrm{m} / \mathrm{m})\end{array}$ & $\begin{array}{c}\mathrm{I}_{\mathrm{cr}}(+) \\
\left(\mathrm{m}^{4}\right)\end{array}$ \\
\hline 7 & 10,65 & $69,00 \cdot 10^{-6}$ \\
\hline 14 & 11,75 & $65,40 \cdot 10^{-6}$ \\
\hline 21 & 12,26 & $63,80 \cdot 10^{-6}$ \\
\hline 28 & 12,37 & $63,40 \cdot 10^{-6}$ \\
\hline
\end{tabular}

A análise seqüencial indicou para o ponto PL1 do 2. ${ }^{\circ}$ pavimento, em cada etapa de construção, os valores mostrados na tabela 11.11 .

TABELA 11.11 - Valores obtidos para o ponto PL1 do 2. ${ }^{\circ}$ pavimento

\begin{tabular}{|c|c|c|c|c|c|c|c|}
\hline ETAPA & $\begin{array}{c}\text { IDADE } \\
(\mathrm{DIAS})\end{array}$ & $\begin{array}{c}\mathrm{M}_{\mathrm{a}}(+) \\
(\mathrm{kN} . \mathrm{m} / \mathrm{m})\end{array}$ & $\begin{array}{c}\Delta \mathrm{e} \\
(\mathrm{cm})\end{array}$ & $\left(\mathrm{I}_{\mathrm{g}} / \mathrm{I}_{\mathrm{e}}\right)$ & $\begin{array}{c}\Delta \mathrm{i} \\
(\mathrm{cm})\end{array}$ & $\begin{array}{c}\Delta \mathrm{i}^{*} \\
(\mathrm{~cm})\end{array}$ & $\begin{array}{c}\Delta \mathrm{i}_{28}{ }^{*} \\
(\mathrm{~cm})\end{array}$ \\
\hline 2 & 7 & 0,70 & 0,130 & 1 & 0,130 & 0,130 & 0,120 \\
\hline 3 & 7 & 10,90 & 1,050 & 1,05 & 1,100 & 0,970 & 0,870 \\
\hline 4 & 7 & 10,90 & 1,050 & 1,05 & 1,100 & 0 & 0 \\
\hline 5 & 14 & 11,90 & 1,170 & 1,28 & 1,500 & 0,400 & 0,380 \\
\hline 6 & 14 & 14,80 & 1,410 & 1,93 & 2,720 & 1,220 & 1,180 \\
\hline 7 & 14 & 17,00 & 1,630 & 2,37 & 3,860 & 1,140 & 1,100 \\
\hline 8 & 14 & 17,00 & 1,630 & 2,37 & 3,860 & 0 & 0 \\
\hline 9 & 21 & 20,00 & 1,880 & 2,91 & 5,470 & 1,610 & 1,600 \\
\hline 10 & 21 & 21,10 & 1,970 & 3,06 & 6,030 & 0,560 & 0,550 \\
\hline 11 & 21 & 10,80 & 1,120 & 1,03 & 1,150 & $-4,880$ & $-4,840$ \\
\hline 12 & 21 & 10,94 & 1,130 & 1,06 & 1,200 & 0,050 & 0,049 \\
\hline 13 & 28 & 13,92 & 1,370 & 1,75 & 2,400 & 1,200 & 1,200 \\
\hline 14 & 28 & 10,94 & 1,130 & 1,06 & 1,200 & $-1,200$ & $-1,200$ \\
\hline serviço & 365 & 15,11 & 1,490 & 2,01 & 2,990 & 1,790 & 1,790 \\
\hline
\end{tabular}


onde:

$\mathrm{M}_{\mathrm{a}}(+)=$ momento fletor total na seção do meio do vão;

$\Delta \mathrm{e}=$ flecha elástica total;

$I_{g}=$ momento de inércia da seção bruta de concreto;

$\mathrm{I}_{\mathrm{e}}=$ momento de inércia efetivo;

$\Delta \mathrm{i}=$ flecha imediata total considerando a perda de rigidez por fissuração;

$\Delta \mathrm{i}^{*}=$ acréscimo de flecha imediata a cada etapa;

$\Delta \mathrm{i}^{*}{ }_{28}=$ acréscimo de flecha imediata a cada etapa supondo a idade de 28 dias.

$\mathrm{Na}$ tabela anterior os momentos fletores e deslocamentos da etapa em serviço são obtidos considerando o acréscimo da parcela quase-permanente (20\%) da sobrecarga de utilização, além das parcelas integrais das ações de revestimento e alvenarias.

Ainda observando a tabela 11.11 nota-se que somente na etapa 3 , aos 7 dias, o momento de fissuração $\mathrm{M}_{\mathrm{cr}}=10,65 \mathrm{kN} . \mathrm{m} / \mathrm{m}$ é ultrapassado no meio do vão. $\mathrm{Na}$ etapa 2 a laje ainda trabalha em regime elástico-linear.

Na tabela 11.12 constam os resultados de flecha elástica e flecha imediata, bem como dos deslocamentos transversais para o tempo infinito devidos à fluência e à retração.

TABELA 11.12 - Deslocamentos transversais para o ponto PL1 do $2 .^{\circ}$ pavimento

\begin{tabular}{|c|c|c|c|c|c|}
\hline & $\Delta \mathrm{e}(\mathrm{cm})$ & $\Delta \mathrm{i}(\mathrm{cm})$ & $\Delta \mathrm{L}(\mathrm{cm})$ & $\Delta \mathrm{r}(\mathrm{cm})$ & $\Delta \mathrm{f}(\mathrm{cm})$ \\
\hline ACI-209 & 1,49 & 2,99 & 3,23 & 1,10 & 7,32 \\
\hline CEB-90 & 1,49 & 2,99 & 4,81 & 1,70 & 9,50 \\
\hline NBR-7197 & 1,49 & 2,99 & 5,08 & 1,26 & 9,33 \\
\hline
\end{tabular}

Os apoios desta laje na direção y são as vigas V401 e V406 que, como já visto, apresentam deslocamentos transversais no meio do vão (pontos PV1/PV2). Assim, 
para se analisar as flechas no ponto PL1 é necessário descontar esses deslocamentos transversais, de modo como se os apoios da laje fossem indeslocáveis.

Além disso, a NBR-6118 (1978) estabelece que as flechas nos elementos estruturais de um pavimento podem ser parcialmente compensadas por contraflechas. Não há a indicação de um limite para essa contra-flecha. Entretanto, entende-se ser coerente especificar no máximo uma contra-flecha igual à flecha imediata total $\Delta \mathrm{i}=2,99 \mathrm{~cm}$. Arredondando, será imaginada uma contra-flecha $\mathrm{CF}=$ $3,0 \mathrm{~cm}$.

A tabela 11.13 exibe os deslocamentos transversais para o tempo infinito, descontando os deslocamentos dos apoios e considerando a contra-flecha.

TABELA 11.13 - Deslocamentos transversais para o ponto PL1 do $2{ }^{\circ}$ pavimento

\begin{tabular}{|c|c|c|c|c|}
\hline & $\begin{array}{c}\Delta \mathrm{f} \\
(\mathrm{cm})\end{array}$ & $\begin{array}{c}\mathrm{CF} \\
(\mathrm{cm})\end{array}$ & $\begin{array}{c}\Delta \mathrm{f}_{\text {viga }} \\
(\mathrm{cm})\end{array}$ & $\begin{array}{c}\text { FLECHA } \\
\text { FINAL }(\mathrm{cm})\end{array}$ \\
\hline ACI-209 & 7,32 & 3,00 & 1,48 & 2,84 \\
\hline CEB-90 & 9,50 & 3,00 & 2,04 & 4,46 \\
\hline NBR-7197 & 9,33 & 3,00 & 2,04 & 4,29 \\
\hline
\end{tabular}

O vão da laje na direção y é $\mathrm{L}=7,35 \mathrm{~m}$, o que pela NBR-6118 (1978) resulta numa flecha admissível de $\mathrm{L} / 300=2,45 \mathrm{~cm}$. Nota-se que as três normas são unânimes em indicar deslocamentos transversais inadmissíveis, embora com valores bastante distintos.

A princípio, poderia se pensar em aumentar a contra-flecha especificada para o centro da laje. Por exemplo, um valor razoável seria igual ao valor da flecha total no instante da entrada em serviço, ou seja, aos 365 dias. Nessa data as ações de construção já teriam provocado além de deformações imediatas, deformações devidas à fluência. Além disso haveria também uma parcela de deformação por causa da retração.

O grande problema em especificar uma contra-flecha de valor muito elevado é saber se a curvatura dada ao elemento estrutural não provocará um afastamento em relação às hipóteses de cálculo normalmente adotadas. A esse respeito, o texto de 
revisão da NBR-6118 (1978) deve trazer um limite de L/350 para as contra-flechas. No caso dessa laje esse limite ficaria em $2,10 \mathrm{~cm}$.

Na questão atual o melhor a fazer é aumentar a espessura da laje L401, aplicar a análise seqüencial e verificar novamente o deslocamento transversal do ponto PL1. Outra opção seria aumentar o valor da resistência característica do concreto para obter um maior módulo de elasticidade, o que provocaria um aumento no custo da obra.

Deve-se chamar a atenção para o fato de que a NBR-6118 (1978) permite uma verificação simplificada da flecha no tempo infinito, a qual segundo análise feita no capítulo 9 leva à conclusão de que a espessura de $15 \mathrm{~cm}$ pode ser utilizada para a laje L401.

Para comparação, a tabela 11.14 mostra os valores obtidos para o ponto PL1 considerando que tanto as ações de peso próprio quanto as referentes à entrada em serviço são aplicadas de uma só vez aos 28 dias, no pavimento isolado.

TABELA 11.14 - Valores obtidos para o ponto PL1 (28 dias)

\begin{tabular}{|c|c|c|c|c|c|c|c|}
\hline ETAPA & $\begin{array}{c}\text { IDADE } \\
(\mathrm{DIAS})\end{array}$ & $\begin{array}{c}\mathrm{M}_{\mathrm{a}}(+) \\
(\mathrm{kN} \cdot \mathrm{m} / \mathrm{m})\end{array}$ & $\begin{array}{c}\Delta \mathrm{e} \\
(\mathrm{cm})\end{array}$ & $\begin{array}{c}\left(\mathrm{I}_{\mathrm{g}} / \mathrm{I}_{\mathrm{e}}\right) \\
\Delta \mathrm{i}\end{array}$ & $\begin{array}{c}\Delta \mathrm{i}^{*} \\
(\mathrm{~cm})\end{array}$ & $\begin{array}{c}\Delta \mathrm{i}^{*} 28 \\
(\mathrm{~cm})\end{array}$ \\
\hline pp/serviço & 28 & 16,60 & 1,53 & 1,83 & 2,80 & 2,80 & 2,80 \\
\hline
\end{tabular}

$\mathrm{O}$ momento de fissuração aos 28 dias é $\mathrm{M}_{\mathrm{cr}}=12,37 \mathrm{kN} \cdot \mathrm{m} / \mathrm{m}$, inferior ao momento fletor atuante, de modo que a seção fissura.

A tabela 11.15 contém os resultados de deslocamento para esse caso.

TABELA 11.15 - Deslocamentos transversais para o ponto PL1 (28 dias)

\begin{tabular}{|c|c|c|c|c|c|}
\hline & $\Delta \mathrm{e}(\mathrm{cm})$ & $\Delta \mathrm{i}(\mathrm{cm})$ & $\Delta \mathrm{L}(\mathrm{cm})$ & $\Delta \mathrm{r}(\mathrm{cm})$ & $\Delta \mathrm{f}(\mathrm{cm})$ \\
\hline ACI-209 & 1,53 & 2,80 & 3,16 & 1,10 & 7,06 \\
\hline CEB-90 & 1,53 & 2,80 & 5,13 & 1,70 & 9,63 \\
\hline NBR-7197 & 1,53 & 2,80 & 5,91 & 1,26 & 9,97 \\
\hline
\end{tabular}


Nota-se que pelo ACI-209R (1992) ocorre uma pequena diminuição no valor da flecha total no tempo infinito, em relação ao indicado na tabela 11.12 considerando a história de carregamentos. Entretanto, para as outras duas normas considerar todas as ações aplicadas de uma vez aos 28 dias estaria a favor da segurança, conduzindo a valores mais elevados para as deformações. Isso não pode de maneira alguma ser generalizado.

Para deixar novamente clara a necessidade da consideração da história de carregamentos na determinação das deformações no pavimento, as tabelas $11.16 \mathrm{e}$ 11.17 mostram os valores obtidos para o ponto PL1 considerando que as ações de peso próprio são aplicadas aos 28 dias e as ações referentes à entrada em serviço aos 365 dias (1 ano).

TABELA 11.16 - Valores obtidos para o ponto PL1 (28-365 dias)

\begin{tabular}{|c|c|c|c|c|c|c|c|}
\hline ETAPA & $\begin{array}{c}\text { IDADE } \\
(\mathrm{DIAS})\end{array}$ & $\begin{array}{c}\mathrm{M}_{\mathrm{a}}(+) \\
(\mathrm{kN} \cdot \mathrm{m} / \mathrm{m})\end{array}$ & $\begin{array}{c}\Delta \mathrm{e} \\
(\mathrm{cm})\end{array}$ & $\begin{array}{c}\left(\mathrm{I}_{\mathrm{g}} / \mathrm{I}_{\mathrm{e}}\right) \\
\Delta \mathrm{i}\end{array}$ & $\begin{array}{c}\Delta \mathrm{i}^{*} \\
(\mathrm{~cm})\end{array}$ & $\begin{array}{c}\Delta \mathrm{i}_{28}^{*} \\
(\mathrm{~cm})\end{array}$ & $(\mathrm{cm})$ \\
\hline $\mathrm{pp}$ & 28 & 12,30 & 1,09 & 1 & 1,09 & 1,09 & 1,09 \\
\hline serviço & 365 & 16,60 & 1,53 & 1,83 & 2,80 & 1,71 & 1,71 \\
\hline
\end{tabular}

O momento de fissuração aos 28 dias é $\mathrm{M}_{\mathrm{cr}}=12,37 \mathrm{kN} \cdot \mathrm{m} / \mathrm{m}$. Observa-se, então, um fato muito interessante: somente aos 365 dias é que ocorreria a fissuração do concreto. Na realidade já aos 7 dias isso acontece, como mostra a tabela 11.11. Esse procedimento acaba escondendo o comportamento não-linear do elemento estrutural durante as etapas de construção. A tabela 11.17 contém os resultados de deslocamento transversal do ponto PL1 para esse caso.

TABELA 11.17 - Deslocamentos transversais para o ponto PL1 (28-365 dias)

\begin{tabular}{|c|c|c|c|c|c|}
\hline & $\Delta \mathrm{e}(\mathrm{cm})$ & $\Delta \mathrm{i}(\mathrm{cm})$ & $\Delta \mathrm{L}(\mathrm{cm})$ & $\Delta \mathrm{r}(\mathrm{cm})$ & $\Delta \mathrm{f}(\mathrm{cm})$ \\
\hline ACI-209 & 1,53 & 2,80 & 2,65 & 1,10 & 6,55 \\
\hline CEB-90 & 1,53 & 2,80 & 3,91 & 1,70 & 8,41 \\
\hline NBR-7197 & 1,53 & 2,80 & 3,83 & 1,26 & 7,89 \\
\hline
\end{tabular}


Agora, nota-se uma diminuição de $10 \%$ a $15 \%$ nos deslocamentos para o tempo infinito em relação aos valores da tabela 11.12.

Por fim, a tabela 11.18 mostra os deslocamentos transversais no tempo infinito para o ponto PL1 do $2^{\circ}$ pavimento supondo que na história de carregamentos as ações da entrada em serviço sejam aplicadas 5 anos após a concretagem do pavimento.

TABELA 11.18 - Deslocamentos transversais para o ponto PL1 do $2^{\circ}$ pavimento com variação da data de entrada em serviço

\begin{tabular}{|c|c|c|}
\hline & $\begin{array}{c}\Delta \mathrm{f}(\infty)_{1} \text { ANO } \\
(\mathrm{cm})\end{array}$ & $\begin{array}{c}\Delta \mathrm{f}(\infty)_{5} \text { ANOS } \\
(\mathrm{cm})\end{array}$ \\
\hline ACI-209 & 7,32 & 7,06 \\
\hline CEB-90 & 9,50 & 8,96 \\
\hline NBR-7197 & 9,33 & 8,67 \\
\hline
\end{tabular}

Há obviamente uma diminuição dos valores das flechas, embora aqui em pequena escala.

Em alguns casos, o cronograma de construção prevê um tempo muito longo para o término da obra. Se houver plena confiança na data de entrada em serviço, pode-se tirar proveito desse fato durante a verificação da deformação excessiva. 


\section{DEFINIÇÃO DO MÉTODO APROXIMADO}

\subsection{Estruturas primárias}

No capítulo 7 foi mostrada a distribuição das ações de construção segundo o método simplificado, definido com base nos estudos de GRUNDY \& KABAILA (1963). Apesar de extremamente prático, este método apresenta algumas limitações já comentadas.

Por outro lado, no capítulo 8 foi definida a análise seqüencial construtiva através de uma modelagem tridimensional das etapas de construção utilizando o método dos elementos finitos.

A aplicação da análise seqüencial às duas estruturas definidas neste trabalho, embora tenha permitido conclusões importantes, exigiu um trabalho exaustivo passo a passo. Isso não é compatível com a praticidade necessária ao dia-a-dia dos escritórios de projeto estrutural.

Por exemplo, para a estrutura definida no capítulo 9 a análise seqüencial construtiva foi considerada até a retirada definitiva dos pontaletes que se apoiavam no $2^{\circ}$ pavimento (etapa 14). Até essa etapa a análise completa exigiu quase 20 processamentos de estruturas parciais. Além disso, para o processamento das etapas que envolveram retirada de pontaletes houve a necessidade de somar ações de etapas anteriores em cada um desses elementos de sustentação.

Não obstante, uma análise minuciosa dos resultados obtidos até aqui permitiu a elaboração de um novo método para a determinação da distribuição das ações durante o processo de construção. Esse novo método, denominado de método aproximado, possui a simplicidade e rapidez do tradicional método de Grundy e Kabaila com a vantagem de ser mais preciso.

A observação da distribuição das ações de construção para duas estruturas tão distintas possibilitou a definição de um método aplicável a qualquer pavimento. 
A idéia de se representar as ações de construção como fatores de carga $\mathrm{k}$ permanece válida. Para recordar, os fatores de carga são expressos em função do valor da ação de peso próprio do pavimento por $\mathrm{m}^{2}(\mathrm{G})$.

No desenvolvimento deste novo método de distribuição de ações não é considerado o peso próprio das fôrmas, nem o peso próprio dos pontaletes. Isso se justifica na medida em que, além de facilitar a determinação das ações de construção, pouco altera os resultados.

Inicialmente, deve-se dizer que as etapas $n \mathrm{~A}$ são momentâneas e imediatamente posteriores às etapas $n-1$. Assim, as etapas $n$ são sempre seguintes às etapas $n-1$, mesmo quando precedidas cronologicamente por uma etapa $n \mathrm{~A}$. Por exemplo, para determinar a distribuição das ações de construção da etapa 2A é necessário reportar-se à distribuição anterior, ou seja, a da etapa 1. Para determinar a distribuição das ações de construção da etapa 2, reporta-se também à etapa 1, já que a etapa anterior 2A é momentânea.

Nas etapas A (concretagem) estão presentes a ação de peso próprio do pavimento $(1,0 \times \mathrm{G})$ e as ações variáveis $(0,85 \times \mathrm{G})$. Esse total de ações $(1,85 \times \mathrm{G})$ é aplicado ao pavimento da figura 8.5 para que, da mesma maneira que na análise seqüencial, seja avaliada a transmissão de ações do concreto fresco do pavimento recém concretado para os pontaletes e pilares de sustentação das fôrmas. Determinase assim uma proporção de ações absorvida por pontaletes e pilares.

Ainda, para todos os pavimentos de quaisquer etapas que envolvam adição de carga e nas quais existam pontaletes ligando o $1 .^{\circ}$ pavimento à fundação rígida, é considerado que o caminhamento das ações adicionadas, até o solo, segue a proporção acima.

Quando não mais existirem pontaletes ligando o $1 .^{\circ}$ pavimento à fundação rígida, na distribuição das ações do pavimento recém concretado (etapa A) para o inferior ainda permanece esta proporção. Porém, agora, para os demais pavimentos da etapa de concretagem e de qualquer outra etapa de carregamento altera-se a proporção.

Há a necessidade de se processar a estrutura da figura 12.1, onde agora os pontaletes não mais se apoiam numa fundação rígida. As características do concreto são consideradas aos 28 dias. 


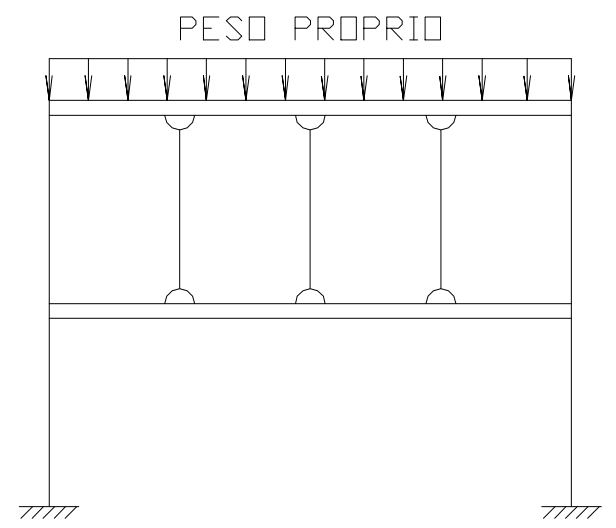

FIGURA 12.1 -Distribuição das ações quando não há pontaletes ligados à fundação rígida

Aplicado o peso próprio (ou outro carregamento semelhante) ao pavimento superior verifica-se a proporção de ações transmitidas aos pontaletes e pilares. As ações transmitidas aos pontaletes são absorvidas pelo pavimento inferior e as transmitidas aos pilares correspondem à absorção do próprio pavimento.

Já para as etapas de descarregamento (retirada de pontaletes) a proporção de distribuição das ações se altera novamente, havendo a necessidade do processamento da estrutura mostrada na figura 12.2. As características do concreto também são consideradas aos 28 dias.

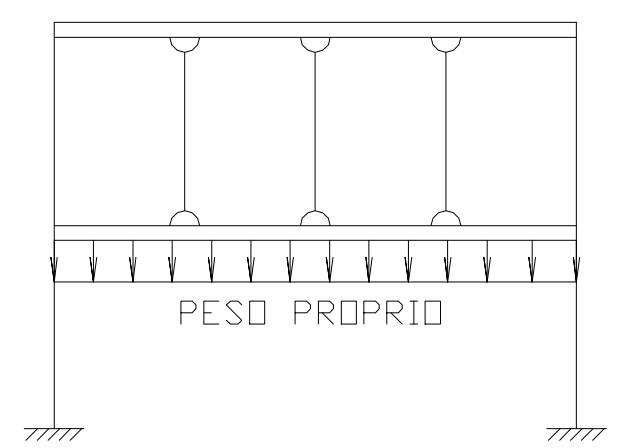

FIGURA 12.2 - Distribuição das ações nas etapas de descarregamento

Aplicado o peso próprio (ou outro carregamento semelhante) ao pavimento inferior uma porcentagem dessa ação é absorvida por ele próprio enquanto o restante é transmitido para o pavimento superior através dos pontaletes tracionados. Como os 
pontaletes normalmente estão comprimidos, uma solicitação desse tipo alivia esses elementos. Esse raciocínio prossegue ao longo da altura da construção, distribuindo as ações dos pontaletes retirados aos pavimentos superiores, sempre na proporção obtida neste processamento.

Nas etapas onde há reescoramento absolutamente nada se altera na distribuição das ações, uma vez que nem mesmo o peso próprio dos pontaletes está sendo considerado.

Estas indicações do método aproximado são válidas para processos de construção com qualquer número de pavimentos escorados e reescorados.

Além disso, se houver retirada parcial de pontaletes e/ou reescoramento parcial, a distribuição de ações com a nova quantidade de pontaletes pode ser determinada com o processamento das correspondentes estruturas, como as das figuras 8.5, 12.1 e 12.2. Essas estruturas necessárias à aplicação do método aproximado serão aqui denominadas de estruturas primárias.

A seguir, o método aproximado é aplicado às estruturas dos itens 8.4 e 9.2 (ambas com processo de construção com dois níveis de escoras mais um nível de reescora) para comparação com os resultados do método simplificado e da análise seqüencial construtiva.

No caso do método simplificado foram adaptadas as etapas A, onde ao peso próprio do pavimento concretado $(1,0 \times \mathrm{G})$ se somam as ações variáveis $(0,85 \times \mathrm{G})$. $\mathrm{Na}$ verdade, originalmente, o método simplificado leva em conta essas ações variáveis simplesmente somando o seu valor ao patamar da máxima ação de construção. Entretanto, como aqui foi definido, considera-se que essas ações atuam somente no instante da concretagem.

\subsection{Aplicação do método aproximado à estrutura do capítulo 8}

A forma dos pavimentos e a posição dos pontaletes da estrutura do item 8.4 são mostradas na figura 8.7.

$\mathrm{O}$ peso próprio do pavimento corresponde a $\mathrm{G}=3,76 \mathrm{kN} / \mathrm{m}^{2}(1,0 \times \mathrm{G})$. Nas etapas A, além dessa ação, atuam ainda $3,20 \mathrm{kN} / \mathrm{m}^{2}(0,85 \times \mathrm{G})$ referentes às ações variáveis. 
O peso próprio do conjunto de 5 pontaletes presente em um pavimento totaliza $0,055 \mathrm{kN} / \mathrm{m}^{2}(0,014 \times \mathrm{G})$, e o peso próprio das fôrmas é igual a $0,20 \mathrm{kN} / \mathrm{m}^{2}(0,056 \mathrm{x}$ G). Ambos não são considerados no método aproximado.

O processamento da estrutura primária da figura 8.5 indica que na concretagem de um pavimento $31,2 \%$ das ações são transmitidas aos pontaletes, enquanto $68,8 \%$ delas são absorvidas pelos pilares já concretados.

Já o processamento da estrutura primária da figura 12.1 mostra que nos carregamentos quando não há pontaletes ligados à fundação rígida $27 \%$ das ações são transmitidas aos pontaletes, enquanto $73 \%$ são absorvidas pelo próprio pavimento.

No caso do processamento da estrutura primária da figura 12.2 fica definido que nos descarregamentos (retirada de pontaletes) 78,5\% das ações são absorvidas pelo pavimento, enquanto $21,5 \%$ delas aliviam a compressão dos pontaletes do nível superior. Essa porcentagem de $21,5 \%$ é transmitida ao pavimento superior e assim por diante.

Estabelecidos os procedimentos necessários à aplicação do método aproximado, a figura 12.3 exibe os resultados. 

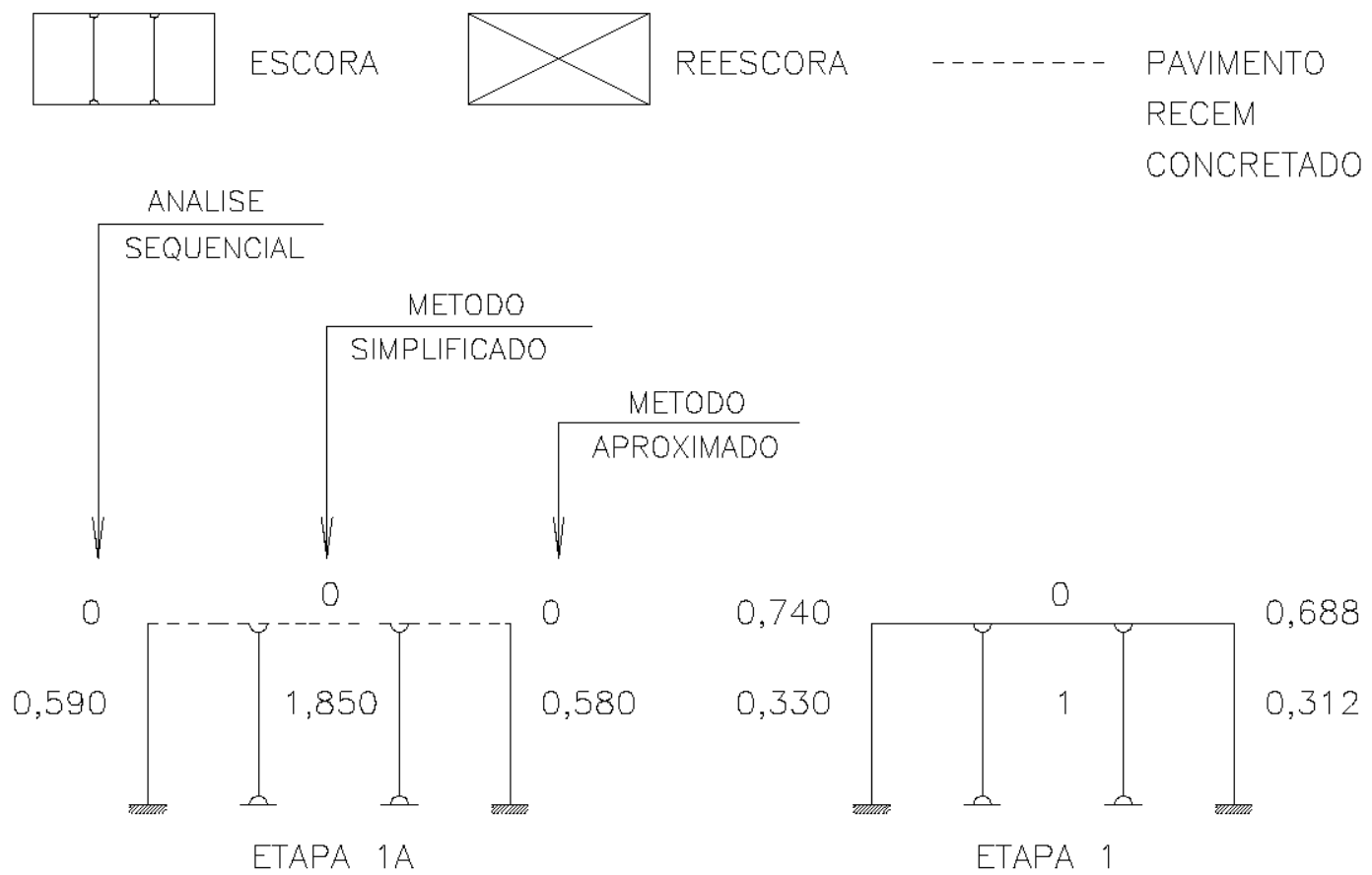

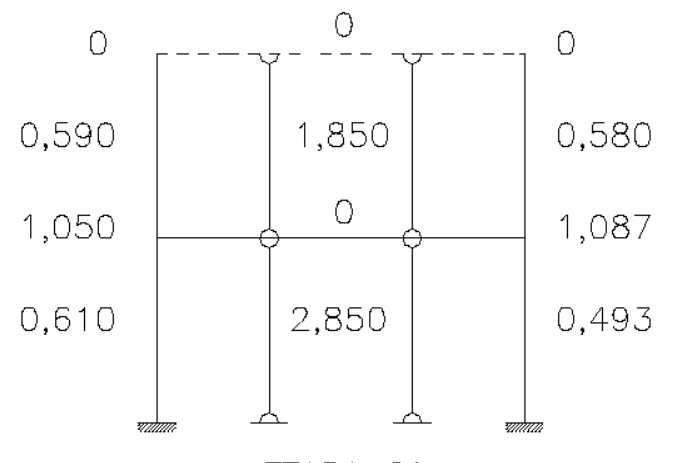

ETAPA 2A

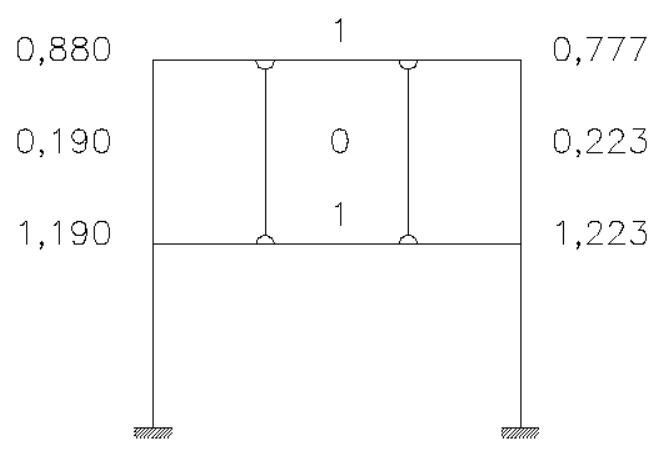

ETAPA 3

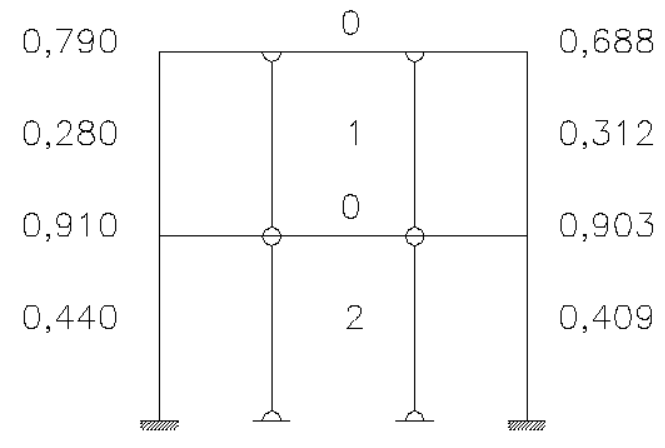

ETAPA 2

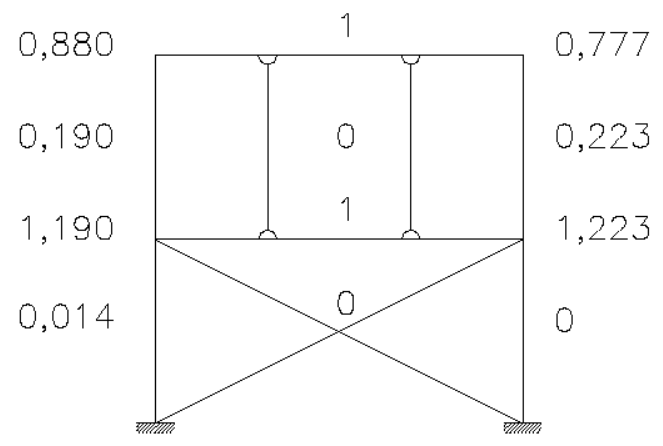

ETAPA 4

FIGURA 12.3a - Distribuição das ações de construção segundo fatores de carga k (x G), para a estrutura do cap.8 

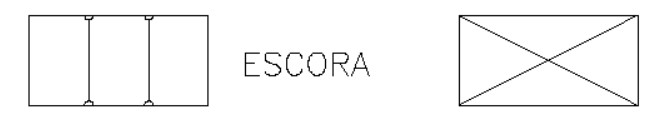

REESCORA

PAVIMENTO

RECEM

CONCRETADO

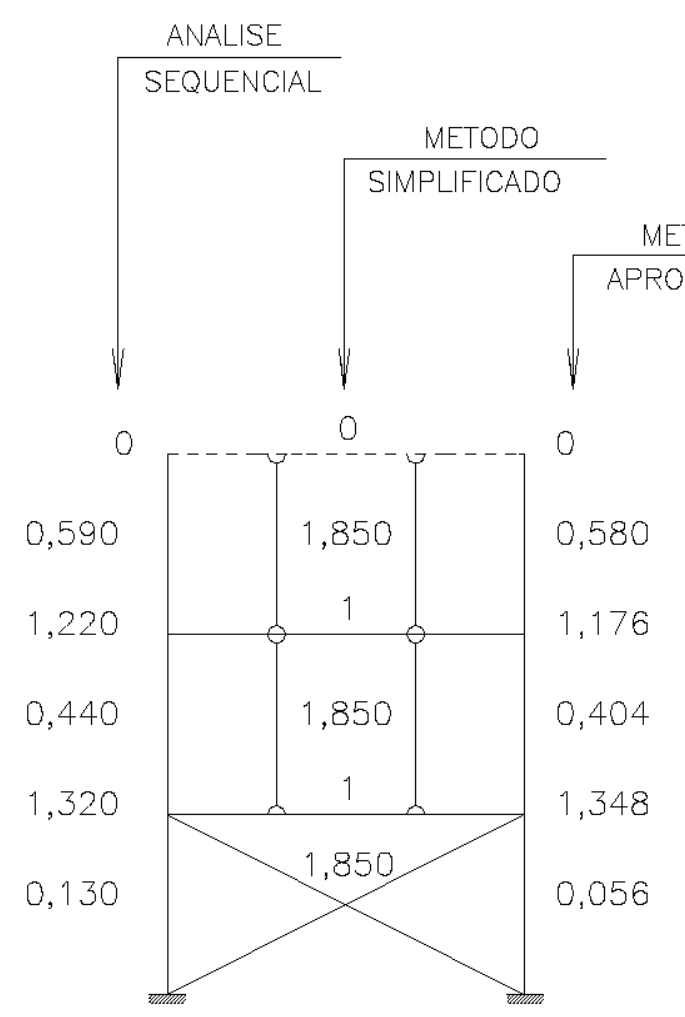

ETAPA 5A

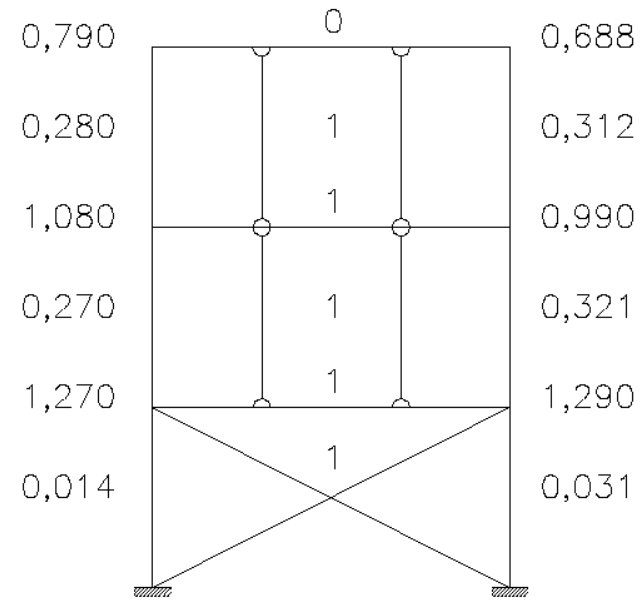

ETAPA 5

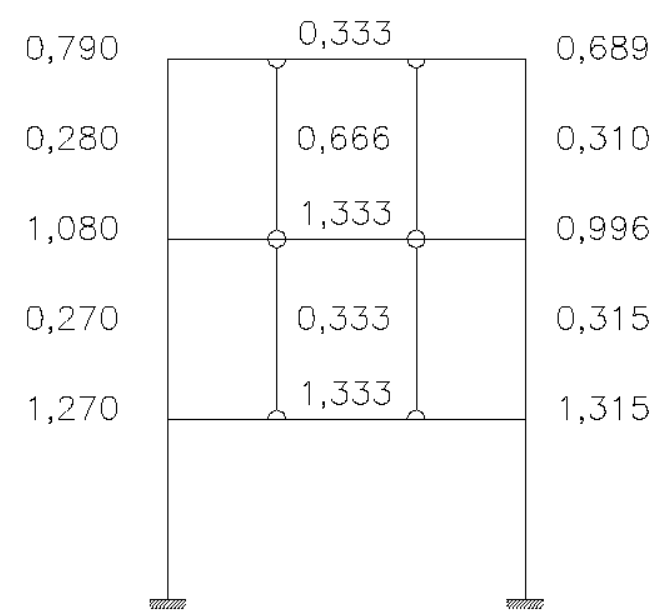

ETAPA 6

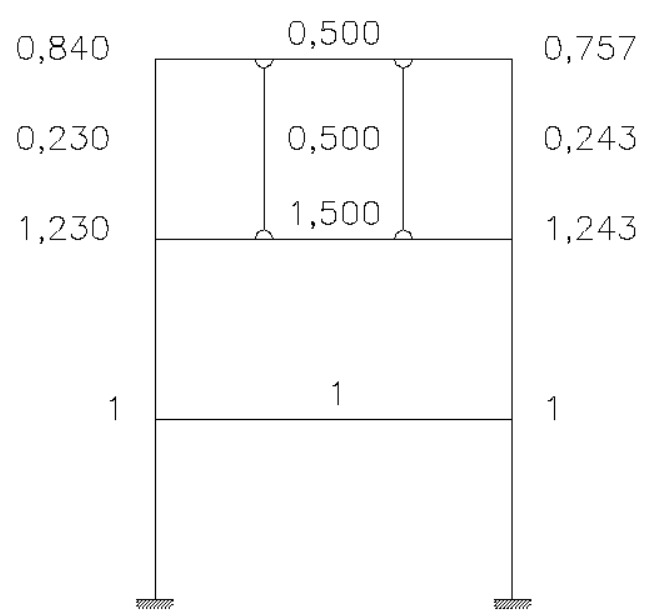

ETAPA 7

FIGURA 12.3b - Distribuição das ações de construção segundo fatores de carga $\mathrm{k}$ (x G), para a estrutura do cap.8 


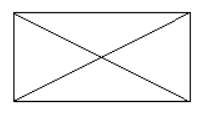

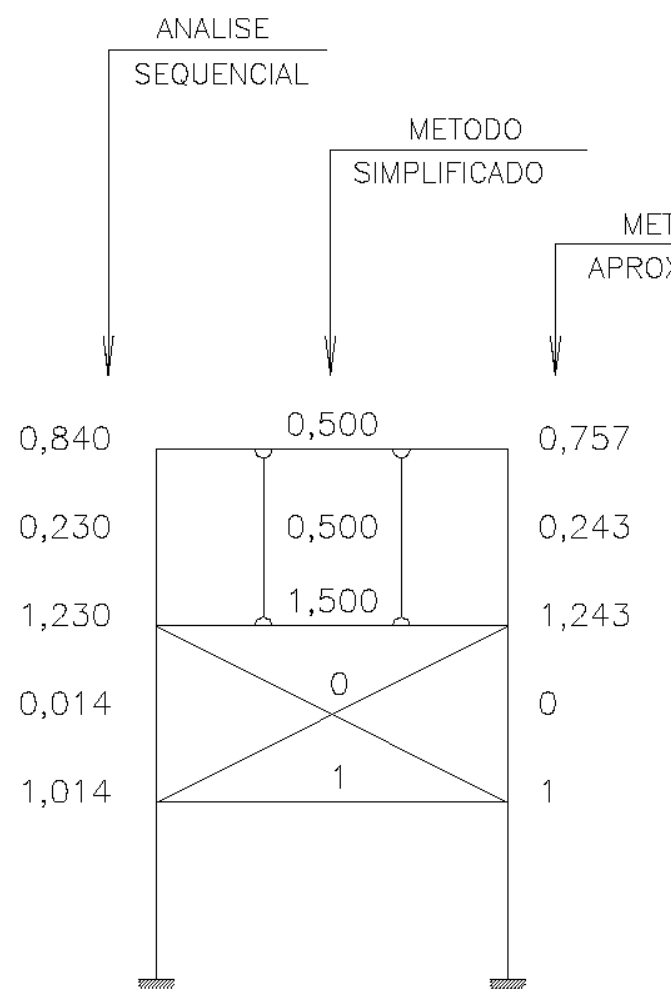

ETAPA 8

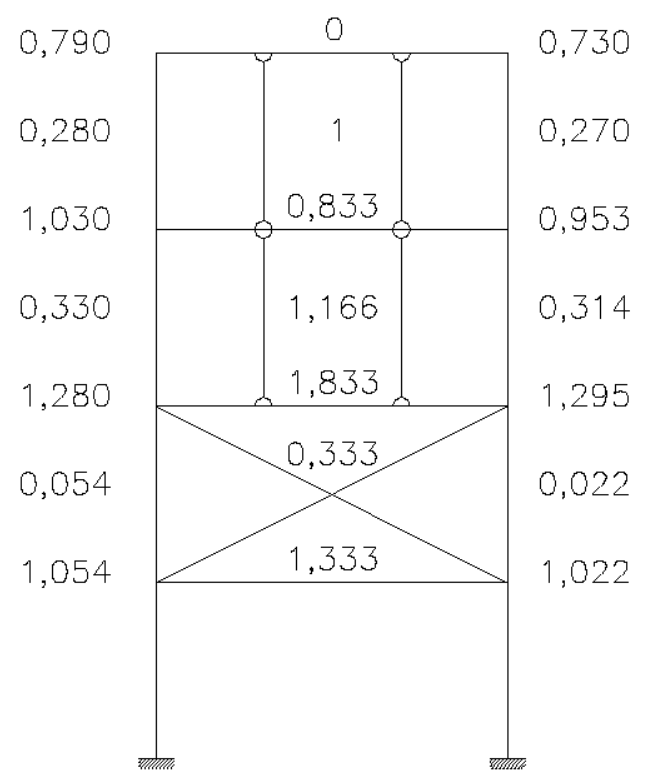

ETAPA 9 


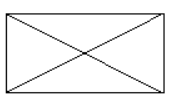

REESCORA

PAVIMENTO

RECEM

CONCRETADO
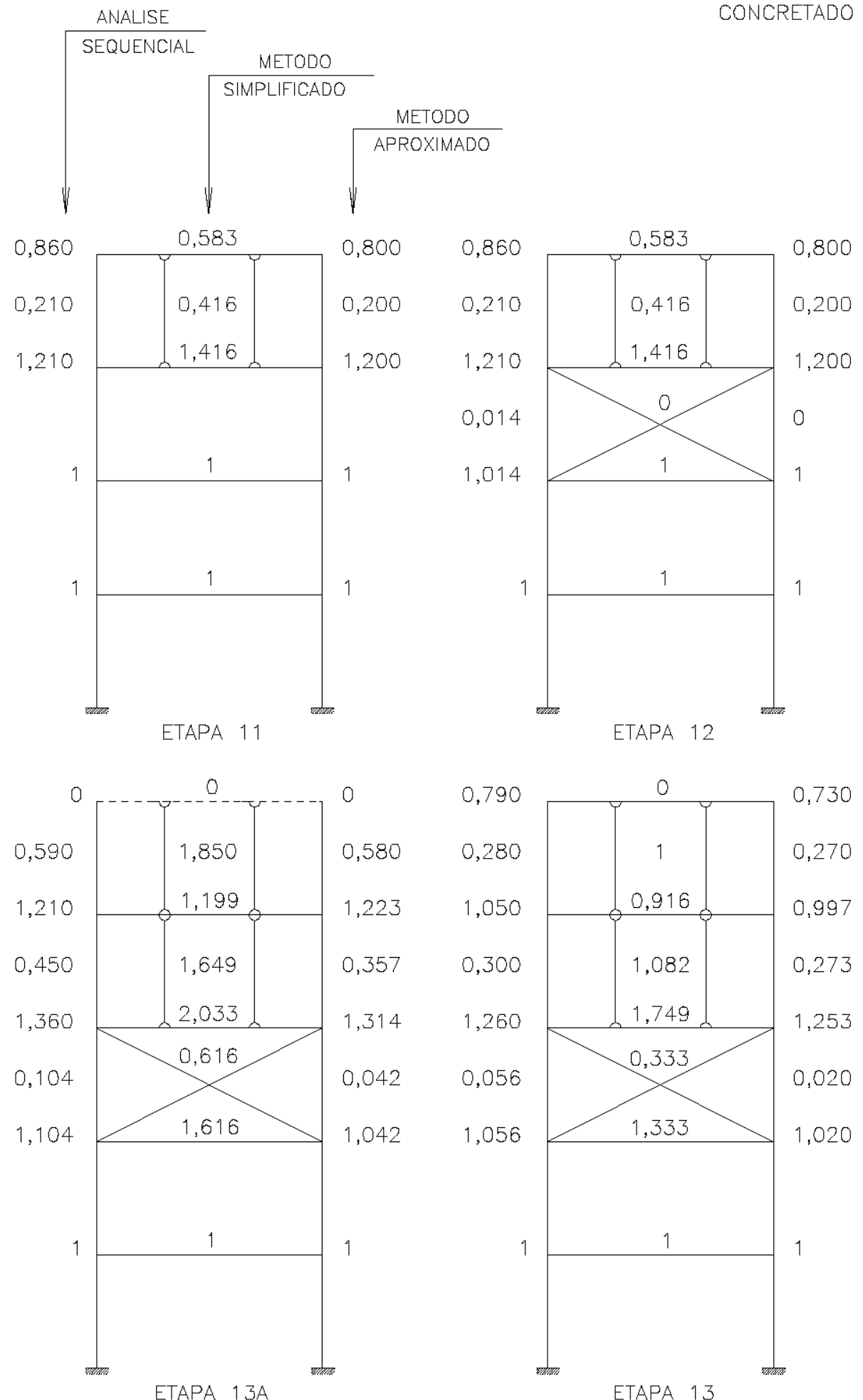

FIGURA 12.3d - Distribuição das ações de construção segundo fatores de carga $\mathrm{k}$ (x G), para a estrutura do cap.8 


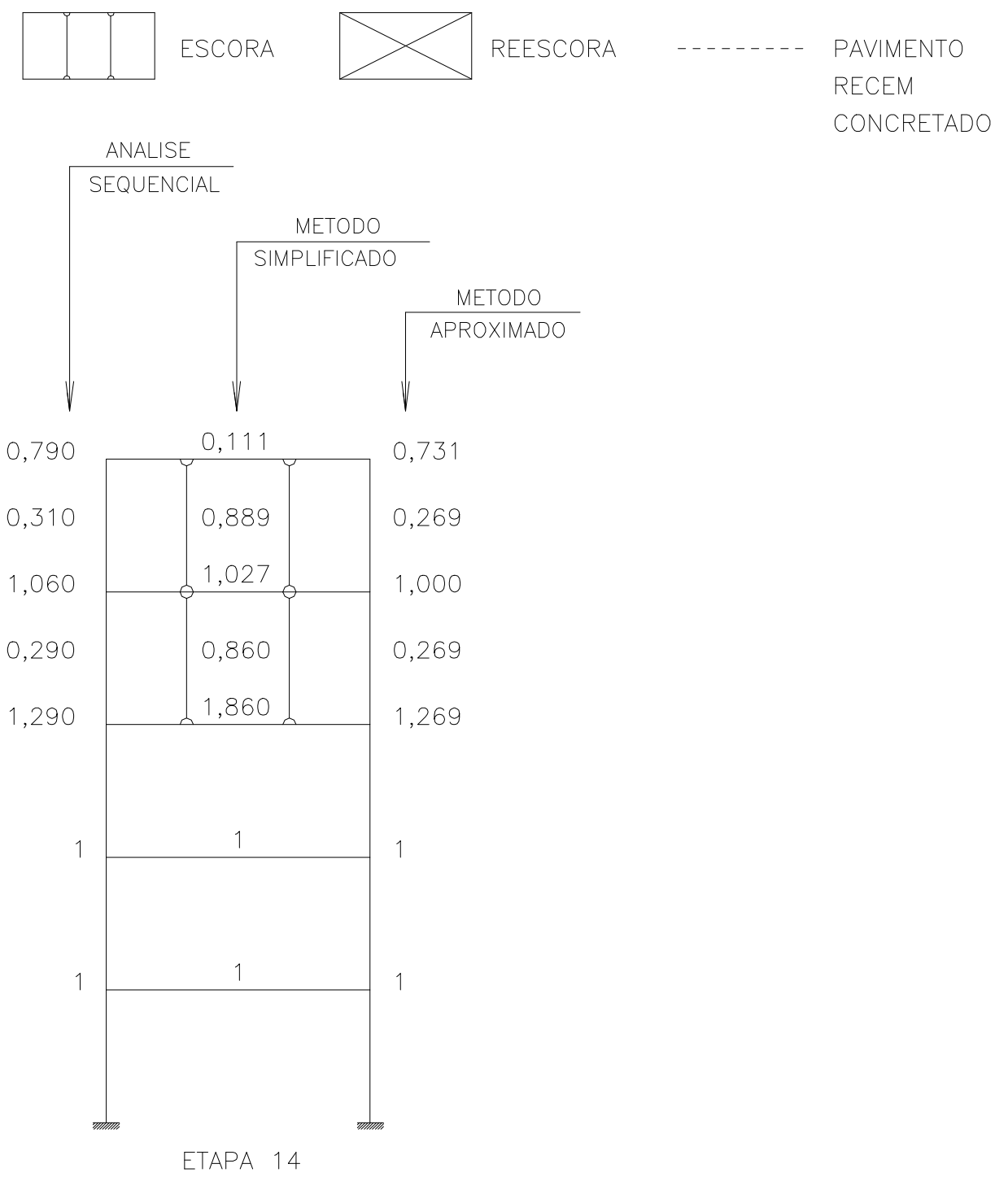

FIGURA 12.3e - Distribuição das ações de construção segundo fatores de carga k (x G), para a estrutura do cap.8

Descreve-se o método aproximado, a seguir.

Na etapa $1 \mathrm{~A}$, como já dito, $31,2 \%$ das ações $(0,580$ x G) são transmitidas aos pontaletes, sendo que o concreto fresco do $1 .^{\circ}$ pavimento não possui capacidade para resistir a qualquer parcela de carregamento.

Atingindo a etapa 1 o concreto já possui determinado amadurecimento, permitindo ao pavimento absorver $68,8 \%$ das ações $(0,688 \times \mathrm{G})$, restando novamente $31,2 \%(0,312 \times \mathrm{G})$ aos pontaletes ligados diretamente à fundação. Deve-se reafirmar as diferenças entre as etapas 1 e 1A: além do amadurecimento do concreto, na etapa 1 deixam de atuar as ações variáveis. 
$\mathrm{Na}$ etapa 2A acontece um novo evento: é concretado o $2 .^{\circ}$ pavimento. Novamente, os pontaletes ligados ao novo pavimento recebem $31,2 \%$ das ações $(0,580 \times \mathrm{G})$. Estas ações são transmitidas ao $1{ }^{\circ}$ pavimento que absorve $68,8 \%(0,399$ x G), repassando o restante $31,2 \%(0,181 \times \mathrm{G})$ para os pontaletes. Assim, o 1. ${ }^{\circ}$ pavimento passa a receber $1,087 \times \mathrm{G}(0,688+0,399)$ e o seu conjunto de pontaletes $0,493 \times \mathrm{G}(0,312+0,181)$.

A etapa 2 se comporta do mesmo modo que a etapa $2 \mathrm{~A}$, lembrando que a somatória de ações deve ser feita também em relação à etapa 1 , já que as etapas A são momentâneas.

Na etapa 3 o novo evento é a retirada do $1 .^{\circ}$ nível de pontaletes, que de acordo com a etapa 2 (imediatamente anterior) está submetido à ação de 0,409 x G. Do total desta ação retirada, 78,5\% (0,320 x G) é absorvido pelo $1 .^{\circ}$ pavimento, que passa a ter $1,223 \times \mathrm{G}(0,903+0,320)$. O restante $21,5 \%(0,089 \times \mathrm{G})$ é absorvido pelo $2{ }^{\circ}$ pavimento, que passa a ter $0,777 \times \mathrm{G}(0,688+0,089)$. Nesta distribuição, as ações do nível de pontaletes entre o $1 .^{\circ}$ e o $2 .^{\circ}$ pavimento sofrem um alívio de $21,5 \%(0,089$ x $\mathrm{G})$, passando a $0,223 \times \mathrm{G}(0,312-0,089)$.

$\mathrm{Na}$ etapa 4 ocorre a reposição dos pontaletes retirados, agora atuando como reescoras. Permanecendo a hipótese de que esses pontaletes são instalados sem carga, esse novo evento não altera a distribuição de ações (o peso próprio dos pontaletes também não é considerado).

Nas etapas 5A e 5 o caminhamento das ações é semelhante ao das etapas $2 \mathrm{~A}$ e 2. Já nas etapas 6 e 7 ocorrem retiradas de pontaletes, da mesma maneira que na etapa 3. Na etapa 8 o $2 .^{\circ}$ pavimento é reescorado, não ocorrendo modificação na distribuição de ações fixada na etapa 7.

$\mathrm{Na}$ etapa 9A é concretado o $4 .^{\circ}$ pavimento. Os pontaletes ligados ao novo pavimento recebem $31,2 \%$ das ações $(0,580 \times \mathrm{G})$. Essas ações são transmitidas ao $3 .^{\circ}$ pavimento. Como não há mais pontaletes ligados à fundação mudam as porcentagens de distribuição de ações entre pavimentos e pontaletes. Agora, o 3..$^{\circ}$ pavimento absorve $73 \%(0,423 \times \mathrm{G})$ das novas ações, repassando o restante $27 \%(0,157$ x G) para os pontaletes. Assim, o $3 .^{\circ}$ pavimento passa a receber $1,180 \times \mathrm{G}(0,757+0,423)$ e o seu conjunto de pontaletes 0,400 x $\mathrm{G}(0,243+0,157)$. As novas ações destes pontaletes $\left(0,157\right.$ x G) são transmitidas ao $2 .^{\circ}$ pavimento que absorve $73 \%(0,114 \times$ $\mathrm{G})$, deixando os restantes $27 \%(0,043 \times \mathrm{G})$ aos pontaletes. O 2. ${ }^{\circ}$ pavimento fica com 
1,357 x G $(1,243+0,114)$ e o seu conjunto de pontaletes com 0,043 x $\mathrm{G}(0+0,043)$. Esta ação de 0,043 x $\mathrm{G}$ é finalmente transmitida ao $1 .^{\circ}$ pavimento, que necessariamente absorve $100 \%$, já que não existem pontaletes sustentando o mesmo. Assim, o $1 .^{\circ}$ pavimento totaliza $1,043 \times \mathrm{G}(1,0+0,043)$.

As distribuições de ações das demais etapas mostradas na figura 12.3 seguem a mesma metodologia das etapas ora descritas.

$\mathrm{O}$ anexo apresenta um gráfico com os resultados dos 3 procedimentos para o 2. ${ }^{\circ}$ pavimento (o mais solicitado) considerando desde a concretagem até a sua liberação definitiva das ações de construção na etapa 14.

\subsection{Aplicação do método aproximado à estrutura do capítulo 9}

A forma dos pavimentos e a posição dos pontaletes da estrutura do item 9.2 são mostradas nas figuras 9.1 e 9.2, respectivamente.

$\mathrm{O}$ peso próprio do pavimento corresponde a $\mathrm{G}=4,48 \mathrm{kN} / \mathrm{m}^{2}(1,0 \times \mathrm{G})$. Nas etapas $A$, além dessa ação, atuam ainda $3,81 \mathrm{kN} / \mathrm{m}^{2}(0,85 \times \mathrm{G})$ referentes às ações variáveis.

$\mathrm{O}$ peso próprio do conjunto de 50 pontaletes presente em um pavimento totaliza $0,06 \mathrm{kN} / \mathrm{m}^{2}(0,013 \times \mathrm{G})$, e o peso próprio das fôrmas é igual a $0,15 \mathrm{kN} / \mathrm{m}^{2}$ $(0,033 \times \mathrm{G})$.

O processamento da estrutura primária da figura 8.5 indica que na concretagem de um pavimento $74,5 \%$ das ações são transmitidas aos pontaletes, enquanto $25,5 \%$ delas são absorvidas pelos pilares já concretados.

Já o processamento da estrutura primária da figura 12.1 mostra que nos carregamentos quando não há pontaletes ligados à fundação rígida $41 \%$ das ações são transmitidas aos pontaletes, enquanto $59 \%$ são absorvidas pelo próprio pavimento.

No caso do processamento da estrutura primária da figura 12.2 fica definido que nos descarregamentos (retirada de pontaletes) 66\% das ações são absorvidas pelo pavimento, enquanto $34 \%$ delas aliviam a compressão dos pontaletes do nível superior.

Estabelecidos os procedimentos necessários à aplicação do método aproximado, a figura 12.4 exibe os resultados. 

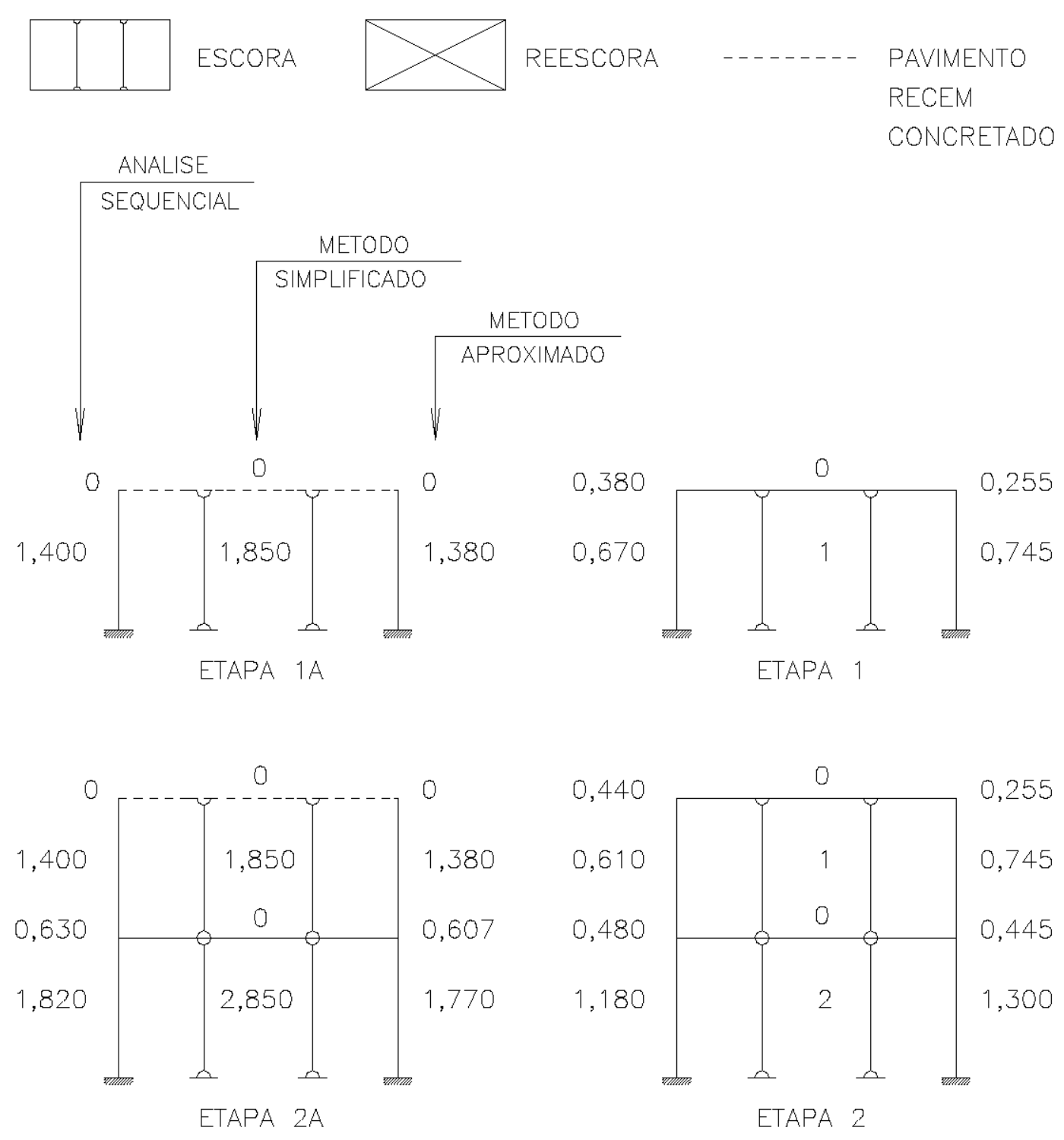

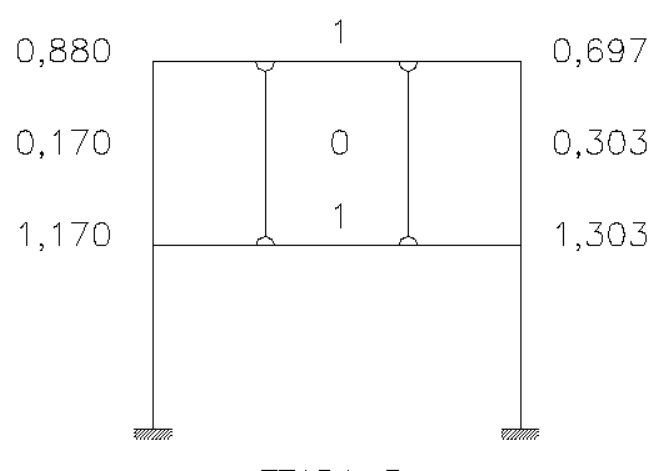

ETAPA 3

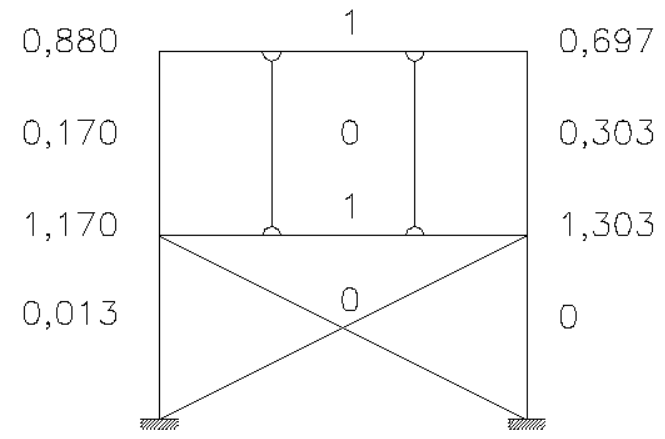

ETAPA 4

FIGURA 12.4a - Distribuição das ações de construção segundo fatores de carga k (x G), para a estrutura do cap.9 


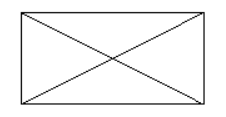

REESCORA

PAVIMENTO

RECEM

CONCRETADO

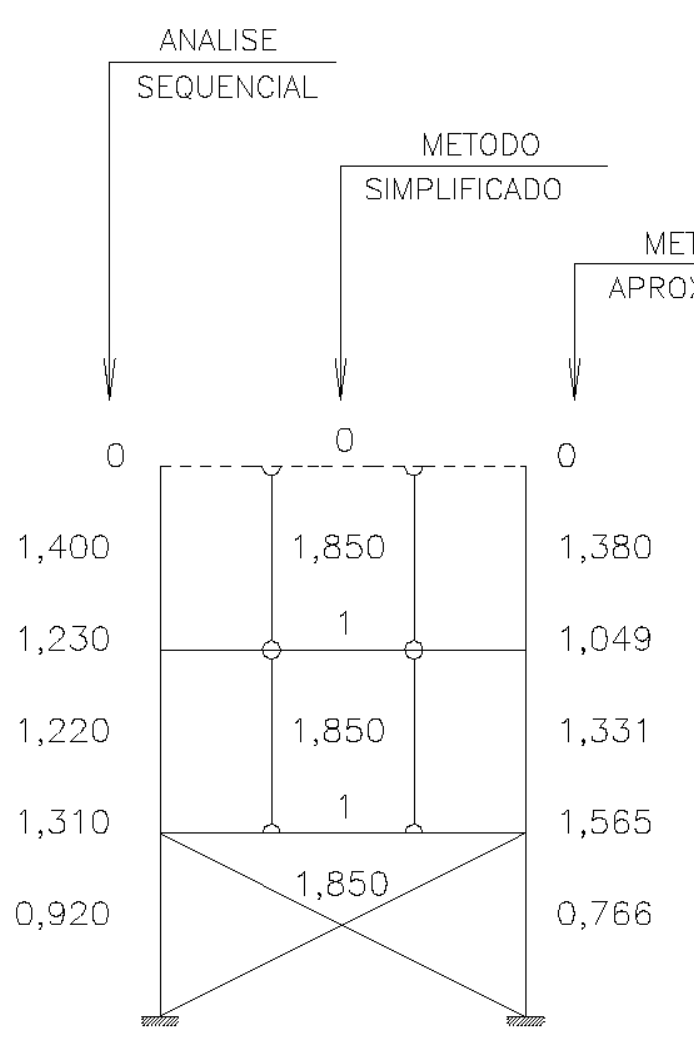

ETAPA 5A

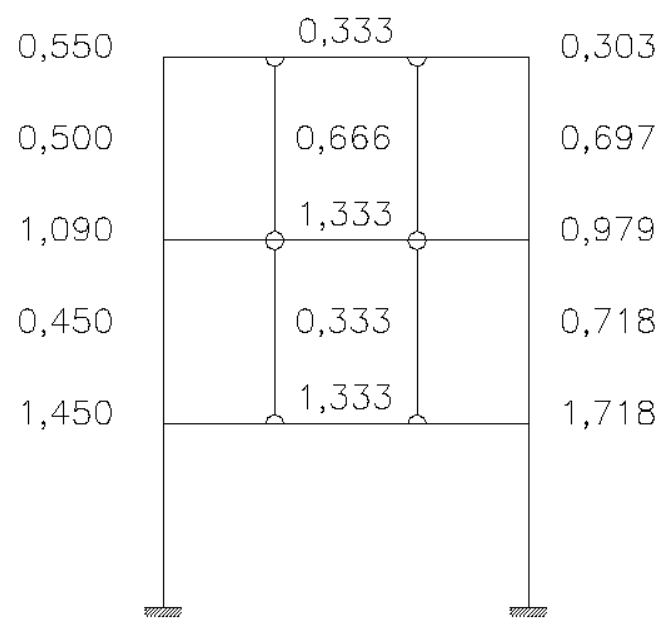

ETAPA 6

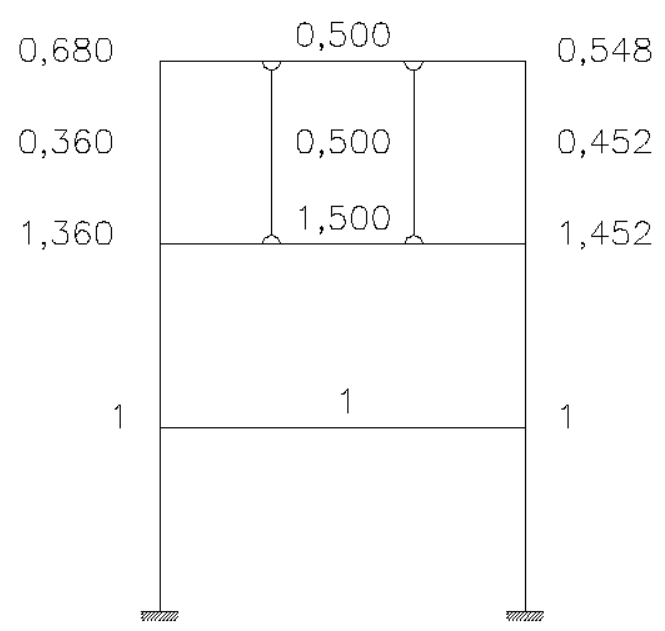

ETAPA 7

FIGURA 12.4b - Distribuição das ações de construção segundo fatores de carga k (x G), para a estrutura do cap.9 


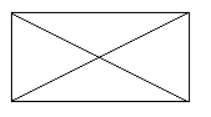

ANALISE

CONCRETADO
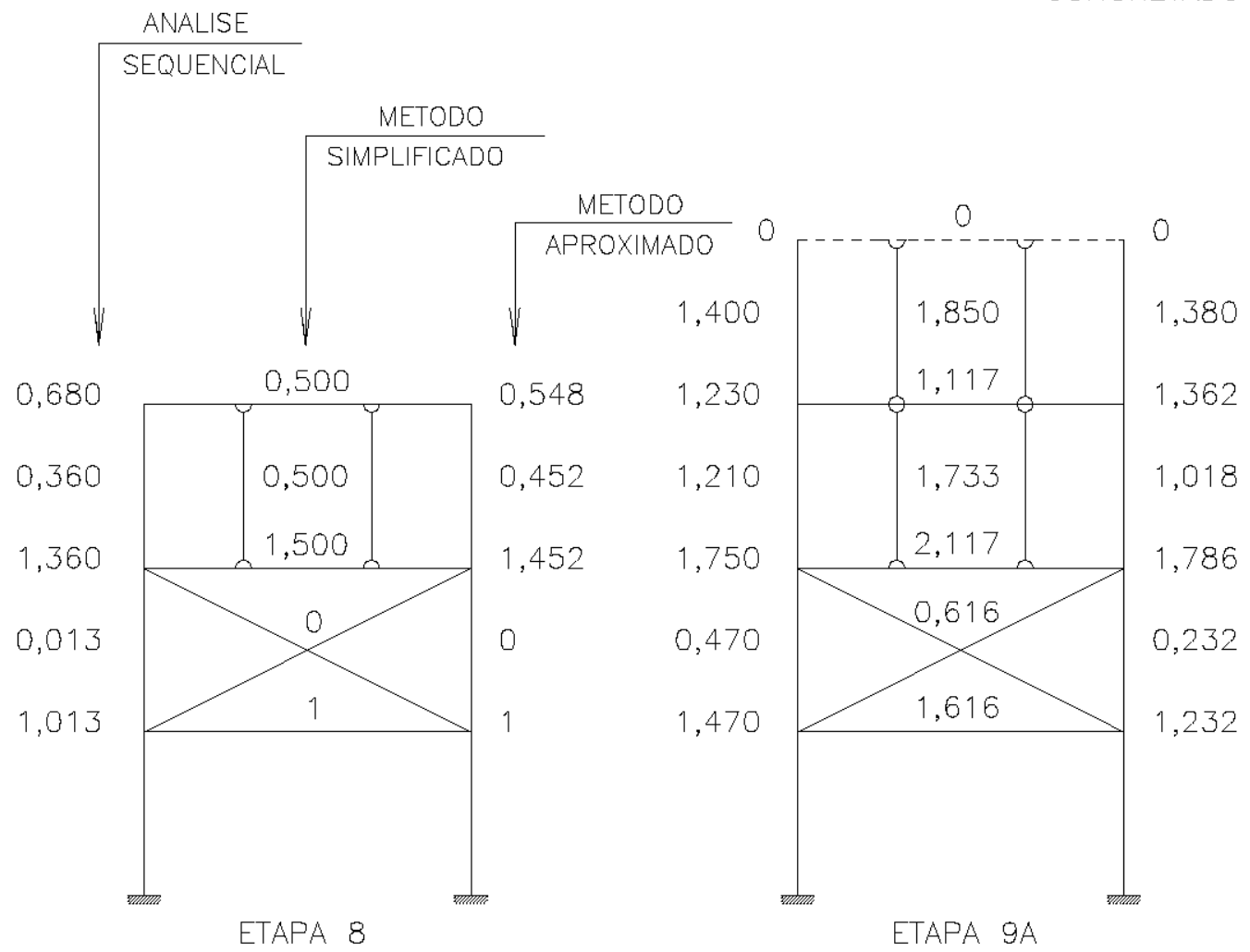

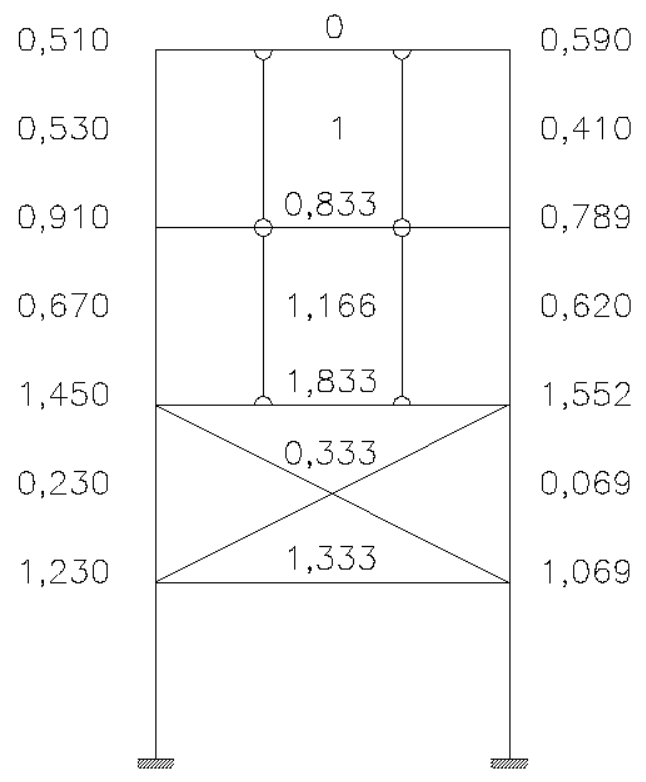

ETAPA 9

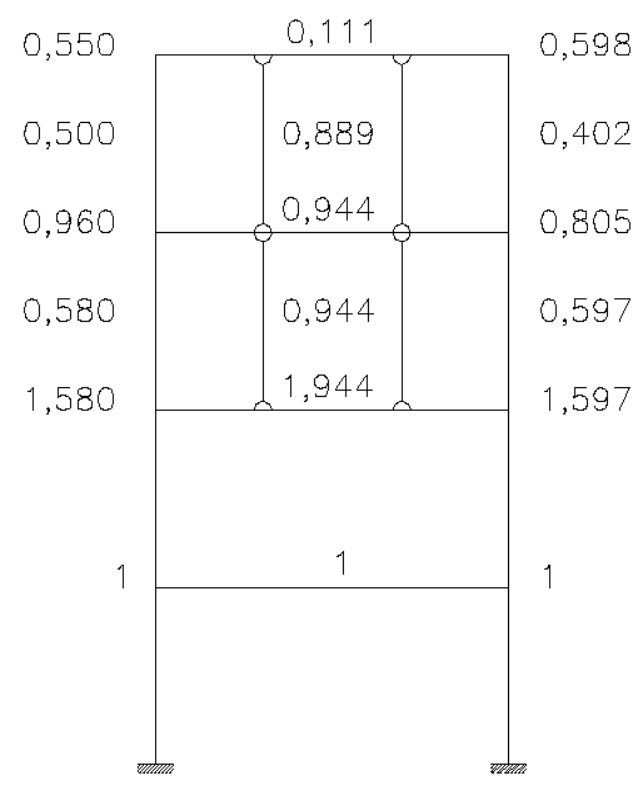

ETAPA 10

FIGURA 12.4c - Distribuição das ações de construção segundo fatores de carga k (x G), para a estrutura do cap.9 

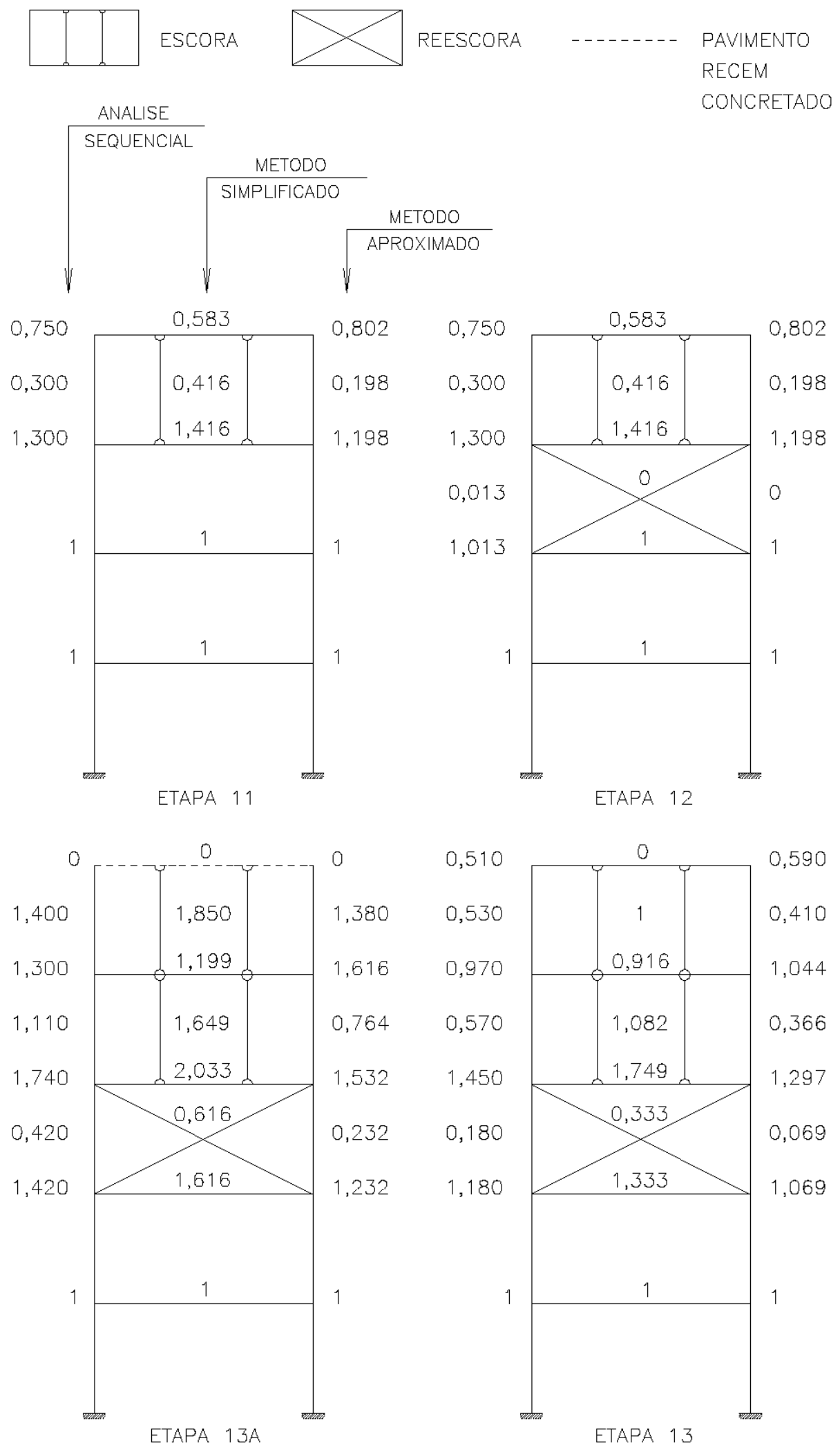

FIGURA 12.4d - Distribuição das ações de construção segundo fatores de carga $\mathrm{k}$ (x G), para a estrutura do cap.9 


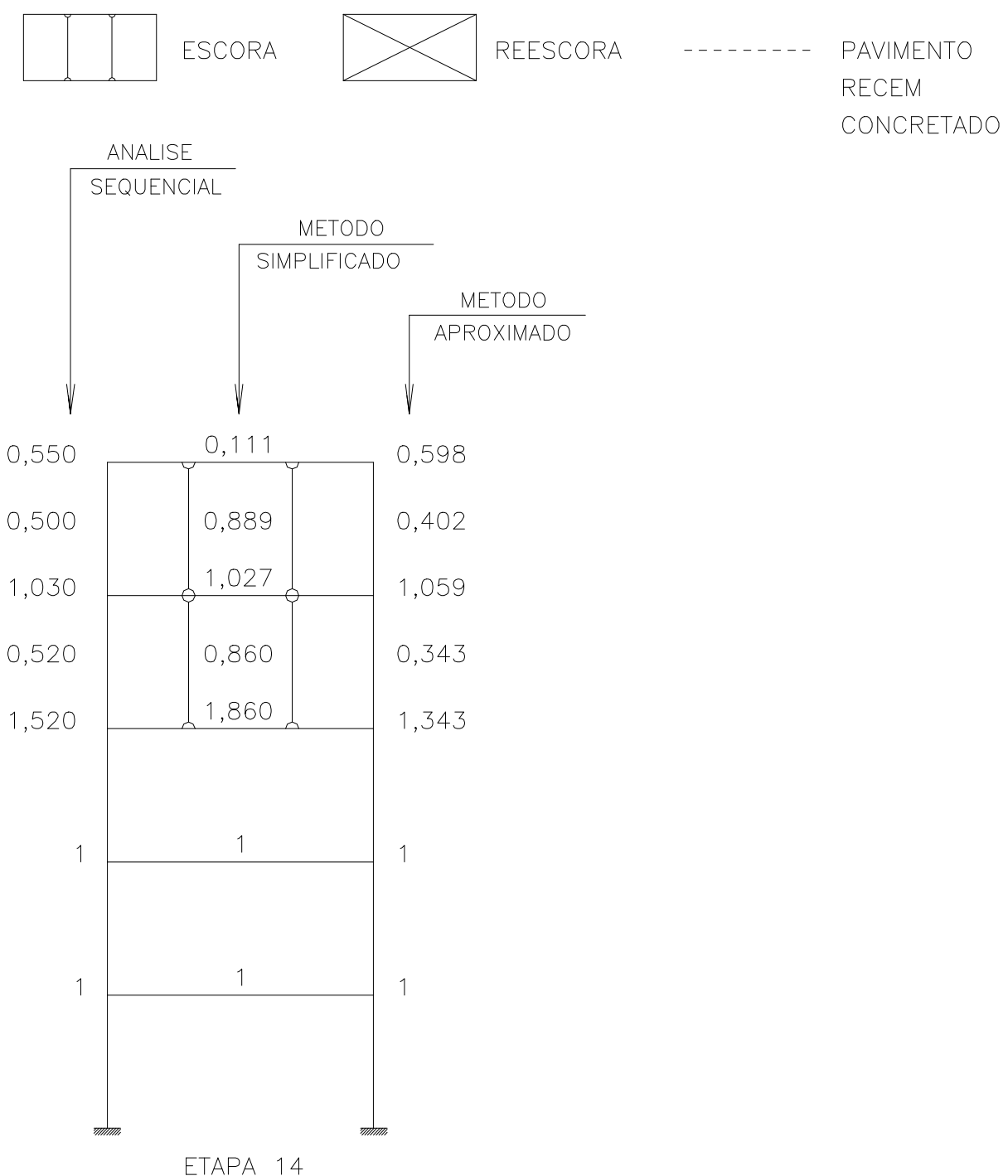

FIGURA 12.4e - Distribuição das ações de construção segundo fatores de carga k (x G), para a estrutura do cap.9

A desenvolvimento do método aproximado se dá exatamente como descrito no item 12.2, somente alterando-se as proporções de distribuição de ações.

$\mathrm{O}$ anexo apresenta um gráfico com os resultados dos 3 procedimentos para o 2..$^{\circ}$ pavimento (o mais solicitado) considerando desde a concretagem até a sua liberação definitiva das ações de construção na etapa 14 . 


\subsection{Análise dos resultados do método aproximado}

A observação dos resultados mostrados nas figuras 12.3 e 12.4 demonstra que conseguiu-se estabelecer um bom método para a distribuição das ações durante a construção.

Os resultados do método aproximado são melhores que os do método simplificado, tendo maior proximidade com os resultados da análise seqüencial (considerada mais realista).

A necessidade de se obter previamente alguns resultados com as estruturas primárias para que se possa utilizar o método aproximado não deve ser encarada como uma dificuldade. Por exemplo, nesse caso, houve a necessidade de apenas 3 processamentos simples.

A estrutura primária da figura 8.5 é muito semelhante à já utilizada para 0 dimensionamento dos elementos estruturais do pavimento. Praticamente a diferença é a introdução dos elementos de barra rotulados nas extremidades para a simulação dos pontaletes.

Já a modelagem da estrutura primária da figura 12.1 se faz com dois pavimentos interligados por um nível de pontaletes. Pode-se inclusive aproveitar a estrutura da figura 8.5.

A estrutura primária da figura 12.2 é exatamente a mesma da figura 12.1, com a diferença de que as ações de peso próprio estão aplicadas no pavimento inferior, ao invés do superior.

Em alguns aspectos o método aproximado até ganha mais simplicidade em relação ao método simplificado. Por exemplo, não há a necessidade de considerar o peso próprio das fôrmas e dos pontaletes. É evidente que, ao não levar em conta essas cargas, em um balanço geral das ações nos pavimentos e nos conjuntos de pontaletes chega-se a valores menores (melhor explicando, as reações de apoio na fundação são menores). Entretanto, esse fato mostrou-se desprezível.

Os resultados do método aproximado acompanham bem os resultados via análise seqüencial construtiva, inclusive quanto à determinação das etapas críticas do processo. As convergências dos valores das ações ao longo da altura do edifício também se assemelham. 
De acordo com os 3 procedimentos a maior solicitação ocorreu no $2 .^{\circ}$ pavimento durante a etapa 9A. A tabela 12.1 mostra os resultados.

TABELA 12.1 - Ações de construção máximas para pavimentos segundo fatores de carga $\mathrm{k}$ (x G) - etapa 9A

\begin{tabular}{|l|c|c|}
\hline & $\begin{array}{c}\text { ESTRUTURA } \\
\text { CAP.8 }\end{array}$ & $\begin{array}{c}\text { ESTRUTURA } \\
\text { CAP.9 }\end{array}$ \\
\hline ANÁL. SEQÜENCIAL & 1,390 & 1,750 \\
\hline MÉT. APROXIMADO & 1,357 & 1,786 \\
\hline MÉT. SIMPLIFICADO & 2,117 & 2,117 \\
\hline
\end{tabular}

No que diz respeito às máximas ações no conjunto de pontaletes, o nível situado entre a fundação e o $1 .^{\circ}$ pavimento possui as maiores ações na etapa $2 \mathrm{~A}$. A tabela 12.2 indica os fatores de carga obtidos.

TABELA 12.2 - Ações de construção máximas para pontaletes segundo fatores de carga $\mathrm{k}(\mathrm{x} \mathrm{G})$ - etapa $2 \mathrm{~A}$

\begin{tabular}{|l|c|c|}
\hline & $\begin{array}{c}\text { ESTRUTURA } \\
\text { CAP.8 }\end{array}$ & $\begin{array}{c}\text { ESTRUTURA } \\
\text { CAP.9 }\end{array}$ \\
\hline ANÁL. SEQÜENCIAL & 0,610 & 1,820 \\
\hline MÉT. APROXIMADO & 0,493 & 1,770 \\
\hline MÉT. SIMPLIFICADO & 2,850 & 2,850 \\
\hline
\end{tabular}

Cabe uma observação no que se refere à estrutura do capítulo 8. Na verdade, de acordo com o método aproximado, para essa estrutura a maior solicitação para pontaletes ocorre em todas etapas A. Para os conjuntos de pontaletes que sustentam os pavimentos recém concretados tem-se um fator de carga $\mathrm{k}=0,580>0,493$.

Em geral, o método simplificado superestima as ações nos pavimentos e pontaletes. Ainda, ele indica que os resultados mostrados nas figuras 12.3 e 12.4 sejam majorados em 10\%, para levar em conta o peso próprio das fôrmas e pontaletes. Assim, na etapa 9A ocorre a maior solicitação para pavimentos, com o $2 .^{\circ}$ 
deles apresentando $\mathrm{k}=2,328(2,117 \times 1,10)$. No caso dos pontaletes, o nível situado entre o $1 .^{\circ}$ pavimento e a fundação exibe, na etapa $2 \mathrm{~A}$, o valor máximo com $\mathrm{k}=3,135$ $(2,850 \times 1,10)$.

Na verdade, o método simplificado já falha ao apresentar os mesmos resultados para estruturas com pavimentos diferentes. O método aproximado corrige isso muito bem estabelecendo preliminarmente algumas distribuições de ações nos carregamentos e descarregamentos. Essas distribuições são características de cada pavimento em particular e são determinadas através dos processamentos das estruturas primárias.

Além disso, alguns outros fatores claramente visíveis no método simplificado são corrigidos no método aproximado.

Primeiramente, a hipótese de se considerar os pontaletes infinitamente rígidos faz com que as ações de peso próprio de pavimentos recém concretados caminhem diretamente para a fundação, enquanto a esta ainda eles estiverem ligados. $\mathrm{Na}$ verdade os pontaletes são deformáveis, possibilitando que os pavimentos do sistema de suporte absorvam ações nesta situação.

Outro ponto a destacar, também causador de distorções nos resultados, é a não absorção de cargas por parte dos pilares quando um pavimento é concretado; com certeza o principal equívoco do método simplificado. Obviamente, uma porcentagem das ações de pavimentos recém concretados são transmitidas aos pilares. Embora o concreto fresco ainda não permita resistência às cargas, os pilares já estão concretados e, como os pontaletes, ajudam na sustentação do pavimento.

Ao contrário do que se imaginava no início deste trabalho, as idades do pavimento não constituem um fator importante na distribuição das ações. De acordo com o método aproximado interessa de fato: a posição do pavimento no sistema de suporte, se se trata de concretagem ou retirada de pontaletes e, finalmente, se há pontaletes ligados à fundação. Em resumo, a velocidade de construção pouco influencia a distribuição das ações.

Embora seja importante estabelecer métodos que se caracterizem pela simplicidade e rapidez na obtenção de resultados, como o aqui particularmente definido, deve-se estar sempre atento às limitações que isso acarreta. 
Por exemplo, os fatores de carga refletem uma média para todo o pavimento, existindo regiões menos ou mais solicitadas pelos pontaletes. Este fato deve ser entendido e sempre levado em consideração. 


\section{NOVA METODOLOGIA PARA VERIFICAÇÃO DOS ESTADOS LIMITES}

Como mostrado neste trabalho, os valores dos esforços solicitantes e deslocamentos nos elementos estruturais dos pavimentos dependem do processo de construção utilizado. Isso vale para os valores finais em serviço e, principalmente, para os valores que ocorrem durante as etapas de construção. Deve-se lembrar também que, embora não sejam consideráveis, existem diferenças entre os esforços solicitantes e deslocamentos finais nos mesmos elementos dos diversos pavimentos ao longo da altura do edifício.

Então, como proceder na prática para a verificação dos estados limites último de esgotamento da capacidade resistente e de utilização no que se refere à deformação excessiva?

O dimensionamento dos elementos estruturais do pavimento (vigas e lajes) deve ser feito considerando a combinação última normal de ações (definida na expressão 5.1) aplicada ao pavimento isolado, uma vez que a diferença entre os esforços solicitantes obtidos desta maneira e os obtidos para cada pavimento via análise seqüencial construtiva são pequenas. Posteriormente, há a necessidade de se determinar qual a máxima solicitação dos pavimentos ao longo do processo de construção para cada idade onde ocorrem os eventos. Deve-se tomar muito cuidado uma vez que uma determinada solicitação aplicada aos 21 dias pode ser menos crítica do que uma com valor inferior aplicada anteriormente, por exemplo aos 7 dias.

O método aproximado fornece os valores das ações atuantes durante a construção em função do peso próprio do pavimento. Assim, simplificadamente, pode-se considerar que o pavimento possui peso próprio majorado pelo fator de carga (k) indicado no método aproximado. Essa ação majorada deve entrar na combinação última de construção, a ser aplicada no pavimento isolado considerando-se a idade 
correta do concreto. As armaduras necessárias nesse caso devem ser comparadas com as existentes, garantindo-se a segurança de todos os elementos estruturais contra o esgotamento da capacidade resistente.

Para a verificação do estado limite de utilização no que se refere à deformação excessiva também podem ser usados os resultados do método aproximado, determinando-se os deslocamentos no pavimento mais solicitado durante a construção.

Do modo como foi definido neste trabalho o processo de construção os pavimentos são concretados nas etapas A, espaçadas por um intervalo fixo de dias denominado ciclo de concretagem. Nas etapas imediatamente seguintes às etapas $\mathrm{A}$ há a mudança de idade, somando-se um ciclo. Deve-se lembrar que as etapas A não participam do somatório dos efeitos da fase de construção para se encontrar esforços solicitantes ou deslocamentos finais. Assim, utilizando o método aproximado, as ações atuantes numa etapa imediatamente anterior a uma etapa A resumem o estado de deslocamento até o seu respectivo ciclo.

$\mathrm{Na}$ verdade, o que está sendo proposto é uma história resumida de carregamentos de construção. Ou seja, o tratamento para determinação dos deslocamentos ao longo do tempo que na análise seqüencial construtiva era feito por etapas, agora é feito por ciclos. Como já dito, as ações finais em cada ciclo são obtidas através do método aproximado verificando-se o fator de carga da etapa imediatamente anterior à etapa A respectiva. Novamente, para verificar os deslocamentos até o ciclo em questão considera-se o pavimento isolado com a idade correta do concreto e com o seu peso próprio majorado pelo correspondente fator de carga.

No penúltimo ciclo o pavimento sempre estará submetido somente ao seu próprio peso, ou seja, será definitivamente liberado das ações de construção apresentando um fator de carga $\mathrm{k}=1,0$.

No último ciclo, além do seu próprio peso, o pavimento estará submetido às ações de revestimento, sobrecarga de utilização e alvenarias. Todas essas ações devem entrar na combinação de utilização com seus valores característicos, com exceção da sobrecarga de utilização que deve entrar com sua parcela quasepermanente, do modo como definido no capítulo 6. 
Portanto, obtidas as curvas de deslocamento ao longo do tempo para os pontos do pavimento crítico pode-se verificar se em alguns deles há o comprometimento do estado limite de utilização no que se refere à deformação excessiva, comparando-se com valores limites de flecha pré-estabelecidos.

Esse procedimento resumido é aplicado à estrutura definida no item 9.1, para comparação com os resultados da análise seqüencial construtiva levando em conta os deslocamentos em cada etapa. Considera-se novamente um processo de construção com dois níveis de escoras mais um nível de reescora. É utilizada a formulação de deformação lenta definida pelo ACI-209R (1992).

Analisam-se os deslocamentos dos pontos PV1/PV2 e PL1, mostrados na figura 9.3.

A tabela 13.1 indica os dados de cada ciclo para esses pontos, descrevendo uma história resumida de carregamentos.

TABELA 13.1 - Dados fornecidos com o processo aproximado, para a estrutura do cap.9

\begin{tabular}{|c|c|c|c|c|c|c|c|}
\hline CICLO & $\begin{array}{c}\text { IDADE } \\
(\mathrm{DIAS})\end{array}$ & $\begin{array}{c}\text { FATOR k } \\
(\mathrm{x} \mathrm{G})\end{array}$ & $\begin{array}{c}\mathrm{f}_{\mathrm{PL} 1} \\
(\mathrm{~cm})\end{array}$ & $\begin{array}{c}\mathrm{f}_{\mathrm{PV} 1 / \mathrm{PV} 2} \\
(\mathrm{~cm})\end{array}$ & $\begin{array}{c}\mathrm{M}_{\mathrm{PL} 1}(+) \\
(\mathrm{kN} . \mathrm{m} / \mathrm{m})\end{array}$ & $\begin{array}{c}\mathrm{M}_{\mathrm{PV} 1 / \mathrm{PV} 2}(+) \\
(\mathrm{kN} . \mathrm{m})\end{array}$ & $\begin{array}{c}\mathrm{M}_{\mathrm{PV} 1 / \mathrm{PV} 2}(-) \\
(\mathrm{kN} . \mathrm{m})\end{array}$ \\
\hline 1 & 7 & 0,697 & 0,85 & 0,17 & 8,54 & 20,68 & $-68,32$ \\
\hline 2 & 14 & 1,452 & 1,65 & 0,33 & 17,78 & 43,06 & $-142,26$ \\
\hline 3 & 21 & 1 & 1,10 & 0,21 & 12,25 & 29,70 & $-98,00$ \\
\hline 4 & 365 & serviço & 1,53 & 0,34 & 16,60 & 47,20 & $-153,00$ \\
\hline
\end{tabular}

onde:

$\mathrm{f}_{\mathrm{PL} 1}=$ flecha elástica no ponto PL1 do pavimento, com peso próprio majorado pelo fator de carga $\mathrm{k}$;

$\mathrm{f}_{\mathrm{PV} 1 / \mathrm{PV} 2}=$ flecha elástica nos pontos PV1/PV2 do pavimento, com peso próprio majorado pelo fator de carga $\mathrm{k}$; 
$\mathrm{M}_{\mathrm{PL1}}(+)=$ momento fletor no ponto PL1 (direção y) do pavimento, com peso próprio majorado pelo fator de carga $\mathrm{k}$;

$\mathrm{M}_{\mathrm{PV} 1 / \mathrm{PV} 2}(+)=$ momento fletor nos pontos $\mathrm{PV} 1 / \mathrm{PV} 2$ do pavimento, com peso próprio majorado pelo fator de carga $\mathrm{k}$;

$\mathrm{M}_{\mathrm{PV} 1 / \mathrm{PV} 2}(-)=$ momento fletor nas extremidades dos vãos dos pontos PV1/PV2 do pavimento, com peso próprio majorado pelo fator de carga $\mathrm{k}$.

No ciclo 4, ao invés de haver a majoração com o fator de carga, processa-se o pavimento com o peso próprio e as ações em serviço (revestimento, alvenaria e a parcela quase-permanente da sobrecarga de utilização).

Nesse caso resumido a fissuração nas vigas V401/V406 ocorre já aos 7 dias, com $\mathrm{M}_{\mathrm{cr}}=16,34 \mathrm{kN} . \mathrm{m}$, da mesma maneira que na análise seqüencial construtiva considerando os deslocamentos a cada etapa. Entretanto, para a laje L401 a fissuração agora só ocorre aos 14 dias, $\operatorname{com} \mathrm{M}_{\mathrm{cr}}=11,77 \mathrm{kN} \cdot \mathrm{m} / \mathrm{m}$. Anteriormente isso acontecia aos 7 dias, $\operatorname{com} \mathrm{M}_{\mathrm{cr}}=10,65 \mathrm{kN} \cdot \mathrm{m} / \mathrm{m}$.

Nota-se, então, que a história resumida da construção deixa de considerar alguns picos de carregamento, que podem provocar uma fissuração prematura.

A tabela 13.2 mostra os resultados obtidos para flecha imediata e deformação lenta no tempo infinito, segundo os dois procedimentos.

TABELA 13.2 - Valores de flecha imediata + deformação lenta, para a estrutura do cap. 9

\begin{tabular}{|c|c|c|}
\hline & $\begin{array}{c}\text { PONTO PL1 } \\
(\mathrm{cm})\end{array}$ & $\begin{array}{c}\text { PONTOS PV1/PV2 } \\
(\mathrm{cm})\end{array}$ \\
\hline $\begin{array}{c}\text { HISTÓRIA POR ETAPAS } \\
\text { (ANÁL. SEQÜENCIAL) }\end{array}$ & 6,22 & 1,26 \\
\hline $\begin{array}{c}\text { HISTÓRIA POR CICLOS } \\
\text { (MÉT. APROXIMADO) }\end{array}$ & 6,27 & 1,13 \\
\hline
\end{tabular}


Para os pontos PV1/PV2 a flecha resultou $10 \%$ menor, enquanto para o ponto PL1 os resultados foram praticamente idênticos. Nesse caso, fica confirmada a eficácia da metodologia para a verificação dos deslocamentos proposta neste capítulo.

No anexo encontram-se gráficos com as curvas ao longo do tempo para os dois procedimentos.

Pode-se, então, aplicar a nova metodologia à estrutura descrita no item 8.4, por exemplo.

O pavimento é mostrado na figura 8.7, definindo-se o ponto 1 no centro da laje L1 e o ponto 2 no meio do vão da viga V1.

A tabela 13.3 mostra os dados de cada ciclo, para esses pontos. Destaca-se que nenhum elemento do pavimento sofre fissuração em toda a história resumida de carregamentos.

TABELA 13.3 - Dados fornecidos com o processo aproximado, para a estrutura do cap. 8

\begin{tabular}{|c|c|c|c|c|c|c|c|c|}
\hline CICLO & $\begin{array}{c}\text { IDADE } \\
(\mathrm{DIAS})\end{array}$ & $\begin{array}{c}\text { FATOR } \mathrm{k} \\
(\mathrm{x} \mathrm{G})\end{array}$ & $\begin{array}{c}\mathrm{f}_{1} \\
(\mathrm{~cm})\end{array}$ & $\begin{array}{c}\mathrm{f}_{2} \\
(\mathrm{~cm})\end{array}$ & $\begin{array}{c}\mathrm{M}_{1}(+) \\
(\mathrm{kN} . \mathrm{m} / \mathrm{m})\end{array}$ & $\begin{array}{c}\mathrm{M}_{2}(+) \\
(\mathrm{kN} . \mathrm{m})\end{array}$ & $\begin{array}{c}\mathrm{M}_{2}(-) \\
(\mathrm{kN} . \mathrm{m})\end{array}$ & $\begin{array}{c}\mathrm{M}_{2}{ }^{*}(-) \\
(\mathrm{kN} . \mathrm{m})\end{array}$ \\
\hline 1 & 7 & 0,777 & 0,046 & 0,016 & 0,73 & 2,11 & $-0,34$ & $-1,22$ \\
\hline 2 & 14 & 1,243 & 0,067 & 0,025 & 1,17 & 3,38 & $-0,54$ & $-1,95$ \\
\hline 3 & 21 & 1 & 0,053 & 0,020 & 0,94 & 2,72 & $-0,43$ & $-1,57$ \\
\hline 4 & 365 & serviço & 0,093 & 0,041 & 1,57 & 5,79 & $-1,19$ & $-3,58$ \\
\hline
\end{tabular}

onde:

$\mathrm{f}_{1}=$ flecha elástica no ponto 1 do pavimento, com peso próprio majorado pelo fator de carga k;

$\mathrm{f}_{2}$ = flecha elástica no ponto 2 do pavimento, com peso próprio majorado pelo fator de carga k; 
$\mathrm{M}_{1}(+)=$ momento fletor no ponto 1 do pavimento, com peso próprio majorado pelo fator de carga k;

$\mathrm{M}_{2}(+)=$ momento fletor no ponto 2 do pavimento, com peso próprio majorado pelo fator de carga $\mathrm{k}$;

$M_{2}(-)=$ momento fletor na extremidade esquerda do vão do ponto 2 do pavimento, com peso próprio majorado pelo fator de carga k;

$\mathrm{M}_{2}{ }^{*}(-)=$ momento fletor na extremidade direita do vão do ponto 2 do pavimento, com peso próprio majorado pelo fator de carga $\mathrm{k}$.

A tabela 13.4 contém os resultados de flecha imediata e deformação lenta para o tempo infinito, obtidos com os dados da tabela 13.3. É novamente utilizada a formulação de deformação lenta definida pelo ACI-209R (1992).

TABELA 13.4 - Valores de flecha imediata + deformação lenta, para a estrutura do cap. 8

\begin{tabular}{|c|c|}
\hline PONTO 1 $(\mathrm{cm})$ & PONTO 2 $(\mathrm{cm})$ \\
\hline 0,21 & 0,092 \\
\hline
\end{tabular}

Esses valores de deslocamento transversal são perfeitamente admissíveis para o pavimento em questão.

Para a verificação da segurança dos pontaletes (ruptura e estabilidade) pode-se também utilizar os resultados do método aproximado. Aplicada a combinação última de construção obtém-se o máximo fator de carga $\mathrm{k}$, atuante em um determinado conjunto de pontaletes. Sabe-se que, nesse conjunto, em verdade os pontaletes estão solicitados por diferentes ações axiais.

Não obstante, usando os resultados do processamento da estrutura primária da figura 8.5 consegue-se estabelecer, aproximadamente, as proporções de ações que cada pontalete recebe do total indicado pelo máximo fator de carga $\mathrm{k}$. 


\section{CONCLUSÕES}

Atualmente não há como prescindir do auxílio da informática no que se refere a projetos de estruturas de edifícios em concreto armado.

Todavia, os resultados matematicamente precisos gerados pelos modernos programas de cálculo estrutural estão sempre atrelados a um modelo adotado. A engenharia não é uma ciência exata e todo modelo estrutural possui um nível de aproximação referente a hipóteses próprias.

Por exemplo, não considerar que a estrutura de um edifício é construída gradativamente em etapas constitui-se numa evidente aproximação em relação à realidade. Todas as aproximações referentes ao modelo adotado devem ser obrigatoriamente conhecidas, entendidas e explicitadas.

Os resultados deste trabalho deixam claro que ao levar em conta o fato das ações de peso próprio serem introduzidas de forma incremental sobre estruturas que acompanham o desenvolvimento da construção, tem-se valores de esforços solicitantes e deslocamentos diferentes daqueles obtidos convencionalmente com o pavimento isolado. Caso se considere essas ações aplicadas de uma só vez na estrutura inteira com todos os pavimentos, o que não é aconselhável, as diferenças tendem a aumentar.

Desta maneira, a conveniência de se adotar uma análise tipo incremental alia-se à necessidade de levar em conta os carregamentos prematuros, não só os referentes ao peso próprio mas também todos aqueles inerentes ao processo de construção de edifícios. Como aqui foi visto, carregamentos prematuros provocam aumento das deformações, além de colocar em risco a segurança.

Nesse sentido, o trabalho estabelece a análise seqüencial construtiva e, a partir da observação dos seus resultados, propõe o método aproximado para a determinação da distribuição das ações entre pavimentos e pontaletes durante a construção. Aliás, 
embora as modelagens feitas aqui considerem pontaletes de madeira, todas as indicações valem igualmente para pontaletes de aço ou qualquer outro material.

Não obstante o trabalho tenha se desenvolvido tendo como alvo as estruturas de edifícios com pavimentos compostos por vigas e lajes, o caminhamento dos estudos acabou levando naturalmente a uma extensão das aplicações da pesquisa. Tanto a análise seqüencial construtiva quanto o método aproximado são válidos para qualquer tipo de pavimento, como os compostos por laje-cogumelo ou laje nervurada.

Espera-se que a nova metodologia para verificação dos estados limites último de esgotamento da capacidade resistente e de utilização no que se refere à deformação excessiva seja útil à Comissão de Estudos para a revisão da NBR-6118 (1978). O caráter prático desta nova metodologia parece atraente para uma norma desse tipo. Além disso, muito pouco está indicado na NBR-6118 (1978) a respeito dos efeitos das ações de construção nas estruturas de concreto armado. 


\begin{abstract}
ANEXO
São apresentados nas páginas seguintes diversos gráficos ilustrativos para as ações de construção, esforços solicitantes e deslocamentos. Esses gráficos foram gerados com o auxílio de planilhas elaboradas através do software EXCEL.

Deve-se esclarecer que o gráfico que mostra a perda de rigidez por fissuração na laje L401 utiliza a expressão empírica desenvolvida por BRANSON (1963), definida no capítulo 6. Nessa expressão são utilizadas as características de resistência e deformabilidade do concreto previstas aos 7 dias.

Com o intuito de evitar uma excessiva quantidade de informações, no caso dos deslocamentos são apresentados os resultados indicados pelo ACI-209R (1992), não deixando de se apresentar comparações com os valores resultantes das formulações do CEB-90 (1990) e da NBR-7197 (1989), quando julgado necessário.
\end{abstract}

Ao mencionar a "fluência" os gráficos se referem aos valores de deformação lenta acrescidos da deformação imediata. 


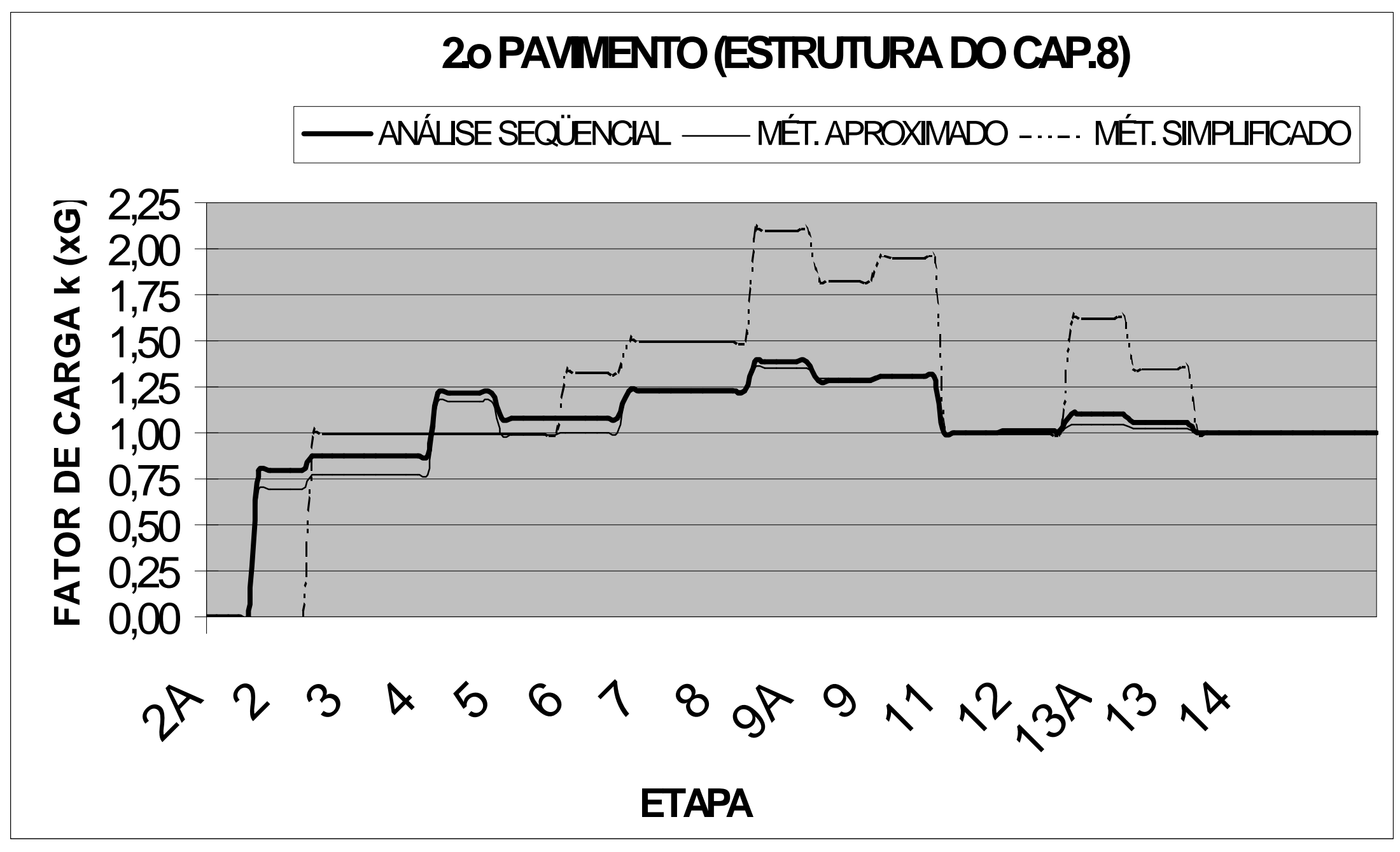




\section{PAVMENTO(ESTRUTURA DOCAP.8)}

\section{-... . ANÁLSESEQ̈̈ENCAL —PROJETO(S/ALV.) P PROJETO(C/ALV.)}

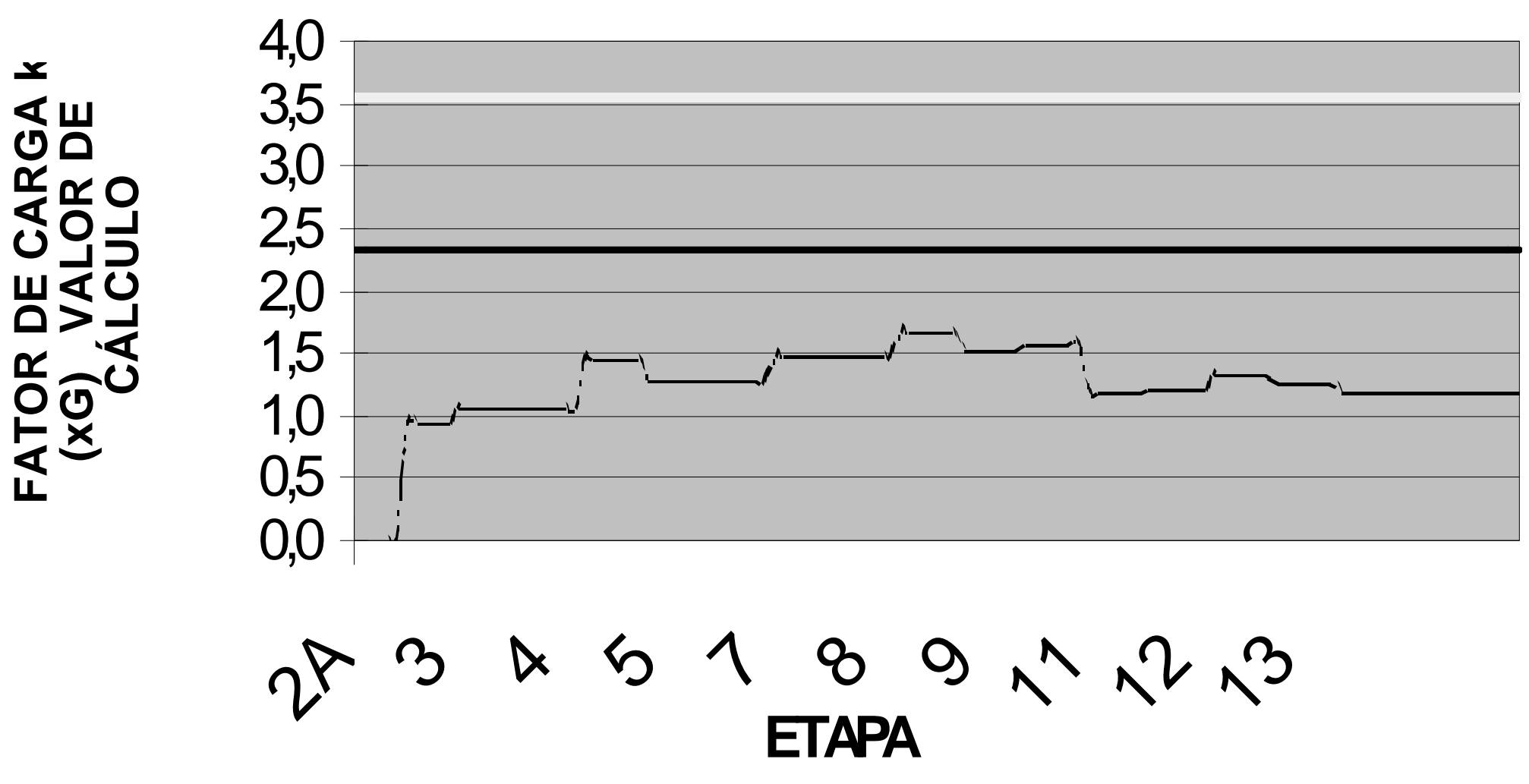




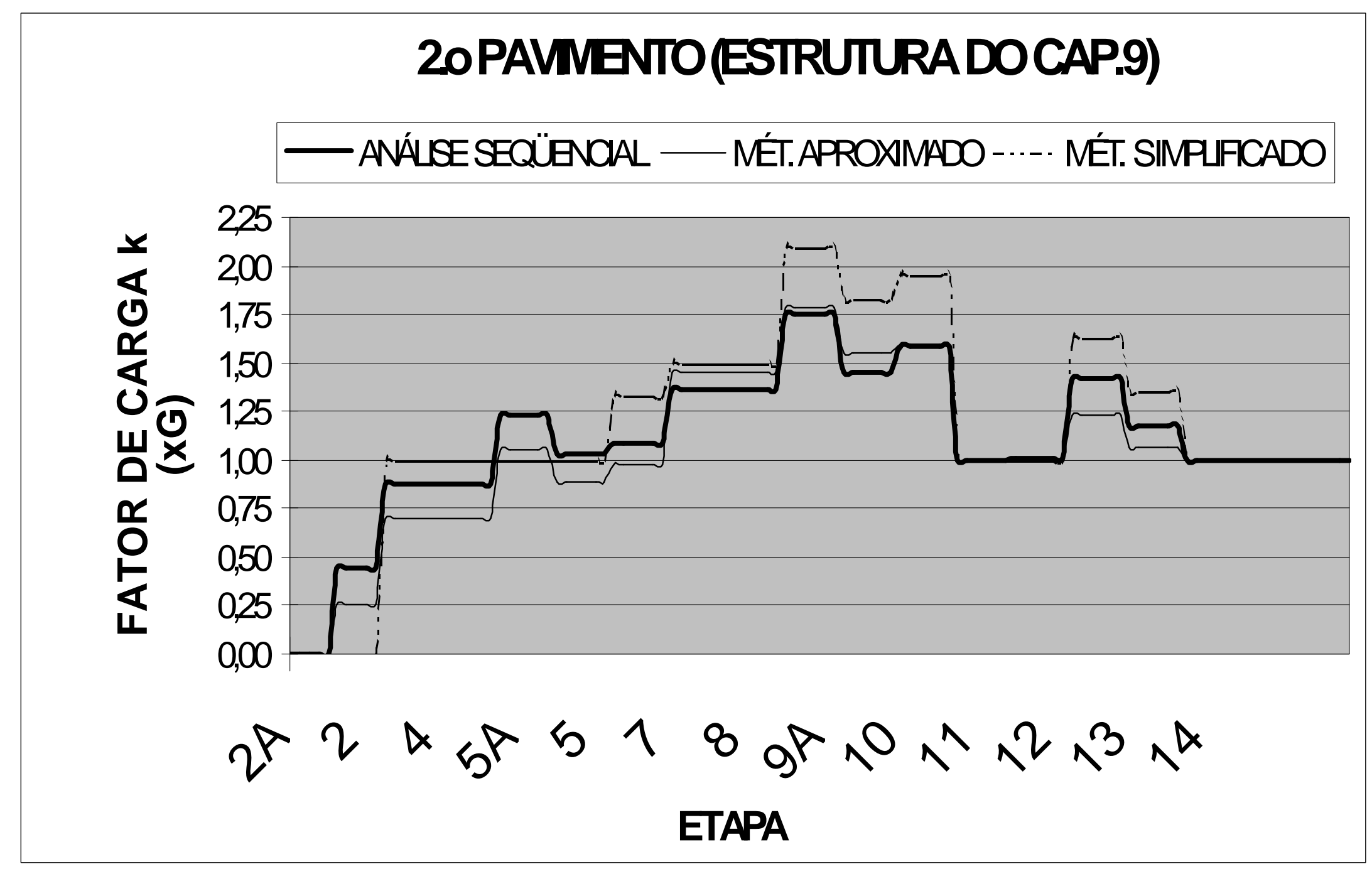




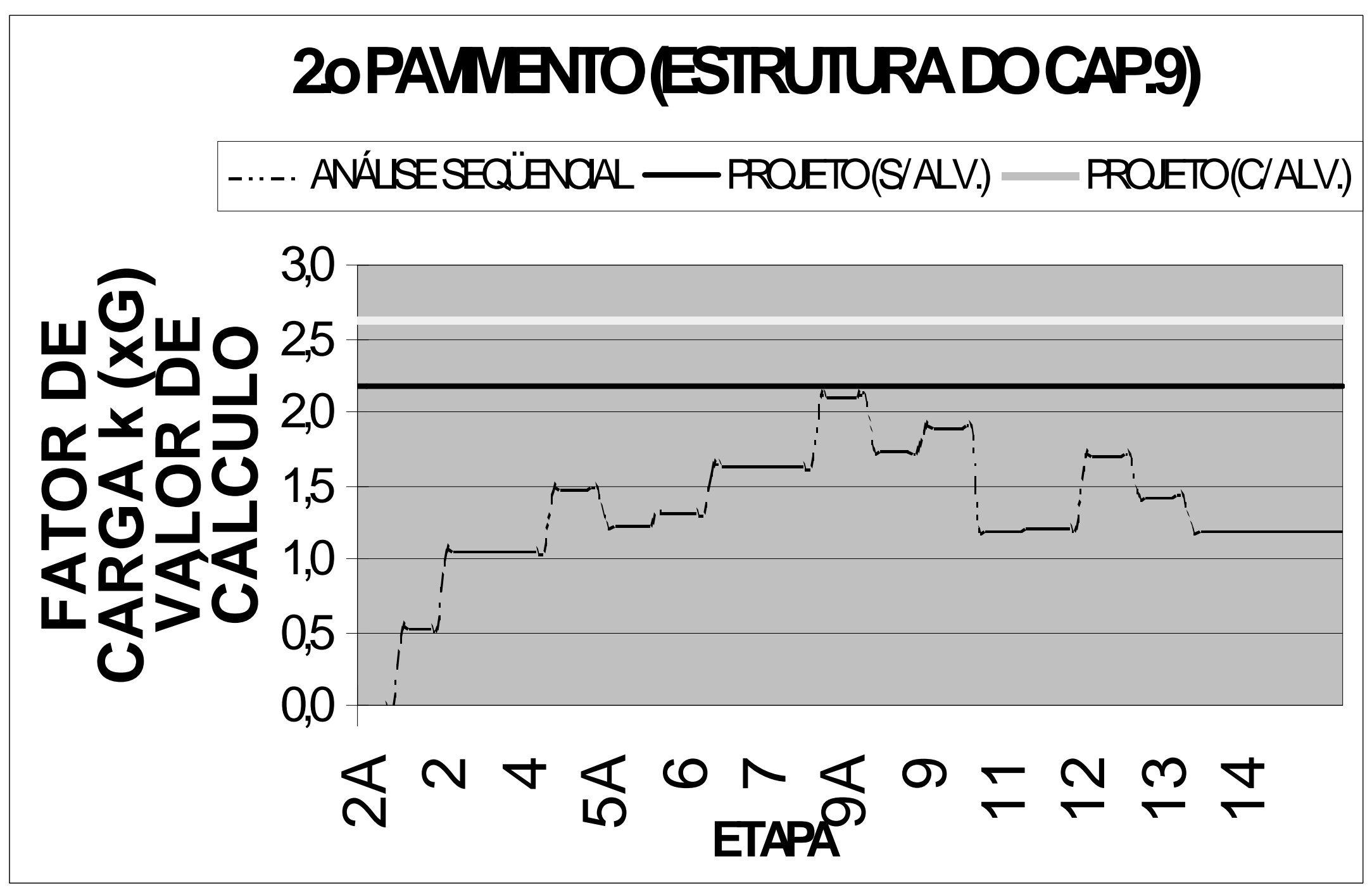




\section{PONTO PV4 (V408) / 2.o PAVIMENTO ANÁLISE SEQÜENCIAL}

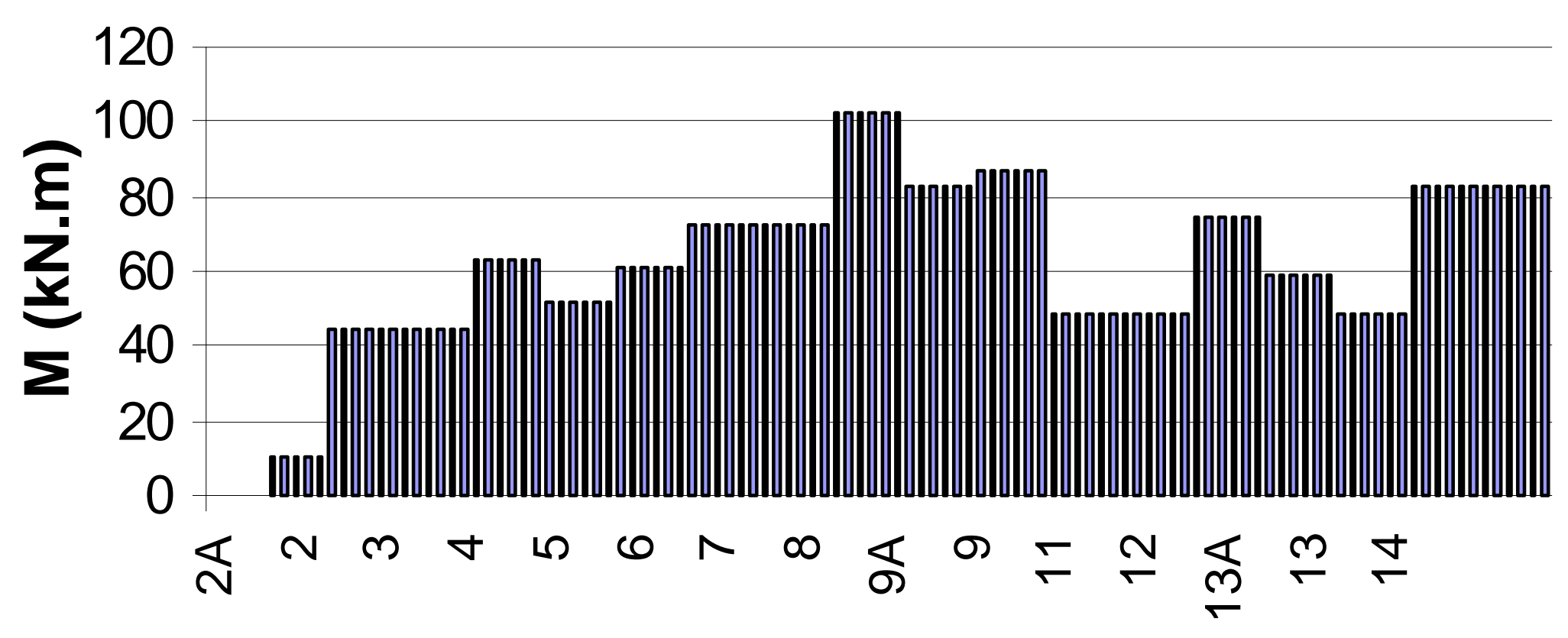

ETAPA 


\section{PONTO PV4 (V408) / 2.0 PAVIMENTO ANÁLISE SEQÜENCIAL}

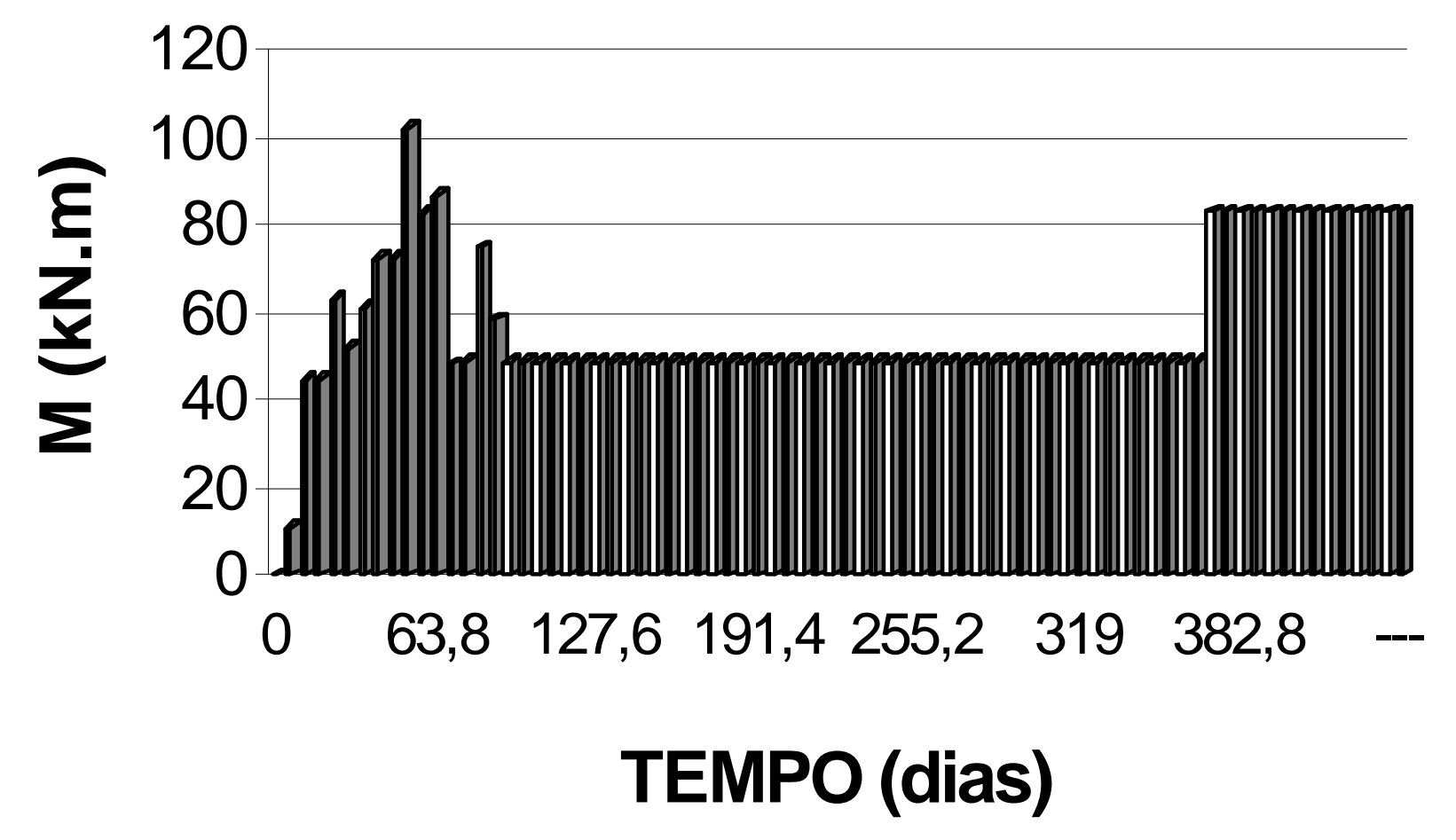




\section{PONTO PV4 (V408) / 2.0 PAVIMENTO ANÁLISE SEQÜENCIAL}

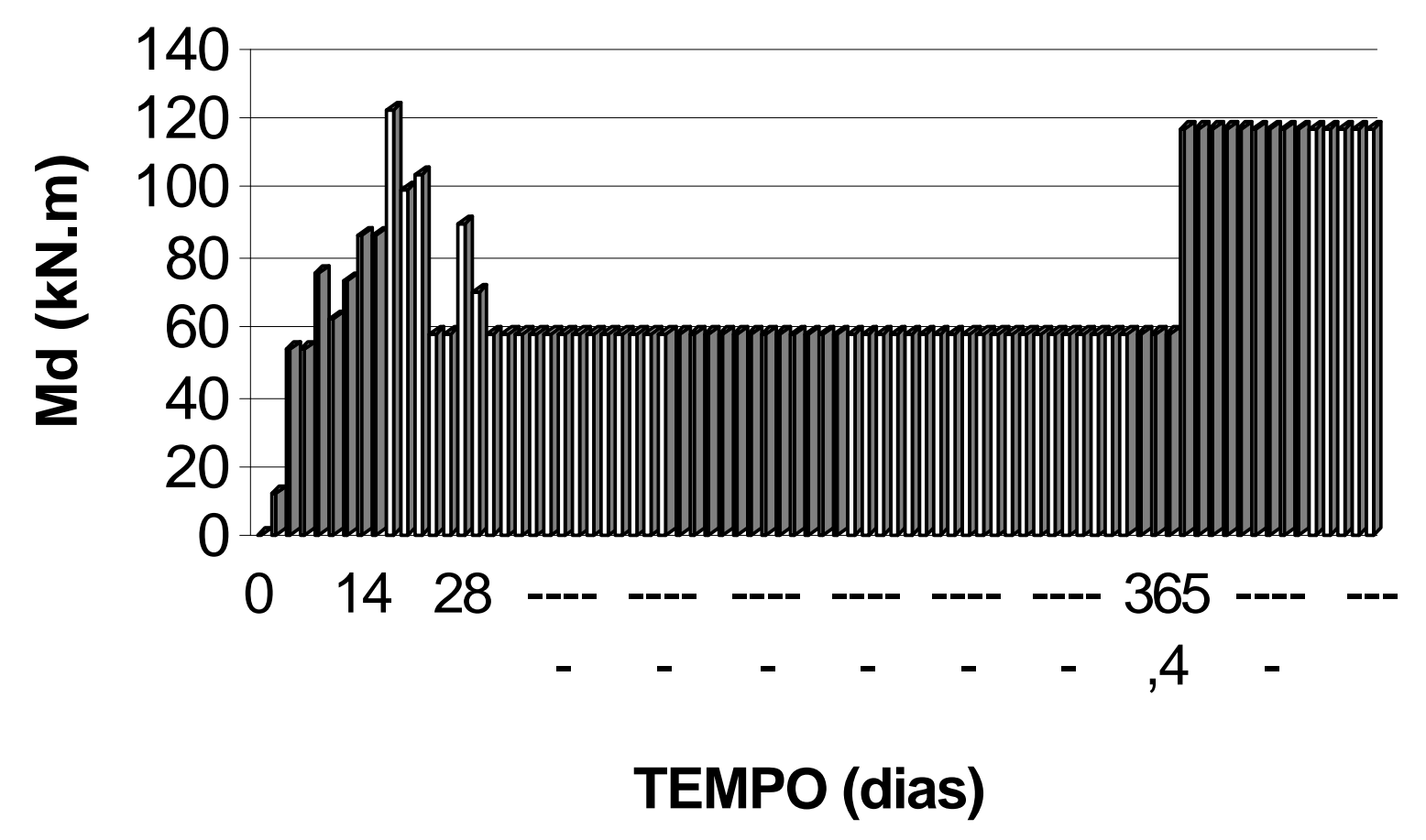




\section{PONTO PV4 (V408) / 2.0 PAVIMENTO}

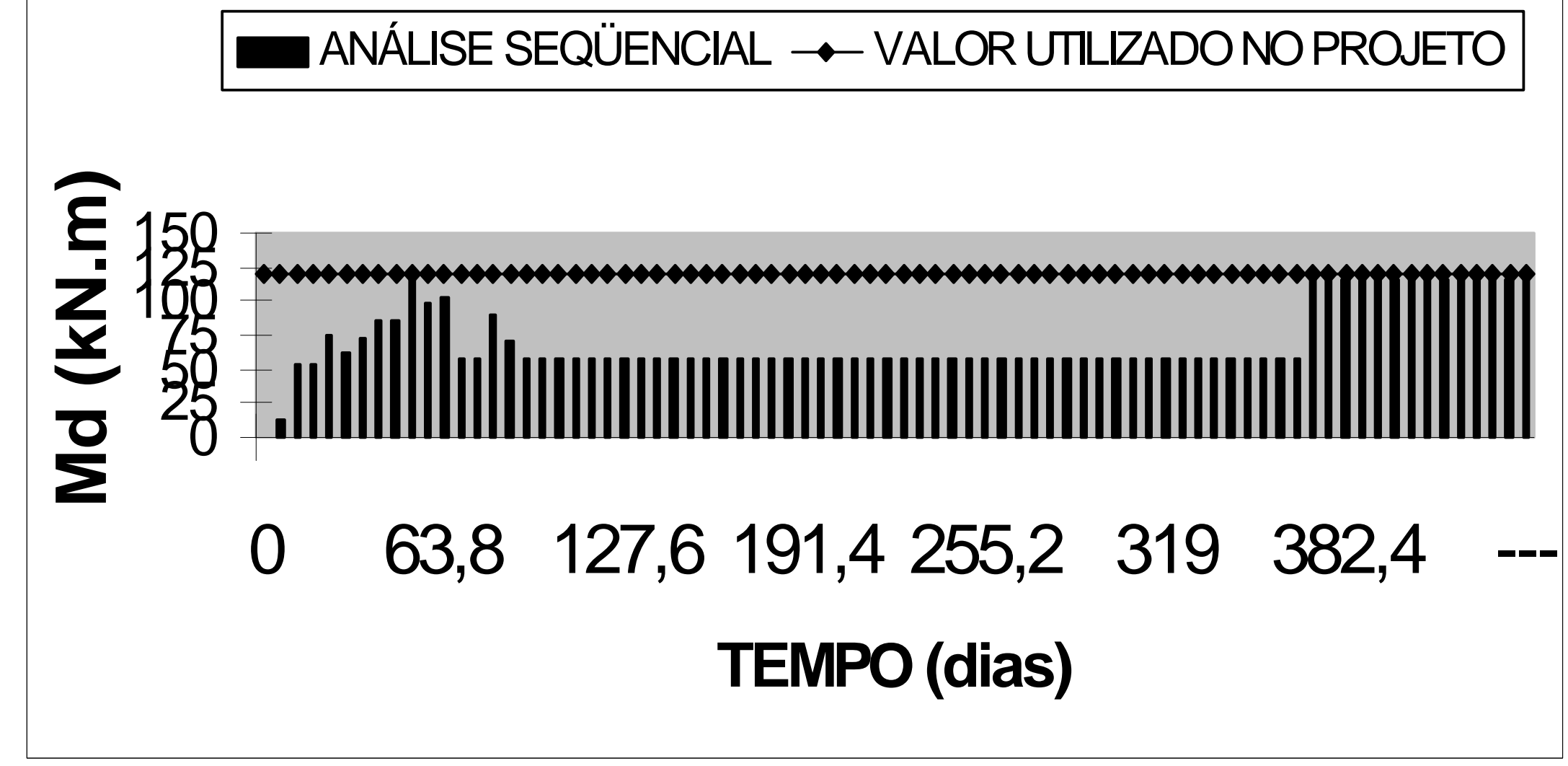




\section{PONIOPL1 (L401) / 20 PAVMENTO ANÁLSESEQÜBNOAL}

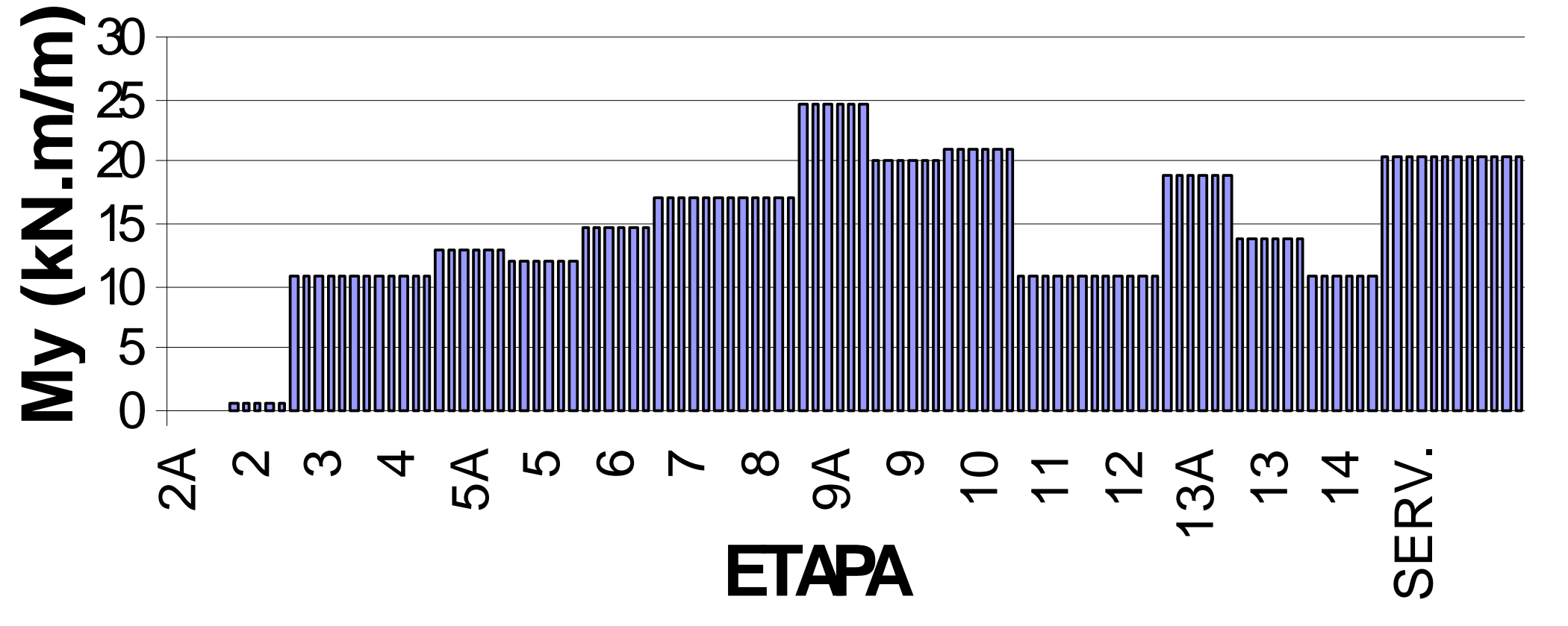




\section{PONIOPL1 (L401) / 2.o PAVMENTO ANÁLSESEQÏGNAAL}

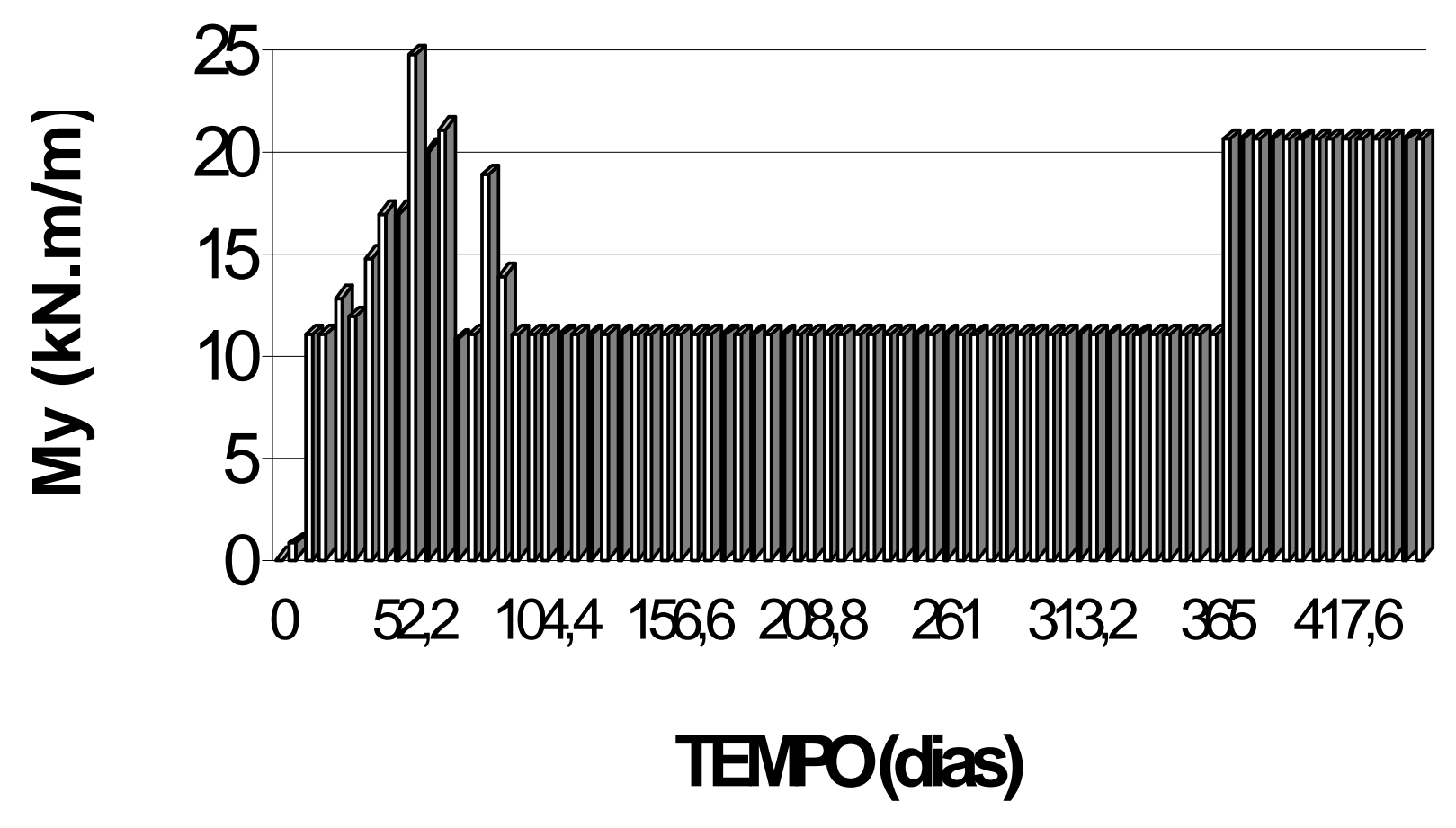




\section{PONTO PL1 (L401) / 2.o PAVIMENTO ANÁLISE SEQÜENCIAL}

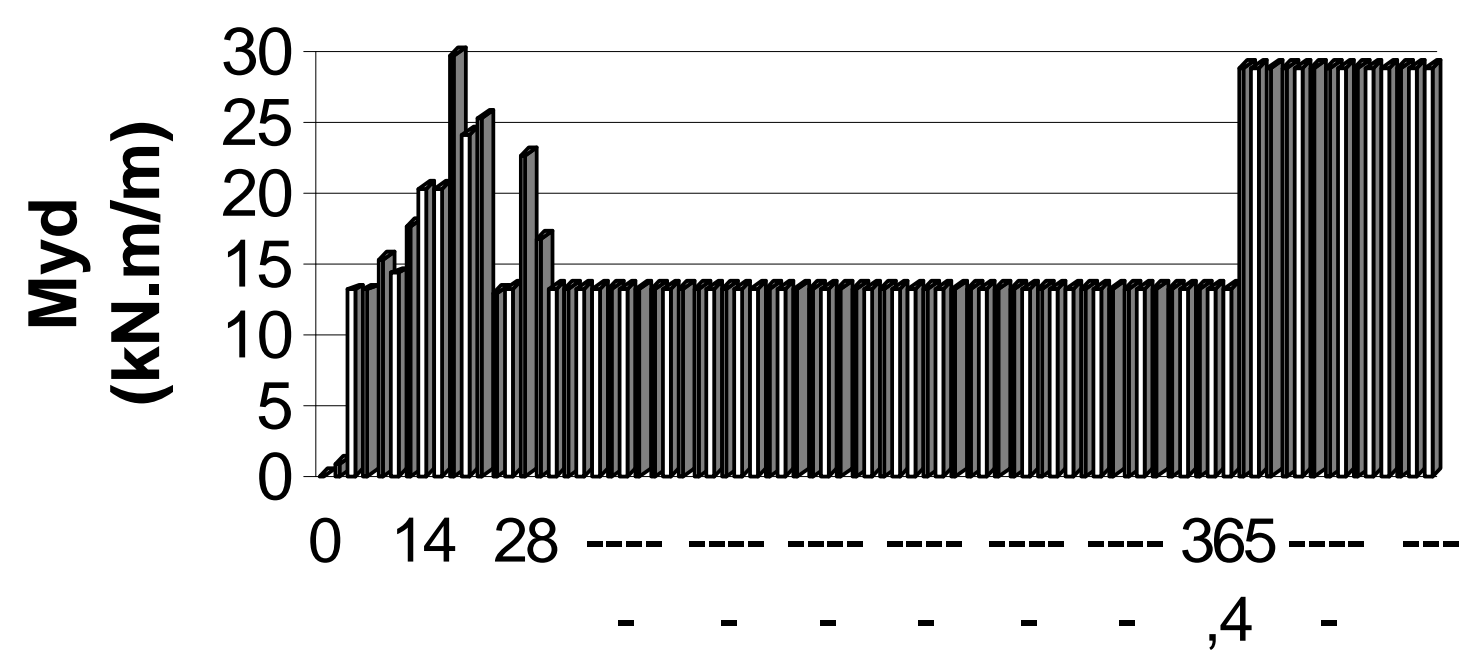

TEMPO (dias) 


\section{PONIOPL1 (L401) / 2O PAVMENIO}

- ANÁLSESEQÏBNCAL - - VALORUTIVADONOPROJEIO

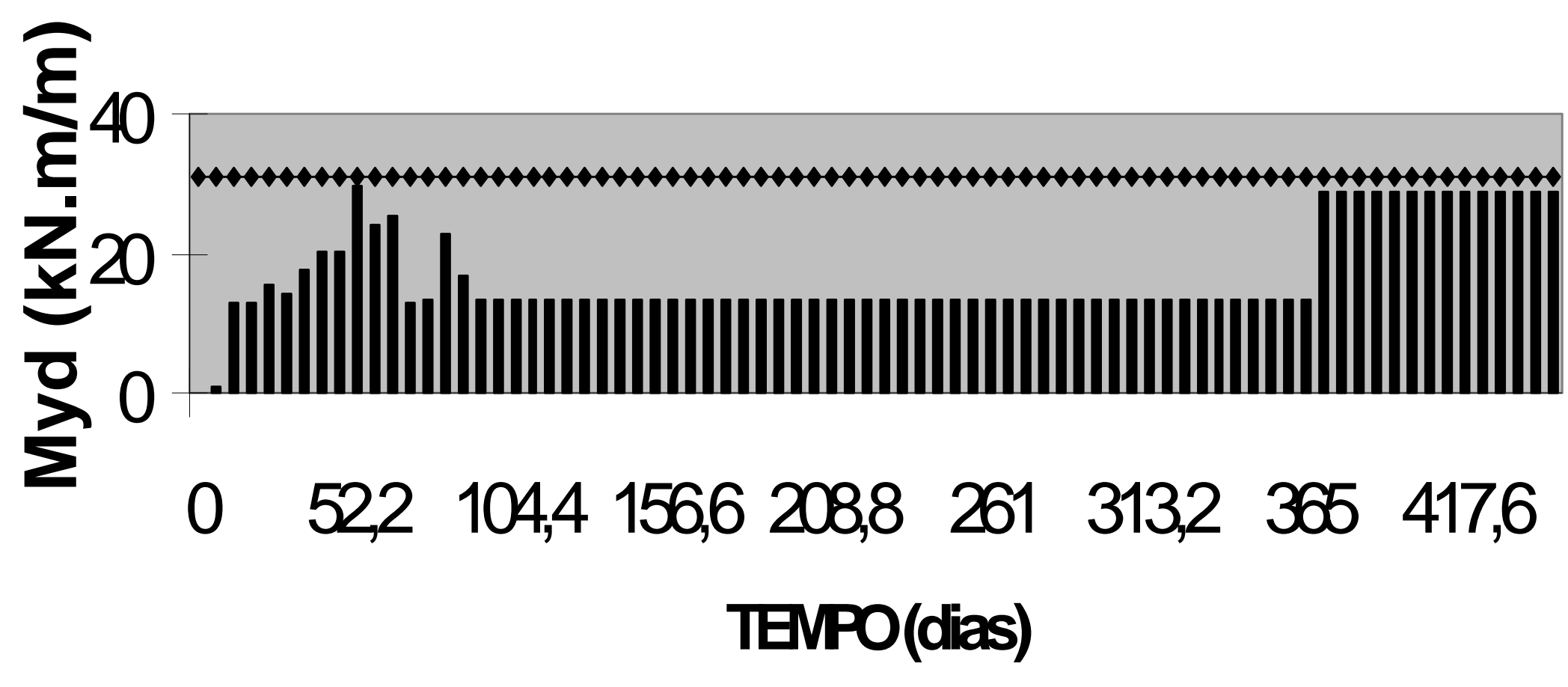




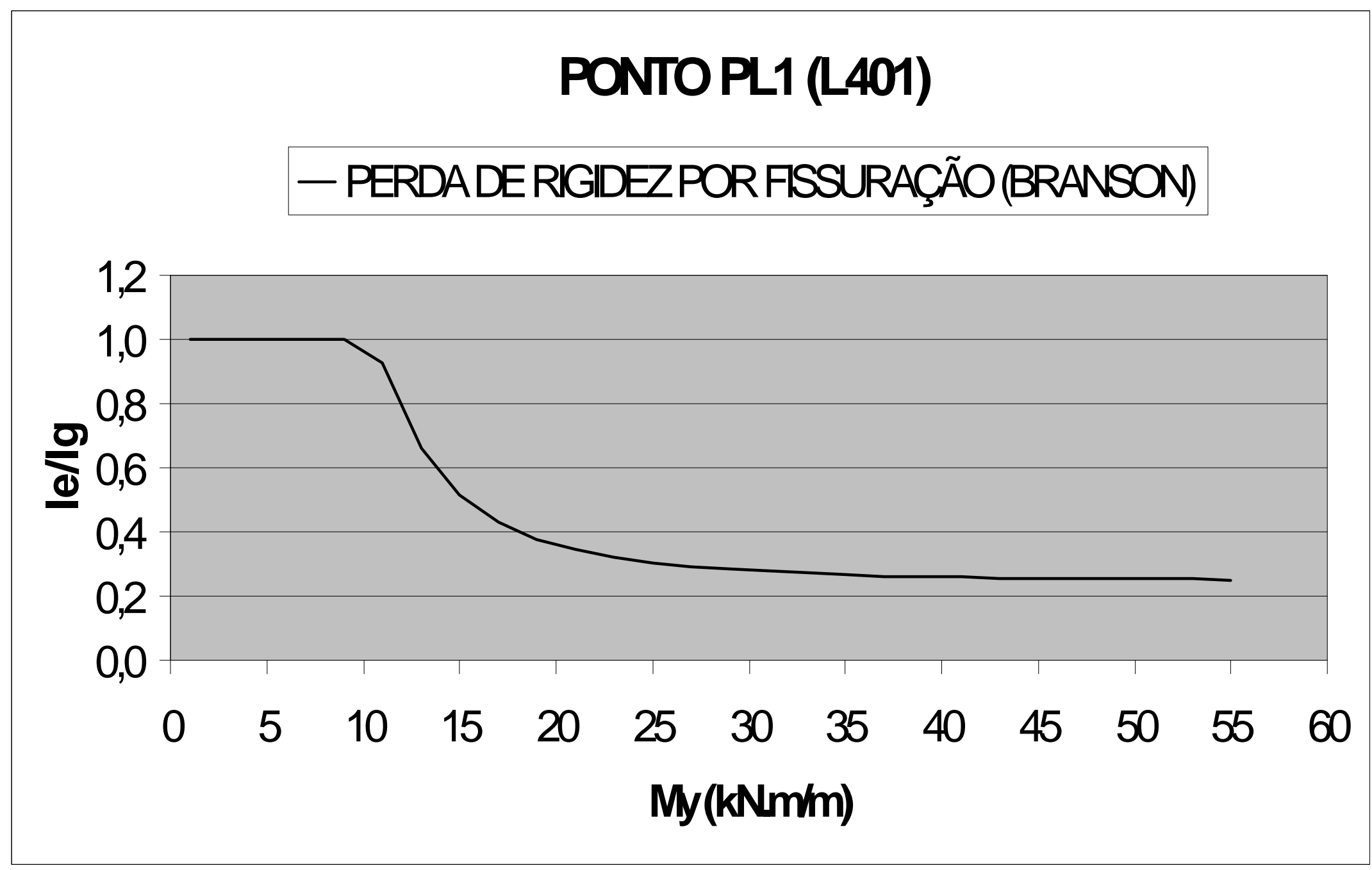




\section{PONIOSPV1PV2 (N401N406) / RETRAÇÃO (AC1209)}

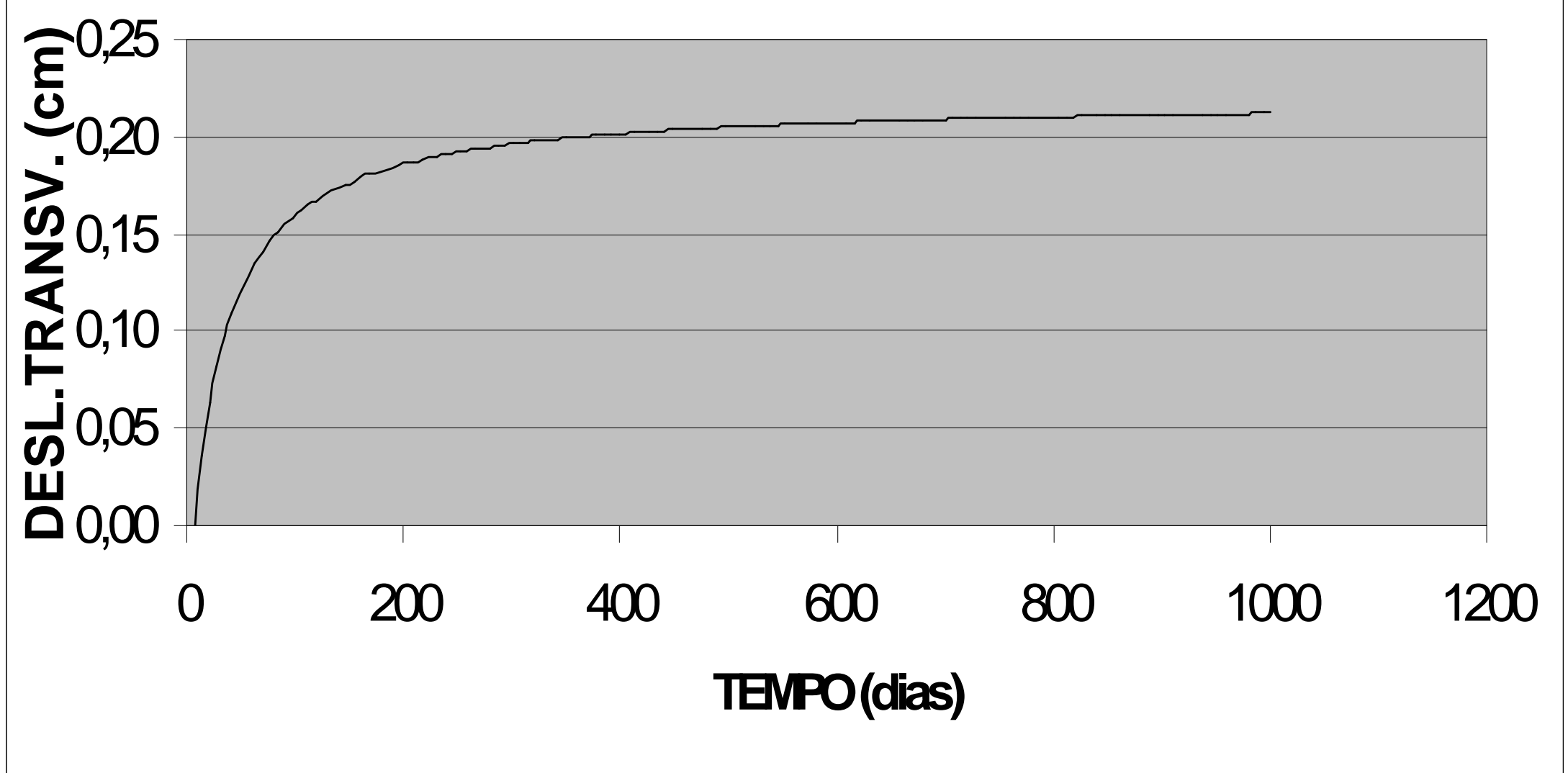




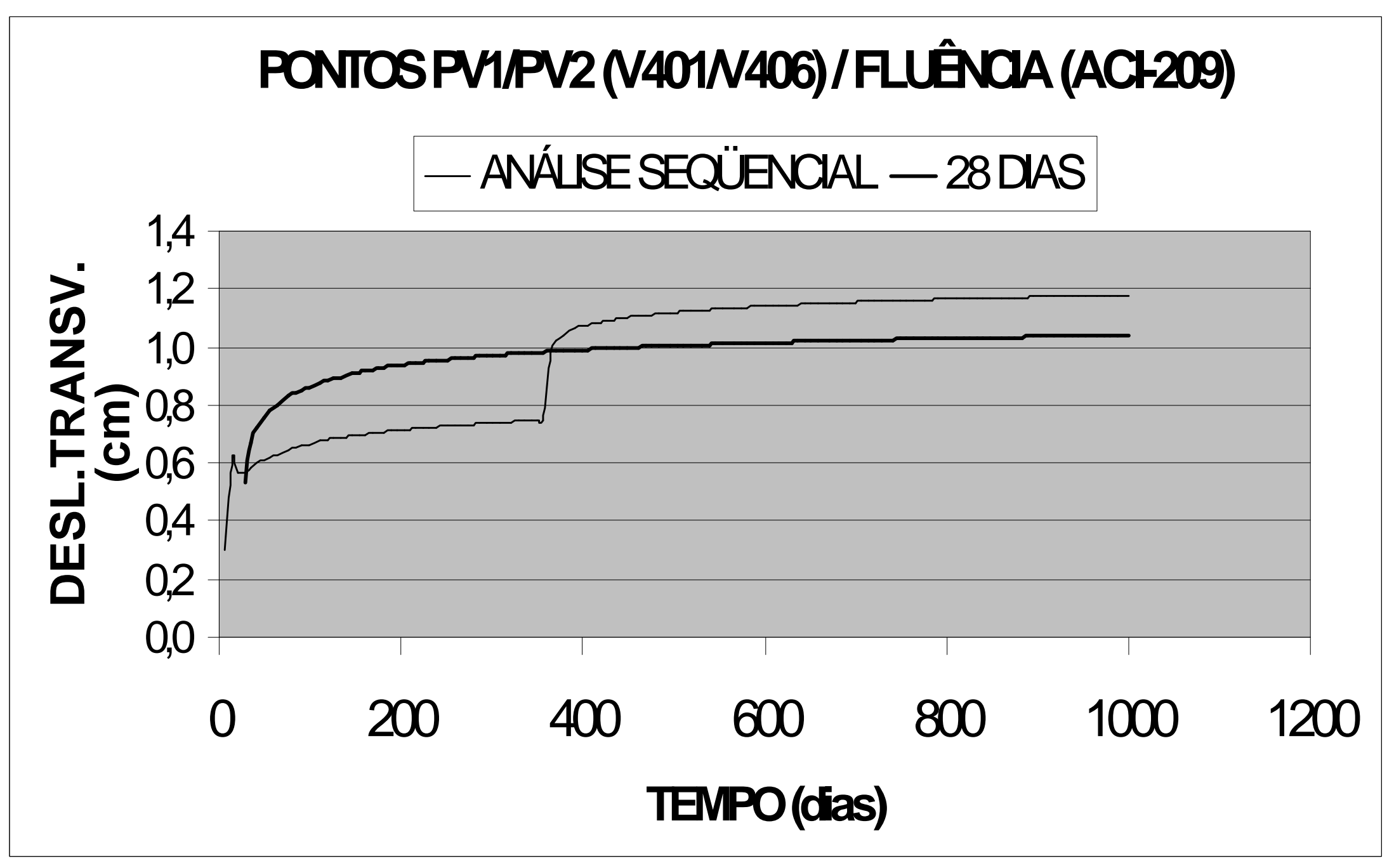




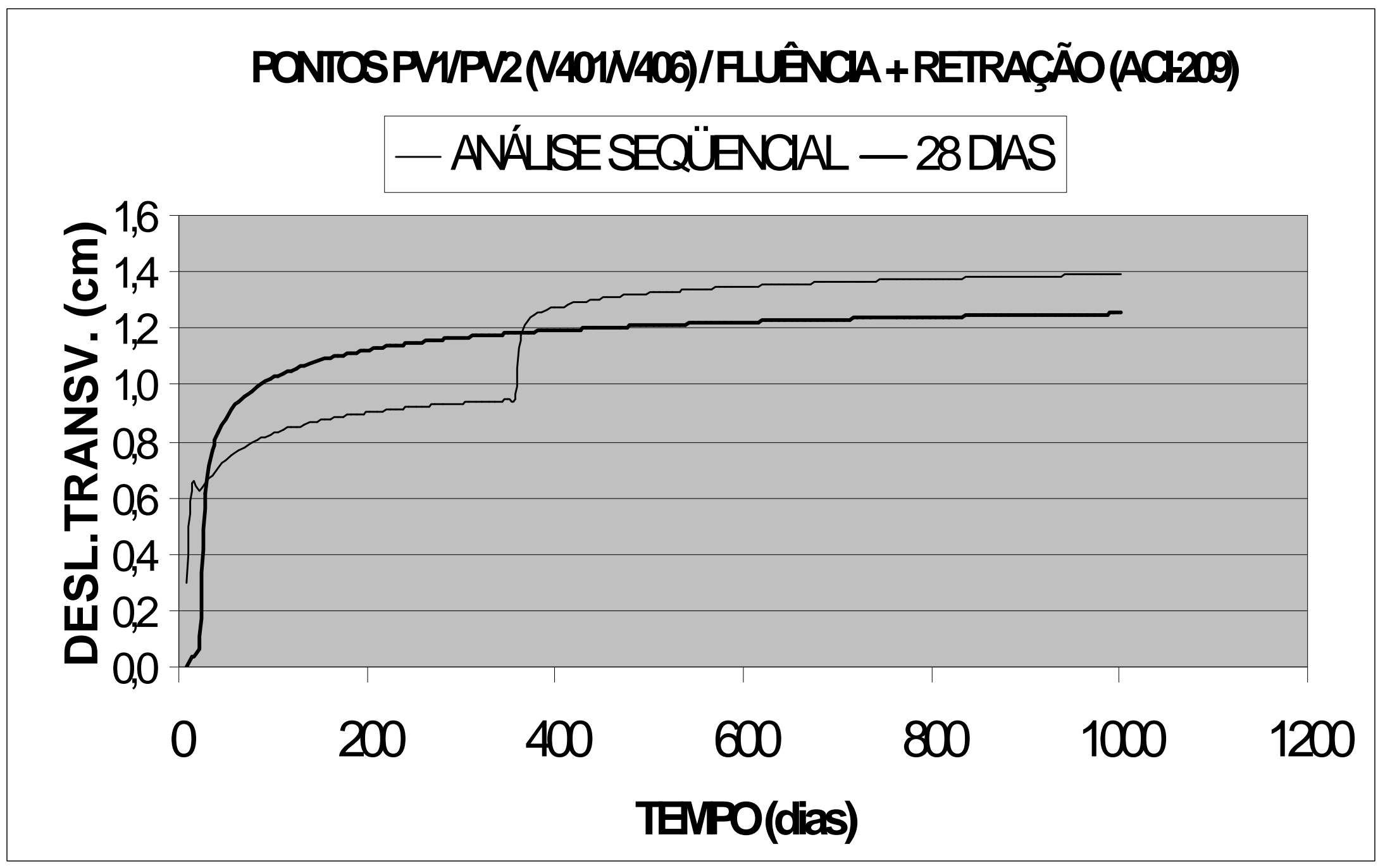




\section{PONIOSPV1PV2(N401N406)/RUĜNCA(AC1209)}

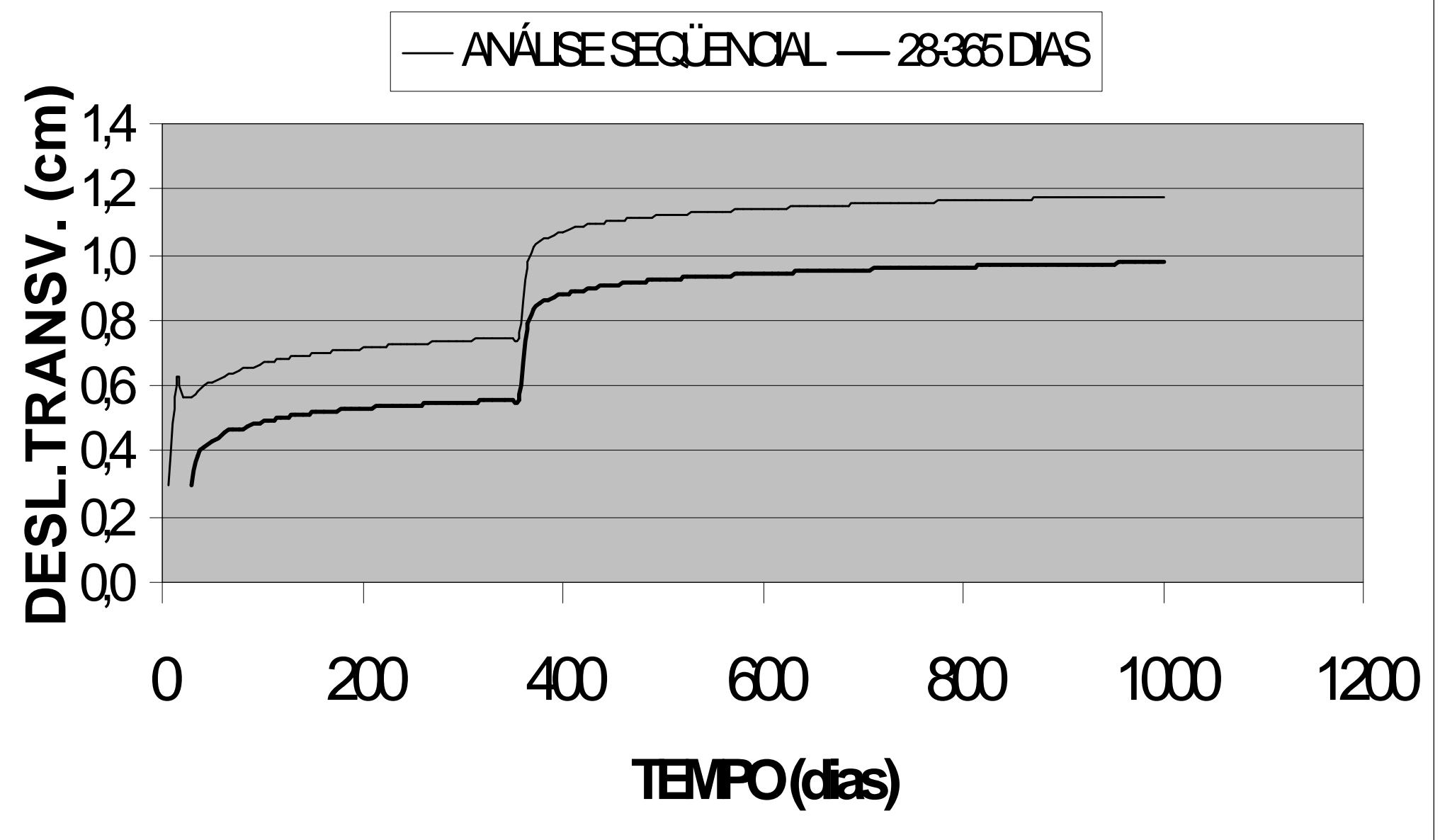




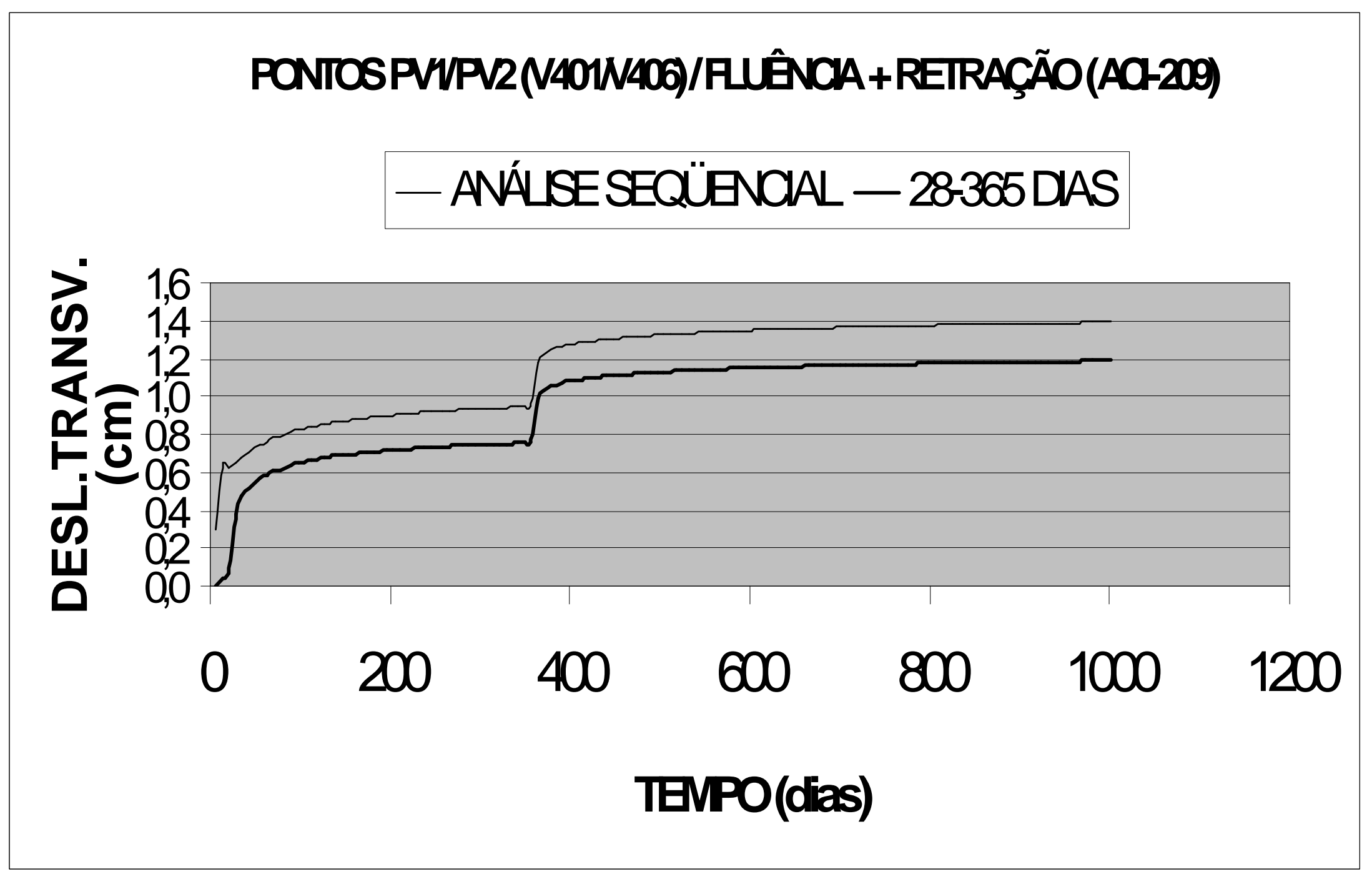




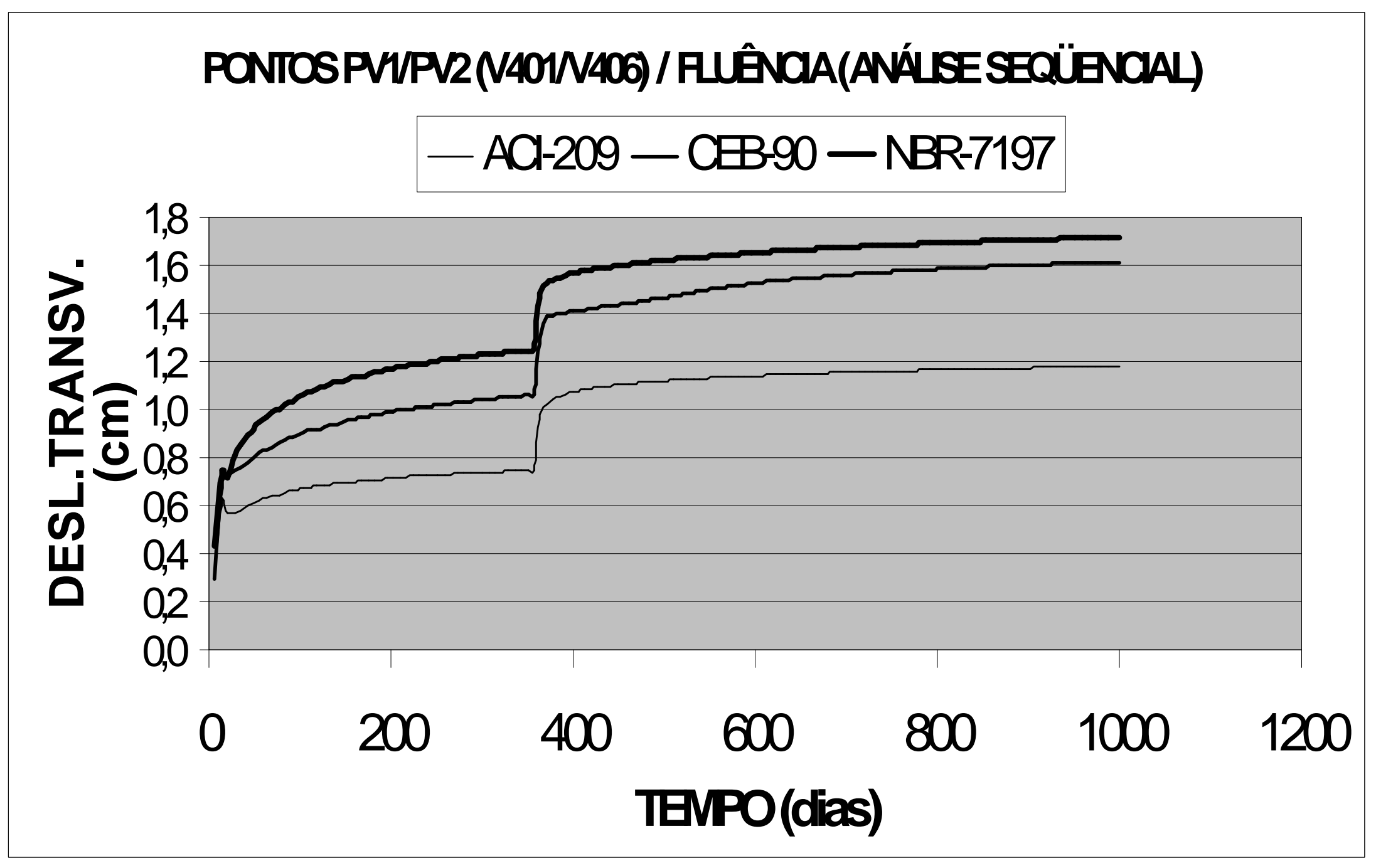




\section{PONIOSPV1PV2(N401N406)/RETRAÇÃO}

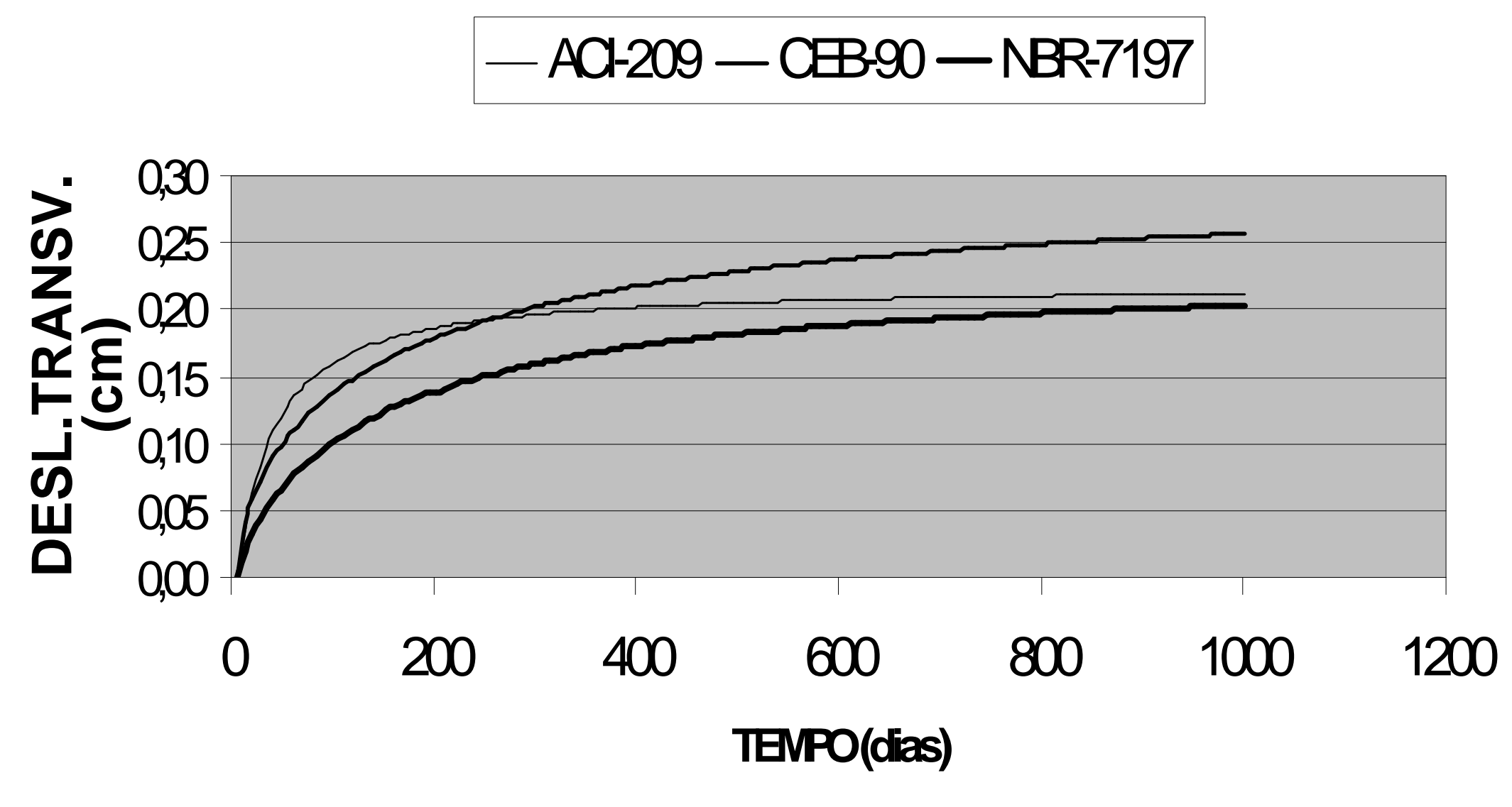




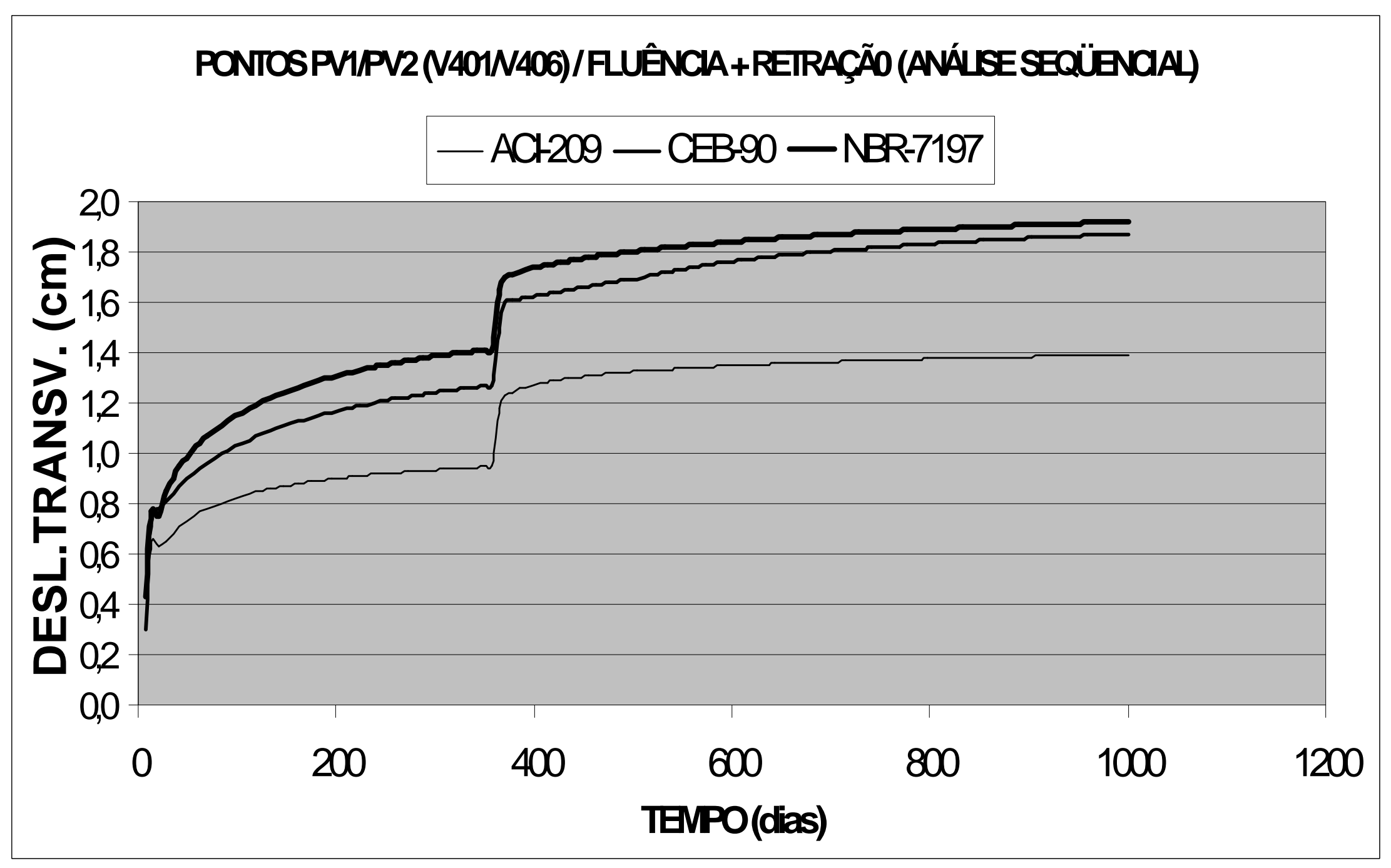




\section{PONTOPL1 (L401)/REIRAÇÃO(ACF209)}

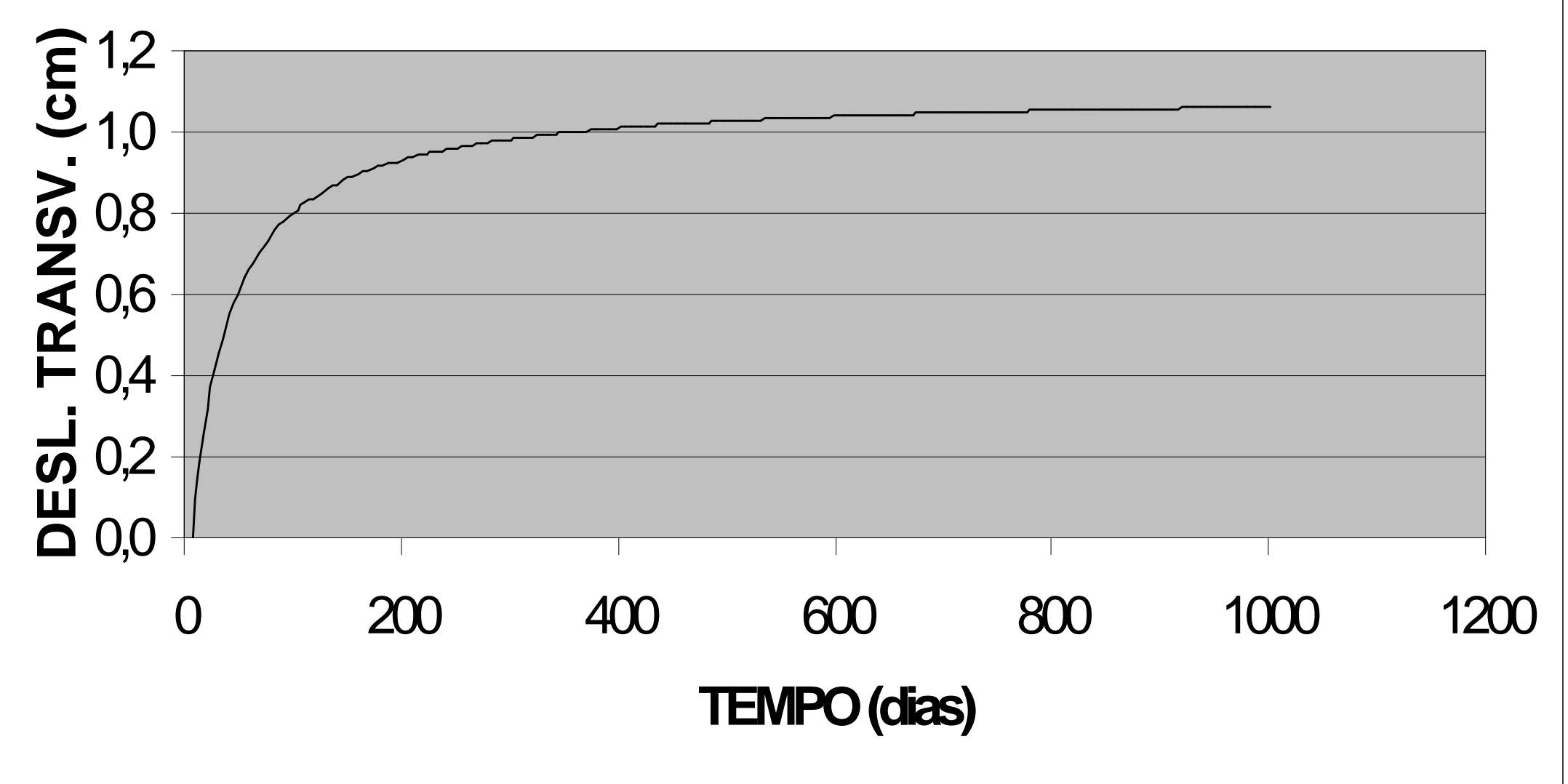




\section{PONIOPL1 (L401)/ RUÊNCAA(ACF209)}

- ANÁLSESEQÜENCAL - 28DAS

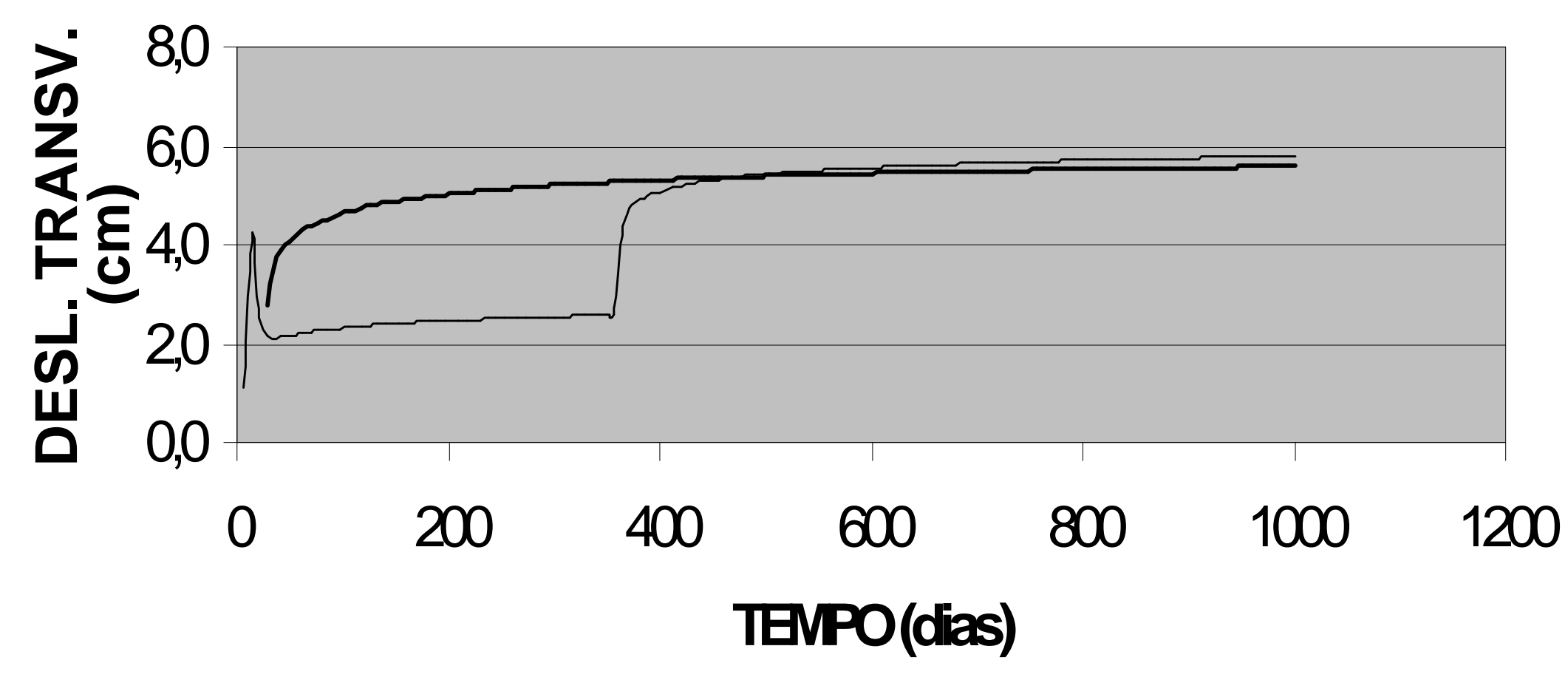




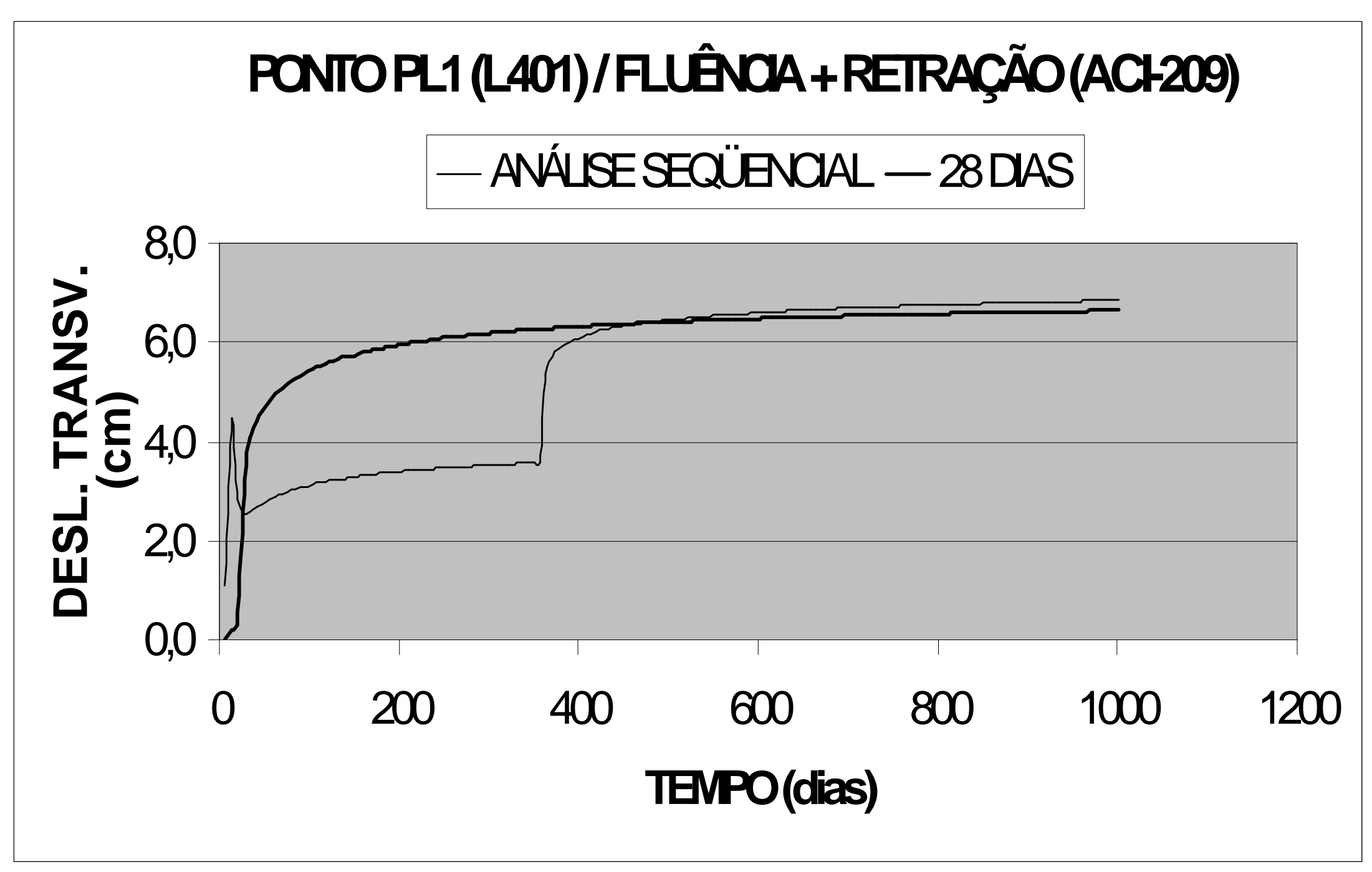




\section{PONIOPL1 (L401)/FLÛ́NCIA(ACF209)}

- ANÁLSESEQÏENCAL — 28365DAS

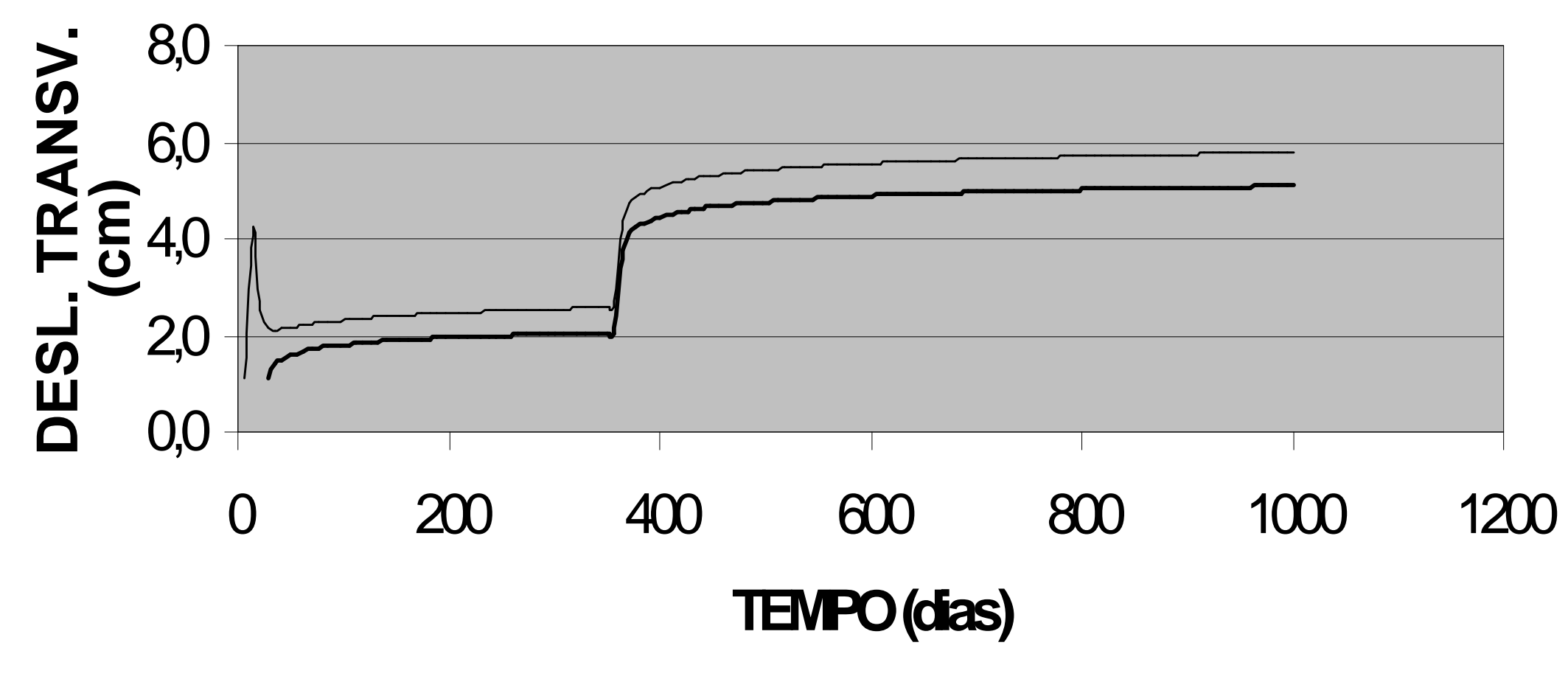




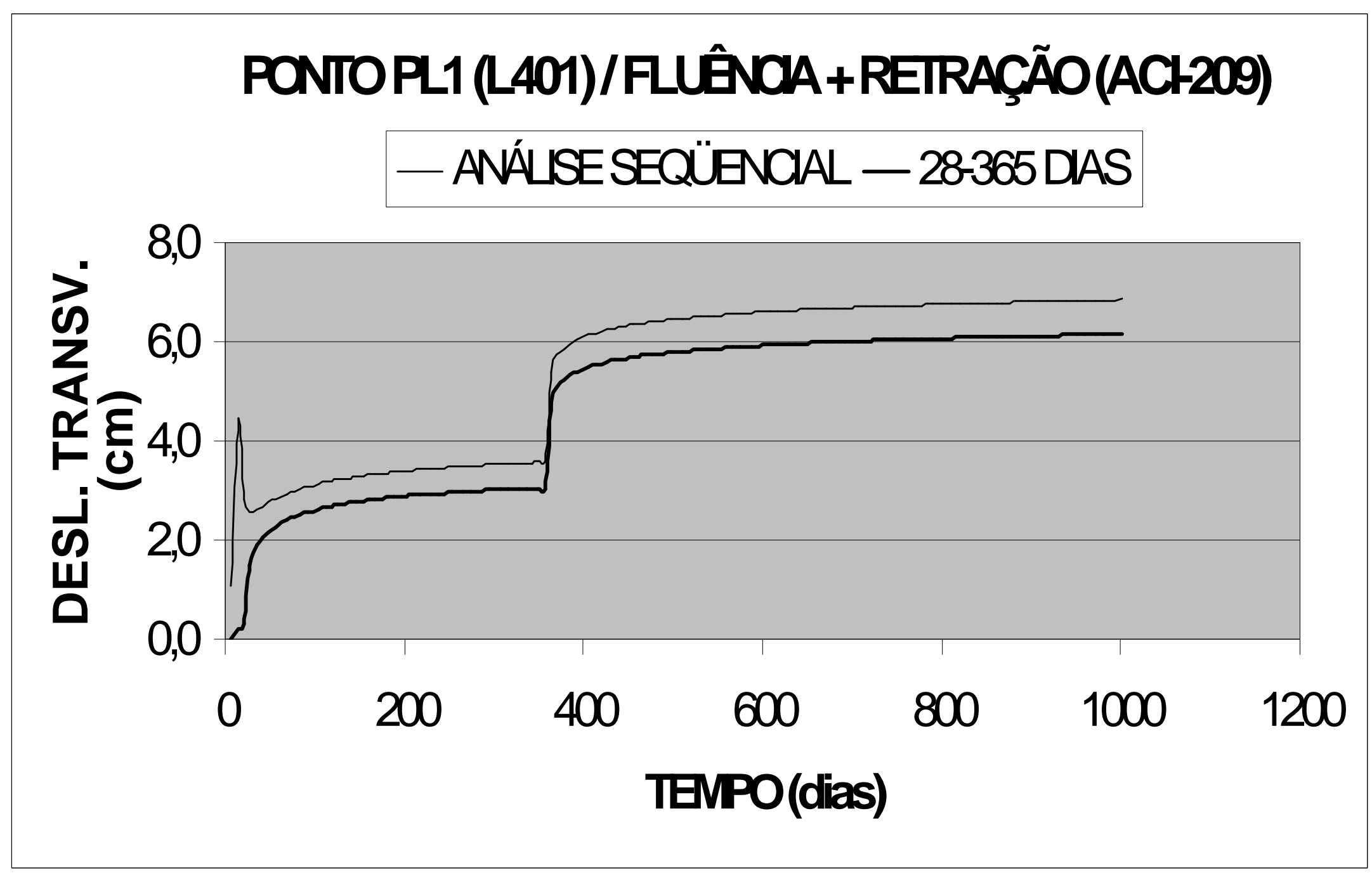




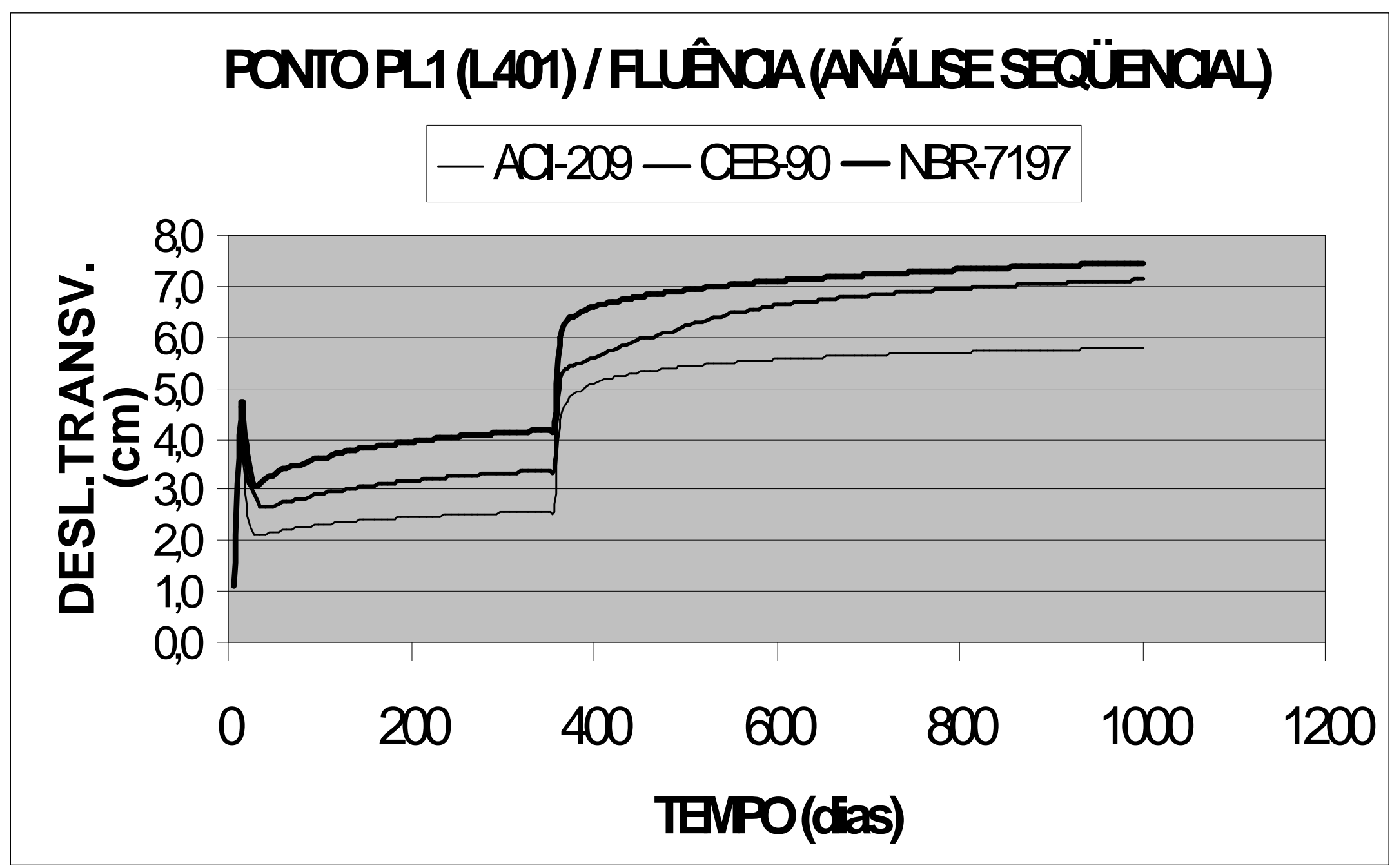




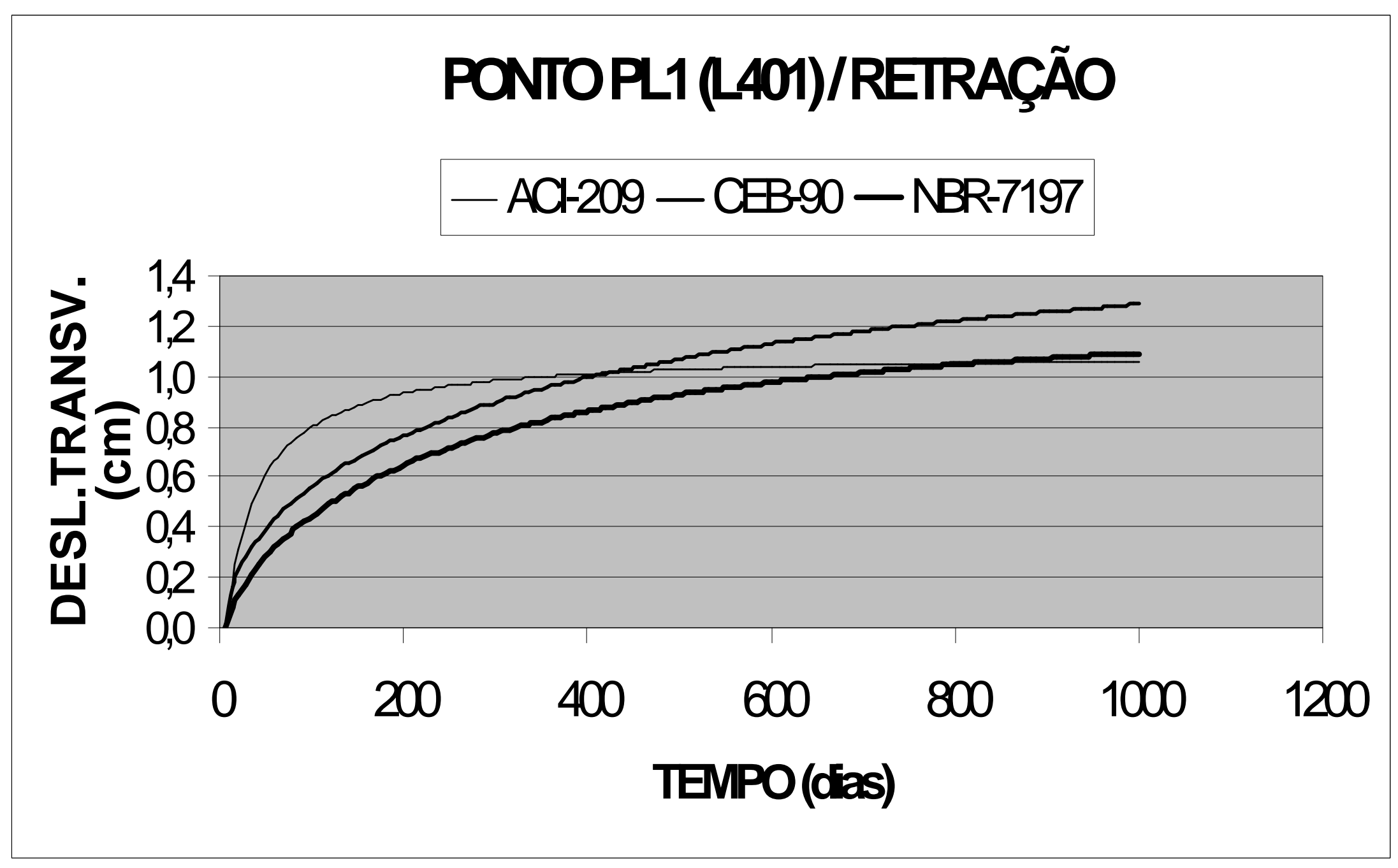




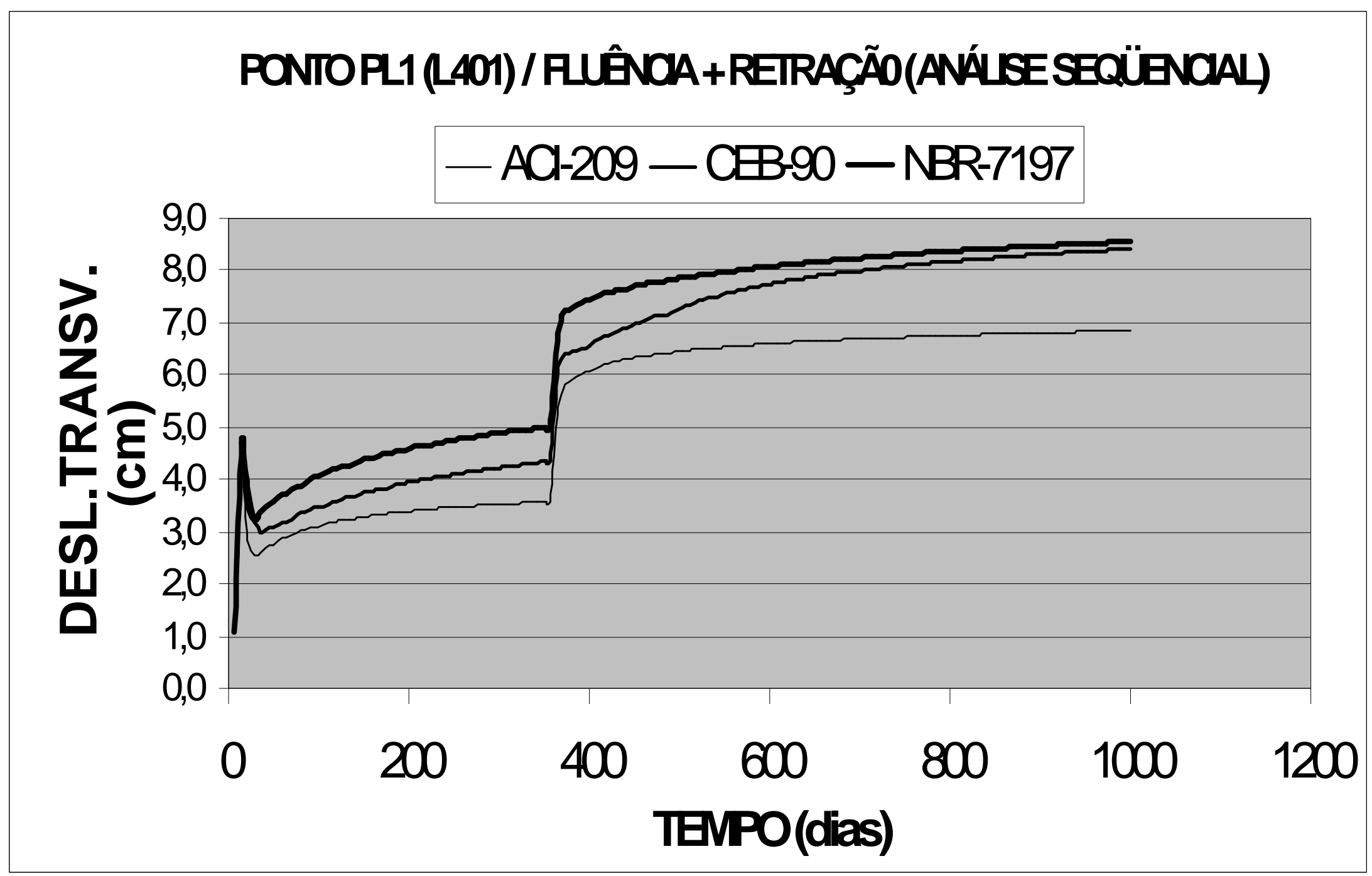




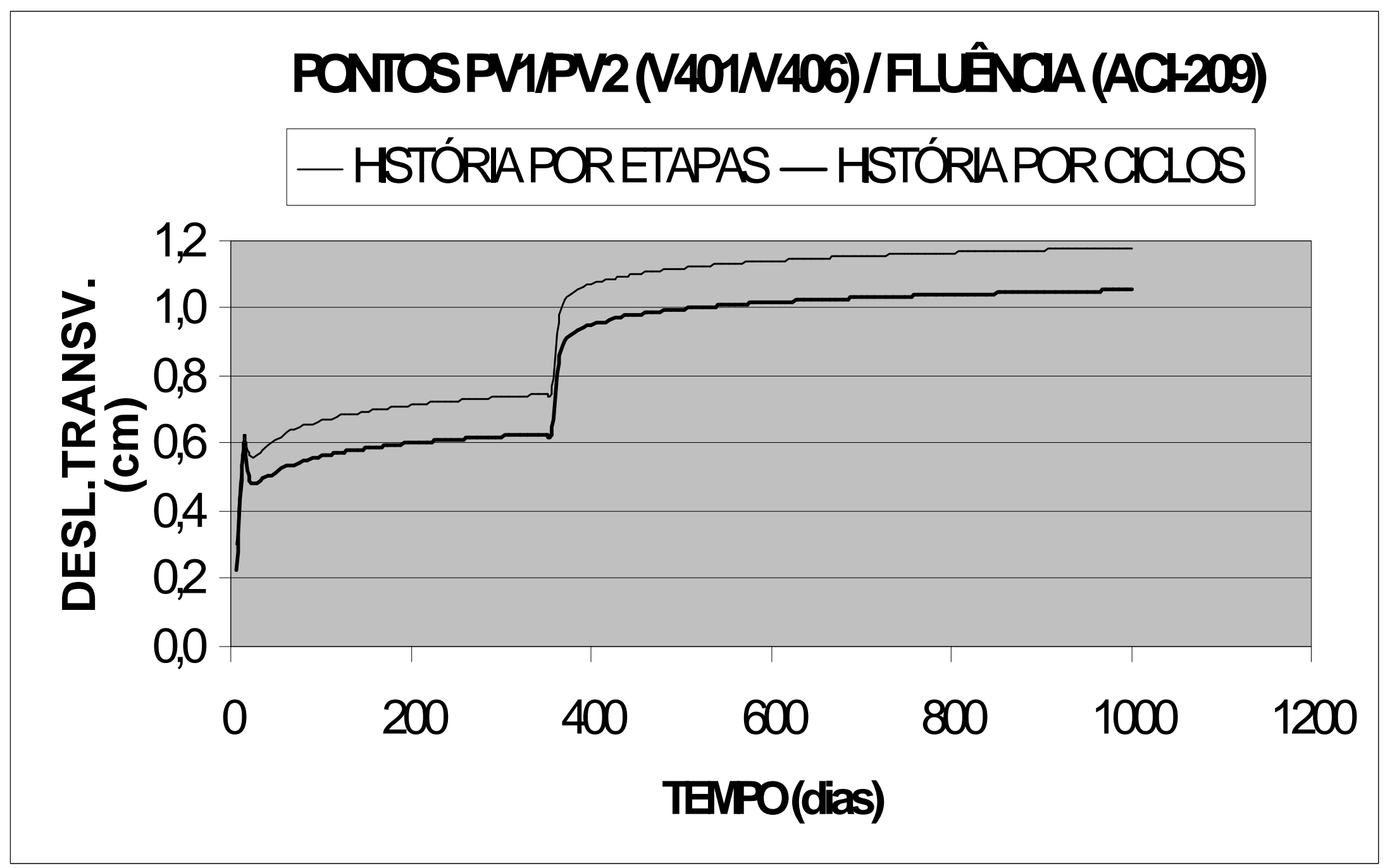




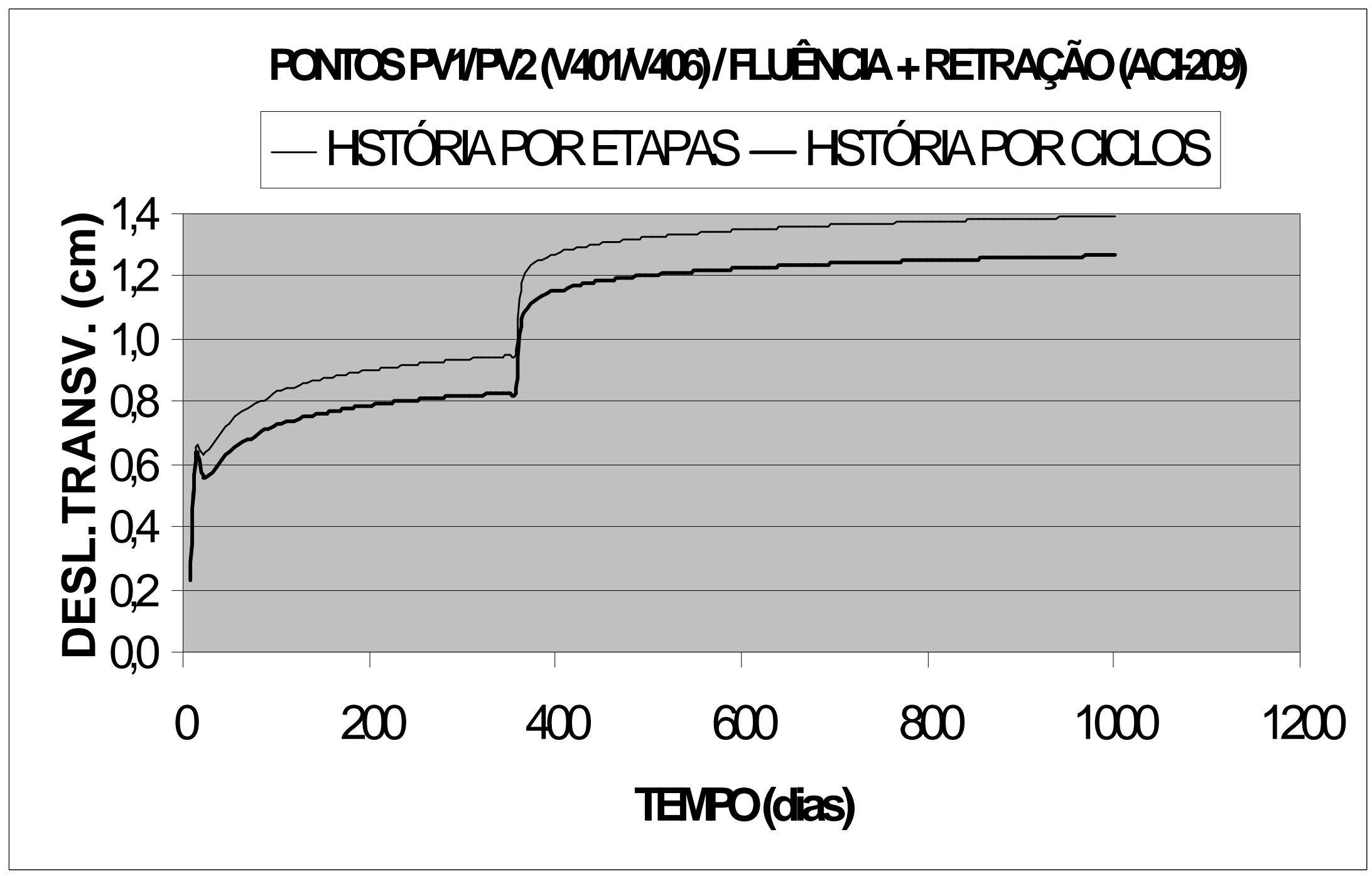




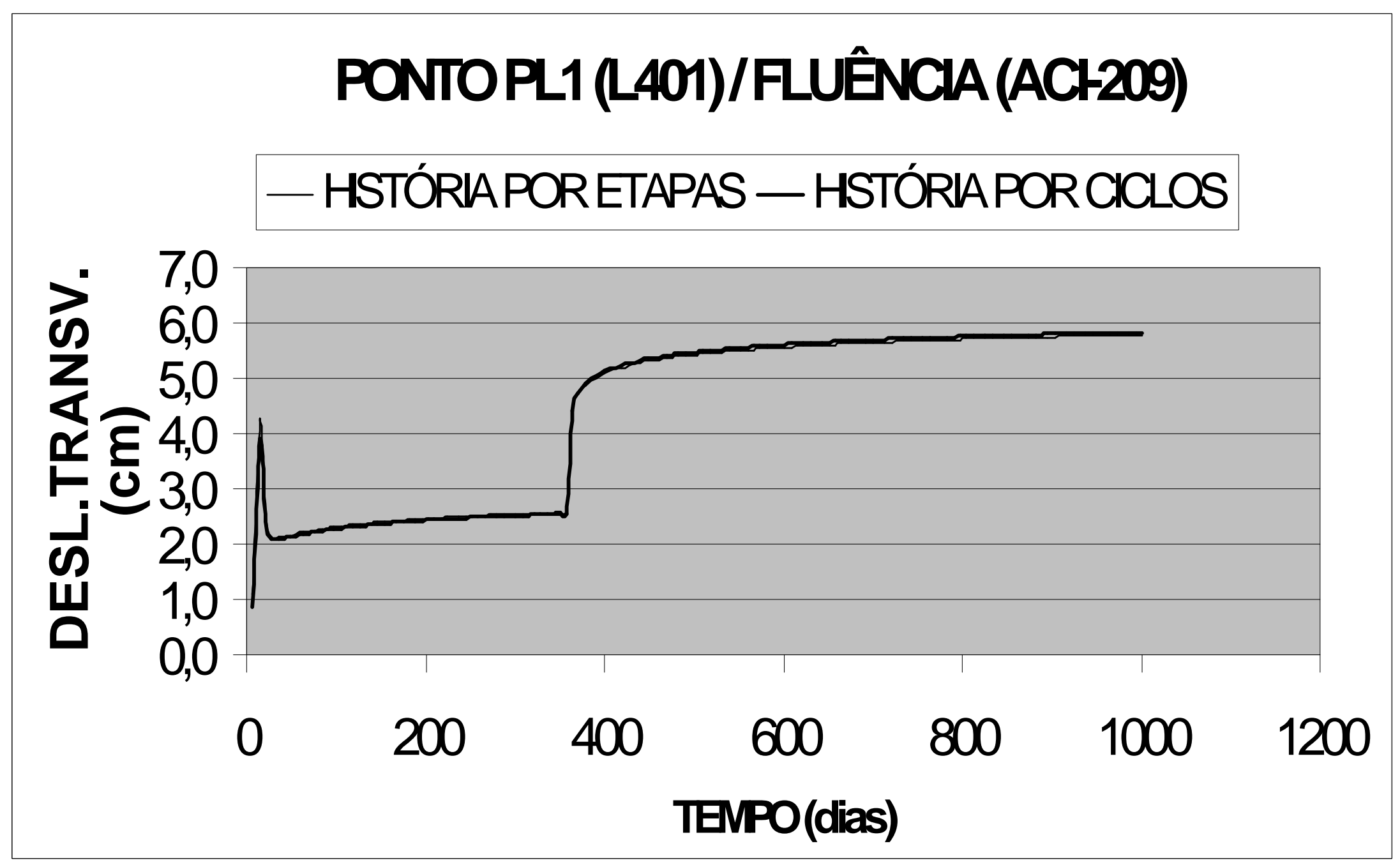




\section{PONIOPL1 (L401)/FLUANCA+FEIRAÇÃO(ACF209)}

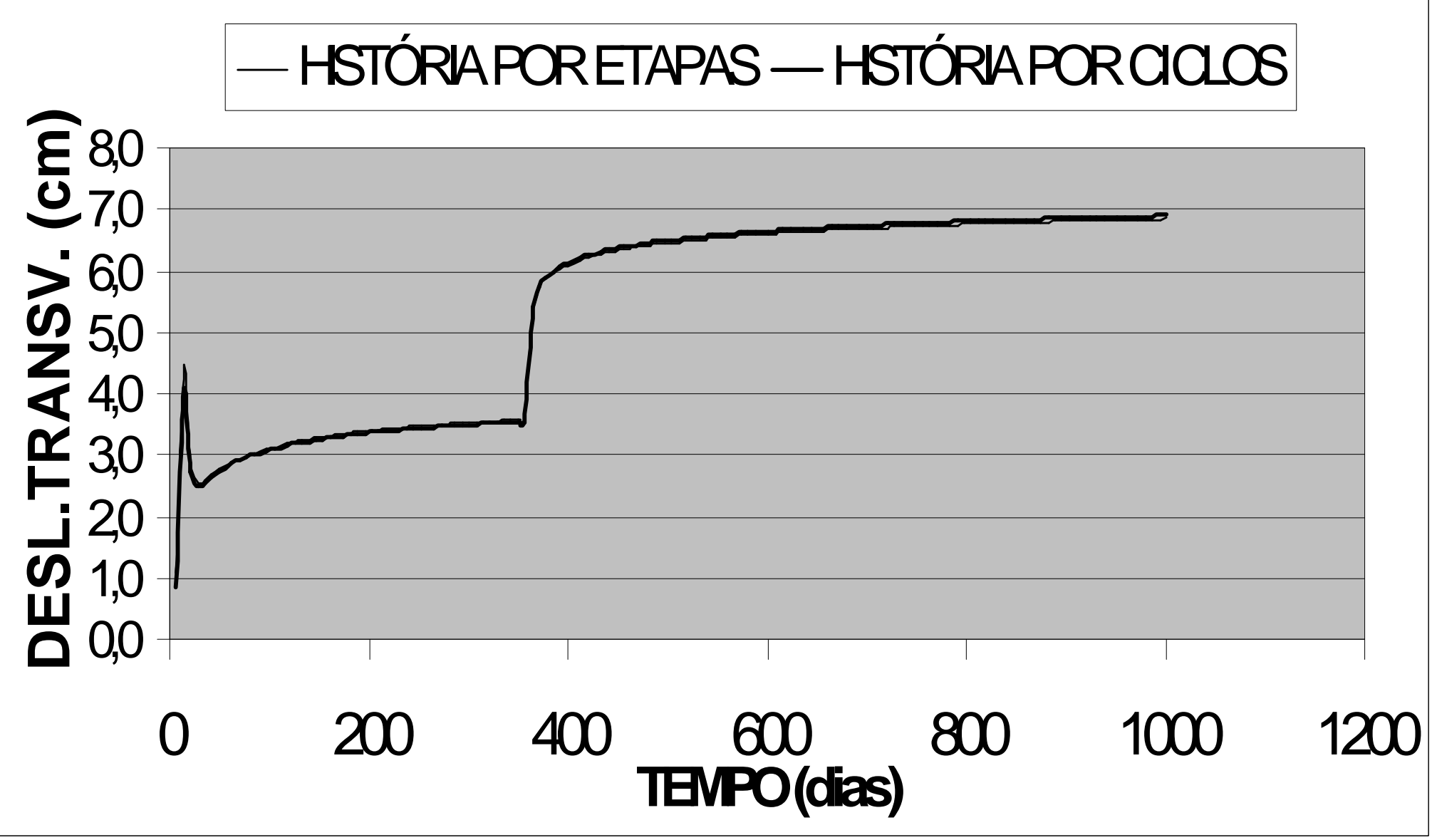




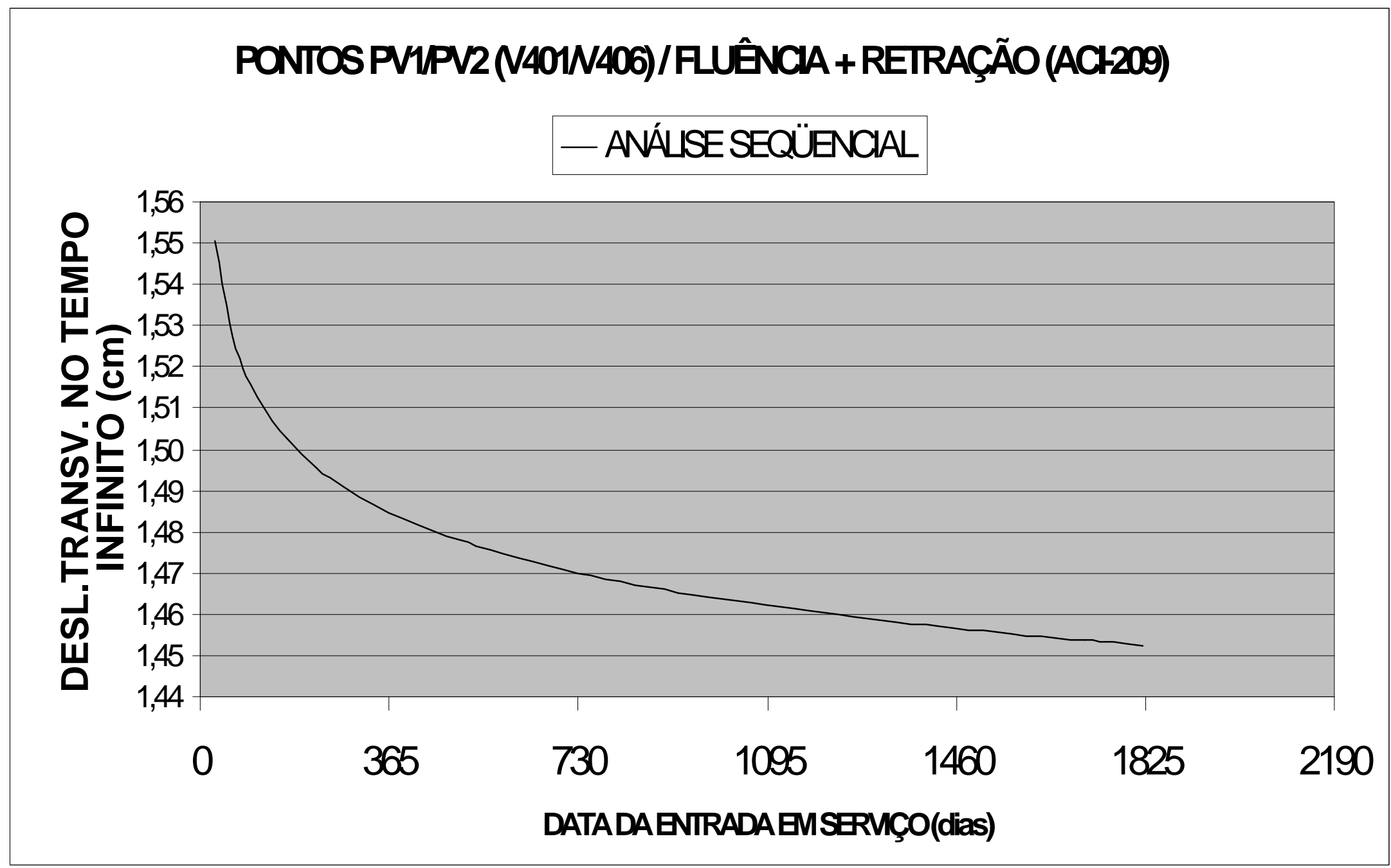




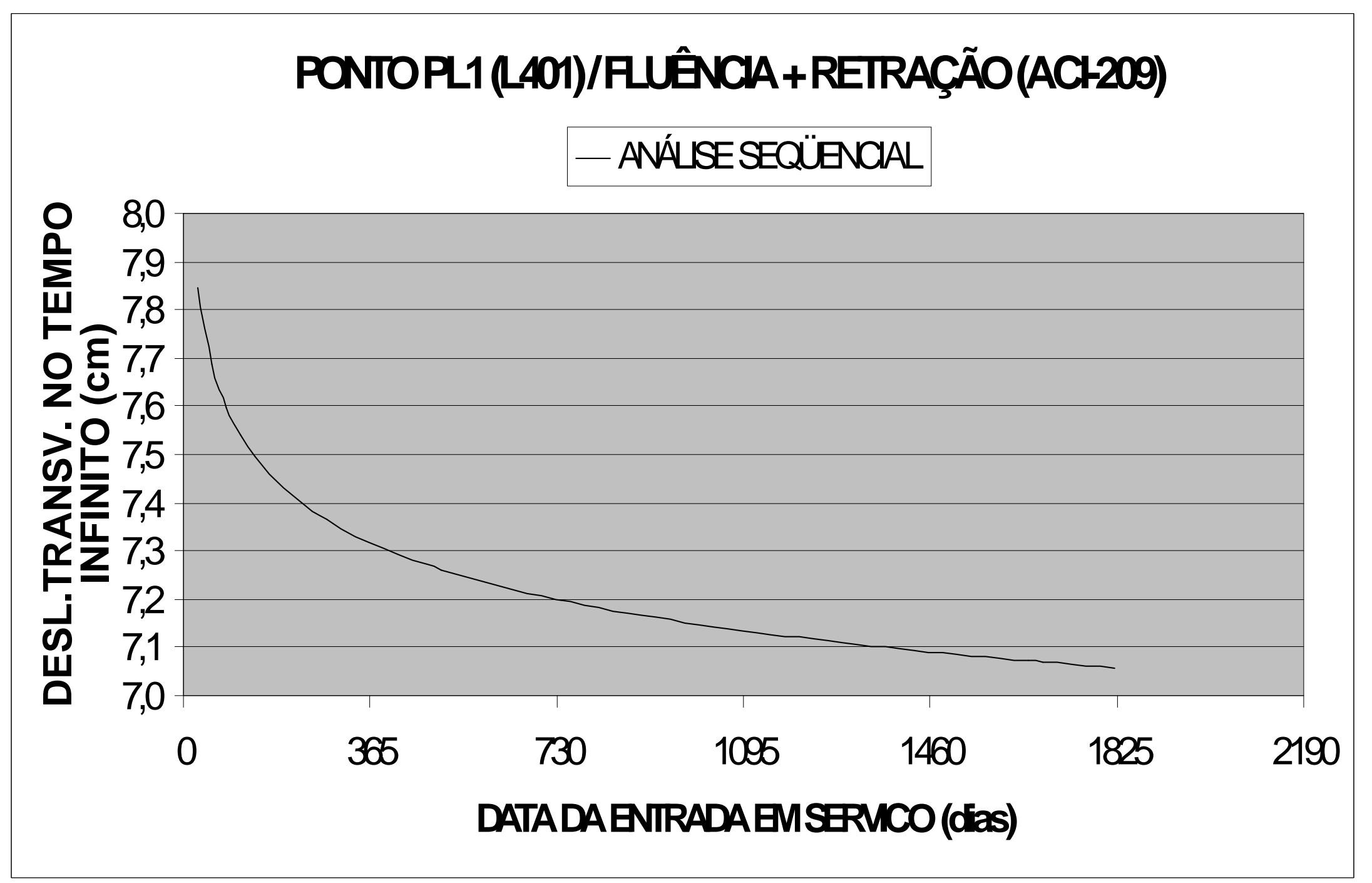




\section{BIBLIOGRAFIA}

ACI COMMITTEE 318 (1989). Building Code Requirements for reinforced concrete, Detroit.

ACI COMMITTEE 209 (1982). Designing for creep and shrinkage in concrete structures, SP-76, Detroit.

ACI COMMITTEE 347 (1988). Guide to formwork for concrete, Detroit.

ACI COMMITTEE 209R (1992). Prediction of creep, shrinkage and temperature effects in concrete structures, Detroit.

ACI Formwork for concrete (1989). SP-4, 464 p.

AGARWAL, R.K.; GARDNER, N.J. (1974). Form and shore requirements for multistory flat slab type buildings. ACI Structural Journal, v.71, No11, Nov., pp. 559-569.

ASSOCIAÇÃO BRASILEIRA DE NORMAS TÉCNICAS (1984). NBR 8681 Ações e Segurança nas Estruturas. Rio de Janeiro, ABNT.

ASSOCIAÇÃO BRASILEIRA DE NORMAS TÉCNICAS (1989). NBR 7197 Projeto de Estruturas de Concreto Protendido. Rio de Janeiro, ABNT.

ASSOCIAÇÃO BRASILEIRA DE NORMAS TÉCNICAS (1997). NBR 7190 Projeto de Estruturas de Madeira. Rio de Janeiro, ABNT. 
ASSOCIAÇÃO BRASILEIRA DE NORMAS TÉCNICAS (1978). NBR 6118 Projeto e Execução de Obras de Concreto Armado. Rio de Janeiro, ABNT.

BRANSON, D.E. (1963). Instantaneous and time-dependent deflections of simple and continuous reinforced concrete beams. Report No 7, Part I. Alabama Highway Research Department, Bureau of Public Roads, Aug., pp.1-78.

BS-8110 Structural Use of Concrete (1985). British Standards Institution. London.

CEB-FIP Model Code for Concrete structures (1990). Evaluation of the time dependent behaviour of concrete. Bulletin d'information No199, Lausanne,201 p.

CHOI, C.K.; KIM, E. (1985). Multistory frames under sequential gravity loads. Journal of Structural Engeneering - ASCE, v.111, No 11, Nov., pp. 2373-2384.

CORRÊA, M.R.S. (1991). Aperfeiçoamento de modelagens usualmente empregadas no projeto de sistemas estruturais de edifícios. São Carlos (SP). Tese (Doutorado) - Escola de Engenharia de São Carlos, Universidade de São Paulo.

CORRÊA, M.R.S.; RAMALHO, M.A. (1993). Considerações sobre a evolução dos esforços solicitantes nas estruturas de concreto armado. Seminário de dosagem e controle dos concretos estruturais. ENCOL S/A, Jul-Set, pp.22-50.

FATTAL, S.G. (1983). Evaluation of construction loads in multistory concrete building. National Institute of Standards and Tecnology. NBS Building Science Series, No 146, Gaithersburg, MD, 139 p.

GARDNER, N.J.; ZHAO, J.W. (1993). Creep and shrinkage revisited. ACI Materials Journal, v.90, No 3, May-June, pp. 236-246. 
GARDNER, N.J. (1985). Shoring, reshoring and safety. Concrete International, v.7, No 4, Apr., pp.28-34.

GARDNER, N.J.; POON, S.M. (1976). Time and temperature effects on tensile, bond and compressive strengths. ACI Journal, Proceedings, v.73, No 7, July, pp. 405-409.

GRAHAM, C.J. (1984). Deflection of reinforced concrete slabs under construction loading. Thesis, Master of Science. University of Alberta, Edmonton.

GRUNDY, P.; KABAILA, A. (1963). Construction loads on slabs with shored formwork in multistory buildings. ACI Structural Journal, v.60, No 12, Dec., pp. 1729-1738.

KRIPKA, M.; SORIANO, H.L. (1992). Sistema para análise incremental construtiva de edificações. XIII CILAMCE, Porto Alegre-RS, pp. 381-390.

LASISI, M.Y.; NG, S.F. (1979). Construction loads imposed on high-rise floor slabs. Concrete International, v.1, No 2, Feb., pp. 24-29.

LEE, H.M. et al. (1988). Analysis of construction loads on slabs and shores by personal computer. Concrete International Design and Construction, v.10, No 6, pp. 21-30.

LEONHARDT, F.; MÖNNIG, E. (1978). Construções de concreto. 2.ed. Berlin, Springer. v.4.

LEVY, S.; HELENE, P. (1996). Cura: como, quando e porquê. REVISTA TÉCHNE, No 20, Jan/Fev., pp. 18-21.

MOSSALAM, K.; CHEN, W.F. (1992). Construction load distributions for laterally braced framework. ACI Structural Journal, v.89, No 4, July-Aug., pp.415-424. 
OLIVEIRA, R.S. (1997). Análise de pavimentos de concreto armado com a consideração da não-linearidade física. São Carlos (SP). Dissertação (Mestrado) - Escola de Engenharia de São Carlos, Universidade de São Paulo.

OSHA - Occupational Safety and Health Administration (1972). Safety and health regulations for construction. U.S. Department of Labor, Washington, 29 CFR, Part 1926, 97 p.

PRADO, J.F.M.A. (1995). Estruturas de edifícios em concreto armado submetidas a ações verticais e horizontais. São Carlos (SP). Dissertação (Mestrado) - Escola de Engenharia de São Carlos, Universidade de São Paulo.

PRADO, J.F.M.A.; CORRÊA, M.R.S.; RAMALHO, M.A (1998). Construction load analysis of concrete structures using computer 3D models. FOURTH WORLD CONGRESS ON COMPUTATIONAL MECHANICS - IACM, Buenos Aires.

PRADO, J.F.M.A.; CORRÊA, M.R.S.; RAMALHO, M.A (1998). Panorama sobre ações construtivas em estruturas de edifícios em concreto armado. REVISTA IBRACON, No 21, pp. 21-31, Abr./Jul.

PRADO, J.F.M.A.; GIONGO, J.S. (1997). Redistribuição de momentos fletores em vigas de edifícios. XXVIII JORNADAS SUL-AMERICANAS DE ENGENHARIA ESTRUTURAL, São Carlos (SP).

PRICE, H.W. (1951). Factors influencing concrete strength. ACI Journal, No 47, Feb., pp. 417-432.

RAMALHO, M.A. (1990). Sistema para análises de estruturas considerando interação com o meio elástico. São Carlos (SP). Tese (Doutorado) - Escola de Engenharia de São Carlos, Universidade de São Paulo. 
RODRIGUES JÚNIOR, S.J. (1996). Ações de construção em lajes de concreto armado. Rio de Janeiro (RJ). Dissertação (Mestrado) - Pontifícia Universidade Católica - PUC/RJ.

SANTOS JÚNIOR, F. (1998). Cálculo de esforços e deslocamentos em pavimentos de edifícios considerando-se modelos próprios para o concreto armado. São Carlos (SP). Dissertação (Mestrado) - Escola de Engenharia de São Carlos, Universidade de São Paulo.

SBAROUNIS, J.A. (1984). Multistory flat plate buildings - construction loads and immediate deflections. Concrete International, v.6,No 2, Feb., pp. 70-77.

SCANLON, A.; GRAHAM, C.J. (1984). Deflections of concrete slabs under construction loading. ACI / SP-86, Mar., pp. 167-184.

SELVARAJ, S.; SHARMA, S.P. (1974). Influence of construction sequence on the stresses in tall building frames. Regional Conference on Tall Buildings, Bangkok, Jan., pp. 197-211.

SHEHATA, L.C.D. et al. (1993). Classificação e propriedades do concreto e do aço. UFRJ/COPPE, Rio de Janeiro (RJ).

SILVANY, T.T. (1996). Deslocamentos transversais em lajes-cogumelo. São Carlos (SP). Dissertação (Mestrado) - Escola de Engenharia de São Carlos, Universidade de São Paulo.

STIVAROS, P.C.; KAMINETZKY, D. (1994). Early-age concrete: construction loads, behaviour and failures. Concrete International, v.16, No 1, Jan., pp. 5863.

SUPERSAP: Super Structural Analysis Program. Califórnia, EUA. 
WAI-FAH CHEN et al. (1985). Construction load analysis for concrete structures. Journal of Structural Engeneering - ASCE, v.111, No 5, May., pp. 1019-1036.

WAI-FAH CHEN et al. (1992). Construction load distributions for laterally braced framework. ACI Structural Journal, v.89, No 4, July-Aug., pp. 415-424.

WAI-FAH CHEN et al. (1991). Determining shoring loads for reinforced concrete construction. ACI Structural Journal, v.88, No 3, May-June, pp. 340-350. 